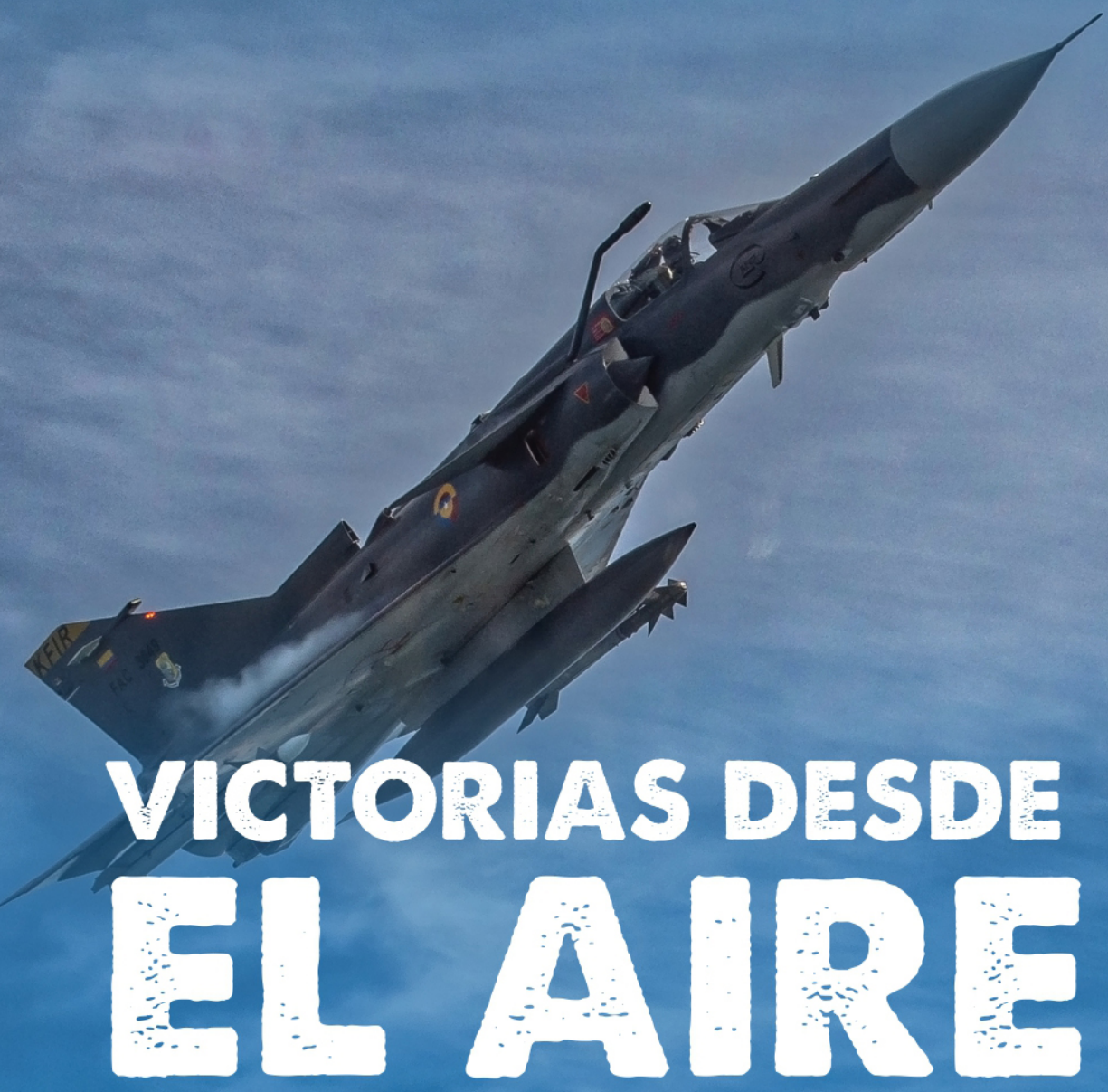

\title{
LA FUERZA AÉREA COLOMBIANA Y EL TÉRMINO DEL CONFLICTO ARMADO
}

CUARTA EDICIÓN

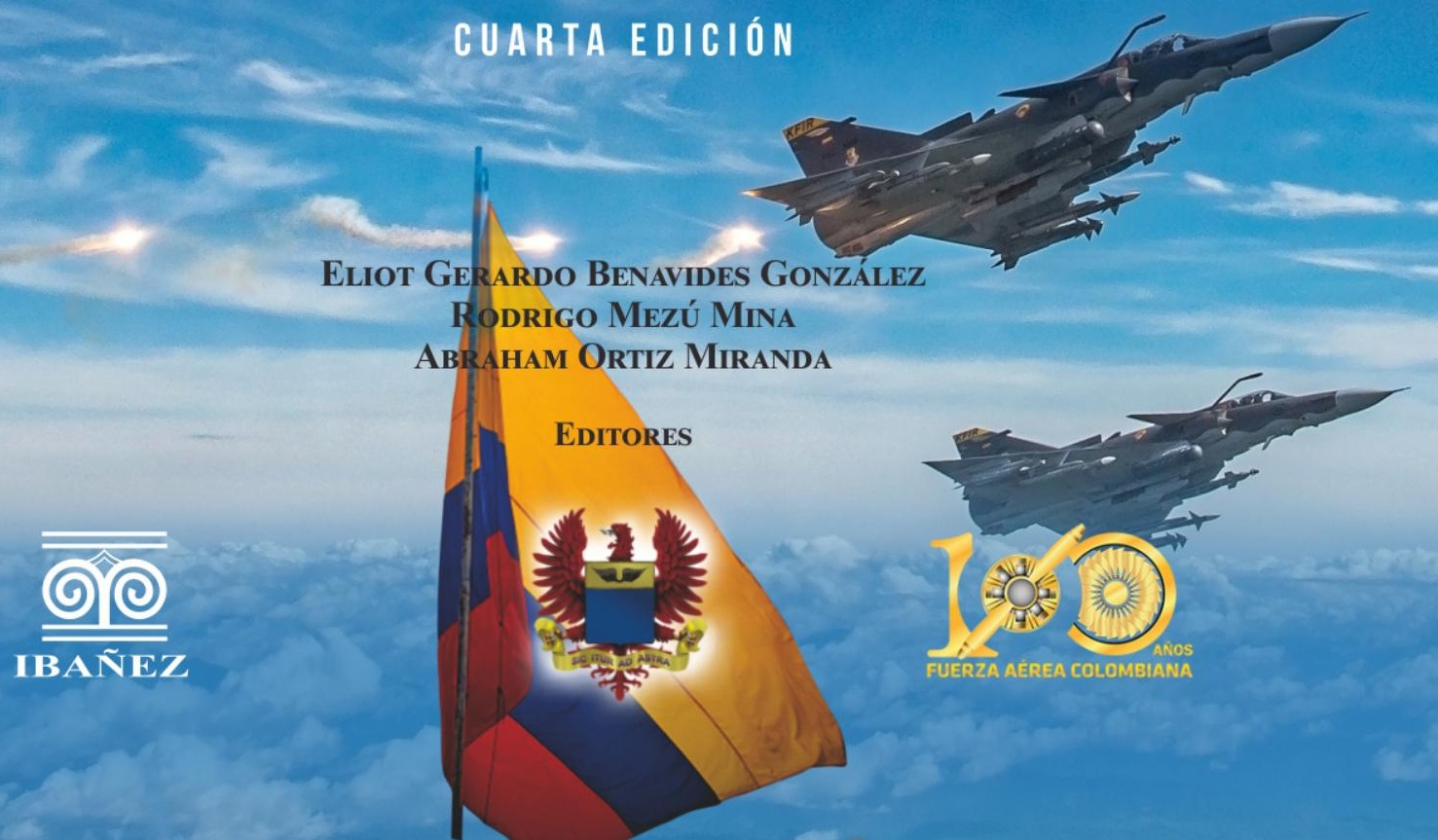





\section{VICTORIAS DESDE EL AIRE: LA FUERZA AÉREA COLOMBIANA}

Y EL TÉRMINO DEL CONFLICTO ARMADO 



\title{
Eliot Gerardo Benavides González Rodrigo Mezú Mina Abraham Ortiz Miranda
}

Editores

\section{VICTORIAS DESDE EL AIRE: LA FUERZA AÉREA COLOMBIANA Y EL TÉRMINO DEL CONFLICTO ARMADO \\ Cuarta Edición}

\author{
Ricardo Esquivel Triana \\ Flavio Enrique Ulloa Echeverry \\ Camilo Andrés Castiblanco Durán \\ Adriana LuCia Marín RamíreZ \\ Daniel Antonio Garzón Moreno \\ Edgar Alfonso Lesmes Abad \\ LUIS IGNACIO BARÓN CASAS \\ Henry Quintero Barrios \\ Alex Edwin Tiuso Malagón \\ JAVIER Alberto CASTRILlón Riascos \\ María Alejandra Santos Barón \\ Juan Guillermo García Serna \\ JuAn CARLos Gómez Ramírez \\ Alexandra Guzmán Durán \\ Gerson Ricardo Jaimes Parada
}
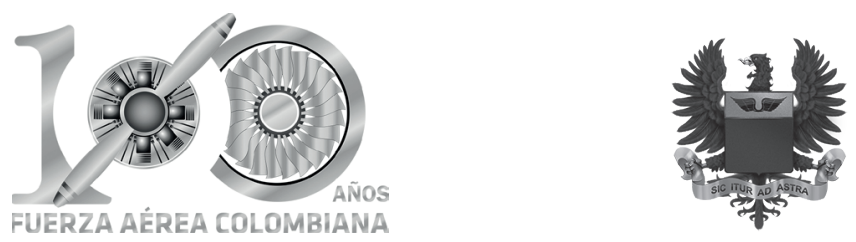
Victorias desde el aire: La Fuerza aérea colombiana y el término del conflicto armado/ Ricardo Esquivel Triana y otros; -- Cuarta edición: Edición Gustavo Ibáñez Carreño. -Bogotá: Grupo Editorial Ibáñez, 2019.

296; $24 \mathrm{~cm}$.

ISBN 978-958-791-061-2

1. Colombia. Fuerza Aérea - Historia 2. Aviación militar - Colombia 3. Mantenimiento de la paz - Colombia 4. Conflicto armado - Colombia I. Esquivel Triana, Ricardo, autor II. Ibáñez Carreño, Gustavo, editor IV. Tít.

$358.40986 \mathrm{~cd} 21$ ed.

A1593096

CEP-Banco de la República-Biblioteca Luis Ángel Arango

"Este libro fue financiado por la Fuerza Aérea Colombiana"

Los artículos publicados en el presente libro son responsabilidad exclusiva de los autores. En ningún caso reflejan la posición oficial de la Fuerza Aérea Colombiana o de alguna dependencia del Gobierno Nacional de Colombia.

\section{(C) Fuerza Aérea Colombiana}

Escuela de Postgrados de la Fuerza Aérea Colombiana "Capitán José Edmundo Sandoval"

Grupo de Investigación Análisis y Contextos

Teléfono: 2134644 Ext. 1715

Bogotá D.C.

(C) Grupo Editorial Ibáñez

Carrera 69 Bis No $36-20$ Sur

Teléfonos: 2300731-2386035

\section{Librería}

Calle 12 B NO. 7-12. L. 1

Tels: $2847524-2835194$

Bogotá, D.C. - Colombia

www.grupoeditorialibanez.com

ISBN: 978-958-791-061-2

Como Citar este Libro: Benavides, E., Mezú, R., y Ortiz, A. (Eds.). (2019). Victorias desde el aire: la Fuerza Aérea Colombiana y el término del conflicto armado - Cuarta Edición. Bogotá, Colombia: Grupo Editorial Ibañez.

Queda prohibida la reproducción parcial o total de este libro por cualquier proceso reprográfico o fónico, especialmente por fotocopia, microfilme, offset o mimeógrafo.

Ley 23 de 1982.

Fotografías

Archivo Fotográfico Revista Aeronáutica Fuerza Aérea Colombiana

Reservados todos los derechos

(B) Fuerza Aérea Colombiana

Diagramación electrónica: Yaneth Guarín A.

Diseño de portada: Equipo Market Share Company

Finalización del Diseño: David Andrés Cortés A. 


\section{Presentación}

Tengo el honor de presentar la cuarta edición del libro Victorias desde el aire: la Fuerza Aérea Colombiana y el término del conflicto armado, como un documento y esfuerzo académico de un grupo multidisciplinario, que tiene como fin primordial responder a dos reflexiones fundamentales: la primera, el sentido y propósito de la FAC en desarrollo del conflicto armado que ha tenido lugar en Colombia, en especial a partir de la década de los años 90 hasta la actualidad. La segunda, abordar la definición del concepto de victoria militar en relación con las condiciones necesarias que se han de alcanzar desde la perspectiva de la Defensa y la Seguridad Nacional, para que el conductor político materializara un Acuerdo de Paz; esto sucedió en el año 2016, cuando el Gobierno Nacional y las autodenominadas Fuerzas Armadas Revolucionarias de Colombia (FARC) firmaron el Acuerdo de Paz.

Así las cosas, esta cuarta edición revisada y actualizada incluye 15 artículos de autoría de reconocidos académicos y distinguidos oficiales de la FAC, quienes en calidad de oficiales activos o en uso de buen retiro, han hecho un ejercicio de historiografía de la FAC y de deber de memoria institucional. En este sentido, los autores enfatizan en aspectos como los siguientes: la resiliencia y la evolución de la FAC como organización military el empleo de la tecnología para enfrentar las distintas amenazas y violencias a las que han asistido tres generaciones de colombianos.

En esta medida, los diferentes escritos registran que a pesar del nivel de amenaza y de degradación del conflicto fue posible alcanzar resultados operacionales y efectos deseados, todo esto a partir de una constante evolución institucional en el marco de la legitimidad y la legalidad, para neutralizar o interrumpir una amenaza persistente y compleja. De ahí el índice de favorabilidad con que goza la FAC frente a los colombianos, precisamente como reconocimiento a su legitimidad y recta actuación en medio de innumerables operaciones aéreas.

De esta manera, la FAC ha aprovechado la ventaja tecnológica y, por sobre todo, la calidad de su capital humano, para actuar e innovar constantemente. También para aplicar la fuerza legítima del Estado en los momentos y espacios requeridos de forma decisiva, en contra de los variados grupos armados organizados (GAO) presentes en el territorio nacional y en sus distintas manifestaciones de violencia. 
Lo anterior se traduce en una capacidad real del Estado y de los colombianos, que ha sido vital para conducir acciones militares junto con las otras Fuerzas (Ejército y Armada Nacional) y con la Policía Nacional, con el fin de defender los intereses de los nacionales, entre ellos la integridad territorial y el orden constitucional, así como la paz de los colombianos.

Mi expectativa es que esta obra ayude a comprender el significado que tiene para los colombianos contar con una Fuerza Aérea centenaria en un contexto particular, pero por sobre todo, que arroje luces sobre la misión en la que se encuentra empeñada la FAC, así como el firme compromiso por parte de todos los hombres y mujeres de esta institución, de continuar trabajando en bien de la Defensa de la Nación y de todos los aspectos de seguridad que atañen los habitantes de este territorio particular y diverso.

Mayor General Ramses Rueda RuedA

Comandante Fuerza Aérea Colombiana 


\section{CONTENIDO}

PRESENTACión.

\section{INTRODUCCIÓN}

DESDE LAS ALTURAS A LA ESCRITURA: LA IMPORTANCIA DE LA MEMORIA HISTÓRICA PARA LA COMPRENSIÓN DEL PAPEL DE LA FUERZA AÉREA COLOMBIANA EN LA TERMINACIÓN DEL CONFLICTO ARMADO INTERNO

Abraham Ortiz Miranda

SOBRE LA NUEVA EDICIÓN ……………………….......................................... 15

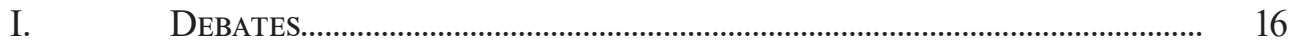

II. MEMORIA PARA LA HISTORIA, HISTORIA PARA LA MEMORIA ..................... 18

III. Hacer Cosas con Palabras: Reflejos del Alma .............................. 20

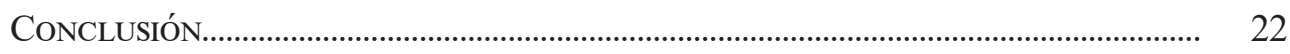

REFERENCIAS.......................................................................................... 23

\section{LA HISTORIA}

FUERZA AÉREA COLOMBIANA Y OPERACIONES DECISIVAS 1998-2015 RicARdo ESQUivel TRIANA

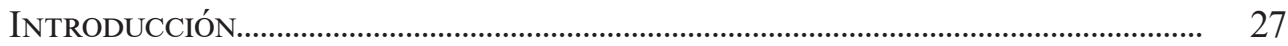

I. Reforma de la Fuerza Pública y nuevo ENFOQUE OPERATIVO (1998-2003) ........................................................ 31

Operación Vuelo de ÁNGEl (Mitú-Nov. 1998): .............................. 33

OPERACión Delta (ZoNa DE DISTENSIÓN-Feb. 2002): ............................ 40

II. PolíticA OFENSIVA Y BOMBARDEO DE PRECISIÓN (2003-2008)...................... 44

OPERACIÓN UNIVERSAL (SEP. 2007)............................................................ 47

OPERACIÓN AROMO (OCT. 2007).................................................................... 49 
III. FUERZA AÉREA, LA DECISIVA Y UNIDADES CONJUNTAS (2009-2015) ........... 52

OPERACIÓN SODOMA (SEP. 2010) ........................................................... 53

OPERACIÓN ODISEO (NOV. 2011)........................................................... 56

IV. A MODO DE CONCLUSIÓN: BALANCE DE OPERACIONES DECISIVAS .................. 60

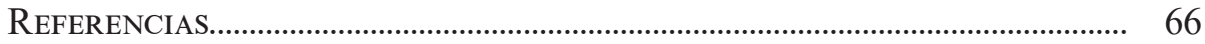

TRANSFORMACIONES HISTÓRICAS EN LA MANERA DE OPERAR DE

LAS FUERZAS MILITARES: REFLEXIONES A PARTIR DE LA OPERACIÓN COLOMBIA

General (RA) Flavio UlloA Echeverry

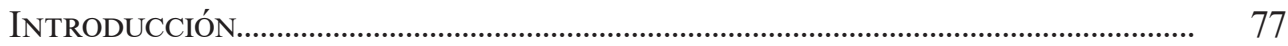

La Operación COLOMBIA .................................................................................. 80

LA INTELIGENCIA MILITAR HUMANA Y EL DESARROLLO TECNOLÓGICO DE LA GUERRA.... $\quad 84$

DeSARROLlO TECNOLÓGICO, DiSCIPLINA MILITAR Y CULTURA DE GUERRA............ 86

A MODO DE CONCLUSIÓN: TRANSFORMACIONES EN EL CONTEXTO OPERACIONAL ........ 87

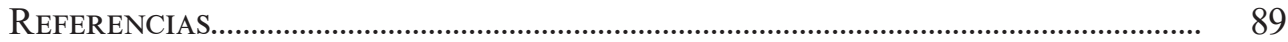

\section{MEMORIA}

\section{OPERACIÓN COLOMBIA: CRÓNICAS Y NARRATIVAS DE DOS PILOTOS DE HELICÓPTERO DE LA FUERZA AÉREA COLOMBIANA}

Grupo de investigación Análisis de Contexto y Posconflicto FAC- Colciencias. Mayor General Luis Ignacio Barón - Mayor General Jorge TAdeo Borbón

Ningún territorio está vedado PARA la Fuerza AÉREa Colombiana

Narrativa del Mayor General Luis Ignacio Barón

La Operación Colombia: MeMorias de un PILOTO de COMBATE

Narrativa del Mayor General Jorge Tadeo Borbón ...................................... 98

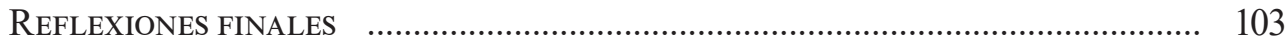

AgRADECIMIENTOS _........................................................................... 103 


\section{NUESTRA PRESENCIA AÉREA, MARCÓ LA DIFERENCIA EN LA RECUPERACIÓN DE MITÚ}

Crónica del General (RA) Édgar A. Lesmes ABAD

La OPERACIÓN VueLo de ÁngeL _....................................................................... 108

PLANEAMIENTO DE LA OPERACIÓN.................................................................... 109

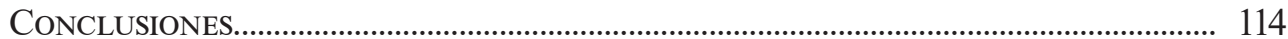

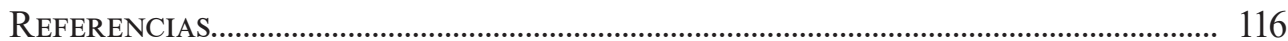

ABRIENDO CAMINOS PARA COLOMBIA: LA FUNCIÓN SOCIAL DE SATENA EN UN ESCENARIO DE POSCONFLICTO

Adriana Lucía Marín Ramírez. Daniel Garzón Moreno. Camilo Andrés CASTIBLANCO

INTRODUCCIÓN

"HAY MUCHOS LUGARES DE LA GEOGRAFÍA COLOMBIANA QUE NECESITAN DE NUESTRO APOYO",

REGIÓN PACÍFICO.

REGIÓN ORINOQUIA

REGIÓN AMAZÓNICA

"Satena es la PUNTa de lanZa DE todas eSAS Regiones"

SATENA Y SU PAPEL EN EL POSCONFLICTO.

CONSIDERACIONES FINALES.

REFERENCIAS.

\section{LA DISPUTA POR LOS CORREDORES DE MOVILIDAD EN LA DÉCADA DE} LOS NOVENTA: REFLEXIONES SOBRE EL CONFLICTO ARMADO INTERNO COLOMBIANO

\section{Mayor General LuIS IGNACIO BARÓN CASAS}

INTRODUCCIÓN. 129

DINÁMICAS TERRITORIALES DEL CONFLICTO ARMADO

TRANSFORMACIONES EN LAS POLÍTICAS DE SEGURIDAD EN COLOMBIA EN LA DÉCADA DEL NOVENTA

CONCLUSIONES. 


\section{LAS FRONTERAS NO ADYACENTES, COMO SOLUCIÓN AL TRÁFICO AÉREO ILEGAL}

Brigadier General Henry QUINTERo BARRIOS

REFERENCIAS. 165

\section{REFLEXIONES OPERACIONALES A PARTIR DE LA EXPERIENCIA DE LAS TOMAS DE PUERTO RICO Y PUERTO LLERAS}

Coronel Alex Edwin Tiuso Malagón

INTRODUCCIÓN 167

Contexto Puerto Rico y Puerto Lleras. 168

REFLEXIONES FINALES 176

REFERENCIAS. 178

\section{LA OPERACIÓN VUELO DE ÁNGEL, PUNTO DE INFLEXIÓN EN EL} CONFLICTO ARMADO COLOMBIANO

\section{María Alejandra SANTOS BaróN}

INTRODUCCIÓN.

1. LOS AÑOS NOVENTA EN EL CONFLICTO ARMADO COLOMBIANO 183

2. La Operación Vuelo de Ángel. 188

2.1. LA TOMA DE Mitú. 188

2.2. La Operación Vuelo de Ángel 190

2.3. Despúes de la Operación Vuelo de Ángel 199

Conclusiones 202

REFERENCIAS. 204

\section{LA DOCTRINA JURÍDICO OPERACIONAL COMO ELEMENTO} PREPONDERANTE EN EL ÉXITO OPERACIONAL DE LA FUERZA AÉREA EN EL SIGLO XXI

Brigadier General JuAN CARLos Gómez Ramírez

EL CONTROL CENTRALIZADO Y LA EJECUCIÓN DESCENTRALIZADA COMO CLAVE EN USO DEL PODER AÉREO 
El Derecho Internacional Humanitario COMO Herramienta CONTUNDENTE EN EL DEBILITAMIENTO DE LA AMENAZA TERRORISTA

THE LARGER LESSONS OF PLAN COLOMBIA: A CASE OF INNOVATION AND SUCCESS

Brigadier General Eliot Gerardo Benavides GonzÁLEZ

INTRODUCTION 221

1. Plan Colombia 223

1.1. Operational Assessment. 225

2. The Key Elements of Plan Colombia 227

2.1. National Leadership, Legitimacy, And Population 227

2.2. U.S. Military doctrine and Plan Colombia 227

2.3. Civil-Military relations in Colombia. 229

2.4. VISION OF CONFLICT RESOLUTION 231

2.5. LARGER LESSONS OF PLAN. 233

3. Conclusions AND ReCOMMENDATIONS 235

REFERENCIAS. 236

\section{CULTURA INSTITUCIONAL PARA LA TRANSICIÓN: COMANDO AÉREO DE COMBATE $\mathrm{N}^{\circ} 2$ Alexandra GuZmán Durán}

INTRODUCCIÓN. 239

1. Metodología. 240

2. HALlazGOS 241

2.1. LO POLÍTICO EN LO MILITAR: UNA MIRADA A LA NEGOCIACIÓN DE PAZ

2.2. ElEMENTOS DE AUTODEFINICIÓN: REPRESENTACIÓN DE LO MILITAR.

2.3. Transformación de la Fuerza AÉrea Colombiana: EL PROCESO DE TRANSICIÓN 
2.4. CACOM 2: APIAY Y SUS APORTES AL PROCESO DE TRANSICIÓN...... 246

3. REFLEXIONES FINALES ............................................................. 247

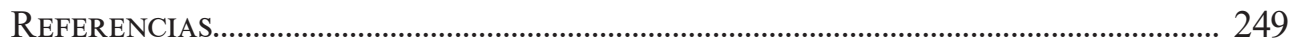

\section{LA INNOVACIÓN COMO EJE DE TRANSFORMACIÓN Y DE CONSTRUCCIÓN SOCIAL Y ECONÓMICA}

Mayor GERSON RiCARDo JAIMES PARADA

Articulación de la Triada, Universidad Empresa Estado ........................ 255

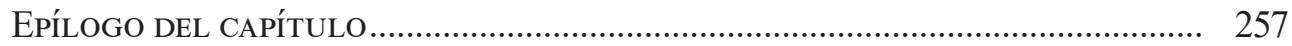

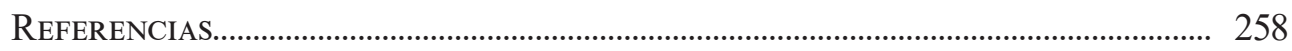

\section{THE ADVANCEMENT OF COLOMBIAN DEFENCE POLICY IN THE LATE} 1990S AND THE EARLY 2000S

Teniente Javier Alberto Castrillón Riascos

THE FARC AND THE DEMILITARIZED ZONE: CHANGING US PERCEPTIONS (1998-2002) ......................................................................... 265

DEFEATING THE FARC: US-GOC MILITARY COOPERATION (2002-2012): ............. 269

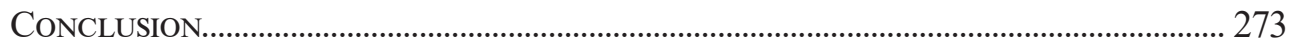

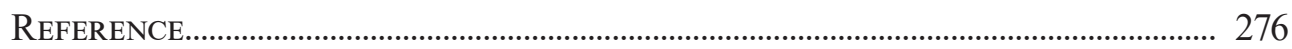

UN BALANCE FINAL

EL APORTE DE LAS FUERZAS MILITARES A LA PAZ EN COLOMBIA Mayor General JuAn Guillermo García SERNA

EL ESTADO-NACIÓN Y LA PAZ _................................................................. 286

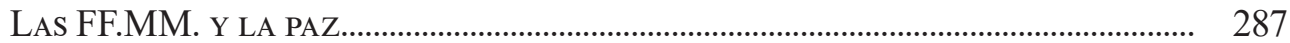

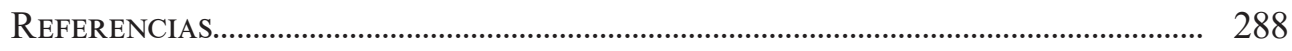




\title{
INTRODUCCIÓN
}

\section{DESDE LAS ALTURAS A LA ESCRITURA: \\ LA IMPORTANCIA DE LA MEMORIA HISTÓRICA PARA LA COMPRENSIÓN DEL PAPEL DE LA FUERZA AÉREA COLOMBIANA EN LA TERMINACIÓN DEL CONFLICTO ARMADO INTERNO}

\begin{abstract}
Subteniente AbRaham ORTIZ Miranda ${ }^{l}$
Todas las grandes cosas son simples, y la mayoría se pueden expresar en simples palabras: libertad, justicia, honor, deber, misericordia, esperanza.

Winston ChuRCHILL
\end{abstract}

\section{SOBRE LA NUEVA EDICIÓN}

La Fuerza Aérea Colombiana presenta la cuarta edición de su libro Victorias desde el aire: la Fuerza Aérea Colombiana y el término del conflicto armado, por motivo de constatar profundas deudas y necesidades. Para empezar, la comunidad académica ha tenido a menos las narrativas de aquéllos hombre y mujeres que permiten explicar todo el andamiaje que conforma el hecho de poder surcar los cielos patrios en una aeronave militar. Lo anterior tiene eco en la medida que la nación entera no ha podido detallar cómo una entidad castrense como la tratada, coadyuvó a que no se resquebrajara totalmente el orden constitucional y, por ende, la paz y bienestar de la ciudadana en general. Por lo tanto, la presente obra permite comprender no solamente los episodios lúgubres de enfrentamiento que vivió el país, sino que, a partir del registro de diversas memorias y testimonios, amplía la mirada de los investigadores sociales con el fin de que el colombiano de a pie nunca padezca aquél terrible diagnóstico de amnesia frente a la entrega que todo el personal de la Institución realiza en pro de su libertad, distinguiéndose así por ser vigías sempiternos de su integridad.

Historiador Universidad Nacional de Colombia - Sede Bogotá. Investigador en historia-Fuerza Aérea Colombiana. Comentarios a: aortizmiranda@gmail.com 
En este ejemplar el uso de la historia oral como herramienta metodológica prevalece por motivo que la misma permite comprender el papel que tuvo esta entidad castrense para la culminación del conflicto armado interno, sobre todo desde la década del noventa del siglo pasado hasta la actualidad. La presente edición, construida, revisada y actualizada en coautoría con reconocidos académicos y distinguidos miembros de la Fuerza Aérea Colombiana, ha sido el resultado de un meditado ejercicio de comprensión histórica de la Institución. Allí destaca la labor desempeñada por el equipo editorial que, con suma rigurosidad y ardua diligencia, estableció parámetros de selección y corrección de los capítulos subsecuentes. Tales lineamientos están basados en el objetivo de recuperar a las personas detrás de los uniformes pixelados arpía, devolviéndoles así sus intrínsecas características humanas. Esta nueva edición pretende volver sobre los valerosos pasos dados por múltiples soldados anónimos del aire, para de tal manera evidenciar las razones que tuvieron para elegir este arduo camino militar, entregarlo todo y nunca renunciar.

\section{DEBATES}

Mucho se ha dicho sobre el papel que la Fuerza Pública colombiana desempeñó durante el marco del conflicto armado interno en el país. Frente a este punto, diversas perspectivas teóricas e historiográficas han entrado en debate durante los últimos años, siendo su carácter múltiple lo que ha impulsado a que las mismas se enfrenten, pero que al mismo tiempo, y de manera paradójica, entre ellas se establezcan acuerdos, tácitos o explícitos, sobre los puntos de partida para la comprensión de la razones históricas que hicieron que la nación se volcara en un enfrentamiento intestino de tan largo aliento; consenso que se ha logrado establecer desde distintos ámbitos académicos en los que se desarrollan y desenvuelven los devenires del conocimiento histórico.

Múltiples han sido las voces rescatadas y reincorporadas a la narrativa histórica de la sociedad colombiana, lo cual ha permitido que el camino a la paz se pueda allanar de manera más sencilla. Es a partir de la capacidad de comprensión que surge de la mencionada reconstitución histórica que el carácter de los poderes políticos y su compromiso al interior de una democracia se vuelca hacia la inclusión, los incentivos y la responsabilidad con su papel constitucional consensuado. No obstante, los mencionados análisis parten de considerar al Estado como la institución de la política por antonomasia, concibiéndolo como un todo, al interior de la cual sus instituciones nunca, o casi nunca, entran en punga, siendo guiadas por objetivos y fines similares y compartidos, no importando los medios y métodos para la consecución de los mismos.

No obstante, tales visiones han repercutido a tal grado que cualquier razonamiento que se realice sobre la transformación histórica de las dinámicas 
de interacción intersubjetiva que se desarrollan al interior de las instituciones estatales, sean presentadas de forma lánguida y opaca. Para el caso de la Fuerza Aérea Colombiana, tal proceso de objetivación de las instituciones políticas ha conformado una prisión historiográfica ${ }^{2}$ que es aún más diciente en la medida en que su actuar legal se enmarca en el ejercicio y mantenimiento del espacio aéreo del país, conduciendo, así, "operaciones aéreas, para la defensa de la soberanía, la independencia, la integridad del territorio nacional, el orden constitucional y el logro de los fines del Estado" (Misión, 2019, párr. 1).

El carácter deontológico de la Fuerza Aérea Colombiana se ha interpretado, acompañado y complementado por multitud de factores que han redundado en la forma de concebir al soldado del aire. Relegando su concepción de humana natura, se ha percibido al piloto y al mecánico de aviación como partes inmanentes de las aeronaves militares colombianas. Al personal que compone la Institución le ha sido negada, en cierta medida, su trascendental dimensión de zoon politikón aristotélico, lo cual ha dado como resultado que se les suspendan, y, hasta cierto punto, supriman sus capacidades de actuar en comunidad y de integrarse por medio del lenguaje. Como un instrumento más de cualquier avión o helicóptero del Estado, los militares de uniforme de pixelado arpía son considerados erróneamente como simples máquinas adiestradas para estar en los cielos en los momentos de conflicto, desvaneciéndose así, todo su carácter de agente histórico. No hay que olvidar que múltiples fueron las agrestes circunstancias de vida que tuvieron que atravesar muchos de ellos durante el desarrollo del conflicto armado interno: con el propósito de la defensa nacional y el cumplimiento del carácter constitucional, tales situaciones se les presentaron con el talante de ser condiciones deshumanizantes. Sin embargo, como res cogitans que son, los miembros de la Fuerza entendieron que, en el ejercicio de su oficio, la noción autopoiética del ser desaparece completamente. Así, su siempre presente sentido de res publica se proyecta como ejercicio crítico contra aquél proceso de instrumentalización conceptual del humano (ARENDT, 1999, 138-181).

Sin embargo, esta abstracción de la capacidad de agencia que tuvo la Fuerza Aérea Colombiana para intervenir oportunamente en el conflicto armado interno, coadyuvando así a su resolución, arroja variadas dudas. Entre las múltiples cuestiones existentes, los distintos autores y capítulos presentes en esta obra,

Para el presente artículo se interpreta la noción de prisión historiográfica a partir de lo planteado por el historiador Max Hering Torres (2017). Si bien, dicho concepto fue implementado por primera vez por parte del reconocido historiador Germán Colmenares, aquí se conceptualiza el término no sólo desde la perspectiva según la cual ciertas obras con carácter histórico han regulado "la construcción de conocimiento", sino también en razón de que mencionados documentos han obstaculizado el fomento e integración de la pluralidad de voces necesarias para la construcción de interpretaciones del pasado más amplias, estando sus relatos muy pocas veces sometidos a la constante y "siempre a evaluación y revisión" (28-29). 
resuelven, de manera cabal, aunque dejando abiertas disímiles puertas para la investigación, la pregunta que se puede formular a partir del siguiente interrogante, amplio y general: ¿cuál fue el papel que tuvo la Fuerza Aérea Colombiana en el marco del conflicto armado interno? Es así que, haciendo uso de la historia oral y de una herramienta metodológica como la entrevista, los textos recogidos en esta edición se plantean como objetivo primordial la recopilación de recuerdos y vivencias que diferentes miembros de este cuerpo castrense agruparon durante el desarrollo de su servicio activo, contribuyendo así a la conformación de la memoria histórica no sólo institucional, sino también nacional.

\section{MEMORIA PARA LA HISTORIA, HISTORIA PARA LA MEMORIA}

Sin obviar la salvedad de que cada uno de los autores presentes en esta obra tiene un deber moral con los argumentos que expone, y que, por lo tanto, lo anterior no funge como representación univoca del pensamiento institucional de la Fuerza Aérea Colombiana, la presente edición de Victorias desde el aire: la Fuerza Aérea Colombiana y el término del conflicto armado, pretende volcar su mirada hacia aquéllos actores históricos ${ }^{3}$ que han sido desatendidos en los distintos estudios académicos, todo con el fin de realizar una reconstitución justa del pasado que incorpore a todos sus protagonistas. Esta necesaria reivindicación social del personal integrante de la institución castrense en cuestión pretende no soslayarlos del relato histórico para así exponer los duelos, traumas y catarsis que sufrieron en el contexto de un enfrentamiento irregular endógeno (BECERRA, 2014, 60-61).

Para que la historia ${ }^{4}$ pueda razonar el pasado y rinda una oportuna explicación del presente, es imprescindible su conexión con la memoria histórica. Aquélla primera práctica científica puede caer bajo los "tentáculos del olvido" en la medida que no realice una apropiación social de los tiempos pretéritos que analiza. Para que su fin de esclarecimiento de la verdad sobre los hechos ocurridos en el pasado sea amplio, incentivador e incluyente, la historia necesita que la memoria histórica le preste sus herramientas para que todos los episodios que antecedieron recobren vida, con lo cual se vuelve indispensable la recolección de testimonios y recuerdos (BECERRA, 2014, 62).

\footnotetext{
3 Pilotos militares, mecánicos de aviación militar, oficiales, suboficiales, soldados y personal civil de la Fuerza Aérea Colombiana.

$4 \quad$ Aquí se sigue una interpretación que se realiza del concepto de historia a partir de lo definido por Lucien Febvre (2000, 28-30). A pesar que se parte de lo argumentado por el reconocido historiador francés de la Escuela de los Annales, dicha noción se puede comprender como aquélla práctica científica que analiza al humano desde todas sus esferas intersubjetivas, siempre partiendo de su factor temporal. Es así que se entiende como práctica científica en la medida que no llega al establecimiento de parámetros históricos de comportamiento de los seres humanos (Leyes Históricas Humanas), aunque si se rige por metodologías científicas para la comprensión del pasado.
} 
No obstante, se debe tener en cuenta que la memoria histórica no es sinónimo de memoria, ya que, si bien, ambas prácticas de estudio del pasado se fundamentan en las experiencias vividas por los distintos agentes históricos de una sociedad, la primera se queda en el plano meramente individual, mientras que la segunda incluso transciende al conglomerado que estudia. Se debe partir de la concepción de que son los humanos quienes gestan la Historia ${ }^{5}$, dada su característica intrínseca natural de coexistencia en comunidad. Dicha vida en sociedad se ve marcada por distintas moralidades que funcionan como vehículos críticos reguladores de lo colectivo, haciendo factible la convivencia de diversas eticidades en un grado aceptable. Tales éticas, es decir, las concepciones relativas "a las acciones de las personas, desde el punto de vista de su obrar en relación con el bien o el mal y en función de su vida individual" (Ética, 2018, párr. 1), se construyen a partir de la existencia de memorias propias de cada persona.

La memoria, o, en otras palabras, la memoria individual, se construye a partir de las vivencias y recuerdos que cada sujeto erige y acumula durante el transcurso de su existencia. Tales reminiscencias del pasado se ven mediatizadas en la medida que acontece el paso del tiempo, además que están determinadas por la posición social en que se ve imbuida la persona portadora de las mismas, su nivel cultural, e inclusive su posición ideológica. Así, la memoria se transforma a la par que se vuelve selectiva. Por su parte, para que la memoria histórica tenga cabida, no sólo basta la reunión de memorias individuales, sino que es imprescindible que esos recuerdos y experiencias vivenciadas y aglomeradas por cada uno de los individuos de una sociedad, tengan eco y repercusiones sobre los mismos en su conjunto. Lo que se quiere decir es que, básicamente, la memoria histórica es memoria colectiva per se: es esa memoria compartida por una misma sociedad, un mismo grupo social o colectivo determinado, lo cual no necesariamente implica que una memoria histórica debe ser evidenciada en carne propia por cada agente histórico, sino que la misma tiene interés colectivo en la medida en que es compartida con otras personas (PAGÈs, 2015, 144-145).

Sin embargo, mencionada simplificación y abstracción de la complejidad de memorias que pueden hallarse en una sociedad determinada, recoge también los vicios selectivos de la memoria, por lo cual puede llegar a un estadio de desarrollo tal que una memoria histórica determinada se constituya como tradición previa a la existencia de individuos ubicados temporalmente adelante. Es así que, el peso que tiene la memoria histórica sobre sus relaciones con la historia y el presente, no se queda en el simple hecho de la reconstitución histórica de un pasado perdido, sino que trasciende al mismo, a tal punto que puede llegar a conformar una visión hegemónica

Se hace la presente distinción debido a que la Historia (con mayúscula) hace referencia al pasado per se de la humanidad en su conjunto, mientras que por historia (con minúscula) se define el campo de prácticas científicas que analizan los tiempos pretéritos. 
general del pasado, la cual se ve materializada e implementada bajo presupuestos morales y de "aprendizajes asociados al mismo" (PAGÈs, 2015, 131-132).

El establecimiento de esa clase de prisiones historiográficas conlleva a que se moldeen nuevas identidades nacionales, convirtiéndose, así, dichos relatos históricos en la "historia totémica" de Pierre Nora, es decir, en historia "destinada a una pequeña parte de la sociedad" (BECERRA, 2014, 66-67), con lo que se da una nueva dinámica de marginalización de actores históricos. Con base en lo anterior, la "nueva" historia desconoce las peculiaridades de los disímiles grupos sociales. Empero, y a pesar de lo anterior, a la memoria histórica se le debe otorgar el tratamiento científico necesario para que pueda agrupar y reestablecer las vivencias de los distintos agentes históricos de una sociedad con el fin de que permita generar dinámicas de relación intersubjetiva incentivadoras e incluyentes bajo el marco de la paz. Dicha práctica científica recupera su base fundamental de construcción de relatos personales capaces de sustentar identidades íntegras y eficaces. Así, los individuos, en medio de su característica intrínseca natural de coexistencia en comunidad, pueden llenar de "sentido al presente y les permite construir razonablemente el futuro" (PAGÈs, 2015, 132-133).

\section{HACER COSAS CON PALABRAS: REFLEJOS DEL ALMA}

La historia oral, entendida como método de investigación histórica, consiente en que la memoria histórica no caiga en la banalidad descrita, la cual consiste en conformar una historia dominante que permita ejercer poder por parte de un determinado sector de la sociedad sobre otro, es decir, evita que se entiendan las relaciones de poder como aquél "interés por garantizar -o procurar garantizar- la obediencia de las personas superando o evitando su oposición” (LUKES, 2007, 29). El uso que hace de fuentes como los testimonios orales, le permite a este tipo de historia una reconstrucción del pasado que puede responder a cuestionamientos complejos sobre el mismo, preguntas estas que se llegan a encontrar en el vacío en razón de la pesquisa de fuentes escritas que se realizó frente a dicho asuntos, lo cual restituye la potencia fundamental de la memoria histórica (MARIEZKURRENA, 2008, 227-228).

La vida cotidiana, los testimonios de "la gente común", y, para nuestro caso, las experiencias de los soldados del aire (muchos de las cuales no se han considerado a sí mismos como protagonistas del devenir histórico, quedando siempre en el anonimato del camuflado pixelado arpía) son imprescindibles para la historia oral en la medida que gestan una reconceptualización de los documentos verbales, los cuales permiten contrastar, confirmar o refutar hipótesis enunciadas a partir de

\footnotetext{
$6 \quad$ Entre comillas debido que puede dar continuidad a dinámicas de exclusión parecidas a las que pretendía combatir y que concebía como inmanentes a la "vieja" historia que trató de destruir.

7 Ver sección II. "Memoria para la Historia, Historia para la Memoria".
} 
fuentes escritas. Con el objetivo de romper la barrera del conocimiento histórico para así avanzar en la comprensión de la realidad pasada, este tipo de historia devuelve su dimensión humana a la Historia, todo en razón a que la evidencia oral ayuda a revelar más sobre el significado que sobre los hechos mismos. Como se ha mencionado ${ }^{8}$, es el humano, en medio de su característica intrínseca natural de coexistencia en comunidad, quien da cabida a la historia. En esa medida, todos los individuos se constituyen como testigos de la Historia, potencia esta que instrumentaliza la historia oral para dar como resultado una "mayor identificación con el pasado, haciéndolo propio" (MARIEZKURRENA, 2008, 228-232).

Como la implementación de la historia oral significa que sobresalgan una serie de sucesos y experiencias, sobre todo de carácter estético sensorial, este tipo de metodología histórica permite que se le pueda otorgar voz a aquellos sujetos que han sido partícipes de algún momento histórico determinado, lo cual los configura como aportadores trascendentales de visiones acerca de un hecho o suceso puntual. De allí que se de relevancia a los significados de vida que están contenidos en la comunidad estudiada, perspectivas estas que permiten el planteamiento de nuevas visiones sobre el pasado que posibilitan comprender, desde nuevas aristas conceptuales y teóricas, el presente en curso. Por medio de la historia oral, la memoria histórica reconstituye aquélla dimensión social en la que se percibe cómo "diversas personas pensaron, vieron, vivieron y construyeron su mundo" (RodríGuez, LuQUe y NAVAS, 2014, 193-195), lo cual permite una comprensión más amplia de la experiencia evidenciada por parte de un grupo de personas subalterno.

La recuperación de los recuerdos y vivencias a los que la historia oral da acceso, permiten lograr que se visibilice, en un primer estadio, el funcionamiento de la sociedad y, en un segundo estadio, de la vida en sí. A través del recuerdo narrado, el humano comprende su existencia, siempre a partir de un relato en que el autor, el narrador y el personaje se armonizan en un solo ente. Dicha labor compagina con los objetivos de la memoria histórica en la medida que reconoce el planteamiento de acciones transformadoras desde la academia para que se rompa con las prisiones historiográficas impuestas (RoDRíGUEZ et al., 2014, 197). No obstante, la riqueza que pueda brindar este tipo de historia no está exenta de caer en las esferas del subjetivismo y del relativismo cuando no se realiza el procedimiento metodológico positivista de contrastación de las fuentes. Bien sea que esta comparación de la información se realice a partir de otros testimonios orales o bien a partir de documentación escrita, la historia oral permite mostrar que incluso los relatos concebidos como falsos dan cuenta del momento histórico que se narra y del presente en que se enuncia, abriendo

8 Ver sección II. "Memoria para la Historia, Historia para la Memoria”. 
nuevas preguntas a la investigación del pasado por motivo de dichas distorsiones o vacíos (MARIEZKURRENA, 2008, 230).

La historia oral implementa, como herramienta primordial para la pesquisa de sus fuentes, la entrevista, a la cual no se puede llegar sin conocimientos amplios sobre el tema a tratar; esto permite la abertura de nuevas vertientes, registrando inclusive hasta lo omitido y no sólo lo dicho. De allí que el fin de la entrevista en la historia oral no sea otro sino el de entender experiencias por motivo que todo lo que aportan es significativo, siendo primordial saber interpretar "la experiencia de una persona, ya que su testimonio nos aporta el privilegio de conocer y comprender las vivencias íntimas" (MARIEZKURRENA, 2008, 231) de la misma.

\section{CONCLUSIÓN}

Para la presente edición de Victorias desde el aire: la Fuerza Aérea Colombiana y el término del conflicto armado, el lector podrá percibir que se hizo una selección acuciosa de los capítulos que debían ser publicados. Tales puestas académicas responden a los parámetros delineados: aportar a la historia y memoria histórica institucional. Con base en esto, los textos de los autores aquí escogidos permiten que la Fuerza Aérea Colombiana pueda contar sus vivencias durante el desarrollo del conflicto armado interno, respondiendo así, como primera aproximación, a la pregunta sobre por qué se dio la necesidad de que la misma actuara para proteger los intereses nacionales consagrados en la Carta Magna.

Es de resaltar la ardua y diligente tarea que desarrollaron los académicos participantes de este nuevo ejemplar donde prevaleció el uso de la entrevista, siendo que la información recopilada sufrió una incansable contrastación positiva con distintos tipos de documentación, sobre todo fuentes escritas. Mencionada doble labor le permite al lector generar un grado de confiabilidad tal que llega cerrar, en gran medida, la brecha de duda que pueda surgir con respecto a la veracidad en los testimonios compilados.

A la par, la construcción de los distintos capítulos tuvo el objetivo claro de coadyuvar a invertir todos aquellos procesos de invisibilidad a los que se ha visto advocada la Fuerza Aérea Colombiana, en especial sus miembros víctimas del conflicto armado interno. Tales planteamientos pretenden aportar a la tarea de otorgar una cabal reparación de aquéllos miembros de la Institución que se vieron afectados por los enfrentamientos armados endémicos. Con lo anterior, no se puede olvidar que ellos mismos han sido relegados por la simple razón de que sus hechos victimizantes se gestaron a raíz de las responsabilidades que el Estado les impuso con el fin de desempeñar su profesión de defensa y protección de la nación (Justicia, 2016). De allí que el empeño trascendental del presente libro 
se proyecte en el restablecimiento de la naturaleza humana del militar investido con el camuflado pixelado arpía.

La presente edición rompe con las prisiones historiográficas que, posiblemente, se han pretendido imponer desde el ejercicio de la memoria histórica por parte de determinadas agremiaciones sociales. Es así que los capítulos subsecuentes tienen como finalidad recuperar tanto los recuerdos como las vivencias que el personal de la Fuerza Aérea Colombiana haya podido tener en el marco de las confrontaciones bélicas endógenas del país, haciendo uso de aquéllas potencias fundamentales que componen tanto la memoria histórica como la historia oral. Los investigadores presentes en esta obra permitieron la construcción de la misma al plantear una perspectiva crítica que propende por la cimentación de un relato histórico más amplio.

En otras palabras, los autores que participaron en la elaboración de este ejemplar, abogan por la edificación de una historia en la cual se abarquen todas las representaciones del pasado que puedan tener los distintos sectores y agentes históricos de la sociedad colombiana. Lo anterior permitirá consolidar la factibilidad de un camino hacia la paz allanado de forma integral, intersubjetivo, incluyente e incentivador.

\section{REFERENCIAS}

Arendt, H. (1999) Crisis de la República. Madrid: Taurus.

Becerra, J. (2014). Historia y Memoria: Una Discusión Historiográfica. Pensar Historia, (5), 59-71.

Justicia. (07 de abril 2016). 'Militares no pueden ser indemnizados bajo Ley de Víctimas': Corte. Según el tribunal, los uniformados reciben reparación por parte de las instituciones castrenses. El Tiempo. Recuperado de: http://www. eltiempo.com/archivo/documento/CMS-16557401

Ética. (2019). Diccionario de la Lengua Española. Edición Tricentenario. Recuperado de https://dle.rae.es/?id=Pm2wZfs|Pm4ASgI

Febvre, L. (2000). Combates por la Historia. Barcelona: Ediciones Atalaya, S.A.

Hering, M. (2017). Editorial: Sin Prisiones Historiográficas. Anuario Colombiano de Historia Social y de La Cultura, 44 (1), 23-32.

Lukes, S. (2007). El Poder. Un enfoque radical. Madrid: Siglo XXI.

Mariezkurrena, D. (2008). La Historia Oral Como Método de Investigación Histórica. Gerónimo de Uztariz, (23-24), 227-233.

Misión. (2019). Fuerza Aérea Colombiana. Recuperado de https://www. incorporacion.mil.co/mision-29 
PAGÈs, P. (2015). Historia y Memoria Histórica: Un Análisis para el Debate. Kultur: Revista Interdisciplinària Sobre la Cultura de la Ciutat, 2 (4), 127-148.

Rodríguez, A., Luque, R., y Navas, A. (2014). Usos y Beneficios de la Historia Oral. ReiDoCrea. Revista de Investigación y Docencia, 3, 193-200. Recuperado de Creativahttp://digibug.ugr.es/bitstream/handle/10481/32326/ ReiDoCrea3-A24.pdf;jsessionid=3CAE2F204943AA5B3B52DEA2F6E0A$0 \mathrm{~F} 0$ ? sequence $=6$ 


\section{LA HISTORIA}





\title{
FUERZA AÉREA COLOMBIANA Y OPERACIONES DECISIVAS 1998-2015
}

\author{
RICARDO ESQUIVEL TRIANA ${ }^{l}$ \\ En cualquier caso, Colombia existe como nación en el mundo actual \\ BusHNELL, 1994. p. 15
}

\section{INTRODUCCIÓN ${ }^{2}$}

En febrero de 2012 Colombia logró que el grupo armado ilegal de mayor tamaño reiniciara diálogos para el cese de sus exacciones ${ }^{3}$. Escasos cuatro meses antes la Fuerza Aérea Colombiana lideró la operación 'Odiseo' en la cual resultó neutralizado el máximo cabecilla de ese grupo denominado FARC ${ }^{4}$. Podría inferirse que con esta operación la Fuerza Aérea fue decisiva para acercar el cese del conflicto armado en Colombia; también podría admitirse que una operación no era suficiente para debilitar al grupo y forzarlo a dialogar. Desde el concepto de victoria decisiva (GRAY, 2012) ambas inferencias se confirman mutuamente.

En primer lugar, incluso en un enfoque de guerra popular prolongada, el objetivo de la guerra es desarmar las fuerzas del contrincante o "privarlas de su capacidad de resistencia, y no significa aniquilarlas a todas físicamente" (MAO, 1968, p. 160).

1 Ph. D. en Historia. Asesor Historia-Fuerza Aérea Colombiana, 2015-2016. Comentarios a: resquivelt@ unal.edu.co

2 Informe de investigación adscrito al proyecto 'Historia FAC 1998-2015', Grupo de investigación 'Análisis en Contexto'-Fuerza Aérea Colombiana (Dirección de Análisis de Contexto y Posconflicto). Los borradores previos se beneficiaron de comentarios de los oficiales FAC: CP. Edison Duarte Parada, CP. Nora Patricia Gutiérrez Rodríguez y ST. Javier Alberto Castrillón Riascos, como de la politóloga (PUJ) Dalia Rodríguez Q. Otra versión modificada se publicó como artículo en EsQuIVEL, R. (2016, Enero-Julio). La Fuerza Aérea Colombiana y el cese del conflicto armado (1998-2015). Rev. Cient. Gen. José María Córdova, 14 (17).

3 Entre febrero 23 y agosto 26 de 2012 se realizó, en La Habana, el "Encuentro exploratorio" con el grupo para definir una agenda de diálogo para la paz. La mesa para dialogar sobre esta agenda se instaló en octubre de ese año, en Oslo (Noruega), y comenzó sus actividades en La Habana (Acuerdo general..., 2012).

4 La transcendencia del dialogo entre el gobierno y ese grupo no necesita debate. Pero siendo aquel un 'grupo armado organizado ilegal', según el DIH, aquí siempre se mencionará así o con sus relativos: 'grupo armado ilegal' o 'grupo ilegal'. Tampoco se asumen los términos del discurso usado por el grupo para describir su devenir porque, según un Manual de Redacción periodística, es un deber de responsabilidad social y de imparcialidad informativa (MENDOZA, 2006. p. 1-29). 
En la operación citada el relevo del cabecilla pudo ser fácil, aunque abrupto, siendo más complejo restablecer la moral de los subalternos que veían amenazados a sus máximos jefes. Solo por esto la operación 'Odiseo' fue una victoria decisiva de la Fuerza Pública porque contribuyó a debilitar la "capacidad de resistencia" del grupo. Si se considera que desde 1998 se han desarrollado operaciones con resultados similares, la noción de victoria adquiere plena confirmación.

En segunda instancia lo decisivo de las operaciones, hasta hoy, es evidente al contrastar el reinicio de diálogos en 2012 con su precedente de 1998. En esta última la Fuerza Pública se recuperaba de dos años de ataques por grandes destacamentos del grupo. En parte por ello, a un mes de posesionarse, el presidente electo Andrés Pastrana (1998-2002) se reunió con el anterior máximo cabecilla y firmaron un acuerdo preliminar para iniciar los diálogos. Sin embargo, enseguida el grupo lanzó una serie de 62 ataques contra instancias gubernamentales, el principal contra la base antinarcóticos de la Policía en Miraflores (Guaviare). Aun así, para iniciar los diálogos, el grupo exigió desalojar la Fuerza Pública de una zona entre Caquetá y Meta y, de nuevo, en noviembre de ese año, el grupo lanzó contra Mitú (Vaupés) el más grande de sus ataques.

El contraste sugiere que, en 1998, el grupo tenía la iniciativa para imponer condiciones. Justo ante el ataque a Mitú la Fuerza Aérea Colombiana lideró una operación decisiva, Vuelo de Ángel, que al recuperar la ciudad frustró los planes de largo plazo de aquel grupo e inauguró su debilitamiento. Todo lo anterior nos lleva a preguntar ¿cómo la Fuerza Aérea se convirtió en el poder decisivo para el cese del conflicto? ¿Cómo se caracterizan las operaciones decisivas que lideró la Fuerza Aérea al efecto?

La respuesta tentativa es que, entre 1998 y 2012 la Fuerza Aérea Colombiana lideró operaciones decisivas para acercar el cese del conflicto interno, así como para preservar la integridad del territorio nacional. Si bien la Fuerza Aérea obedece a las directrices trazadas por el Gobierno a través del Comando General de las Fuerzas Militares, durante ese periodo la Fuerza Aérea inició su cuarto momento histórico. ${ }^{5}$ Su capacidad decisiva se demuestra con la diversidad en las operaciones que debió cumplir bien fuera por decisión gubernamental, o bien como respuesta inmediata ante los ataques del grupo ilegal usando grandes destacamentos, del mismo modo que cumplió la paciente labor de neutralizar a los cabecillas. Antes vale aclarar que es una victoria decisiva.

Parafraseando a Valencia (1998), los cuatro momentos de la Fuerza Aérea Colombiana serían: 1) la instauración en 1916 de la aviación militar en Colombia, que alcanza hasta la proyección del poder aéreo sobre Leticia (1932); 2) el decreto en 1942 de autonomía operativa bajo el nombre Fuerza Aérea Nacional. Entonces, a raíz de los pactos de seguridad con Estados Unidos durante la segunda guerra mundial, el país adquirió equipos y envió pilotos y mecánicos a especializarse en ese país; 3) la adquisición en 1969 de la flotilla de helicópteros UH-1H, junto con aviones Mirage-5 el año siguiente, que reflejaron más las necesidades del país desde entonces; 4) la nueva proyección de poder aéreo desde 1998, que en parte se analiza en este capítulo. 
Según Gray (2002) el concepto victoria decisiva exige ciertas precisiones, una de ellas es ratificar que el uso de la fuerza militar es un instrumento de decisión usado por los estados, aunque su resultado no siempre es la decisión esperada (Gray, 2002, p. 9). Otra precisión es que la victoria decisiva en lo militar conduce a decisiones políticas, en cualquier caso, considerando una gama de opciones aceptables. Ejemplo de lo primero es que con el conflicto interno se decidió que Colombia es un estado-nación que puede existir por sí mismo (Bushnell, 1994). Ejemplo de lo segundo, es que desde 1998 el grupo ilegal venía sufriendo derrotas militares y su dirigencia no lo consideraba una derrota decisiva, pero en 2012 aceptó dialogar.

En este sentido la victoria decisiva puede manifestarse en tres niveles (GRAY, 2002, p. 11): a) el operacional, cuando la victoria decide el resultado de una campaña, p. ej. la 'Operación J.M.' (2003-2005); b) a nivel estratégico, cuando la victoria decide quién gana en lo militar, p. ej. la serie de operaciones exitosas que llevaron a debilitar al grupo y sentarse a dialogar; c) la victoria decisiva a nivel político, es la que se negoció en La Habana.

Pese a lo anterior un desafío para este capítulo fue cómo construir historia militar y sobre un período inmediato. Siguiendo a KeEgAN (1995) sería inconcebible afirmar que en Colombia ha habido guerra, en cuanto ese autor sostiene que: "El desierto, la tundra, las selvas tropicales y las grandes cordilleras son inhóspitas al soldado y al viajero. El intento de combatir en terreno sin agua o sin carreteras es imposible y cuando en tal terreno se llega al combate suele tratarse de escaramuzas entre tropas especializadas muy bien equipadas" (p. 9798). Así este criterio nos ubica cómodamente en el concepto de conflicto interno. Pero dado que, en Colombia, durante los diferentes períodos del conflicto, el peso principal de neutralizar a los grupos armados ilegales correspondió a las Fuerzas Militares sería inicuo soslayar un enfoque de historia militar.

Si en un debate disciplinar, entre narrar acontecimientos o analizar estructuras, triunfó lo segundo, también se abrió paso la Nueva Historia de las Batallas. Destacado exponente de esta, KeEgAN (1990) al afirmar que los ejércitos se crearon para combatir, enfatizó que la historia militar debe tratar sobre las batallas. Y continúa, porque es a través de lo que los ejércitos hacen, es decir, "ganar o perder batallas- como se cambian las vidas de las naciones y de los individuos" (KeEGAN, 1990, p. 40). Allí mismo advertía también contra la retórica de la historia, un peligro para el historiador (sobre todo en Colombia), donde solo importa lo que hicieron (o dijeron) los generales, los oficiales y los políticos, obviando la experiencia colectiva.

No obstante, KEEGAN impone otra salvedad para una historia de las batallas en Colombia, al afirmar que en los conflictos tercermundistas la experiencia de los soldados no es en batalla: "Porque hay una diferencia fundamental entre 
el tipo de escaramuza esporádica y a pequeña escala que es como la pequeña caldera del soldado y lo que entendemos como una batalla. Una batalla debe obedecer las unidades dramáticas de tiempo, lugar y acción." (KeEGAN, 1990, p. 26) Excluye así a la principal característica de la táctica de guerrillas usada por los grupos armados ilegales: rehuir el combate, mientras realizan un constante desgaste o golpes de mano.

En consecuencia, aquí, reivindicamos una historia de los combates, primero, porque como parte de su misión constitucional las Fuerzas Militares no pueden rehuir el combate con tales grupos; de hecho, el gobierno les impuso perseguirlos y responder a sus aleves ataques ${ }^{6}$. Segundo, porque el combate irregular, análogo a las batallas, supone un conflicto de voluntades y debe conducir a una decisión, ${ }^{7}$ la derrota del otro en uno de los niveles citados arriba con GRAY (operacional, estratégico o político). Pero al reivindicar los combates se interpone otro desafío metodológico, que trasciende la esencia del conflicto colombiano: cómo construir historia (pasado) de un acontecimiento vigente (presente). La dificultad para el historiador sería que no conozca todos los efectos de los acontecimientos (SAUVAGE, 1998, p. 66).

Por lo anterior, este capítulo debió orientarse como una historia del tiempo presente (o historia inmediata). Es decir, aceptó la necesidad de explicar el presente dada la aceleración de la historia. Siendo que la misma vigencia del conflicto impide consultar y/o exponer fuentes confidenciales, primero recurrió a las fuentes publicadas aceptando el debate socio-político sobre la historia (Barros, 2006, párr. 14). Al respecto KEEGAN sugería dos técnicas: primera, reconstruir la experiencia humana en la batalla (e. g. el combate -Espino, 2001, p. 165), improbable por la restricción de fuentes acotada y solo promisoria a futuro con la tendencia reciente de memoria histórica. La segunda opción, fue la asumida aquí en lo metodológico, inicialmente al seleccionar los combates que militares y académicos coinciden en considerar decisivos; luego, presentar someramente los contextos, el geográfico y el político, en los cuales se produjeron; después, describir el combate en sí y, por último, un balance de sus resultados ${ }^{8}$.

$6 \quad$ Son los gobiernos quienes deciden cómo emplear la Fuerza Pública: "Con los decretos 1268 (abril 18) y el 1362 (abril 29) de 1948, se asignaron a las Fuerzas Militares funciones de policía, debido al licenciamiento total del personal de la Policía (...) Desde entonces las Fuerzas Militares de Colombia no han regresado a sus cuarteles porque se les ha ordenado combatir" (...) a los diferentes grupos armados ilegales y al crimen organizado (EsquIVEL, 2001. p. 123).

7 Una salvedad adicional aplica a nuestro caso de estudio: "Las misiones de combate de la FAC no necesariamente involucran la entrega de armamento; por ejemplo, una aeronave C-130 puede realizar una misión de combate cuando transporta tropas como parte de la maniobra militar para neutralizar las amenazas, o una aeronave de comando y control realiza misiones de combate para dirigir las acciones bélicas en el campo de batalla." (FAC, 2013, Manual, p. 79).

8 Dicho autor describe cada batalla "a fragmentos" (KeEGAN, 1990, p. 89), entre otros incluye según el caso: Campo de batalla; El Plan; La preparación; El Ejército; Las tácticas; El bombardeo; Preliminares finales; La batalla; Infantería vs. Ametralladoras; Los heridos; Motivación para combate. 
Para cumplir lo anunciado aquí se analizarán seis operaciones decisivas, entre 1998 y 2014, encuadradas en tres ciclos de la evolución de la Fuerza Aérea Colombiana9. En un primer ciclo, de 1998 a 2003, cuando confluye un proceso de reforma con la adopción de una doctrina conjunta que incluye las operaciones 'Vuelo de ángel' y 'Delta'. Un segundo ciclo, de 2003 a 2008, reflejo de una política gubernamental ofensiva cuyo mayor desarrollo fue el bombardeo de precisión, incluye las operaciones 'Universal' y 'Aromo'. Desde 2009 hasta el presente, un tercer ciclo, donde la Fuerza Aérea realiza el esfuerzo principal al tiempo que se activan más unidades conjuntas, incluye las operaciones 'Sodoma' y 'Odiseo'. Al final, un balance de las seis operaciones magnifica la capacidad decisiva de la Fuerza Aérea por cuanto simultáneamente cumplió cientos de misiones de aplicación de la fuerza y de control del espacio aéreo.

\section{REFORMA DE LA FUERZA PÚBLICA Y NUEVO ENFOQUE OPERATIVO (1998-2003)}

La naturaleza del conflicto armado interno en Colombia fue mutando en cada uno de sus períodos, ${ }^{10}$ transcurridos entre el siglo XX y el XXI, es decir que variaron tanto sus causas como sus actores de origen político y delincuencial (Sánchez, 2009, p. 23). Tal mutación reflejó un cambio progresivo en los esfuerzos nacionales para resolver el conflicto y, por ende, estimuló un ajuste en el modo de operar de la Fuerza Aérea. La escasa historiografía sobre la Fuerza Aérea en el conflicto colombiano describe el cambio desde un ocasional suministro de apoyo aerotáctico al Ejército Nacional, en operaciones de contra-guerrilla (VILLALOBOS, 1993, p. 246, 336), hasta el permanente alistamiento para operaciones conjuntas y de combate directo (FAC, 2005, p. 184).

Desde el primer período del conflicto interno en Colombia hasta 1998, el gobierno incrementó esporádicamente sus recursos para contener ${ }^{11}$ a los grupos

9 Sobre el período previo el suscrito autor preparó en 2016 otro análisis cuya referencia sería: EsQuiveL, R. (2017). Transformación aerotáctica y conflicto en Colombia, 1985-1998. Boletín de Historia y Antigüedades, 864.

10 Del conflicto armado interno en Colombia se dice que un primer período fue 1930-1932, con foco entre Soatá y Málaga (Guerrero, 1991); un segundo, bajo el eufemismo 'La Violencia', fue 1948-1957, con focos en los Andes centrales y Llanos Orientales; el tercer período, lo inició el MOEC, de Tulio Bayer, en 1961 (Sánchez y Peñaranda, 1997; Valencia, 1992). Este último ahora se subdivide en tres períodos: el primero, va hasta 1982, origen de grupos armados ilegales de izquierda (FARC, ELN, EPL) y de derecha (M-19); el segundo, 1982-1996, donde los anteriores grupos subsumen al narcotráfico y surgen grupos armados de extrema derecha (Autodefensas ilegales); un tercer sub-período, 1996-2005, de "guerra contra la sociedad" (parafraseando a Pecaut, 2001). No obstante, citando el Protocolo 2 de Ginebra (1948) y dadas sus ínfimas cifras, se dice que no hubo conflicto ni guerra entre 1961-1982 (González, 2013, p. 11). Más variantes sobre esta caracterización del conflicto en Comisión Histórica (2015), aunque allí no se diferencia entre la historia del país y la del conflicto.

11 Se afirma que "El crecimiento [del Ejército] obedeció a una concepción estratégica de contención, bajo el eufemismo del 'control del orden público'.” (Santos, J., 2002, p. 51) 
armados ilegales. Incluso durante la década de 1990 cuando se intensificó el conflicto, las Fuerzas Militares pasaron de tener aproximadamente un número de 139.000 efectivos en 1992 a 146.000 en 1998, es decir, un incremento solo del 5\%. Aún sobre el número más alto, entonces, las Fuerzas Militares poseían una escasa superioridad de 2.3 a 1 frente a los grupos ilegales ${ }^{12}$ (EsQuiveL, 2001, p. 125).

La Fuerza Aérea, durante esa década de 1990, tampoco tuvo un incremento significativo excepto por la adquisición en 1992 de aviones de instrucción y en 1993 de helicópteros livianos y pesados (43 Hughes, 23 Bell, 8 UH-60). Otras adquisiciones vinieron después en el marco del Plan Colombia, cuyo presupuesto se aprobó en julio del 2000 por el Congreso de EE.UU., enfatizando la lucha contra el narcotráfico y el fortalecimiento de la Policía Nacional.

No obstante, en diciembre de 1998, la recuperación de Mitú fue un hecho que alteró la naturaleza del conflicto al evidenciar la capacidad decisiva de la Fuerza Aérea para derrotar a los grupos armados ilegales en su intención de desestabilizar al país. Tal capacidad empezó a desarrollarse progresivamente en medio del debate entre dos enfoques doctrinarios: uno, que además de imitar a EE.UU. se ajustaba a las imposiciones de la guerra fría; otro, que intentaba responder a las necesidades nacionales frente al conflicto (helicópteros, no caza bombarderos), al desarrollo de las regiones atrasadas (Satena) y responder a desastres.

La acción decisiva de la Fuerza Aérea en Mitú sobrevino justo cuando el gobierno iniciaba diálogos de paz con el grupo armado ilegal, lo que incrementó el impacto positivo de la acción sobre la solución negociadora. Los diálogos se prolongarían durante más de tres años, sin cesar las hostilidades y mientras la Fuerza Pública consolidaba una reforma para adecuarse al conflicto.

Esta reforma para un nuevo período de conflicto, se intensificó simultáneamente con el inicio del gobierno Pastrana y luego con el llamado Plan Colombia. EE.UU. suministraría a Colombia armas y entrenamiento para combatir el narcotráfico, mientras el gobierno colombiano adelantaría programas de desarrollo alternativo con fondos propios y europeos. Dada la urgencia de fortalecer a la Fuerza Pública, en particular sus capacidades contra los grupos ilegales, el Plan Colombia adquirió mayor relevancia. La capacidad de la Fuerza Aérea, contra el narcotráfico y contra los grupos ilegales, sería decisiva en el conflicto.

La recuperación de Mitú inauguró un cambio en la forma de operar la Fuerza Aérea, sin abandonar su misión de asegurar el espacio aéreo colombiano, ${ }^{13}$ un

\footnotetext{
12 Según las teorías vigentes la ventaja debería ser 10 a 1 para derrotar a los grupos armados ilegales; súmese a esa deficiencia que Colombia, distraída en el conflicto interno, tenía una desventaja de 24,5 a 1 para defender su territorio de los vecinos, como se explica en EsQuiveL, 2001. pp. 124-128.

13 La recuperación de Mitú también figura como la primera de la serie de operaciones exitosas de la Fuerza Pública que desde entonces incluyeron las de: Puerto Rico y Puerto Lleras (julio 1999); Hato
} 
logro que fue aprovechado en siguientes operaciones o que llevó a desarrollar nuevos desarrollos tácticos y tecnológicos. La Fuerza Aérea desplegó nuevas unidades, incorporó nuevas tecnologías, recibió nuevos equipos, adaptándose más a las condiciones de guerra asimétrica donde la velocidad, la sorpresa y la precisión superan las tácticas de guerrilla de los grupos armados ilegales. La neutralización del máximo cabecilla del grupo ilegal FARC, en noviembre de 2011, confirmó la efectividad de la Fuerza Aérea para hacer valer el control del territorio nacional por el gobierno.

\section{Operación Vuelo de Ángel (Mitú-Nov. 1998) ${ }^{14}$}

Campo de combate: El departamento del Vaupés, con $54.135 \mathrm{~km} 2$, es uno de los más extensos de Colombia y es más grande que países como Costa Rica o Suiza. Hace parte de la reserva forestal de la Amazonia, en la zona de transición entre los llanos de la Orinoquia y la selva amazónica; cubierto en gran parte por bosques, con clima húmedo tropical y temperatura media de 27 grados centígrados. El departamento está habitado por unas 27 etnias indígenas pertenecientes a las familias lingüísticas Makú, Arawak y Tukano, que representan $85 \%$ de la población del departamento. Su densidad poblacional es de 1,35 habitantes por kilómetro cuadrado sumando Mitú, la mayor concentración de población, y los demás municipios; a su vez, el $37 \%$ de la población se ubica en zonas urbanas.

La población indígena del Vaupés se ha readaptado según los sucesivos embates de la extracción de recursos: entre fines del siglo XIX y mediados del siglo XX, la del caucho. Desde la década de 1950, la explotación de maderas y especies exóticas. Desde la década de 1970, el auge del narcotráfico, impactando el crecimiento urbano de Mitú y Carurú. Desde la década de 1980, el oro superpuso otra ola de explotación que mantuvo a Mitú como centro de comercialización. No obstante, el control del cultivo y de la producción de base de coca lo ejerció el grupo ilegal, primero sobre el Alto Vaupés y luego sobre el resto del departamento (ACNUR, 2007, p. 7).

Mitú es la capital del departamento del Vaupés, un municipio con cerca de 7.000 habitantes, ubicada a $200 \mathrm{~m}$. de altitud sobre la margen derecha del río Vaupés, en la frontera con Brasil. Aunque en 1936 fue erigido el poblado, en parte para reafirmar la presencia colombiana frente a la influencia brasilera (PEÑA, 2011, p. 70, 81), hace apenas unos 40 años fue reconocido como municipio. Esa lenta evolución es atribuible tanto a la baja densidad poblacional como a su ubicación.

Corozal (agosto 1999); 'Berlín' (Santander, noviembre 1999); San Juan de Sumapaz (2000); ‘Gato Negro' (Vichada, febrero 2001); 'Tsunami’ (Nariño, mayo 2001), según El Tiempo (2001, agosto, p. 1-17).

14 La reconstrucción de esta Operación y de las demás en este capítulo sigue fuentes secundarias. Para el caso 'Vuelo de Ángel' las fuentes, aun las de miembros de la Fuerza Aérea, todas divergen en los detalles de cómo ocurrieron los hechos; para mayor objetividad el libro incluye sobre las mismas operaciones más descripciones realizadas desde otras disciplinas. 
El municipio constituye un resguardo indígena, excepto el área del casco urbano $(5 \mathrm{~km} 2)$. Fue un asentamiento ancestral de la etnia Cubeo, pueblo de la familia Tukano, sobre el cual intervinieron sucesivas misiones clericales. Ya en el siglo XX jesuitas y monfortianos indujeron la concentración de población en Mitú, convirtiéndose el municipio en polo de atracción de las comunidades indígenas para interactuar entre sí y con los servicios del Estado, como tal una expresión de democracia y de identidad colombiana en la Amazonia (Peña, 2011, p. 186).

Mitú está aislado del centro de Colombia. Por vía carreteable solo puede conectarse con la localidad de Monforth, a $54 \mathrm{~km}$ de distancia; aunque hay una extensa red de caminos que conectan a las comunidades del departamento. Tampoco es muy accesible por vía fluvial con el interior del país, dado que el río Vaupés abunda en raudales que limitan la navegabilidad. Desde el municipio de Carurú hasta Mitú el viaje puede tomar dos días. Por el mismo río Vaupés, que sirve de línea fronteriza con Brasil, desde Yabaraté toma unas 24 horas para llegar a Mitú; así como el río se conecta con el río Negro y el Amazonas.

Por lo anterior la vía aérea se convirtió en la principal forma de acceso. La pista aérea de Mitú se remonta a la década de 1920, la que años después se amplió reorientándola en sentido norte-sur, en ambas ocasiones por iniciativa de las misiones clericales. Al efecto cuenta con el servicio de vuelos nacionales de Satena y de servicios de carga regionales que cumplen otras aerolíneas (Alcaldía de Mitú, 2015).

Mitú es así un municipio importante, además del hecho de ser una capital de departamento, por reunir tres atributos relevantes para el futuro del país: uno, ser el polo de desarrollo de los resguardos indígenas alrededor; dos, ser un municipio expresión del dominio colombiano de la Amazonia y, tres, por ubicarse en la frontera con Brasil.

Preparación: Ya en 1986 se registró un hostigamiento del grupo ilegal contra el cuartel de policía en Mitú, a la par con las exacciones contra la población. A partir de 1993 se incrementó la presión del grupo sobre la población a través del reclutamiento forzoso, el desplazamiento forzado, el tributo al cultivo de coca y la cooptación del aparato político local (Vicepresidencia de la República, 2003, p. 7).

Desde abril de 1996, con el ataque en Puerres (Nariño), el grupo venía realizando acciones ofensivas contra poblaciones y unidades militares aisladas, para dispersar los recursos de las FF.MM. y pasar de la guerra de guerrillas a la de movimientos ${ }^{15}$.

15 MAO en su teoría de guerra popular prolongada aludió a tres etapas según la correlación de fuerzas, para las propias: defensiva estratégica; 'preparación' para la siguiente y, esta, la contraofensiva estratégica. Aparte aludió a tres "formas de lucha": de guerrillas, de movimientos y de posiciones (1968, p. 176). Aplicadas a su país en 1937, donde fuerzas regulares chinas resistían la invasión de fuerzas regulares japonesas, subrayó que la guerrilla (golpea y huye) era un auxiliar y usada eventualmente por campesinos en cualquier etapa. El grupo ilegal FARC se inició en forma de guerrilla según el 
Si bien, a partir de acciones similares en Las Delicias y El Billar, las Fuerzas Militares pudieron reaccionar ante estos ataques con mayor rapidez, cantidad y calidad del apoyo aéreo; así como con planes "mucho mejor estructurados" (Pardo, 2004, p. 546). No obstante, en 1998, la seguridad en Mitú era cubierta por 90 efectivos de la Policía Nacional, más 30 auxiliares bachilleres indígenas.

A mediados de 1998 inició el nuevo gobierno elegido por los colombianos, que presidía Andrés Pastrana. Este acordó, conforme a su campaña electoral, realizar diálogos de paz con el grupo ilegal FARC en una zona de distensión ${ }^{16}$. No obstante, el grupo ilegal persistiría en sus acciones armadas, según informe que difundió su dirigencia dos días después del ataque a Mitú (Semana, 1998, Diciembre, párr. 1). El ataque contra Mitú fue el tercero del grupo en 1998, en marzo lo hizo contra la Brigada Móvil 3 en El Billar y, en agosto, se tomó la base antinarcóticos de Miraflores auspiciada por Estados Unidos (Martínez, 2006, p. 288).

El combate: El domingo 01 de noviembre de 1998, pasadas las 4:00 de la mañana, unos 600 efectivos del grupo ilegal Farc (Restrepo, 1999) atacaron el municipio de Mitú $^{17}$. Siendo los blancos principales el cuartel de Policía, la Caja Agraria y la pista de aterrizaje, también fueron objeto de ataque entre otros los edificios de la Registraduría, los juzgados, las sedes de Telecom, la Escuela de Administración Pública, la Fiscalía y el Vicariato. Al efecto el grupo empleó, además de fusiles, ametralladoras M-60, lanzagranadas MGL-40 mm, morteros $60 \mathrm{~mm}$ (Radio Santafé, 2015), armas no convencionales ${ }^{18}$. Hacia las 16:30 el grupo logró tomar el casco urbano. Al parecer, el grueso del grupo se desplazó por el río Vaupés, pasando por Miraflores (Guaviare) donde meses antes se desalojó a la Fuerza Pública (MOE, 2010, p. 6). El control de Mitú fue recuperado por la Fuerza pública al cabo de 72 horas.

En el Comando General de las Fuerzas Militares, considerando que Mitú era inaccesible por tierra y que la pista del municipio estaba controlada por el contrincante, se decidió lanzar una operación aérea desde San José del Guaviare. Este municipio, capital del departamento de Guaviare, está ubicado a 180 millas (300 km) de Mitú. En consonancia, el Comando de la Fuerza Aérea ordenó

modelo cubano del 'foco' y en, la acepción maoísta, la etapa defensiva. En 1982, por decisión de sus cabecillas, habría pasado a la etapa de 'preparación' por incremento de efectivos, así que agregaron el 'Ep' (ejército del pueblo) a su nombre (CNMH, 2013, p. 114). Apenas en 1993 plantean desarrollar una guerra de movimientos, o sea, concentrar sus efectivos para golpear a la Fuerza Pública. En este intento fue que el grupo fracasó y ahora está sentado en la mesa de negociación.

16 Más detalles sobre esta zona en el apartado siguiente de este capítulo.

17 Otras fuentes mencionan hasta 1.500 efectivos del grupo ilegal. Aquí se prefiere la cifra más conservadora de 600 efectivos, porque aun así daría una ventaja a los atacantes de 6 a 1 contra los 90 policías de Mitú; también, porque no obtuvimos evidencia que respalde ninguna cifra.

18 P. ej. lanzar pipetas de combustible, unas rellenas con gasolina y otras con explosivos y metralla. 
coordinar la operación a la Base Aérea de Apiay (CACOM 2) ${ }^{19}$ ubicada a 270 millas (490 km.). Para la operación en Mitú, la Fuerza Aérea empleó aviones de transporte táctico $(\mathrm{CN}-235)$ y pesado $(\mathrm{C}-130)$, aviones de ataque y combate AC47T, AT-27, OV-10 y A-37, aeronaves de ala rotatoria utilitarios UH-60 y artillados AH-60 (FAC, 2005, p. 200; Pardo, 2004, p. 543). No obstante, los helicópteros no tenían autonomía para ir y regresar hasta Mitú (véase tabla 1).

Tabla 1. Distancias otros municipios y Mitú.

\begin{tabular}{|l|l|l|r|}
\hline \multicolumn{1}{|c|}{ Distancia } & \multicolumn{1}{c|}{ Millas } & \multicolumn{1}{c|}{ Distancia } & \multicolumn{2}{c|}{ Millas } \\
\hline Apiay a San José & 100 & San José a Mitú & 180 \\
\hline Apiay a Mitú & 270 & San José a Querarí & 31 \\
\hline Apiay a Querarí & 290 & Mitú a Querarí & 336 \\
\hline
\end{tabular}

Fuente: Elaboración propia.

Hacia las 6:15, desde la base de Apiay se envió un avión AC-47T (popularmente llamado 'Fantasma') para apoyar a los policías que resistían el ataque; este llegó a Mitú hacia las 7:40. Veinte minutos antes, habían llegado dos aviones OV10 Bronco para realizar bombardeo contra los atacantes. El segundo AC-47T, proveniente de la base de Tres Esquinas, llegó a las 8:45 para relevar al primero (FAC, 2005, pp. 193-194).

Eran las únicas “aeronaves que tenían capacidad de vuelo para llegar a Mitú y sostener combates durante tres o cuatro horas (...). Las tripulaciones harían contacto directo con el Comando de Policía de Mitú y así conocerían el lugar desde donde los atacaban y analizarían la situación para planear los apoyos.” (MARTínez, 2006, p. 291) Para asegurar las comunicaciones, desde Apiay se envió un avión T-27 para que sobrevolara a 22.000 pies de altura, entre San José del Guaviare y Mitú.

No obstante, fue casi imposible que las aeronaves usaran su armamento. Los pilotos al establecer contacto radial con el cuartel de policía, fueron alertados que los atacantes disparaban desde el hospital y desde una escuela, sin precisar donde se ubicaban. El cuartel mismo estaba rodeado de viviendas civiles, desde

19 Comando Aéreo de Combate-CACOM. La Fuerza Aérea comprende seis de estos comandos, con base en Puerto Salgar CACOM 1, en Apiay CACOM 2, en Malambo CACOM 3, en Melgar CACOM 4, en Rionegro CACOM 5, en Tres Esquinas CACOM 6; también cuatro Grupos Aéreos, con base en Leticia GAAMA, en San Andrés GACAR, en Yopal GACAS y en Marandúa GAORI. Además cuenta con el Comando Aéreo de Transporte Militar -CATAM, en Bogotá y el Comando Aéreo de Mantenimiento -CAMAN en Madrid. 
donde otros miembros del grupo disparaban. Una dificultad adicional es que no había información cartográfica sobre Mitú. En Apiay se recurrió a un policía, que sirvió en Mitú, para levantar un croquis del casco urbano ${ }^{20}$. Este se entregó al primer relevo de pilotos enviados al municipio sitiado; cada tripulación que regresaba ayudó a perfeccionar el croquis.

Otra dificultad para la operación aérea fue disponer de una zona de aterrizaje cercana a Mitú. Sin olvidar que los aviones de transporte y los helicópteros no tenían autonomía de vuelo para viajar hasta el municipio y regresar. Otras poblaciones del departamento no tenían la seguridad adecuada para las aeronaves y las tropas. La única opción fue una pista al otro lado de la frontera, en Querarí, un puesto de vigilancia del ejército brasilero en el vecino municipio de São Gabriel da Cachoeira ${ }^{21}$, a $56 \mathrm{~km}$ de Mitú. Pero tampoco había información disponible sobre las especificaciones de la pista, así que se envió un AC-47T para hacer reconocimiento, confirmar las coordenadas y tales especificaciones.

A través del Comando de la Fuerza Aérea se gestionó un permiso diplomático. El gobierno Pastrana invocó razones humanitarias para que Brasil permitiera establecer un puente aéreo, así reabastecer las aeronaves y evacuar los heridos. Mientras se obtenía el permiso, la Fuerza Aérea coordinó en Apiay la concentración de los aviones de combate y transporte, como los equipos de tanqueo FARE, ${ }^{22}$ provenientes de todo el país. Se solicitó a la base antinarcóticos de la Policía en San José del Guaviare encargarse del suministro del combustible JP4 hasta Querarí. También en San José, la Fuerza Aérea reunió personal técnico, controlador aéreo, armamento, helicópteros y aviones.

En Apiay, se concentraron los primeros 120 soldados, con 6 helicópteros UH60 y 2 helicópteros AH-60L (Arpía) ${ }^{23}$. A las 14:55 fueron enviados hacia San José para esperar la autorización brasilera, a su vez tendrían que esperar en Querarí a que el aprovisionamiento de combustible estuviera listo. Hacia las 16:00 horas se recibió la autorización de Brasil para usar la pista de Itibare, setenta millas al sur y por tiempo limitado; minutos después el grupo ilegal lograba copar el municipio.

A esta misma hora el primer C-130 (Hércules), con 100 soldados, y un CN-235 Nurtanio, el cual trasportaba tres tanques de gasolina (cerca de 1.500 galones),

$20 \quad$ El croquis se anexa en otro capítulo de este libro.

21 Del lado brasilero, hacia 2003, se contaban 10 bases dependientes del Comando Militar Amazónico con sede en Manaos. Este incluye tropas de infantería de selva, ingenieros, un comando naval y dos aéreos, además de la Policía Federal (Vicepresidencia de la República, 2003, p. 15). Existe un acuerdo de seguridad entre los gobiernos de Colombia y Brasil, que facilita la colaboración en la zona.

22 FARE: Forward Air Refueling Equipment, un equipo de reabastecimiento de combustible en áreas remotas.

23 Los helicópteros UH-60 (Black Hawk) son dotación en la Fuerza Aérea y en la Aviación del Ejército. Pueden ser para transporte de tropa (UH-60L) o artillados para combate (AH-60L, Arpía) con dos ametralladoras .50 y lanzacohetes (MARTíNEZ, 2006. p. 296). 
partieron de Apiay hacia San José. A mitad de camino se les ordenó dirigirse a Querarí, para arribar hacia las 17:30 horas, una vez reiterado el trámite ante Brasil. El C-130 fue el único enviado, la pista resultó más angosta y corta de lo que sus señales oficiales indicaban. En adelante, el transporte tuvo que hacerse en aviones $\mathrm{CN}-235$, con capacidad solo para 50 soldados. Mientras, hacia las 17 horas, el AC-47T que sobrevolaba Mitú perdió comunicación radial con el cuartel atacado. Su tripulación pudo observar impotente como el grupo ilegal sacaba a los policías del cuartel y los conducía hacia embarcaciones a la orilla del río.

A las 17:30, desde San José partió una escuadrilla de 7 helicópteros, 5 UH60 y 2 AH-60L, con 172 soldados del Batallón de Contraguerrilla 52 y 20 policías del Grupo Jungla. La mayoría de soldados de aquella unidad habían sufrido el ataque del grupo ilegal en El Billar; luego de pasar una temporada de reentrenamiento estaban dispuestos a cambiar su suerte. La orden era realizar un asalto aerotransportado en cercanías a Mitú, pero la noche llegó antes y dado que solo el helicóptero líder disponía de visores nocturnos, la escuadrilla debió seguir a Querarí (FAC, 2005, p. 195).

Considerando que en la selva la oscuridad es total, hacia las 18:00 se ordenó al AC-47T volar sobre Querarí para lanzar bengalas que iluminaran la aproximación de los helicópteros a la pista. Las aeronaves y la tropa enviada a Querarí, debieron pernoctar allí. Sin agua, sin comida, las tropas del Ejército sin comunicación radial y el equipo para bombear el combustible falló. A pesar de la falta de información precisa, a las 21:00 horas se realizó un pre-briefing ${ }^{24}$ decidiéndose improvisar los puntos de desembarco bajo la escolta de los helicópteros AH-60L.

De regreso el AC-47T, en la oscuridad, pudo detectar los movimientos del grupo ilegal mientras aseguraban el control en Mitú. Se procedió a neutralizar con efectividad suficiente para causar grandes bajas entre el grupo (Martínez, 2006, p. 302). Entre tanto en Apiay, arribaron un avión C-130, dos CN-235 provenientes de CATAM, en Bogotá, y un AC-47T desde la base de Palanquero (Perea \& Murcia, 2014, p. 31).

El lunes 02 de noviembre, siendo las 03:20 horas, un avión C-212 salió de la base de Tres Esquinas (Caquetá) hacia Querarí llevando equipos FARE y dos operarios para los mismos. Entre las 03:50 y 4:50 de la mañana partieron desde la base de Apiay hacia Querarí dos aviones CN-235 llevando combustible y alimentos. Hacia las 4:30 el AC-47T, los dos OV-10 y el T-27 reiniciaron sus operaciones. En Querarí, a las 5:30 horas se cumplió el suministro de agua y raciones para los 270 soldados concentrados allí, como fue reabastecido de combustible el componente aéreo táctico de la Fuerza Aérea.

$24 \quad$ Briefing: anglicismo que denomina una reunión previa al vuelo, donde se detallan los aspectos de la misión a cumplir y se verifican algunos procedimientos tácticos. 
La gestión diplomática ante Brasil logró una autorización solo para operar entre las 9.00 y las 15:00, hora colombiana. Así, desde la primera hora dos AH60L hicieron selección de campos y ablandamiento; posteriormente, los cinco UH-60 desembarcaron las tropas en lugares asignados a 7 kilómetros de Mitú, siempre escoltados por los $\mathrm{AH}-60 \mathrm{~L}$ y por un $\mathrm{AC}-47$ a mayor altura. "El enemigo fue detectado a las 09:45 horas por un Arpía, los UH-60L artillados procedieron al ataque." (Perea \& Murcia, 2014, p. 33) A las 11:30 horas terminó la primera fase de desembarco, 250 soldados.

Una hora y media después inició el combate en tierra con el grupo ilegal, los helicópteros no pudieron dar apoyo por falta de combustible, así que solo el AC-47T y los OV-10 pudieron proveer cobertura. El grupo ilegal había montado 35 puntos de emboscada contra las tropas, que resultaron en la muerte de 16 efectivos del Batallón 52 y 4 policías, así como heridos 30 militares y 4 policías. Mientras el Comando del Ejército insistió en que debían reforzarse las tropas así como evacuar los heridos y muertos, lo que se cumplió durante el resto del día y la noche transportándolos respectivamente al Hospital Militar en Bogotá o a Villavicencio.

Una vez vencida la autorización brasilera, desde Querarí regresaron a San José 4 helicópteros de transporte UH-60. De igual modo, los CN-235 regresaron a San José y Apiay con los equipos FARE. Así que las tropas que combatían sobre Mitú solo quedaron con el apoyo del AC-47T, con sus equipos de monitoreo, y de los OV-10, con visores nocturnos y radios con seguridad de voz (Martínez, 2006, p. 304); sin mayor descanso para las tripulaciones. Hacia las 17:00 horas, las tropas en tierra iniciaron un repliegue defensivo; a la misma hora que Brasil otorgó una nueva autorización para usar la pista de Querarí por 24 horas.

La autorización no fue informada a la base de Querarí, así que cuando a las 21:00 arribó un CN-235 proveniente de San José con combustible, los brasileros retuvieron a la tripulación de la aeronave ${ }^{25}$. Aclarada la confusión, a las 22:00 horas, helicópteros con visores nocturnos salieron de San José con otro grupo de soldados hacia Querarí; les siguieron tres aviones CN-235, volando solo por instrumentos. Entonces no todas las tripulaciones disponían de visores nocturnos, debido a que Estados Unidos restringió el suministro de ayudas a la Fuerza Aérea durante el gobierno Samper (MARTínEZ, 2006, p. 304).

El martes 03, el grupo ilegal comenzó a huir. Ese día, de madrugada, el AC-47T detectó con su sistema FLIR a miembros del grupo que huían por el río, neutralizó a varios de ellos y les hundió una embarcación. En conjunto,

25 Según Brasil las operaciones colombianas en Querarí excedieron el carácter humanitario, las considero operaciones de guerra y violatorias de los tratados internacionales. Por ello el gobierno brasilero envió luego una protesta oficial a su homólogo colombiano. 
las aeronaves lograron destruir 17 embarcaciones (El Tiempo, 1998). Hacia las 8:00, el AC-47T detectó otra columna en movimiento y procedió a neutralizarla, causándole unas 80 bajas. El combate por el ingreso al casco urbano se intensificó desde el martes a las 16:00 y siguió hasta las 5:00 horas del día siguiente (Padilla, 1998). Al amanecer del miércoles 04 de noviembre, los primeros soldados entraron a Mitú. Cuatro manzanas a la redonda del cuartel de policía habían sido destruidas por el grupo.

Los balances: En el ataque del grupo ilegal contra Mitú resultaron 21 policías muertos y 10 heridos. Entre los civiles, 16 fueron muertos y otros 9 heridos. La recuperación del municipio por la Fuerza Pública se saldó con la muerte de 16 militares y 4 policías, heridos 20 militares y otros 4 policías. El grupo ilegal se llevó secuestrados 61 policías, entre estos los miembros del mando policial y 14 miembros indígenas. Los secuestrados fueron internados en campos de concentración en medio de la selva, algunos por más de trece años y otros finalmente muertos en cautiverio.

Pese a tan trágico saldo, la recuperación de Mitú es reconocida como un éxito de la Fuerza Pública. "La operación Vuelo de Ángel fue el resultado de un programa de readecuación de las Fuerzas Militares, que dio vuelta a una situación reiteradamente desfavorable."'(Pardo, 2004, p. 546) El propósito del grupo ilegal, iniciado agosto de 1996 en Las Delicias, de pasar a la guerra de movimientos se frenó en Mitú. Sus ataques en masa contra unidades de la Fuerza Pública, en el suroriente del país, pasaron a ser una desventaja ante la capacidad de reacción y de alistamiento de la Fuerza Aérea Colombiana.

\section{OPERACión DELTa (ZoNa DE DiSTENSIÓN-FEB. 2002)}

Entre el 7 de noviembre de 1998 y el 20 febrero de 2002, por decisión del gobierno Pastrana, funcionó una 'zona de distensión' que estuvo bajo control del grupo ilegal. Esta zona, además de prórrogas sucesivas, fue ratificada como prerrogativa presidencial por la Corte Constitucional (2001). No obstante, durante los más de tres años que se mantuvo, el grupo no solo prosiguió sus acciones armadas, sino que hizo de la zona una base del narcotráfico y otros delitos.

Campo de combate: La 'zona de distensión' incluyó cinco municipios, en detalle: La Macarena, Vistahermosa, Mesetas y La Uribe (estos cuatro del departamento del Meta), más San Vicente del Caguán (del departamento del Caquetá). Por ende, el Presidente ordenó a la Fuerza Pública retirarse de dichos municipios (El País, 2013), en suma, un área de $43.090 \mathrm{~km} 2$ (véase tabla 2). En particular el Ejército debió abandonar el cuartel del Batallón Cazadores, en San Vicente, y la Policía Nacional cada uno de sus cuarteles por municipio. 
Tabla 2. Municipios de la zona de distensión 1998-2002

\begin{tabular}{|c|c|c|c|c|c|}
\hline Municipio & La Macarena & Vistahermosa & Mesetas & La Uribe & San Vicente \\
\hline Extensión $\mathrm{km} 2$ & 11.200 & 4.900 & 2.000 & 7.116 & 17.874 \\
\hline $\begin{array}{l}\text { Habitantes } \\
\text { urbano / rural }\end{array}$ & $2.700 / 11.500$ & $6.200 / 11.100$ & $3.000 / 10.470$ & $967 / 9.300$ & $7.288 / 40.000$ \\
\hline Economía & Agrícola; ganadería & Agrícola; ganadería & Agrícola; ganadería & Agrícola; ganadería & Agrícola; ganadería \\
\hline $\begin{array}{l}\text { Producción } \\
\text { coca has./kilos } \\
\text { x mes }\end{array}$ & $3.200 / 2.200$ & $950 / 600$ & $420 / 280$ & $800 / 540$ & $5.000 / 3.400$ \\
\hline Acceso & $\begin{array}{l}\text { Aéreo;río Guay- } \\
\text { abero }\end{array}$ & Carretera; río Güejar & Carretera; trochas & Trochas; río Duda & Carretera; ríos. \\
\hline Interconexión & $\begin{array}{l}\text { San Vicente del } \\
\text { Caguán, Guaviare }\end{array}$ & Granada & Uribe, Granada & $\begin{array}{l}\text { Caquetá, Huila, } \\
\text { Tolima, C/marca. }\end{array}$ & Huila, Meta \\
\hline $\begin{array}{l}\text { A t a q u e s } \\
\text { grupo ilegal }\end{array}$ & 1977 & 1998 (marzo) & 1998 (marzo) & 1998 (agosto) & nd. \\
\hline
\end{tabular}

Fuente: Elaboración propia basada en Semana (1998, Octubre).

Otra particularidad de la zona de distensión es que estaba incrustada en el Parque Nacional Natural de La Macarena. Tres de los municipios de tal zona eran parte del parque, a saber, La Macarena, Vistahermosa y Mesetas. En particular Vistahermosa alberga una de las mayores concentraciones de cultivos de coca del país. ${ }^{26}$ Desde este municipio, siguiendo por el río Güejar que sirve al Parque como límite por el norte, se ubicaba una cadena de comercialización de la coca; todo controlado por el grupo ilegal (FIP, 2006, p. 3).

Aunque el Parque de La Macarena tiene tres sectores diferenciados, a saber: hacia el occidente, vegas de los ríos Duda y Guayabero; hacia el oriente, llanura selvática entre los ríos Güejar, Ariari y el Guayabero Sur. La Sierra de La Macarena, con alturas entre los 300 y los 2000 metros sobre el nivel del mar. Predomina el clima amazónico norte, o sea, de tipo tropical con dos estaciones: una de lluvias, de abril a noviembre, de carácter torrencial (entre 250 a $450 \mathrm{~mm}$ mes); una estación de sequía, de diciembre a marzo, con temperatura hasta de $30^{\circ}$ centígrados. Los ríos y quebradas son abundantes y bastantes caudalosos (GonZÁLEZ, 1990, pp. 120-122). Hasta aquí un medio geográfico en el cual no debería haber guerra al decir de KeEgAN (1995).

En esta área el foco decimonónico de la colonización fue La Uribe, desde 1951 el eje de poblamiento se trasladó a San Juan de Arama, el primer poblado que se fundó bajo el dominio español en los Llanos colombianos (ESQUIVEL, 2002). La Uribe pasó a depender de San Juan en 1959, igual que otros caseríos que nacen entonces alrededor del Parque Nacional, entre ellos Mesetas, Vistahermosa, La

26 En 2004, se estimó que en el Parque habían 2.707 Has. cultivadas y Vistahermosa se concentraba en Vistahermosa, según la UNODC (citado FIP, 2006, p. 5). 
Macarena y Puerto Rico (Meta). Entre 1979 y 1982 se produjo una avalancha de colonos en estos municipios, atraídos por el auge del cultivo de la coca, alterando los ecosistemas del Parque Natural (GonzÁLEZ, 1990, p. 129). Es en ese contexto que el grupo ilegal ganó influencia en el área.

Durante la vigencia de la zona de distensión, el grupo ilegal procuró extender su dominio atacando sistemáticamente los municipios colindantes. Así ocurrió en el departamento del Meta con Puerto Lleras, Lejanías, Puerto Rico, San Juanito, El Calvario, Mapiripán, Puerto Concordia (El Tiempo, 1999). Igual pretendió en el Tolima con Purificación, la Alpujarra, Villarrica, Icononzo, Algeciras y Roncesvalles, además de concentrar efectivos en Prado y Cunday. La intención era establecer un corredor desde el municipio de Colombia (Huila) hasta la zona de distensión, en límites con los departamentos del Cauca y el Valle, para facilitar los tráficos ilegales hacia el Pacífico (El Tiempo, 2000).

A julio de 2000, unos 24 municipios alrededor de la zona de distensión habían sido hostigados regularmente. En consecuencia, la Policía se retiró paulatinamente de esos municipios. En el Departamento del Caquetá, entre ellos El Doncello, Puerto Rico, El Paujil y Cartagena del Chairá, así como los corredores viales que conectaban estos municipios con San Vicente, Montañita y Florencia (Colprensa, 2013).

La preparación: Al establecerse en 1998 la zona de distensión por orden presidencial, la Fuerza Aérea determinó que el Escuadrón de Reconocimiento debía prepararse para asumir el control aéreo de tal zona. Durante la década anterior este Escuadrón había fortalecido sus capacidades para, entre otras, realizar aerofotografía, fotointerpretación, monitoreo de señales de radio HF y VHF; así como recibió un avión Súper King B-300 equipado como plataforma de inteligencia de señales. Precisamente el reconocimiento aéreo se convirtió en un medio para vigilar las actividades del grupo ilegal en la zona de distensión; misión que progresivamente debió incrementar sus horas de vuelo y el volumen de información al respecto (Esina, 2014).

Cuando en febrero de 2002 el gobierno Pastrana decidió recuperar el control sobre los cinco municipios, debió sopesarse que en los planes del Ejército Nacional se preveían seis meses para lograrlo. Por su parte, la Fuerza Aérea preveía en su planeamiento facilitar el ingreso de las tropas de tierra en un plazo no superior a 15 días y entregó al Presidente la información sobre los objetivos para una operación aérea de 72 horas continuas (PEREA \& Murcia, 2014, p. 51).

La diferencia de tiempo es atribuible a la paciente labor de reconocimiento aéreo. En efecto la Jefatura de Inteligencia de la Fuerza Aérea había compilado, en los tres años previos, información precisa a partir del reconocimiento y vigilancia sobre la zona. Sobre esa información se logró identificar una serie de objetivos de la infraestructura que el grupo ilegal erigió allí para la producción y el tráfico de narcóticos. 
El plan: La Fuerza Aérea comprometió a sus diversas instancias de planeamiento. Al seleccionar los objetivos, por encima de todo, se evaluó que ninguno podía ubicarse en poblados o aledaños a estos. Los objetivos tampoco podían incluir alguno de los campos de concentración de los secuestrados por el grupo ilegal. Respecto a los objetivos próximos a zonas pobladas el Comando de la Fuerza Aérea decidió excluirlos. Respecto a los secuestrados, las tareas de información fueron coordinadas con las demás agencias de información de las Fuerzas Militares y de la Policía Nacional (Perea \& Murcia, 2014, p. 51, 54).

Varios de los Comandos Aéreos tuvieron una parte de la operación: CACOM 1, en Palanquero, sirvió como base de lanzamiento de las aeronaves Kfir, Mirage y T-37; desde CACOM 2, en Apiay, se lanzaron las aeronaves A-37, AC-47T, OV10 y T-27; CACOM 6, en Tres Esquinas, fue la base adelantada para la operación y recuperación de los T-27.

Por su parte, el Centro de Comando y Control de la Fuerza Aérea dispuso de su red de comunicaciones VHF. Según Perea \& Murcia (2014, p. 59), este sistema no garantizaba el contacto con las aeronaves al momento de descender sobre los objetivos para ejecutar su misión. Algo similar ocurría con la cobertura de radar, disponiendo solo del radar civil en Villavicencio para controlar el sector oriental de la zona objetivo y del radar de la base aérea de Tres Esquinas para el sector occidental.

El Comando de la Fuerza Aérea dispuso que el comando de la Base Aérea de Apiay (CACOM 2) desarrollara la operación. Allí se concentraron el personal y los equipos, incluyendo los técnicos en combustibles, comunicaciones, grupos SAR de búsqueda y rescate (RUBIANO, 2002).

Para recuperar la zona se activaron los planes 'Delta y Tora'. La denominada Operación Delta, correspondió a la Fuerza Aérea. Se usaron 31 aeronaves en total, todas con la capacidad de emplear lentes de operación nocturna (NVG). Según el tipo de misión a cumplir y las capacidades del equipo, evidenciando la versatilidad del poder aéreo, se detalla su uso en la tabla 3, así:

Tabla 3. Misiones y aeronaves en Operación Delta (2002)

\begin{tabular}{|l|l|l|}
\hline \multicolumn{1}{|c|}{ Misión } & \multicolumn{1}{|c|}{ Aeronave } & \multicolumn{1}{c|}{ Tipo de aeronave } \\
\hline \multirow{4}{*}{ Ataque e interdicción } & C-7 (Kfir) y M-5 (Mirage) & Superioridad aérea \\
\cline { 2 - 3 } & AT-27 y T-37 & Entrenamiento; acondicionadas para lanzar bombas \\
\cline { 2 - 3 } & OV-10A (Bronco) & Apoyo aéreo cercano \\
\hline \multirow{2}{*}{$\begin{array}{l}\text { Interdicción y apoyo } \\
\text { aéreo cercano }\end{array}$} & AC-47T (Fantasma) & Apoyo aéreo cercano \\
\cline { 2 - 3 } & AB-212 Rapaz & Helicópteros \\
\cline { 2 - 3 } & AH-60L Arpía II y III & \\
\hline
\end{tabular}




\begin{tabular}{|l|l|l|}
\hline $\begin{array}{l}\text { In t e l i g e n c i a, } \\
\text { vi g i l a n c i a y } \\
\text { recon oci mi ento } \\
\text { técnico }\end{array}$ & SA2-37 B y King 350 & Avión plataforma \\
\hline Asalto aéreo & Bell 212, Huey II y UH-60 & $\begin{array}{l}\text { Helicópteros para inserción de tropas y evacuar } \\
\text { heridos }\end{array}$ \\
\hline Despliegue de tropas & B-707, C-130 y CN-235 & Transporte \\
\hline
\end{tabular}

Fuente: Elaboración propia basada en Perea \& Murcia (2014, p. 53).

El combate: A las 5 del jueves 21 de febrero, la Fuerza Aérea inició la 'Operación Delta' con el bombardeo contra los objetivos previamente fijados, 85 en total, entre campamentos, talleres, bodegas de repuestos y de insumos, una pista ilegal en La Macarena; en conjunto infraestructura dedicada al narcotráfico. Para ello se utilizaron bombas de 150, 200 y 250 libras. Un balance del primer día de operaciones registró 56 salidas de aeronaves y solo un Kfir impactado por fuego enemigo, el cual pudo regresar a su base (EFE, 2002).

Después que terminó esta primera fase, la Fuerza Aérea continuó con las misiones de apoyo a las fuerzas del Ejército para la recuperación de las cabeceras municipales de la zona. A esta se le llamo 'Operación TH (Todo Honor)' (El País, 2003). Como tal, la Operación Delta se prolongó hasta el 26 de mayo de 2002, sumando "312 salidas con aeronaves de transporte e inteligencia y 233 salidas con aeronaves de combate" (FAC, 2005, p. 210); además de batir los objetivos previamente seleccionados, se brindó movilidad y apoyo logístico al Ejército.

Motivación para el combate: Recién concluyó la Operación Delta y Tora hubo un reconocimiento verbal a cada uno de los escalones que contribuyó a su éxito, notorio en cuanto participaron más de 10 tipos de aeronaves y se desarrollaron una gama amplia de misiones diferentes, todo con "cero accidentes" denotando un alto nivel de entrega (Rubiano, 2002).

Dado que Apiay se convirtió en la base de lanzamiento y recuperación de gran parte de las misiones de la Operación $\mathrm{TH}$, luego tuvo que coordinar con los diferentes mandos participantes. Entre estos se incluyeron el mismo Comando de la Fuerza Aérea, así como los respectivos comandantes del Comando Específico de la Operación TH, el del Teatro de Operaciones, el de la Fuerza de Despliegue Rápido, el de la Cuarta División, el de la Séptima Brigada, los de las Brigadas Móviles 6 a y $7^{\mathrm{a}}$ y la Policía Nacional.

\section{POLÍTICA OFENSIVA Y BOMBARDEO DE PRECISIÓN (2003-2008)}

Según SPENCER (2011) los desarrollos previos además de debilitar al grupo ilegal "crearon las condiciones para atacar a los líderes medianos y altos [así que en 
2007] mediante un bombardeo de precisión se dio el primer gran golpe dando de baja al Negro Acacio [...] luego se continuó con Martín Caballero [...] y a partir de entonces se siguió toda una secuencia de golpes importantes." (p. 107). Si bien en el pasaje citado se reconoce a 2007 como el año de los golpes exitosos, y veremos que fue gracias a la evolución táctica de la Fuerza Aérea, ${ }^{27}$ también se sugiere extender tales desarrollos desde 2002 hasta 2010, una interpretación de mayor contenido político que evidencia la dificultad de construir historia inmediata.

Vale recordar que el lapso 1998-2001 para las Fuerzas Militares fue de ofensiva permanente y una reforma que reflejó la asimilación de lecciones aprendidas. Según Leal (2010) estos factores tendieron a la inercia entre 2002-2006, dado que se redujo las acciones del grupo ilegal, pero sin propinarle algún golpe contundente (párr. 2). Por ello, afirma, la Política de Seguridad Democrática (Mindefensa, 2003) y su expresión militar, el Plan Patriota, fue tan ineficaz que llevó a su rediseño como Política de Consolidación (Mindefensa, 2007). Si a esta política, entre 2006 y 2010, con las mejoras en la inteligencia y las operaciones conjuntas, achaca los resultados destacados de 2007 y la misma 'Operación Jaque' en 2008 (LeAL, 2010, párr. 3), no explica la inercia del período previo.

Por el contrario, Spencer (2011) subraya que desde 2002 la estrategia de las Fuerzas Militares fue exitosa. En tal estrategia los mayores éxitos se lograron con las operaciones ofensivas de las Brigadas Móviles del Ejército Nacional y su articulación al Plan Patriota; en el período aquellas pasaron de ser 8 a 17 brigadas. La fase inicial del plan fue la operación 'Libertad I', iniciada en 2003, con la cual se frustró el cerco que pretendía el grupo ilegal sobre Bogotá y Cundinamarca. En la siguiente fase, se creó la Fuerza de Tarea Omega para volcar el esfuerzo sobre el sur del país; parte de este esfuerzo fue el inicio de las operaciones especiales contra los cabecillas del grupo ilegal (SPENCER, 2011, p. 86).

Un factor que coadyuvó a este éxito fue la desmovilización de los grupos de autodefensas ilegales. Con estos grupos, luego de firmarse el "Acuerdo de Santa Fe de Ralito" en julio de 2003, los diálogos llevaron a una desmovilización gradual que concluyó tres años después. El proceso también llevó a expedir la ley 975 de 2005, de "Justicia y Paz", para facilitar los procesos de paz, la reincorporación social de los miembros de los grupos armados ilegales y la reparación a las víctimas $^{28}$ (CNMH, 2014). Con menos frentes que atender, la Fuerza Pública pudo

$27 \quad$ Ya en 2001 se presentaron los avances en inteligencia aérea, como aviones con equipos de intercepción de radio y telefonía, de detección de calor; se incorporaron helicópteros artillados y blindados y se demostró una nueva técnica de bombardeo donde participaban aviones A-37, K-Fir C-7 y el AC-47T (El Espectador, 2001, Diciembre, p. 7A).

28 Entonces se creó la Comisión Nacional de Reparación y Reconciliación-CNRR-y a su interior se formó el Grupo de Memoria Histórica; este el precedente del CNMH, entre cuyos productos iniciales estaban en 2009 "Recordar y narrar el conflicto" y "Memorias en tiempo de guerra". 
concentrar más recursos en las zonas que el Plan Patriota determinó prioritarias. No obstante, algunos desmovilizados pasaron a conformar las denominadas 'Bandas criminales', generando una evolución del conflicto.

La diferencia a considerar es que, antes de estas operaciones del 2007, el esfuerzo principal solían realizarlo las Fuerzas Especiales con la Fuerza Aérea como apoyo. Ahora, con una mejor inteligencia, a la Fuerza Aérea tocaba el esfuerzo principal y luego llegaban las Fuerzas Especiales a consolidar. Priest (2013) atribuye aquellos éxitos a un programa de la CIA con apoyo del Joint Special Operations Command (JSOC), iniciado en 2003 para rescatar a tres estadounidenses secuestrados por el grupo ilegal; el programa mejoró los sistemas de inteligencia colombianos, pero no logró hallar a los rehenes ni neutralizar a los cabecillas del grupo (PRIEST, 2013, párr. 34).

Las soluciones llegaron desde la Fuerza Aérea. Allí los asesores estadounidenses propusieron usar 'bombas inteligentes'. Para lograrlo el presidente Uribe debió solicitarlas a su homólogo Bush. Luego se buscó adaptar el sistema Raytheon de los cazas estadounidenses a los A-29 Súper Tucano, sin éxito, pero funcionó en el viejo A-37 Dragonfly. Por último, el escollo legal lo resolvió un pool de abogados de la Casa Blanca, la CIA, los Departamentos de Justicia, de Defensa y de Estado: era procedente usar tales bombas contra los cabecillas de un grupo considerado una amenaza para Colombia y como narcotraficantes amenaza para EE.UU.; pero la CIA debía monitorear su uso para cumplir con la certificación de derechos humanos exigida por el Congreso de ese país (PRIEST, 2013, párr. 41-45).

No obstante, la Fuerza Aérea Colombiana debió desarrollar una nueva táctica para usar las 'bombas inteligentes'. El ataque aéreo lo inicia el A-37 que desde gran altura activa la bomba, seguido por los A-29 que volando más bajo lanzan bombas ordinarias sobre el mismo objetivo; así se buscaba ocultar el uso de la 'bomba inteligente'. Luego un AC-47, también volando bajo, con sus ametralladoras neutraliza el área inmediata en tierra alrededor del objetivo. En septiembre de 2007, por primera vez, se empleó este recurso contra alias 'Negro Acacio' y, pocas semanas después, el segundo fue alias 'Martín Caballero'. 'La muerte de los dos cabecillas provocó la deserción masiva en los destacamentos que ellos dirigían e inauguró la desintegración del grupo ilegal” (PRIEST, 2013, párr. 49).

\section{OPERACIÓN UNIVERSAL (SEP. 2007)}

Campo de combate: Entre San José del Guaviare y Barrancominas (Guainía). Barrancominas aunque es una localidad rural con menos de 1000 habitantes, era un epicentro de la producción de coca entre los departamentos de Vichada y Guainía. Aquella localidad contaba con una pista de 1.800 metros, convertida en la vértebra del narcotráfico, con un promedio de 80 vuelos mensuales. Desde 
allí una flotilla de lanchas remontaba el río Guaviare para recoger la producción de coca del grupo armado, la que negociaban con los grupos de autodefensa, los narcotraficantes del Norte del Valle o los brasileños (Semana, 2007).

El objetivo sería alias 'Negro Acacio', el cabecilla quien controlaba el narcotráfico y la adquisición ilegal de armas en el oriente del país; con aquella actividad generaba hasta un $80 \%$ de los ingresos del grupo ilegal. Al efecto mantenía contactos internacionales, como demostró la operación que en 2001 produjo la captura de alias Fernandinho, narcotraficante brasilero (Semana, 2001). Además, en 1999 negoció con el funcionario peruano Montesinos la compra de un lote de fusiles. Estaba acusado de narcotráfico, secuestro, tortura, homicidio agravado, terrorismo, extorsión, hurto, entre otros delitos, por lo que existían 23 órdenes de captura y una solicitud de extradición en su contra (Semana, 2007).

La preparación: En 2001, la Operación 'Gato negro' tuvo como objetivo principal neutralizar al cabecilla. Con ello se desarticularía el corredor de movilidad entre la Zona de distensión y los departamentos fronterizos, como desarticularía el tráfico ilegal que, desde las zonas de cultivo en los departamentos del Guaviare, Vichada y Guainía, conectaba con los países fronterizos, con Surinam y Paraguay. Previamente la Fuerza Aérea adelantó misiones de inteligencia aérea, con sus aviones plataforma Awac y Orión, registrando con rayos infrarrojo la información de apoyo para la Fuerza de Tarea Conjunta del Sur, con base en Tres Esquinas (Caquetá).

La operación se desarrolló en Barrancominas (Guainía), liderada por la Fuerza de Despliegue Rápido (FUDRA) y el Grupo Aéreo de Oriente (GAORI) de la Fuerza Aérea Colombiana. Aunque el cabecilla logró escapar, la operación condujo a la captura de alias Fernandinho, narcotraficante brasilero, así como la incautación de insumos, avionetas, vehículos venezolanos y brasileros, un cargamento de armas, entre otros materiales (VÁSQUEZ, 2001).

Desde entonces se cuentan seis intentos ${ }^{29}$ más de la Fuerza Pública para neutralizar al cabecilla (BEDOYA, 2007). En 2007, como resultado de una efectiva tarea de inteligencia, se realizó la Operación Sol Naciente. Una operación conjunta, desarrollada por la Fuerza de Tarea Omega, y coordinada con la Policía

$29 \quad$ Intentos resumibles así: desde 2001 inteligencia del Ejército volvió a infiltrar su campamento en el Meta, se planeó una operación 'Gato Negro II' pero se frustró porque llegó a la prensa; en 2003, en límites entre los departamentos de Meta y Vichada, el Ejército Nacional y la Fuerza Aérea efectuaron la operación 'Zorro', después de identificar uno de sus principales campamentos, no obstante logró huir (FAC, 2003); la operación 'Implacable' en Cumaribo (Vichada); en 2004 se ubicó su nuevo campamento, cuyo asalto tampoco produjo el resultado esperado; de nuevo se infiltró su campamento sobre el río Papunaua (Guaviare), en 2005, durante la operación Troya fue atacado el grupo de lanchas donde se desplazaba y volvió a escapar; un año después se logró infiltrar uno de sus anillos de seguridad, lo que llevó a la Operación 'Sol Naciente' cuando el cabecilla fue neutralizado. 
Nacional y el DAS, dirigida a neutralizar a alias el 'Negro Acacio'. La información de inteligencia se orientó no solo a confirmar la ubicación del campamento, también a constatar que no hubiera secuestrados allí (El País, 2007). Primero hubo un bombardeo de su ubicación, luego ingresaron las tropas para efectuar el barrido de la zona.

El combate: Con pocas horas de anticipación, en la Base Aérea de Apiay (Meta), el comandante del Escuadrón 211 recibió la orden de alistar tripulaciones para seis aviones en condiciones NVG. El liderazgo del comandante era desafiado con esa orden, cómo organizar de la mejor manera a los pilotos disponibles. Entre estos contaba con pilotos instructores y pilotos operacionales de gran experiencia, otros recién llegados de vacaciones o con poca experiencia, un grupo muy disímil. Aún más, cómo el Escuadrón podía realizar un ataque nocturno cuando nunca se había siquiera discutido sobre ello.

Hacia la medianoche, el comandante debió presentarse ante su jefe en la Base para recibir más detalles. El ataque lo realizarían dos A-37 y seis A-29B, contra un objetivo ubicado a 190 millas de Apiay, a cualquier hora desde ese momento. Muy pocos detalles para el comandante, en una operación "que por primera vez se realizaría en la Fuerza Aérea, ocho aviones con NVG, ataque simultáneo a la hora $\mathrm{H}$ contra un objetivo que no sabía que era pero que suponía era muy importante.”' (ESCOM 211, Informe Operación 'Universal', septiembre 25, 2007).

A las 01:00 horas, del sábado 01 de septiembre de 2007, se actualizó a las tripulaciones con solo un dato adicional: las coordenadas de un área general. Había que prepararse para el despegue en menos de 30 minutos, incluido un briefing de 5 minutos con los pilotos para explicar la maniobra a realizar. La hora de despegue cambió, se autorizó a las 04:00 horas. Los A-29B iniciaron su vuelo de crucero en dos escuadrillas de a tres aeronaves cada una, la segunda manteniendo contacto visual con la primera.

Desde el control de la operación se ordenó retrasar 15 minutos el ataque. Las aeronaves debían sostenerse en sobrevuelo, problema para el comandante del escuadrón cuya aeronave solo tenía un tanque de combustible. Las demás aeronaves disponían de dos tanques, es decir, disponían de una hora más para sostenerse en vuelo. Pero a continuación se anunció un nuevo retraso mientras los A-37 despegaban. También la nubosidad aumentó obligando a desplazar el escuadrón a un nuevo sitio para sobrevolar manteniendo el contacto visual.

Recibidas entonces las coordenadas específicas y estimando su llegada al objetivo el líder de los A-37 determinó la hora del ataque. Las condiciones meteorológicas empeoraban con el pasar de los minutos así que el comandante del escuadrón, buscando mejores condiciones, ordenó proceder al punto y descender; en la transición la segunda escuadrilla se separó y tampoco se veía el terreno. A escasas millas del objetivo, a las 4:33 horas, los A-37 liberaron sus 
bombas y en seguida los A-29B picaron para liberar las suyas. Sin el peso de las bombas la aeronave del comandante de escuadrón pudo regresar con combustible suficiente a su base.

Mientras regresaban, los pilotos escucharon el reporte que desde un AC47T confirmaba que el objetivo había sido impactado y la infraestructura del grupo ilegal había sido inutilizada. El bombardeo de precisión realizado por las aeronaves Súper Tucano, tuvo un margen de error de escaso un metro; ello usando bombas de 500 libras. (El Tiempo, 2007). Apenas en la base, al presentar su misión cumplida, el comandante del Escuadrón 211 escuchó de su jefe que el objetivo era alias el 'Negro Acacio'.

El mal tiempo demoró una segunda fase. Tropas de Fuerzas Especiales que volaban a bordo de cinco helicópteros Black Hawk no pudieron realizar el asalto. Apenas a las 11:10 estaban de regreso en San José del Guaviare. A las 16:45 la Fuerza Aérea realizó un nuevo ablandamiento y una hora después vino el asalto al campamento. Este fue copado en solo 25 minutos, pero la oscuridad impidió hacer un barrido de la zona obligando a las tropas a emboscarse para pasar la noche. El domingo en la mañana, a las 07:00 horas se realizó un segundo desembarco (El País, 2007; El Tiempo, 2007).

\section{Operación Aromo (OCT. 2007)}

Campo de combate: El área de la operación se encuentra entre los municipios de Zambrano, Carmen de Bolívar y San Jacinto. Esta área hace parte de la más conocida como los Montes de María, rodeada de sierras escarpadas y vegetación tupida, que corre desde el interior del país hacia la costa Caribe. El municipio de Carmen de Bolívar, el epicentro de la operación, tiene una extensión de $954 \mathrm{~km} 2$ y una población (a 2005) de 67.952 habitantes. Su geografía es quebrada, dada su ubicación dentro del sistema orográfico de los Montes de María.

Carmen de Bolívar, asentado sobre áreas indígenas descendientes del Finzenú, es fundación dieciochesca del dominio español. Su actividad económica actual está determinada por la ganadería extensiva y la producción de tabaco para exportación. Se une a través de la carretera Troncal de Occidente con la costa Caribe y el interior del país; por la Ruta del Sol con el César, por la Troncal de Oriente hacia los Santanderes y tiene acceso al Río Magdalena por carretera intermunicipal (Alcaldía de El Carmen, 2013). La operación se cumplió en la zona Aromeras Sur, a ocho kilómetros de Carmen de Bolívar.

El objetivo era neutralizar al cabecilla del grupo ilegal que delinquía entre los departamentos de Bolívar y Sucre, alias 'Martín Caballero'. Sus exacciones incluían la extorsión, el secuestro, la siembra de minas antipersonal y atentados terroristas contra la población y la Fuerza Pública. La Fiscalía General de la 
Nación lo acusó, entre otros delitos cometidos de 1992 a 2006, de los ataques a Puerto López (Antioquia), San Cayetano, San Jacinto y Córdoba (Bolívar), de varios atentados terroristas en Cartagena y en las vías del departamento de Bolívar, y del secuestro del ex ministro Araujo. En suma, era responsable de causar 420 muertos y 896 heridos civiles, así como de causar 218 muertos y 336 heridos entre miembros de la Fuerza Pública (GÉLvez et al, 2014, p. 84-88). Por lo anterior se determinó que era un objetivo de alto valor estratégico (OMAVE) a ser neutralizado.

La preparación: Entre marzo y octubre del 2007 se desarrolló la 'Campaña Alcatraz', dirigida contra el narcotráfico manejado por el grupo ilegal FARC en los departamentos de Bolívar y Sucre. En las dos primeras fases, en marzo y abril, luego de una intensa labor de inteligencia, tropas del Comando Conjunto del Caribe neutralizaron parte de las cuadrillas que delinquían en la zona (Mindefensa, 2007, Campaña, párr. 3). En la tercera fase, en octubre y llamada 'Operación Aromo', correspondió a la Fuerza Aérea neutralizar al cabecilla del grupo.

La información sobre el objetivo la obtuvo la Fuerza Conjunta de Acción Decisiva (FUCAD). La Jefatura de Operaciones Especiales Conjuntas (2007; hoy CCOES) asignó a la Armada Nacional recoger la información sobre el objetivo. Una de las fuentes de información fue el mismo ex ministro Araujo, quien permaneció secuestrado por el grupo ilegal durante seis años (del $2000 \mathrm{al}$ 2006). El cabecilla también fue objeto de interceptación de las comunicaciones, de seguimiento personal y desplazado de forma conveniente por la maniobra de fuerzas terrestres. Los anteriores factores llevaron a reducir el margen de error de su ubicación por radiogoniometría a 20 metros, en la zona rural del municipio del Carmen de Bolívar (GÉLvez et al, 2014, p. 90). Confirmada su ubicación se ordenó aplicar el poder aéreo contra el objetivo.

El 23 de octubre, hacia las 20:00 horas, de parte de la Jefatura de Operaciones Especiales se recibió en CACOM 3 (Malambo, Atlántico) la información para la operación. Veinte minutos después se hizo el planeamiento con el comandante del grupo de combate aéreo. De modo que a las 21:00 horas se dispuso armar las aeronaves y llegado ese material, entre las 23:00 horas y las 05:00 del día siguiente se adelantó la configuración de las mismas. Después de actualizar alguna información, apenas a las 16:30 se ordenó iniciar las misiones asignadas. En ese momento, con un briefing de solo 5 minutos los pilotos fueron avisados de su misión; una medida para garantizar la reserva sobre el objetivo a alcanzar.

Las tácticas: El 24 de octubre de 2007, a las 17:30 horas, despegaron dos aviones A-29B desde la base de CACOM 3. Cinco minutos después les siguieron cinco aviones A-37B; debían realizar una misión de ataque estratégico ${ }^{30}$. A las

30 En los medios de prensa se hace un manejo equívoco sobre los conceptos de ataque y bombardeo. La misión u operación de "ataque estratégico", aunque acción ofensiva desde el aire contra objetivos 
18:10 horas, se les sumó un avión SA2-37B para apoyarlos con la misión de servicios para el combate y operar como controlador aéreo. Para evitar que el grupo ilegal rastreara la operación, en las comunicaciones aeronáuticas se procedió como si fueran aeronaves comerciales.

Durante la operación los pilotos también mantuvieron silencio de radio, al tiempo que debió preverse evitar la alteración del tránsito aéreo del sector. Igual se previó no afectar a las tropas terrestres, listas a corta distancia para ocupar el objetivo. Para esto el SA2-37B se sostuvo en sobrevuelo reconociendo con sensor infrarrojo para coordinar el asalto aéreo y las tropas de superficie; vale subrayar que se trataba de una operación nocturna.

El mismo día, a las 18:35 horas, despegaron con dirección al objetivo un helicóptero AH-60L ('Arpía') y en seguida un UH-60, con equipo de visión nocturna (NVG). El primero perteneciente al CACOM 5, con base en Rionegro (Antioquia), el segundo era de la Aviación del Ejército. El despegue se hizo desde la pista de Zambrano (Bolívar), sede de la Brigada de Infantería de Marina 16 (BRIM-16). El helicóptero AH-60L debía cumplir dos misiones: de apoyo aéreo cercano y de defensa aérea. Este Arpía no podía disparar a más de $500 \mathrm{~m}$. por fuera del área objetivo, para no afectar a las propias tropas que hacían parte de los cierres y observatorios en tierra. También debía designar dos zonas de desembarco, una $200 \mathrm{~m}$. hacia el sur del objetivo y otra a $200 \mathrm{~m}$. hacia el norte del mismo (GÉLVEZ et al, 2014, p. 94).

El combate: A las 17:52 horas, dos A-37B lanzaron bombas de precisión sobre el objetivo; en seguida y hasta las 17:54, otros tres A-37B y los dos A-29 lanzaron bombas ordinarias alrededor de donde se encontraban los miembros del grupo que protegían al cabecilla. "En un minuto y 47 segundos los aviones entregaron armas en una superficie de una hectárea lo cual demuestra el alto grado de precisión y coordinación de los pilotos de combate de la Fuerza Aérea Colombiana." (GÉLVEZ et al, 2014, p. 93). En total se lanzaron 32 bombas, cuya precisión fue del 100\% sobre el objetivo.

Pasado el bombardeo, a las 18:45 horas, arribó al objetivo el helicóptero AH60L, escogió la zona de desembarco sur y lo preparó con cohetes y munición .50, como en seguida designó la zona norte al UH-60 e iniciaron el estacionario para la inserción por rappel de los comandos. En la zona sur desembarcaron 18 comandos del BACOA ${ }^{31}$ para consolidar el objetivo; en la zona norte otros 17 para impedir la

militares en tierra y agua, procura neutralizar los centros de gravedad del contrario (FAC, 2013, Manual, p. 87). El "bombardeo estratégico" se remite al paradigma doctrinal de las guerras mundiales cuando se bombardeó masiva e indiscriminadamente las retaguardias enemigas; pese a su nula efectividad, solo medio siglo después se adoptó paulatinamente el "bombardeo de precisión" (HAULMAN, 2014. p. 156).

31 Batallón de Comandos, creado en 2002 durante el gobierno Pastrana, para atacar objetivos de alto valor y lanzar asaltos aéreos sobre el campo enemigo; primero dependió del Comando de Operaciones Especiales del Ejército (RAMSEY, 2009, p. 98; Moyar et al., 2014. p. 30). 
fuga de los efectivos del grupo ilegal. Mientras el AH-60L se quedó en apoyo de las tropas, el UH-60 retornó a Zambrano por el otro destacamento de comandos.

No obstante, al bombardeo los helicópteros fueron recibidos con disparos de los miembros del grupo ilegal, incluso de ametralladora M-60. Una vez desembarcados los comandos de la segunda zona tuvieron que pedir apoyo de fuego, "comenzando así una combinación de armas tanto de la tropa como del Arpía con cohetes, munición calibre .50, ametralladoras, lanza granadas, fusilería y bengalas durante varios minutos" (GÉLVEZ et al, 2014, p. 104). Luego de solicitar alto al fuego iniciaron el registro y encontraron al cabecilla muerto, pese a que su gente de huida intentó llevarse el cuerpo; otros 18 efectivos del grupo también fueron neutralizados por la Fuerza Pública.

Motivación para combate: “'Alcatraz' fue una exitosa operación conjunta de las Fuerzas Militares de Colombia donde la Armada Nacional aportó la inteligencia, la Fuerza Aérea realizó el ataque estratégico y el Ejército Nacional consolidó la operación" (GÉLVEZ et al, 2014, p. 99). La Armada Nacional fue la fuerza que durante más tiempo enfrentó a la fracción del grupo ilegal en los Montes de María, perdiendo 242 efectivos entre oficiales, suboficiales e infantes de marina. También la Policía Nacional perdió unos 20 efectivos a manos del grupo en esa región del país (ARC, 2007, párr. 8).

\section{FUERZA AÉREA, LA DECISIVA Y UNIDADES CONJUNTAS (2009-2015)}

En alguna perspectiva foránea el relativo éxito de Colombia, contra el narcotráfico y los grupos armados ilegales, es atribuible al desarrollo a largo plazo de capital humano en la Fuerza Pública. Esta tendencia la complementaron los asesores estadounidenses con la promoción de oficiales y funcionarios colombianos a posiciones de liderazgo (Moyar et al, 2014, p. ix). En otra perspectiva el desarrollo de una capacidad nacional a largo plazo es evidente por cuanto la Política de Seguridad Democrática (Mindefensa, 2003) fue continuación de la "Iniciativa para la paz" (1988) del gobierno Barco y de la "Estrategia contra la violencia" (1991) del gobierno Gaviria; estas dos, políticas con una visión político-estratégica del conflicto (Santos, J., 2007, p. 354). El aparente bache entre ellas lo explica el diferendo con EE.UU. durante el período Samper y el giro de énfasis que propició el gobierno Pastrana.

Después de las exitosas operaciones de 2007 y 2008, parecía que el conflicto se había estancado. Los críticos del primer gobierno Santos lo atribuyeron a la presión de este sobre la Fuerza Pública para neutralizar cabecillas del grupo ilegal (MoyAR et al., 2014, p. 39); a su vez, este grupo mantenía la capacidad de daño y un número importante de efectivos. La presión generaba mayor competencia entre los 
componentes de la Fuerza Pública, como sus agencias de inteligencia eran reacias a compartir información más que todo la pertinente para las fuerzas de élite.

Así cada instancia tendía a responder solo por los objetivos asignados por el gobierno. El Comando Conjunto de Operaciones Especiales-CCOES, creado en 2009 y dependencia directa del Ministro de Defensa, debía neutralizar a la cúpula del grupo ilegal. La Brigada de Fuerzas Especiales, que dependía exclusivamente del Ejército Nacional, debía neutralizar a los cabecillas de nivel medio. Las unidades elite, dependientes del Ejército, la Armada y la Policía, debían responder por otros objetivos; pero si alguna unidad regular o de inteligencia tenía información conducente a neutralizar algún cabecilla podía proceder.

La misma tendencia de despliegue de fuerzas élite implicó más tiempo peinando zonas rurales, algo que muchos miembros del Ejército preferían al disminuir la posibilidad de daños colaterales en áreas pobladas. No obstante, gran parte de la Fuerza Pública estaba dispersa en tareas de protección de la infraestructura nacional. Por ende, el grupo ilegal pudo recobrar su influencia en estas aéreas; lo que fue el principal logro del gobierno Uribe, la seguridad de la población, pareció afectarse con aquella tendencia (MoYAR et al., 2014, p. 41-42).

La Fuerza Aérea, excepto por el componente aéreo incluido en el CCOES, debía garantizar para todos el dominio del espacio aéreo. No obstante, los análisis estadounidenses, de la National Defense University (Spencer, 2011, p. 90) y la Joint Special Operations University (MoYAR et al., 2014, p. 36), coinciden en el papel decisivo de la Fuerza Aérea: antes, las fuerzas terrestres realizaron el esfuerzo principal contra objetivos de alto valor; ahora, con el bombardeo de precisión la Fuerza Aérea realizó el esfuerzo principal, luego las fuerzas élite aseguraban la zona y las demás fuerzas terrestres apoyaban tal esfuerzo.

Ejemplo de ello podría ser la Operación Sodoma, en 2010, que implicó la participación del CCOES, las Fuerzas Especiales y la Fuerza Aérea. Una operación decisiva por cuanto neutralizó a alias 'Jojoy', miembro de la cúpula del grupo ilegal y el cabecilla más agresivo desde 1996. "Su muerte definitivamente marcó el fin de una era" (SPENCER, 2011, p. 109).

\section{OPERACIÓN SODOMA (SEP. 2010)}

Campo de combate: El municipio de La Uribe colinda con la Serranía de La Macarena. El campamento del cabecilla estaba ubicado a $26 \mathrm{~km}$. al suroeste del municipio, tenía una extensión de $300 \mathrm{~m} 2$, con una construcción en concreto y túneles de escape. Rodeado a su vez por otros 12 campamentos, que albergaban en conjunto unos 400 miembros del grupo ilegal (BEDOYA, 2010). El complejo contaba con bodegas, áreas de reunión, enfermería, sastrería y maquinaria fabril; protegido con minas y ametralladoras antiaéreas .50 y M-60. La seguridad del 
complejo se escalonaba en tres anillos, el primero era el inmediato al cabecilla; el segundo, a 100 metros, y un tercero a 500 metros. Conformaba así un perímetro con un efectivo ubicado cada metro en promedio.

Considerando que ese destacamento del grupo ilegal que delinquía en los departamentos de la Orinoquia intensificó sus acciones, para su debilitamiento el objetivo era neutralizar al cabecilla alias 'Mono Jojoy'. El prontuario de este sumaba más de 105 delitos, entre ellos lesiones personales, homicidio agravado, secuestro extorsivo, terrorismo, tráfico de armas y narcotráfico; por los que acumulaba más de 8 órdenes de captura y había sido condenado a más de 150 años de prisión (GÉLVEZ et al, 2014, p. 109-111). Fue responsable de los ataques a la base de Patascoy (Nariño, 1998) y de La Carpa (Guaviare), de los secuestros de la candidata política Betancur (2002), del ex gobernador A. Jara, el asesinato de la ex ministra C. Araujo y el plagio de un niño, hijo de la política Clara Rojas. En suma, era responsable de causar cientos de muertos y heridos civiles, como entre miembros de la Fuerza Pública (GÉLVEz et al, 2014). Por lo anterior se determinó que era un objetivo de alto valor estratégico (OMAVE) a ser neutralizado.

La preparación: Definido dicho cabecilla como uno de los objetivos, mientras una de las 'burbujas' ${ }^{32}$ del CCOES actualizaba permanentemente la información, el Comando dirigía las acciones sobre el terreno para reducir paulatinamente el área de ubicación del objetivo (GÉLvez et al, 2014, p. 114-115). Como esfuerzo conjunto y coordinado, en este caso, la 'burbuja' estuvo a cargo de la Armada Nacional, pero recibió los insumos de inteligencia técnica y táctica del Ejército Nacional; de inteligencia de imágenes aéreas y satelitales de la Fuerza Aérea; y de inteligencia humana de la Policía Nacional (GÉLvez et al, 2014, p. 115).

Algunos intentos previos para neutralizar al objetivo fallaron porque los enlaces al interior de la Fuerza Pública necesitaban mejorarse o porque los anillos de seguridad del cabecilla fueron efectivos para impedir el acceso. En este orden, si con las tropas de superficie se determinó un área general de 10 $\mathrm{km} 2$; con la inteligencia policial la ubicación del objetivo se precisó dentro de $1 \mathrm{~km} 2$. Precisión esta que permitía el uso adecuado del poder aéreo. De modo que al planear la operación el esfuerzo principal recayó sobre la Fuerza Aérea.

Una premisa permanente de la operación fue la reserva de la información. Pese al flujo de información desde las diferentes agencias del Estado, solo unos pocos individuos en el CCOES, en la 'burbuja', en la planeación y en su preparación conocieron los detalles finales para neutralizar el objetivo. A mediados de septiembre de 2010 cuando, de nuevo, se confirmó su ubicación hubo una febril actividad del personal de inteligencia de la Fuerza Pública para consolidar la

32 Burbuja es una denominación no oficial que define al equipo encargado de reunir la información sobre un objetivo específico (GÉLVEZ et al, 2014. p. 114-115). 
información. Desde el viernes 17 de septiembre en la base militar de Larandia el alto mando intensificó los preparativos. En cinco días se ultimaron los detalles de la operación (El Diario, 2010; Semana, 2010b).

El área de la operación presentó dificultades adicionales, entre ellas: la abundante pluviosidad que afecta la movilidad en tierra; la permanente nubosidad que entorpeció el reconocimiento aéreo y la vegetación espesa que dificultó identificar la infraestructura del área. Aquí la Fuerza Aérea aportó otro de sus atributos: los analistas de imágenes apoyaron el lograr el mayor nivel de precisión en la información, determinando los rumbos de entrada, las zonas de desembarco, entre otros detalles que garantizaron el cumplimiento de las misiones aéreas (GÉLVEZ et al, 2014, p. 118).

Una de las misiones era de ataque estratégico, el bombardeo simultáneo sobre la ubicación del cabecilla y sobre la disposición de armas antiaéreas del grupo ilegal. Esta última también con el fin de garantizar la superioridad aérea en el área de la operación. Superioridad que a su vez aseguraba la vida de las tripulaciones como de las Fuerzas Especiales al desembarcar. No obstante, la principal limitación era el tiempo. Luego que la inteligencia policial ubicó el objetivo en un radio de $1 \mathrm{~km} 2$, debía procederse dentro de 24 horas antes que el cabecilla se moviera a otra ubicación.

Las tácticas: Como responsable del esfuerzo principal de la operación, la Fuerza Aérea comprometió unos 30 aviones de combate, inteligencia, transporte y ambulancia; más helicópteros artillados, de transporte y de rescate. Así como el apoyo del sistema logístico y su Centro de Comando, Control y Comunicaciones. No obstante, la "fase final del planeamiento desafió las capacidades distintivas, al proponer a las tripulaciones una hora de ataque a escasos 120 minutos del inicio del briefing" (RUEDA, 2011). El desarrollo de la operación correspondió a la Fuerza de Tarea Conjunta Omega; Aviación del Ejército empleó 34 helicópteros, para transportar no menos de 700 efectivos.

El martes 21 de septiembre, en la mañana, comenzó el avance de las tropas de superficie. Pero solo en la madrugada del miércoles 22 se inició el bombardeo. Para este se usaron 'bombas inteligentes', cuya capacidad de acertar en la selva es casi milimétrica ${ }^{33}$. Cumplido el bombardeo, se realizaría el desembarco de 400 comandos con apoyo cercano de los helicópteros Arpía. También apoyados por un AC-47T, que adicionalmente haría reconocimiento de las vías de acceso al campamento por donde podrían huir los miembros del grupo ilegal. La tarea de los primeros comandos en desembarcar era copar a los guardias de los cerros aledaños al campamento, neutralizando su acción sobre las aeronaves de bombardeo (Semana, 2010a).

33 Entre ellas: una bomba de gravedad de 500 lbs., acondicionada con un GPS para guiarla por láser (Raytheon's Enhanced Paveway II) y que puede lanzarse desde una aeronave A-37 Dragonfly (PRIEST, 2013). 
En suma, siempre habría una aeronave con medios técnicos de inteligencia para ofrecer información de combate; y siempre habría una aeronave con armamento para apoyo cercano de las tropas. Estas misiones ocuparon más de 24 horas, pero se hizo el relevo oportuno de las tripulaciones (GÉLvEZ et al, 2014, p. 120). Todas las aeronaves dispusieron de equipos de visión nocturna.

El combate: El miércoles 22 de septiembre de 2010, a las 01:00 horas se realizó el bombardeo sobre el primer objetivo, la ubicación del cabecilla. Una hora después de lo planeado, cuando se garantizó su ubicación. Las aeronaves que debían atacar el segundo objetivo, las armas antiaéreas, no despegaron a la espera de que mejoraran las condiciones climáticas.

Media hora después llegó el primer grupo de comandos, que una vez desembarcaron debieron recibir apoyo de los helicópteros artillados y del AC-47T ante la reacción de los miembros del grupo ilegal. No obstante, se logró consolidar el área de desembarco, los combates se intensificaron alrededor del primer objetivo (GÉLVEZ et al, 2014, p. 121). Ante esta reacción, hacia mediodía del miércoles fue necesario realizar un segundo bombardeo y desembarcar más tropas.

Otras aeronaves procedieron a neutralizar los puestos de guardia del grupo ilegal, en cada uno de los anillos de seguridad que rodeaban al objetivo. Después de 27 horas de combate los comandos pudieran avanzar hacia tal objetivo y confirmar que el cabecilla había sido neutralizado (Semana, 2010a). En la operación resultaron muertos más de 20 miembros del grupo ilegal. Entre los soldados 16 fueron heridos en combate. También murió uno de los perros antiexplosivos del Ejército.

\section{OPERACIÓN OdiseO (NOv. 2011)}

Campo de combate: Suárez (Cauca) fue elevado a municipio hace poco más de un cuarto de siglo. Por su ubicación en las estribaciones de la Cordillera Occidental y aledaño al río Cauca en sus inmediaciones se levantó el embalse e hidroeléctrica de Salvajina. De vieja estación de ferrocarril pasó a tener una carretera rudimentaria, que le comunica con los municipios vecinos de Buenos Aires, al norte, y de Morales, al sur; aunque el embalse aglutina un sistema de comunicación fluvial más denso. Su poblamiento es atribuido a la riqueza aurífera y otros minerales, que junto con las obras del embalse atrajo la inmigración (Alcaldía de Suárez, 2012).

Lejos del casco urbano de Suárez, por camino de herradura y ascendiendo a 2.000 metros de altura en la cordillera, se encontraba el campamento de alias 'Alfonso Cano'. En una zona al norte del departamento del Cauca que sirve de corredor con los departamentos del Tolima y Huila, así como da paso hacia el Pacífico (Noguera, 2011, Noviembre). 
Alias 'Cano' fue cabecilla del Bloque Occidental del grupo ilegal, cuya área de acción era el Macizo Colombiano con injerencia en los departamentos del Tolima, Huila, Valle, Cauca, Nariño y Putumayo. Desde mayo de 2008 asumió como máximo cabecilla del grupo ilegal, por lo cual "era el principal Objetivo Militar de Alto Valor Estratégico (OMAVE) asignado por el Gobierno al Ejército Nacional" (Gamba et al., 2012, p. 16). Entre otros delitos de los que fue responsable figuran la muerte de seis niños de la policía cívica en Algeciras (Huila, 1990); muerte de la familia Turbay en Caquetá (2000); secuestro de 9 civiles en Neiva (2001); secuestro y muerte de doce diputados del Valle del Cauca (2007); atentados con bomba en Toribío (Cauca, 2001) y contra el Club El Nogal en Bogotá (2003); ataques con armas no convencionales contra las poblaciones de Florida, El Mango, Paujil, Miranda, Jambaló; reclutamiento forzado de menores.

Por lo anterior, en su contra existían más de 94 órdenes de captura por delitos como terrorismo, homicidio, secuestro y lesiones personales, entre otros. Ordenó los ataques contra las bases militares de Las Delicias (Putumayo, 1996) y El Billar (Caquetá, 1998), así como contra la base de la Armada Nacional en el cerro Tokio (Valle). También de los ataques al municipio de Planadas (1994), a unidades del Batallón Caicedo (Purificación, 1994), el secuestro de policías en San Antonio (Tolima, 1994), emboscada a unidad policial en Ortega (Tolima, 1994), la muerte de cuatro policías en Dolores (Tolima, 1996). Fue condenado por la toma de Mitú en 1998, por el ataque a Puerto Lleras (Meta, 1999), por la masacre en Tierra Alta (...), por la muerte de un niño en Vistahermosa (Meta), por el ataque a unidades de la Fiscalía en San José de Apartadó (Antioquia, 2002) (GÉLVEZ Et al., 2014, pp. 129-132; Vanguardia Liberal, 2011).

La preparación: Desde 2009 la Central de Inteligencia del Ejército intensificó la recogida de información sobre el cabecilla. Unidades de Fuerzas Especiales hicieron reconocimiento de la zona donde se ubicaba aquel, incluso franqueando sus anillos de seguridad. El CCOES planeó una operación, realizada en mayo de 2010 sin éxito. El ciclo se repitió, lanzando una segunda operación en agosto de ese año. Y una vez más se repitió así, en junio 2011, se lanzó una operación con igual resultado fallido (GÉLVEZ et al., 2014, p. 136, 139; CASTRILLÓN, 2011).

La recogida de información se efectuó a través de medios de inteligencia humana (desmovilizados, capturados, infiltrados y análisis documental); inteligencia técnica (monitoreo de comunicaciones e interceptación de celulares). Esta tarea con acompañamiento permanentemente de unidades de la Fiscalía General de la Nación; e inteligencia de combate, cumplida por las tropas de la Quinta División en el área de operaciones.

El reconocimiento lo hicieron miembros de las Fuerzas Especiales, traspasando los anillos de seguridad del objetivo en cada ocasión previa a las operaciones. En total lograron infiltrarse en ocho ocasiones obteniendo detalles sobre la ubicación 
de campamentos, la identificación de los individuos allí y las evidencias que confirmaban la presencia del cabecilla (alimentación, rutina diaria, armamento, etc.). Las sucesivas operaciones, desde mayo de 2010 hasta julio de 2011, presionaron a que el cabecilla se fuera desplazando progresivamente hacia el sur. Desde el Cañón de Las Hermosas (municipio de Chaparral, Tolima), pasando por Planadas (Tolima) y Santa Ana (Huila), hasta llegar a Belalcázar (Cauca) (Las Fuerzas, 2011, p. 3).

Aparte de las operaciones directas contra el cabecilla, los anillos de seguridad fueron sucesivamente debilitados, desde marzo de 2010, por acción de las tropas de la Quinta División del Ejército y de la Fuerza de Tarea del Sur del Tolima. Subalternos o miembros de tales anillos fueron muertos o capturados en desarrollo de acciones en San Miguel, Planadas, Natagaima y Río Blanco (Tolima), en Aipe (Huila) y en Páez (Cauca). Además de la información recopilada en cada ocasión, el debilitamiento de su entorno de seguridad condujo a que, en julio de 2011, el objetivo se desplazara hacia el Cauca buscando más protección (Gamba et al., 2012, pp. 60-62).

Inteligencia de la Policía confirmó que efectivos del grupo ilegal, en el municipio de Suárez, tenían la tarea de proteger al cabecilla (BEDOYA, 2012). De hecho, la Policía vigilaba a otro cabecilla, quien lideraba el Bloque Occidental del grupo y quien luego murió al lado del máximo cabecilla en la Operación Odiseo (Reportero 24, 2011). En suma, se trató de una operación conjunta y coordinada. Conjunta entre el Ejército Nacional y la Fuerza Aérea; coordinada entre las tropas del Ejército Nacional, la Policía Nacional y el Cuerpo Técnico de Investigación de la Fiscalía General.

Los Estados Mayores de las Fuerzas Especiales del Comando General prepararon la operación durante los 19 días antes de su ejecución. Se escogieron cuatro bases de lanzamiento: Popayán, Cali, Tuluá y Palmira. Más de 30 helicópteros de la Aviación del Ejército y soldados de las Fuerzas Especiales se concentraron en la plataforma de lanzamiento para realizar la operación. Para el apoyo aéreo cercano más de 15 aeronaves de transporte, reconocimiento, combate, inteligencia, tácticas y aeronaves "medicalizadas" ${ }^{34}$ fueron empleadas durante la operación (Las Fuerzas, 2011, p. 3).

Las tropas de las Fuerzas Especiales del Ejército Nacional que inicialmente estaban concentradas en Tolemaida, comenzaron su despliegue una semana antes. Estas tropas hacían parte de la Brigada de Fuerzas Especiales, unidad que combatió al grupo ilegal en los Montes de María y algunos de cuyos efectivos participaron en la Operación Sodoma. El 04 de noviembre, a las 01:00 horas, las tropas comenzaron su embarque en aeronaves C-130. A las 5:30 estaban a bordo de los Black Hawk, pero el clima obligó a esperar.

34 El término 'medicalizada' es anglicismo; la palabra más adecuada sería, según la RAE, "medicinal. adj. Perteneciente o relativo a la medicina" (2001). 
La Fuerza Aérea comprometió en la operación 3 Aviones A-37; 5 Aviones A-29 Súper Tucano; 4 Helicópteros Arpía; 3 Aviones C-130, 2 aviones AC-47T y un helicóptero de rescate; para un total de 18 aeronaves (Infobae, 2011). Parte de la Aviación del Ejército se concentró en Palmira (Valle) listos para la acción, 30 helicópteros Black Hawk; algunas de sus tripulaciones estuvieron un año antes en la Operación Sodoma.

El combate: Odiseo fue una operación diurna, realizada a horas no comunes para diferenciarla de otras operaciones. La operación se lanzó el viernes 04 de noviembre de 2011 en el área del municipio de Suárez (Cauca). Hacia las 08:30 horas aeronaves A-37 y A-29 Súper Tucano, de la Fuerza Aérea, realizaron un bombardeo alrededor de la ubicación del cabecilla, su alojamiento y el de sus lugartenientes. En seguida 18 helicópteros Black Hawk de la Aviación del Ejército desembarcaron las tropas de Fuerzas Especiales usando la técnica de rappel, mientras recibían apoyo de helicópteros Arpía de la Fuerza Aérea. De la primera oleada de helicópteros siete fueron impactados por los miembros del grupo que disparaban una ametralladora M-60 y una .50 (Bolaños, 2011).

Una aeronave de la Fuerza Aérea desde 5.000 pies de altura realizó el comando y control de todas las fases de la operación. A las 13:00 ya habían desembarcado 969 tropas en los diferentes sitios para bloquear las rutas de escape. La resistencia del grupo alrededor de la ubicación del cabecilla hizo necesario un segundo bombardeo. Los combates se sostuvieron durante el transcurso del día. Copada la ubicación del cabecilla se procedió a identificar los muertos y recoger evidencias por agentes del Cuerpo Técnico de la Fiscalía; del cabecilla solo estaban sus elementos personales.

Al caer la noche se hizo otra inspección del alojamiento y sus alrededores. Justo a las 21:19 horas, en uno de los puntos de bloqueo, un efectivo de Fuerzas Especiales detectó con sus lentes de visión nocturna el intento de huida del que resultó ser el cabecilla (Gamba et al., 2012, p. 64-66; Gélvez et al., 2014, p. 137). La inmediata preocupación fue evitar que sus compinches recuperaran el cadáver, por lo que el AC-47T y los Tucano mantuvieron su apoyo a las tropas de superficie.

Motivación para combate: Una operación para dar con el cabecilla, en febrero de 2008, al sur del Tolima se saldó con 40 bajas del Ejército, entre heridos y muertos. Luego en persecución del mismo, por las estribaciones del río Ata, 42 militares cayeron por efecto de las minas anti-personal sembradas por el grupo ilegal. En abril de 2010, mientras perseguían al cabecilla, dos helicópteros colisionaron causando la muerte 7 militares.

"Cuando la Fuerza Pública logra el objetivo, dar de baja a Cano y consolidar la estrategia el sur del Cauca, se nota un cambio en la guerra, quedando desestabilizado el secretariado y todos los atentados terroristas a gran escala. Las FARC sufren una pérdida que aún no se han podido recuperar, pues su reemplazo 
alias 'Timochencho' no está en el país y han perdido la iniciativa. Tal es así, que las FARC posterior a la pérdida de Cano no han podido consolidar una guerra de guerrillas, ha limitado sus operaciones, y ha perdido influencia en territorios, no tienen un líder representativo. Esto ha sido positivo para el ambiente político, que en medida de sus pérdidas, ofreció unos diálogos de paz, que fueron acogidos inmediatamente por el grupo insurgente." (GÉLVEZ et al., 2014, p. 137)

Un balance, en noviembre de 2011, luego de la neutralización del cabecilla destacó cuatro factores que permitieron al estado colombiano debilitar al grupo ilegal (El Tiempo, 2011, noviembre). Primero una política de estado que, según varios autores citados más arriba, puede remontarse al gobierno Barco (1988) pero a la que los gobiernos Pastrana y Uribe dieron un giro decisivo. Política que incluiría mínimo tres aspectos: modernización de la Fuerza Pública, acción integral y consolidar capital humano. El otro factor fue la ventaja aérea que, desde 1998 con la recuperación de Mitú, frustró el plan del grupo para pasar a una guerra de movimientos y debilitó su dirigencia.

La Fuerza Aérea también fue clave en un tercer factor, la inteligencia. En efecto las virtudes de la inteligencia aérea llevaron a recuperar en mínimo tiempo la zona de distensión y desde 2007 se complementaron con su modernización en otras Fuerzas para ubicar a los cabecillas del grupo ilegal. Un cuarto factor ha sido la progresiva adopción del enfoque de operaciones conjuntas que inició también en 1998 con la 'Fuerza de Tarea Conjunta'.

\section{A MODO DE CONCLUSIÓN: BALANCE DE OPERACIONES DECISIVAS}

En marzo de 2015 el gobierno Santos anunció la suspensión de los bombardeos contra el grupo ilegal. El gobierno adujo que era en reciprocidad luego que este anunció un cese temporal de acciones violentas. Pero el temor a los bombardeos lo admitió ya en 2012 uno de los cabecillas del grupo (Verdad Abierta, 2015, párr. 2). Así que estamos ante un efecto de lo decisivo que resultó el bombardeo de precisión realizado por la Fuerza Aérea Colombiana. En particular una consecuencia de la evolución de las capacidades de la Fuerza Aérea, incluyendo desde la adopción de sistemas de visión nocturna y de los aviones Súper Tucano, hasta las bombas guiadas por láser.

El bombardeo de precisión permitió, en 2002, recuperar la zona de distensión en muy corto tiempo. Como permitió, desde 2007, debilitar al grupo ilegal en sucesivas operaciones sobre las que hay algún consenso cuáles tuvieron mayor impacto en el conflicto (véase tabla 4). Una versión de prensa incluye 12 operaciones de bombardeo (Verdad Abierta, 2015); otra alude al "Top 5" de los bombardeos, en orden de importancia, en las operaciones 'Fénix', 'Sodoma', 
'Odiseo', 'Sol naciente’ y en 1990 la operación 'Colombia' (Vanguardia Liberal, 2015). Otra más, resalta la coordinación Fuerza Aérea y Policía Nacional que entre 2008 y 2009 neutralizó 12 cabecillas del grupo. Más reciente, en 2015, sendos bombardeos contra fracciones del grupo en Cauca y Chocó neutralizaron 54 de sus efectivos, entre estos dos cabecillas que fueron 'negociadores' en La Habana; hecho por el cual el grupo intentó el reinicio de sus acciones violentas.

Como se ha insistido aquí, un acierto que hizo decisivas estas operaciones fue usar el bombardeo de precisión contra los cabecillas del grupo armado ilegal. Tratándose de cabecillas de fracción (llámense bloques, frentes o columnas) su neutralización redundó, en varias ocasiones, en la desarticulación de las respectivas fracciones. Según el Ministerio de Defensa (2015, Junio, p. 1), entre 2010 y 2015, se neutralizaron 60 cabecillas de diferente nivel y otros 17.261 miembros (entre muertos, capturados y desmovilizados) del grupo. Otro balance especifica que fue entre 2007 y 2011 cuando se neutralizaron los máximos cabecillas $^{35}$. Lo cierto es que, desde entonces, el grupo decidió limitarse a usar tácticas de guerrilla y multiplicar los actos terroristas para mantener su vigencia como tal (Mindefensa, 2015, p. 18 y 2012, p. 13). Por lo mismo, no es casual que el porcentaje de municipios atacados por los grupos ilegales se incrementó en 2012 y 2013 (8\% de 1.102 municipios; Mindefensa, 2015, Junio, p. 4).

Tabla 4. Operaciones decisivas con bombardeo de precisión 2007-2015

\begin{tabular}{|c|c|c|c|c|c|}
\hline Año & Mes & Operación / Tipo & Área & Cabecilla & Fracción \\
\hline \multirow[t]{2}{*}{2007} & Septiembre & Sol naciente / Conjunta & Guainía & 'Negro Acacio' & 16 \\
\hline & Octubre & Aromo & Bolívar & 'Martín Caballero' & 37, Caribe \\
\hline \multirow[t]{2}{*}{2008} & Marzo & Fénix & Putumayo & 'Raúl Reyes' & Cúpula \\
\hline & Julio & Gibraltar/Conjunta & Cauca & 'Dago' & 6 \\
\hline 2009 & Diciembre & $\begin{array}{l}\text { Oriente/Coordinada FAC- } \\
\text { Ponal }\end{array}$ & Antioquia & 'Danilo' & 9 \\
\hline \multirow[t]{3}{*}{2010} & Marzo & $\begin{array}{l}\text { Baltazar / Coordinada } \\
\text { FAC-Ponal }\end{array}$ & Tolima & 'Enrique Zúñiga' & 50 \\
\hline & Septiembre & $\begin{array}{l}\text { Fortaleza II / Coordinada } \\
\text { FAC-Ponal }\end{array}$ & Putumayo & 'Domingo Biojó' & 48 \\
\hline & Septiembre & Sodoma / Conjunta & Meta & 'Mono Jojoy’ & Oriental \\
\hline 2011 & Noviembre & Odiseo/Conjunta & Cauca & 'Alfonso Cano' & Cúpula \\
\hline 2012 & Marzo & Armagedón/Conjunta & Meta & $\begin{array}{l}6 \text { cabecillas: 'Arcesio } \\
\text { Niño', 'Gildardo'... }\end{array}$ & 27 \\
\hline
\end{tabular}

35 Dos balances diferentes provienen de la misma instancia de Mindefensa y de la misma fecha (2015, junio): uno es el de la gestión del Ministro de Defensa saliente; el segundo va más atrás en el tiempo para sugerir las líneas de acción del Ministro entrante. En perspectiva de política estatal, la diferencia reflejaría el abandono definitivo de la tendencia instaurada desde 2002. 


\begin{tabular}{|l|l|l|l|l|c|}
\hline 2013 & Enero & Elipsis / Conjunta & Córdoba & 'Jacobo Arango' & 5 \\
\cline { 2 - 6 } & Agosto & $\begin{array}{l}\text { Darién / Coordina da } \\
\text { FAC-Ponal }\end{array}$ & Chocó & 'Silver' & 57 \\
\hline $\mathbf{2 0 1 4}$ & Enero & Conjunta & Arauca & 'Franklin Morales' & 10 \\
\hline $\mathbf{2 0 1 5}$ & Mayo & Conjunta & Cauca & 'Jairo Martínez' & 29 \\
\cline { 2 - 6 } & Mayo & Conjunta & Chocó & $\begin{array}{l}\text { 'Román Ruiz' y } \\
\text { 'Emiro Chaqueto' }\end{array}$ & Noroccidente, 18 \\
\hline
\end{tabular}

Fuente: Elaboración propia basada en Gamba et al. (2012); Gélvez et al. (2014); Mindefensa (2011, p. 32); Semana (2009, Diciembre 6); Vanguardia Liberal (2015, Agosto 4); Verdad Abierta (2015).

El mismo gobierno al anunciar en 2012 el comienzo de los diálogos de paz sostuvo que esto era un efecto de las operaciones decisivas de la Fuerza Pública durante la década precedente. Dado que los diálogos se realizarían sin un cese de las hostilidades, puede ser simple coincidencia que ese año, en febrero, comenzó a aplicarse el plan de guerra ${ }^{36}$ 'Espada de Honor' (Mindefensa, 2012, p. 19; Semana, 2012, Febrero). El plan tuvo como objetivo inicial desarticular a los grupos armados y sus áreas base; es decir, no se centraría solo sobre los cabecillas sino más sobre las estructuras y sus redes de apoyo. Ya el mismo 2012 se divulgó como logro preliminar que solo el $41 \%$ de tales estructuras pudieron realizar alguna acción armada (Mindefensa, 2013, p. 14). Así para cumplir ese objetivo, el plan contempló una ofensiva simultánea con Fuerzas de Tarea Conjunta para cada una de las áreas predefinidas ${ }^{37} \mathrm{y}$ apoyadas por unidades de policía judicial.

También al anunciarse el plan de guerra en 2012 se sugiere cuan decisivas fueron las operaciones mencionadas. El contexto estratégico sobre el cual se articula aquel admitía: "No hay amenaza nacional sino amenazas locales diferenciadas." Para luego explicar: "Por cuenta de ello, la Fuerza Pública combate en la actualidad diferentes amenazas localizadas: el terrorismo de las FARC y del ELN y el crimen organizado..." (Mindefensa, 2013, p. 11). Es decir, los grupos ilegales reducidos en sus efectivos y en su iniciativa, se retiraron hacia pequeñas zonas de refugio. Aquel contexto se reiteró en balance del año siguiente, aunque el Plan Espada de Honor si sufrió reajustes enfatizando que debía persistir en la neutralización de estructuras y en la preservación de los avances de seguridad. En consonancia parece haberse restringido el "espectro de definición del enemigo, dándole una mayor relevancia al ELN y a las bandas criminales." (Mindefensa, 2014, p. 12)

36 Plan de Guerra: "Es el principal documento dentro de los documentos secundarios de la defensa nacional. Su elaboración corresponde al Estado Mayor Conjunto, con base en la decisión del Comandante General de las Fuerzas Militares, derivada de la apreciación estratégica militar general." (FAC, 2013, p. 29).

37 De las Fuerzas de Tarea -F.T. - se reforzaron la F.T. Omega, la F.T. del Sur del Tolima (Zeus) y la F.T. de Nudo de Paramillo (Aquiles). Se crearon cuatro más, a cargo del Ejército Nacional, la Apolo para el área del norte del Cauca, Pegaso para Nariño, Quirón para Arauca y Vulcano para Catatumbo. Una más, a cargo de la Armada Nacional, Poseidón para el Litoral Pacífico y, otra, a cargo de la Fuerza Aérea, Ares para Vichada; en total 9 F.T. 
Si bien lo anterior confirma que las operaciones de bombardeo cumplidas por la Fuerza Aérea Colombiana fueron decisivas para acercar el cese del conflicto armado en Colombia. La capacidad decisoria de la Fuerza Aérea se manifiesta en otros cientos de operaciones diferentes realizadas simultáneamente y que son parte de sus funciones militares. A saber, una de esas funciones es aplicar la fuerza y para cumplirla realiza operaciones de ataque estratégico entre las que se incluye, a su vez, el bombardeo de precisión. No interesa aquí explicar los tipos de operaciones de la doctrina aérea, además que su registro estadístico se somete a los énfasis de cada política de gobierno, pero la tabla 5 resume cuáles y cuantas fueron también decisivas.

Para el caso, desde 2003 la Política de Seguridad Democrática enfatizó en la defensa de poblaciones para contrarrestar la arremetida de los grupos armados ilegales. Al efecto la Fuerza Aérea garantizó la superioridad aérea, realizó misiones de ataque aéreo, de inteligencia aérea, de comando y control, entre otras. La tendencia decreciente de las cifras, de 33 a solo 2 o 0 operaciones, evidenciaría que la Fuerza Aérea contribuyó no solo a repeler en cada suceso a tales grupos sino a disuadir progresivamente otros ataques a poblaciones (FAC, 2008, Informe, p. 5; FAC, 2008, Memoria, p. 1).

Dicha tendencia decreciente permitió a la Fuerza Aérea ajustar los medios para intensificar los ataques estratégicos, ${ }^{38}$ entre los años 2006 y 2007, como se ve en la tabla 5. Más arriba se advirtió que, desde 2007, ello se hizo usando el bombardeo de precisión contra los cabecillas. Pero regularmente fue dirigido a destruir campamentos e infraestructura de los grupos ilegales. Luego, en 2012, la Fuerza Aérea debió intensificar tales ataques, también en respuesta al incremento de acciones terroristas mencionada más arriba; entonces se realizaron 934 operaciones de aplicación de la fuerza, es decir, de ataque, interdicción y apoyo aéreo; las dos primeras incluidas en el Plan Campaña Aérea, sumaron 553 acciones ofensivas (FAC, 2012, p. 1).

En consonancia destaca, a lo largo del período analizado, una tendencia homogénea de la Fuerza Aérea en la realización de operaciones de apoyo aéreo cercano, propias de la misión típica de contra-poder terrestre. Como tal el apoyo aéreo ofrece protección y ventaja táctica a las propias tropas de tierra que se encuentran en combate (FAC, 2013, Manual, p. 90); lo que significa que la Fuerza Aérea ha sido imprescindible en las operaciones del Ejército, la Infantería de Marina y la Policía. Entre 2011 y 2012, de nuevo, debió intensificar tal apoyo bien en la campaña contra el narcotráfico o dentro del Plan Espada de Honor.

La capacidad decisoria de la Fuerza Aérea es menos fortuita si se considera que en 2011 superó varios de sus indicadores de la década previa: el número de

38 Dice ajuste de los medios porque fue después, en 2008, que la Fuerza Aérea recibió 15 aviones A-29, 8 aviones T-37, 4 helicópteros Huey II y 2 UH-60, y 3 aviones transporte C-295. 
horas voladas (87.692 en octubre); el alistamiento de aeronaves ( $73,5 \%$, siendo el promedio mundial de $70 \%$ ) y, todo lo anterior, con el tamaño de flota más grande (319 aeronaves) alcanzado por el país (FAC, 2011, p. 9-11).

Tabla 5. Tipo y número de operaciones Fuerza Aérea ${ }^{39}$.

\begin{tabular}{|l|l|l|l|l|l|l|l|l|l|l|l|l|}
\hline & $\mathbf{2 0 0 3}$ & $\mathbf{2 0 0 4}$ & $\mathbf{2 0 0 5}$ & $\mathbf{2 0 0 6}$ & $\mathbf{2 0 0 7}$ & $\mathbf{2 0 0 8}$ & $\mathbf{2 0 0 9}$ & $\mathbf{2 0 1 0}$ & $\mathbf{2 0 1 1}$ & $\mathbf{2 0 1 2}$ & $\mathbf{2 0 1 3}$ & $\mathbf{2 0 1 4}$ \\
\hline Defensa de poblaciones & 33 & 21 & 19 & 7 & 2 & 2 & $(0)$ & $(2)$ & & & & \\
\hline $\begin{array}{l}\text { Ataque a campamentos / } \\
\text { y estratégicos }\end{array}$ & 109 & 242 & 304 & 757 & 690 & 443 & $(136)$ & $(47)$ & $(11)$ & $(10)$ & n.d. & $(0)$ \\
\hline Apoyo aéreo cercano & 316 & 334 & 323 & 328 & 305 & 292 & $(119)$ & 200 & 366 & 381 & n.d. & 133 \\
\hline Interdicción & n.d. & n.d. & n.d. & n.d. & n.d. & n.d. & n.d. & 268 & 369 & 543 & n.d. & 244 \\
\hline & & & & & & & & & & & & \\
\hline Trazas sospechosas & 639 & 462 & 329 & 159 & 76 & 43 & 16 & 12 & 20 & 17 & 15 & 06 \\
\hline Aeronaves inmovilizadas & & n.d. & 12 & 9 & 13 & 45 & 92 & 101 & 52 & 84 & 113 & 166 \\
\hline Aeronaves inutilizadas & & n.d. & 7 & 7 & 7 & 9 & 15 & 15 & 32 & 28 & 43 & 25 \\
\hline Lanchas inmovilizadas & & & & & 5 & 22 & 9 & n.d. & n.d. & 3 & 10 & 20 \\
\hline
\end{tabular}

Fuente: FAC. Informes de gestión, 2006 a 2014; Mindefensa (2010, p. 217, 230); Neira (2014). [Entre paréntesis, cifra parcial; n.d.: datos no disponibles].

Por último, otro ámbito en el cual la Fuerza Aérea fue decisiva para acercar el cese del conflicto armado en Colombia, ha sido la lucha contra el narcotráfico. Aunque ya en 1984 el embajador de EE.UU. en Colombia, Lewis Tambs, denunció el nexo entre los grupos armados ilegales y el narcotráfico (El Espectador, 2010, párr. 4), apenas en noviembre de 2002 el gobierno Bush $^{40}$ autorizó que la asistencia estadounidense contra el narcotráfico en Colombia se usara también contra la insurgencia (MoYAR et al., 2014, p. 28).

Con la reactivación, al año siguiente, del programa de interdicción la Fuerza Aérea Colombiana reforzó la defensa nacional. Al efecto, ese mismo 2003, EE.UU. prestó a Colombia 3 aeronaves Cessna Citation 560, plataformas para localizar

39 Las operaciones con Aplicación de la Fuerza incluyen: Ataques estratégicos (contra el centro de gravedad del enemigo, sean cabecillas, infraestructura y medios de comunicación); Interdicción (ataques a movimientos y abastecimientos del enemigo con el fin de neutralizar, demorar o destruir su capacidad delictiva); Apoyo aéreo cercano (provee apoyo directo a las fuerzas de superficie para asegurar la supervivencia de las fuerzas amigas), concentrando el esfuerzo principal en las áreas del Salto Estratégico, buscando a través de este tipo de operaciones doblegar la voluntad de lucha del enemigo"... (FAC, 2010, Memoria, p. 1).

40 Evaluando el Plan Colombia Rabasa y Chalk objetaban que atacar el narcotráfico debilitaría a los grupos ilegales, apoyando la idea de una intervención del resto de Suramérica contra Colombia (2001, p. 93-94). Tal intervención fue tema en 1998 y 1999: desde el Senado de EU hasta la OEA(El Tiempo, 1998-12-7, p. 9A; Tiempo, 1999-06-9, p. 1A), con variada oposición de Brasil, Chile, Cuba y Perú (Esquivel, 2001. p. 73-75). 
las trazas $^{41}$ de aviones ilegales y dedicados al narcotráfico. Las zonas de este control aéreo incluyeron las fronteras con Brasil, Panamá, Perú y Venezuela, y el mar Caribe (El Tiempo, 2003, Agosto; El Espectador, 2003, Mayo). La Fuerza Aérea logró reducir los vuelos ilegales que usaban el espacio aéreo colombiano, de 639 trazas sospechosas detectadas en 2003 se redujo a 6 en 2014 (NeIRA, 2014, párr. 12).

Del mismo modo, al tiempo que reducía los vuelos ilegales la Fuerza Aérea incrementó su efectividad contra los medios usados por el narcotráfico. Pasó de inmovilizar 12 aeronaves (2005) a 113 (2013), como pasó de inutilizar 7 (2005) a 43 (2013) aeronaves. Desde el 2007 el programa de interdicción se hizo extensivo a medios marítimos, incrementando la seguridad marítima de Colombia en asocio con la Armada Nacional. La interdicción aérea y marítima contra el narcotráfico redujo los flujos financieros y de contrabando de los grupos ilegales en Colombia, aunque estos se financian también con la minería ilegal.

El papel decisivo de la Fuerza Aérea en el control del espacio aéreo de Colombia, hizo que los flujos del narcotráfico se desplazaran hacia otros países de la región. Por ello, la Fuerza Aérea asumió el establecimiento de convenios y de procedimientos de interdicción con países como: Estados Unidos, Brasil, Perú, Ecuador, Chile y Paraguay. También reforzando la interdicción en el Mar Caribe, "se han podido establecer contactos directos con Honduras, Venezuela, México, Nicaragua, Guatemala, Panamá, Belice, Haití y República Dominicana, donde se han presentado excelentes resultados operacionales en la lucha mundial contra el narcotráfico." (FAC, 2012, p. 6)

Por lo anterior, y según dispuso el Plan Espada de Honor, en 2012 la Fuerza Aérea recibió a su cargo la Fuerza de Tarea de Acción Conjunta, Combinada e Interagencial 'ARES'. Con sede en Marandúa (Vichada), ${ }^{42}$ en la base del Grupo Aéreo del Oriente -GAORI-, esta Fuerza tiene como propósito combatir el narcotráfico y a los grupos armados ilegales en los departamentos de Arauca, Vichada y Guainía (FAC, 2015, Marzo; FAC, 2013, Marzo). En 2015, la Fuerza de Tarea ARES realizó una de las operaciones contundentes contra la minería ilegal, afectando en $\$ 20.050$ millones por mes los ingresos del grupo ilegal (La Reportería, 2015, Mayo).

\footnotetext{
$41 \quad$ Trazas aéreas, se refiere a la trayectoria descrita por un punto luminoso sobre la pantalla de radar; cfr. acepción RAE (2001). Diccionario de la Lengua Española (22. ed.). Madrid: Espasa.

42 Marandúa, puesto adelantado del Comando Aéreo $\mathrm{N}^{\circ}$. 2, fue primero en 1994 estación de un radar TPS-43 operado por la Fuerza Aérea de EU; desde 1996 se hizo sede del GAORI (FAC, 2004, Agosto) y desde 2012 sede también de la Fuerza de Tarea 'Ares' (FAC, 2015, Marzo).
} 


\section{REFERENCIAS}

\section{Fuentes primarias}

Acuerdo general para la terminación del conflicto y la construcción de una paz estable y duradera (2012, Agosto 26). Recuperado de: https://www.mesadeconversaciones.com.co/sites/default/files/acuerdogeneralterminacionconflicto.pdf

Corte Constitucional (2001, Enero 24). Sentencia C-048 /01. Recuperado de: http://www.corteconstitucional.gov.co/sentencias/2001/C-048-01.rtf

Fuerza Aérea Colombiana -FAC (2014). Informe de gestión 2014. Bogotá: La Fuerza. Recuperado de: https://www.fac.mil.co/informe-2014-0

Fuerza Aérea Colombiana -FAC (2013). Informe de gestión 2013. Bogotá: La Fuerza. Recuperado de: https://www.fac.mil.co/informe-2013

Fuerza Aérea Colombiana -FAC (2013). Manual de doctrina básica aérea y espacial (MADBA; 4a. ed.). Bogotá: La Fuerza. (Manual FAC 0-E, Público). Recuperado de: https://www.doctrinafac.mil.co/manual-de-doctrina$\mathrm{b} \% \mathrm{C} 3 \% \mathrm{~A} 1$ sica-a $\% \mathrm{C} 3 \%$ A9rea-y-espacial-mabda

Fuerza Aérea Colombiana -FAC (2012). Informe de gestión 2012. Bogotá: La

Fuerza. Recuperado de: https://www.fac.mil.co/informe-2012

Fuerza Aérea Colombiana -FAC (2011). Informe de gestión 2011. Bogotá: La

Fuerza. Recuperado de: https://www.fac.mil.co/informe-2011

Fuerza Aérea Colombiana -FAC (2010). Informe de gestión 2010. Bogotá: La

Fuerza. Recuperado de: https://www.fac.mil.co/informe-2010

Fuerza Aérea Colombiana -FAC (2010). Memorias al Congreso 2009-2010.

Bogotá: La Fuerza. Recuperado de: https://www.fac.mil.co/memorias-alcongreso-2009-2010

Fuerza Aérea Colombiana -FAC (2009). Informe de gestión 2009. Bogotá: La

Fuerza. Recuperado de: https://www.fac.mil.co/informe-2009

Fuerza Aérea Colombiana -FAC (2008). Informe de gestión 2008. Bogotá: La

Fuerza. Recuperado de: https://www.fac.mil.co/informe-2008

Fuerza Aérea Colombiana -FAC (2007). Informe de gestión 2007. Bogotá: La Fuerza. Recuperado de: https://www.fac.mil.co/informe-2007

Fuerza Aérea Colombiana -FAC (2006). Informe de gestión 2006. Bogotá: La Fuerza. Recuperado de: https://www.fac.mil.co/informe-2006

Fuerza Aérea Colombiana (2004, Agosto). Grupo Aéreo del Oriente-GAORI. Marandúa (Vichada): La Fuerza. 
Ministerio de Defensa Nacional -Mindefensa (2015, Junio 22). Acta de informe de gestión. Bogotá: El Ministerio. Recuperado de: https://www.mindefensa.gov. co/irj/go/km/docs/Mindefensa/Documentos/descargas/Prensa/Documentos/ informe_empalme_mindefensa_pinzon.pdf

Ministerio de Defensa Nacional (2015). Memorias al Congreso 2014-2015. Bogotá: Imprenta Nacional. Recuperado de: https://www.mindefensa.gov. co/irj/go/km/docs/Mindefensa/Documentos/descargas/Prensa/Documentos/ memorias2014-2015.pdf

Ministerio de Defensa Nacional (2014). Memorias al Congreso 2013-2014. Bogotá: Imprenta Nacional. Recuperado de: https://www.mindefensa.gov. co/irj/go/km/docs/mindefensa/documentos/descargas/prensa/documentos/ memorias2013-2014.pdf

Ministerio de Defensa Nacional (2013). Memorias al Congreso 2012-2013. Bogotá: Imprenta Nacional. Recuperado de: https://www.mindefensa.gov. $\mathrm{co} / \mathrm{irj} / \mathrm{go} / \mathrm{km} /$ docs$/$ mindefensa/documentos/descargas/prensa/documentos/ memorias2012-2013.pdf

Ministerio de Defensa Nacional (2012). Memorias al Congreso 2011-2012. Bogotá: Imprenta Nacional. Recuperado de: https://www.mindefensa.gov. co/irj/go/km/docs/mindefensa/documentos/descargas/prensa/documentos/ memorias2011-2012.pdf

Ministerio de Defensa Nacional (2011). Informe del Ministro al Congreso [2010-2011]. Bogotá: Imprenta Nacional. Recuperado de: https://www. mindefensa.gov.co/irj/go/km/docs/Mindefensa/Documentos/descargas/ Prensa/Documentos/memorias2010-2011.pdf

Ministerio de Defensa Nacional (2010). Memorias al Congreso 2009-2010. Bogotá: Imprenta Nacional. Recuperado de: https://www.mindefensa. gov.co/irj/go/km/docs/Mindefensa/Documentos/descargas/normatividad/ estrategiaplaneacion/sistemadecontrolinterno/gpa/informesdegestion/ memorias2009-2010.pdf

Ministerio de Defensa Nacional (2007). Política de Consolidación de la Seguridad Democrática. Bogotá: El Ministerio. Recuperado de: https://www.oas.org/ dsp/documentos/politicas_publicas/colombia\%202.pdf

Ministerio de Defensa Nacional (2007, Febrero). Rendición de cuentas 20022006. Bogotá: El Ministerio. Recuperado de: https://www.mindefensa.gov. co/irj/go/km/docs/mindefensa/documentos/descargas/sobre_el_ministerio/ rendicioncuentas/audiencia_publica_2002_2006.pdf

Ministerio de Defensa Nacional (2003). Política de Defensa y Seguridad Democrática. Bogotá: El Ministerio. Recuperado de: https://www.oas.org/ $\mathrm{csh} / \mathrm{spanish} /$ documentos/Colombia.pdf 
Presidencia de la República (1998). Resolución No 85 del 14 de octubre de 1998 “Por la cual se declara la iniciación de un proceso de paz, se reconoce el carácter político de una organización armada y se señala una zona de distensión". Recuperado de: http://pdba.georgetown.edu/clas\%20research/library $\% 20$ and $\% 20$ documents/peace\%20processes/1998-2002/1998\%20oct_resolucion\%2085.doc

Vicepresidencia de la República (2003). Los derechos humanos en el departamento del Vaupés. Bogotá: La Vicepresidencia. Recuperado de: http://reliefweb. int/sites/reliefweb.int/files/resources/a42d0dfe62e5b79fc1256e2900494151govcol-col-28jan10.pdf

Fuentes secundarias / Artículos indexados y libros

BARros, C. (2006). «L'historiographie et l'histoire immédiates: l'expérience latine de l'Histoire en débat (1993-2006)». Recuperado de: http://www.h-debate. $\mathrm{com} /$ Spanish/presentaciones/lugares/Toulouse/Toulouse_es1.htm

Bushnell, D. (1994). Colombia una nación a pesar de sí misma: De los tiempos precolombinos a nuestros días. Bogotá: Planeta.

Centro Nacional de Memoria Histórica-CNMH (2013). Guerrilla y población civil: trayectoria de las Farc 1949-2013. Bogotá: Imprenta Nacional.

Comisión Histórica del Conflicto y sus Víctimas (2015, Febrero). Contribución al entendimiento del conflicto armado en Colombia. Recuperado de: https://www.mesadeconversaciones.com.co/sites/default/files/informe $\% 20$ comisi_n $\% 20$ hist_rica $\% 20$ del $\% 20$ conflicto $\% 20 \mathrm{y} \% 20$ sus $\% 20$ v_ctimas. $\% 20$ la $\% 20$ habana $\% 2 \mathrm{c} \% 20$ febrero\%20de $\% 202015$.pdf

EsPINO, A. (2001) La renovación de la historia de las batallas. Revista de historia militar, 91, pp. 159-174. Recuperado de: http://publicaciones.defensa.gob.es/ docs/default-source/revistaspdf/rhm_091.pdf?sfvrsn=0\&download=true

Esquivel, R. (2003). Un laberinto impuesto. En: Rabasa, Á. El laberinto colombiano: propuestas para la resolución del conflicto. (pp. 47-58) Bogotá: Universidad Externado.

EsQuivel, R. (2002, Abril). Colonización y violencia en los Llanos, 1949-1953. Memoria y Sociedad, 6 (11), pp. 57-84. Recuperado de: http://revistas. javeriana.edu.co/index.php/memoysociedad/article/view/7748

EsQuivel, R. (2001). Colombia indefensa. Bogotá: Planeta.

Fuerza Aérea Colombiana -FAC (2005). Vocación de victoria Fuerza Aérea Colombiana 1990-2005. Bogotá: FAC. 
Fundación Ideas para la paz -FIP (2006, Febrero 3). La guerra de La Macarena. Siguiendo el conflicto, 40. Recuperado de: http://archive.ideaspaz.org/images/ boletin_conflicto40.pdf

Gamba, R., Prado, J., Prieto, C. \& Tarazona, A. (2012). La Operación Odiseo: un análisis desde la prospectiva militar (Trabajo de grado CEM). Bogotá: Escuela Superior de Guerra.

GÉlvez, L., Correa, A., Gutiérrez, J., Henao, A. \& Rojas, D. (2014). Historiografía contemporánea de la Fuerza Aérea Colombiana: operaciones Sol naciente, Fénix, Alcatraz, Odiseo y Sodoma (Trabajo de grado CEM). Bogotá: Escuela Superior de Guerra.

GonZÁlez, H. (1990). Antecedente geográfico de La Macarena (p. 115-143). En: Universidad Nacional. La Macarena: Reserva biológica de la humanidad; territorio de conflictos. Bogotá: Editorial UN. Recuperado de: http://www. bdigital.unal.edu.co/1435/5/03CAPI02.pdf

Gray, C. (2002, April). Defining and Achieving Decisive Victory. Carlisle, PA: Strategic Studies Institute.

Guerrero, J. (1991). Los años del olvido. Bogotá: Tercer Mundo.

Haulman, D. (2014). Precision Aerial Bombardment of Strategic Targets: Its Rise, Fall, and Resurrection (pp. 148-157). Air Power History, 60th Anniversary.

Keegan, J. (1995). Historia de la guerra. Barcelona: Planeta.

KeEgan, J. (1990). El rostro de la batalla. Madrid: Ediciones Ejército.

MaO, Tse-tung (1968). Sobre la guerra prolongada. Obras Escogidas. Pekín: Ediciones en Lenguas Extranjeras. T. 2. Recuperado de: https://www. marxists.org/espanol/mao/escritos/pw38s.html

Martínez, G. (2006). Hablan los generales: las grandes batallas del conflicto colombiano... Bogotá: Norma.

Misión de Observación Electoral -MOE (2010). Monografía político electoral Departamento de Vaupés 1997 a 2007. Bogotá: MOE.

Moyar, M., Pagan, H. \& Griego, W. (2014, July). Persistent Engagement in Colombia (Report 14-3). MacDill AFB (Fl.): JSO University. Recuperado de: http://jsou. socom.mil/pubspages/jsou14-3_moyar-pagan-griego_colombia_final.pdf

PARdo, R. (2004). La historia de las guerras. Bogotá: Ediciones B.

Pecaut, D. (2001). Guerra contra la sociedad. Bogotá: Espasa.

PeÑA, J. (2011). Mitú: ciudad amazónica, territorialidad indígena. Leticia: Universidad Nacional de Colombia. Recuperado de: http://www.bdigital. unal.edu.co/9726/ 
Perea, L. \& Murcia, J. (2014). Historiografía contemporánea de la Fuerza Aérea Colombiana: operaciones 'Vuelo del ángel' y 'Retoma zona de distensión' (Trabajo de grado CEM). Bogotá: Escuela Superior de Guerra.

Rabasa, A., y Chalk, P. (2001). Colombian Labyrinth: The Synergy of Drugs and Insurgency and Its Implications for Regional Stability. Santa Mónica: RAND. Recuperado de: Rabasa, http://www.rand.org/pubs/monograph_ reports/MR1339.html

SÁNCHEZ, G. (coord.) (2009). Colombia: violencia y democracia. Medellín: IEPRI.

SÁnchez, G. y Peñaranda, R. (Eds.) (1997). Pasado y presente de la violencia en Colombia. Bogotá: Cerec.

Santos, J. (2007). Historia militar del Ejército de Colombia. Bogotá: Centro de Estudios Históricos del Ejército.

Santos, J. (2002). El Ejército en la guerra irregular de Colombia: una visión histórico-estratégica del conflicto colombiano (1948-2002). Bogotá: Imprenta FF.MM.

Santos, M. (2014). El poder de la Fuerza Aérea Colombiana: La operación Vuelo de Ángel y el cambio en la asimetría de poder entre las FF.MM y las Farc-ep (Trabajo de grado Ciencia Política). Bogotá: Universidad del Rosario.

Sauvage, P. (1998, Diciembre) Una historia del tiempo presente. Historia Crítica, n. 17 , p. $59-70$.

SPencer, D. y Gómez, J. et al. (2011, Junio). Colombia: Camino a la recuperación: seguridad y gobernabilidad 1982 -2010. Washington: CHDS. Recuperado de: http://digitalndulibrary.ndu.edu/cdm/ref/collection/chdspubs/id/18089

Valencia, Á. (1992). Testimonio de una época. Bogotá: Planeta.

Villalobos, J. (1993). Fuerza Aérea Colombiana (v. 5). En: Valencia, A. Historia de las Fuerzas Militares de Colombia. Bogotá: Planeta.

Prensa y páginas web:

ACNUR (2007). Diagnóstico departamental Vaupés. Recuperado de: http://www. acnur.org/t3/uploads/media/COI_2190.pdf?view $=1$

Alcaldía de El Carmen de Bolívar (2013, Noviembre 1). Nuestro municipio. Recuperado de: http://www.elcarmen-bolivar.gov.co/informacion_general.shtml

Alcaldía de Mitú (2015, Febrero 20). Nuestro municipio. Recuperado de: http:// www.mitu-vaupes.gov.co/index.shtml

Alcaldía de Suárez (2012, Agosto 28). Nuestro municipio. Recuperado de: http:// suarez-cauca.gov.co/informacion_general.shtml 
Armada Nacional de Colombia-ARC (2007...) Continúa operación 'Alcatraz'. Recuperado de: https://www.armada.mil.co/eng/node/5104

Bedoya, J. (2012, Octubre 23). Así cayó ‘Alfonso Cano'. El Tiempo. Recuperado de: http://www.eltiempo.com/archivo/documento/cms-12330024

Bedoya, J. (2010, Septiembre 23). Así se planeó y ejecutó la Operación 'Sodoma'. El Tiempo. Recuperado de: http://www.eltiempo.com/archivo/documento/ cms-7960880

Bedoya, J. (2007, Diciembre 18). Se acabó la suerte del 'Negro Acacio'. Recuperado de: http://www.eltiempo.com/archivo/documento/mam-2770504

Bolaños, E. (2011, Noviembre 7). Así se vivió 'Odiseo'. El Espectador. Recuperado de: http://www.elespectador.com/noticias/judicial/asi-se-vivioodiseo-articulo-310039

Castrillón, G. (2011, Diciembre 17). La 'Operación Odiseo', la muerte de Alfonso Cano. El Espectador. Recuperado de: http://www.elespectador. $\mathrm{com} / \mathrm{muerte}$-de-alfonso-cano/operacion-odiseola-muerte-de-alfonso-canoarticulo-317180

Centro Nacional de Memoria Histórica -CNMH (2014). Proceso de paz con las Autodefensas Unidas de Colombia -AUC. Recuperado de: http:// centromemoria.gov.co/wp-content/uploads/2014/11/Proceso_de_paz_con_ las_Autodefensas.pdf

Colprensa (2013, Junio 7). Condenan a la Nación por segunda vez por despeje de 'El Caguán'. Frontera Informativa. Recuperado de: https://fronterainformativa. wordpress.com/author/fronterainformativa/

EFE (2002, Febrero 21). Continúan bombardeos contra las Farc: tres civiles muertos. Cooperativa. Recuperado de: http://www.cooperativa.cl/p4 noticias/site/artic/20020221/pags/20020221165200.html

El Diario (2010, Septiembre 24). Así se construyó la Operación Sodoma. Recuperado de: http://www.eldiario.com.co/seccion/judicial/as-se-construyla-operaci-n-sodoma100923.html

El Espectador (2010, Diciembre 11). La diplomacia con Washington. Recuperado de:-http://www.elespectador.com/impreso/articuloimpreso-239868diplomacia-washington

El Espectador (2003, Mayo 4). El ABC de la interdicción (p. 14A; versión impresa).

El Espectador (2001, Diciembre 16). Una inteligencia a prueba (p. 7A; versión impresa).

El País (2013, Julio 16). Condenan a la presidencia por robo de ganado en zona de despeje. El País On line. Recuperado de: http://www.elpais.com.co/elpais/ temas/andres-pastrana/ 
El País (2007, Septiembre 4). "Tropas del Ejército dieron de baja al 'Negro Acacio'. Recuperado de: http://historico.elpais.com.co/paisonline/notas/ Septiembre042007/nac00.html

El País (2003, Febrero 20). Un año de la retoma del Caguán. El País On line. Recuperado de: http://historico.elpais.com.co/paisonline/calionline

El Tiempo (2011, Noviembre 6). Cuatro claves del Estado que pusieron a las Farc en su peor momento. Recuperado de: http://www.eltiempo.com/archivo/ documento/CMS-10713652

El Tiempo (2011, Noviembre 5). [Mapa: Zona de ofensiva contra Alfonso Cano]. Recuperado de: https://esperanzaav.wordpress.com/page/21/

El Tiempo (2007, Septiembre 5). La muerte de 'El sietevidas'. Recuperado de: http://www.eltiempo.com/archivo/documento/cms-3710030

El Tiempo (2003, Agosto 22). Cacería a mil vuelos del narcotráfico. Recuperado de: http://www.eltiempo.com/archivo/documento/MAM-1002293

El Tiempo (2001, Agosto 19). Últimas operaciones exitosas (p. 1-17; versión impresa).

El Tiempo (2000, Julio 17). Farc amplían zona de distensión. Recuperado de: http://www.eltiempo.com/archivo/documento/mam-1280032

El Tiempo (1999, Agosto 16). La guerrilla deja sin policía a municipios. Recuperado de: http://www.eltiempo.com/archivo/documento/mam-896475

El Tiempo (1999, Junio 9). Fuerza de intervención pide EU a la OEA (p. 1A; versión impresa).

El Tiempo (1998, Diciembre 7). Viraje de EU frente a Colombia (p. 9A; versión impresa).

El Tiempo (1998, Noviembre 4). Batalla nocturna para recuperar Mitú. Recuperado de: http://www.eltiempo.com/archivo/documento/mam-846204

Escuela de Inteligencia Aérea-ESINA (2014, Julio 10). Historia de la JIN. Recuperado de: https://www.esina.mil.co/historia-1

Fuerza Aérea Colombiana -FAC (2003, Mayo 23). Tras el Negro Acacio. Recuperado de: http://www.academiahistoriaaerea.mil.co/tras-el-negro-acacio

Fuerza Aérea Colombiana (2015, Marzo 27). Fuerza de Tarea Conjunta ARES conmemora tres años al servicio del país. Recuperado de: https://www.fac. mil.co/fuerza-de-tarea-conjunta-ares-conmemora-tres-a $\% \mathrm{C} 3 \% \mathrm{~B} 1$ os-alservicio-del-pa $\% \mathrm{C} 3 \% \mathrm{ADs}$

Fuerza Aérea Colombiana (2013, Marzo 28). Fuerza de Tarea de Acción Conjunta... Recuperado de: https://www.fac.mil.co/fuerza-de-tarea-de-acci\%C3\%B3n- 
conjunta- $\%$ E2\%80\%9Cun-s\%C3\%B3lo-esfuerzo-decisi $\% \mathrm{C} 3 \% \mathrm{~B} 3 \mathrm{n}-\mathrm{y}-$ contundencia $\%$ E2\%80\%9D-\%E2\%80\%9Cares $\%$ E2\%80\%9D

Giraldo, J. (2014, Octubre 20). El fuerte bombardeo que precedió el abatimiento de 'Cano'. Noticias RCN. Recuperado de: http://www.noticiasrcn.com/ nacional-pais/el-fuerte-bombardeo-precedio-el-abatimiento-cano

GonzÁlez, C. (2013). Los nombres de la guerra en la memoria histórica. Recuperado de: http://centromemoria.gov.co/wp-content/uploads/2013/11/ Los-nombres-de-esta-guerra.pdf

Infobae (2011, Noviembre 5). Así fue la "Operación Odiseo" que acabó con la vida de Alfonso Cano. Recuperado de: http://www.infobae. com/2011/11/05/1037324-asi-fue-la-operacion-odiseo-que-acabo-la-vidaalfonso-cano

La Reportería (2015, Mayo 16). Anostumus, la más dura operación contra la minería ilegal en la última década. Recuperado de: http://www.lareporteria. com/contenidos/Info_Segundo_Nivel.php?Id_CN2=639\&Id_CN1=20\#. Vn79i7aGuko

Las Fuerzas (2011, Noviembre). Contundencia contra terroristas de las Farc. Las Fuerzas, 11. Recuperado de: http://www.cgfm.mil.co/documents/10184/177460/ las-fuerzas-11.pdf/ff4f0fa4-166e-4a18-8ccd-9d9ac6217eae

LeAl, F. (2010, Enero 18). La política de seguridad democrática. Razón Pública. Recuperado de: http://www.razonpublica.com/index.php/conflicto-drogasy-paz-temas-30/693-la-polca-de-seguridad-democrca.html

Mendoza, M. (2006, Marzo 26). Llamar las cosas por su nombre. El Tiempo. (p. 1-29; versión impresa).

Ministerio de Defensa Nacional-Mindefensa (2007). Campaña militar 'Alcatraz'. Recuperado de: http://www.mindefensa.gov.co/descargas/Documentos Home2/martin_caballero.pps

NeIRA, J. (2014, Noviembre 19). Lecciones aprendidas en la lucha contra el narcotráfico. En Comisión Interamericana para el control del abuso de drogas -CICAD- 56 . Período de Sesiones, Guatemala. Recuperado de: http://www. cicad.oas.org/apps/Document.aspx?Id=3029

Noguera, I. (2011, Noviembre 6). El Chirriadero, donde murió 'Cano', punto inhóspito en las montañas. El Tiempo. Recuperado de: http://www.eltiempo. com/archivo/documento/CMS-10713662

Padilla, N. (1998, Noviembre 5) Colombia: el ejército recuperó el pueblo copado por las Farc. Clarín. Recuperado de: http://edant.clarin.com/diario/1998/11/05/ i-04201d.htm 
Priest, D. (2013, December 21). Covert action in Colombia. The Washington Post. Recuperado de: http://www.washingtonpost.com/sf/investigative/2013/12/21/ covert-action-in-colombia/

Radio Santafé (2015, Mayo 27). Condenan a 20 años de cárcel a 2 guerrilleros de las Farc por toma de Mitú en donde fueron masacradas 43 personas. Recuperado de: http://www.radiosantafe.com/2015/05/27/condenan-a-20anos-de-carcel-a-2-guerrilleros-de-las-farc-por-toma-de-mitu-en-dondefueron-masacradas-43-personas/

Reportero 24 (2011, Noviembre 5). Colombia: El operativo que acabó con (a) Alfonso Cano. Recuperado de: http://www.reportero24.com/2011/11/ colombia-el-operativo-que-acabo-con-a-alfonso-cano/

Restrepo, O. (1999, Marzo 22) Mitú: el inicio de la contraofensiva. El Tiempo. Recuperado de: http://www.latinamericanstudies.org/colombia/mitu3.htm

Rubiano-Groot, R. (2002, Julio) El vuelo del Pegaso en la zona Delta. Revista Aeronáutica, 231.

Rueda, R. (2011, Diciembre). Sodoma reafirma la superioridad de la Fuerza Aérea en las operaciones militares. Revista Aeronáutica, 263.

Semana (2012, Febrero 2). La nueva estrategia contra las Farc. Recuperado de: - http://www.semana.com/nacion/articulo/la-nueva-estrategia-contrafarc/253985-3

Semana (2010a, Septiembre 25). Pilotos cuentan detalles de la operación 'Sodoma'. Recuperado de: http://www.semana.com/nacion/articulo/pilotoscuentan-detalles-operacion-sodoma/122486-3

Semana (2010b, Septiembre 23). Así fue la operación 'Sodoma' que dio muerte a 'Jojoy'. Recuperado de: http://www.semana.com/nacion/articulo/asioperacion-sodoma-dio-muerte-jojoy/122357-3

Semana (2009, Diciembre 6). Golpes silenciosos. Recuperado de: http://www. semana.com/nacion/articulo/golpes-silenciosos/111440-3

Semana (2007, Septiembre 3). Mindefensa dice que las autoridades destruyeron 'el bunker' de las Farc, en el corazón de la selva. Recuperado de: http://www. semana.com/on-line/articulo/mindefensa-dice-autoridades-destruyeron-elbunker-farc-corazon-selva/88048-3

Semana (2001, Abril 9). Golpe maestro. Recuperado de: http://www.semana. com/nacion/articulo/golpe-maestro/45585-3

Semana (1998, Diciembre 12). El síndrome de Jacobo. Recuperado de: http:// www.semana.com/nacion/articulo/el-sindrome-de-jacobo/37900-3 
Semana (1998, Octubre 10). Cuál despeje. Recuperado de: http://www.semana. com/nacion/articulo/cual-despeje/37484-3

Valencia, A. (1998, diciembre). Cuarto momento militar del siglo XX. Revista de las Fuerzas Armadas, n. 169.

Vanguardia Liberal (2011, Noviembre 6). El paso a paso de la operación 'Odiseo'. Recuperado de: http://www.vanguardia.com/actualidad/ colombia/130287-el-paso-a-paso-de-la-operacion-odiseo

Vanguardia Liberal (2015, Agosto 4). Conozca el top 5 de los bombardeos a las Farc. Recuperado de: http://www.vanguardia.com/colombia/322212conozca-el-top-5-de-los-bombardeos-a-las-farc

VÁsquez, C. (2001, Marzo 1). Golpe al Tranquilandia de las Farc. El Tiempo. Recuperado de: http://www.eltiempo.com/archivo/documento/mam601662

Verdadabierta.com (2015, Marzo 11). Los bombardeos cambiaron la guerra en Colombia. Recuperado de: http://www.verdadabierta.com/procesosde-paz/farc/5659-los-bombardeos-cambiaron-la-guerra-en-colombia 



\title{
TRANSFORMACIONES HISTÓRICAS EN LA MANERA DE OPERAR DE LAS FUERZAS MILITARES: REFLEXIONES A partir de la Operación Colombia
}

\author{
General (RA) FLAVIO ULLOA ECHEVERRY ${ }^{1}$
}

\section{INTRODUCCIÓN}

Las Fuerzas Militares en una democracia tienen como objetivo garantizar todos los esfuerzos para debilitar o destruir las amenazas bélicas que operan por fuera de los límites territoriales, proveer la seguridad interna contra la amenaza subversiva de fuerzas internas que pretendan debilitar o destruir el Estado y sus instituciones dentro de su territorio, y también aportar a la seguridad interna apoyando el desarrollo de la Nación o cuando aparecen amenazas que reducen el poder del Estado. Para que las Fuerzas Militares puedan operar requieren de una política institucional que le provea los lineamientos y los requerimientos para su actuación en términos de la voluntad política y el soporte del Estado. De la política institucional se deriva la política operacional, que determina como ellas deben actuar.

Examinar cómo las Fuerzas Militares de Colombia han venido operando en el último siglo y en especial el desarrollo que han tenido desde el año 2000 al 2015 es el propósito de este trabajo, además de hacer un análisis en los aspectos que mejoraron ostensiblemente su actuación para lograr una victoria sobre la subversión, el terrorismo, el narcotráfico y las organizaciones criminales. Hay que incluir en este trabajo a la Policía Nacional, que en Colombia ha jugado un papel importante, pero que además a partir de la segunda mitad del siglo XX se reestructuró en una institución dependiente del Ministerio de Defensa Nacional, integrándose así en este ente gubernamental a la defensa y la seguridad de la Nación. Este aspecto es un diferenciador notable con la mayoría de países en el mundo, $\mathrm{y}$ ha venido jugando un papel decisorio en el resultado final.

Aquellos aspectos que permitieron un desarrollo muy importante de la Fuerza Pública colombiana (Fuerzas Militares y Policía Nacional) son los siguientes: 
La cultura militar, la organización, la tecnología, el desarrollo de capacidades especiales, la inteligencia militar y la estrategia de defensa y seguridad. Todos estos aspectos fueron reconocidos en su conjunto por el Pentágono en el marco de los encuentros y conversaciones operacionales entre las dos fuerzas en las cuales participé en el 2013 como jefe de la delegación colombiana; y por la OTAN y las fuerzas de defensa europeas en el marco de la visita de nuestro ministro de Defensa Juan Carlos Pinzón Bueno, en la cual participé como Jefe del Estado Mayor Conjunto. Este análisis estará determinado en el tiempo desde los años sesenta hasta 2015 , no sin antes dejar en claro y en forma muy breve algunos antecedentes históricos.

Si bien el Ejército de Colombia y la Armada tienen sus orígenes con el Ejército Libertador $^{2}$, el Ejército viene a tener una estructura institucional a partir de la reforma militar del presidente Rafael Reyes. "Reyes comprendió la necesidad de contar con unas Fuerzas Armadas permanentes, profesionales, adecuadamente estructuradas y neutrales en materia política. Se inició en 1906, la expedición de una serie de decretos que permitieron la reorganización del régimen salarial y de las zonas militares que existían en el país, así como la contratación de la Misión Militar Chilena, que condujo a la fundación de la Escuela Militar de Cadetes de San Diego". La Armada República de Colombia, tras sucesivos cambios y restructuraciones, toma en 1936 la forma institucional que requería nuestro país.

La Aviación Militar nace en 1919 durante el gobierno del presidente Marco Fidel Suárez, y durante el conflicto con el Perú actúa como una fuerza independiente, bajo el comando del Cr Herbert Boy y con comunicación directa con el presidente Enrique Olaya Herrera. En 1942 alcanzó su plena autonomía y se estructura como la Fuerza Aérea Colombiana.

Durante el Conflicto con el Perú las Fuerzas Militares tienen una destacada actuación que permitió, por una parte, recuperar nuestra integridad territorial y dar un avance significativo a la capacidad militar de nuestra Nación, en especial a la Fuerza Aérea y a la Armada que en muy poco tiempo se equiparon y organizaron para entrar en la guerra, y por otra alcanzar el reconocimiento y la valoración de nuestro territorio.

En las décadas de los años cuarenta y cincuenta Colombia se ve envuelta en una violencia partidista política que afecta notablemente el desarrollo del país, y que también involucra a las Fuerzas Militares. Entre 1951 y 1956 Colombia participa con el Ejército y la Armada en la guerra de Corea, lo que hace que las Fuerzas Militares no solamente sean bien equipadas sino que además reciban capacitación y entrenamiento que mejoraron enormemente sus capacidades. 
Después de este rápido resumen, entro a realizar el análisis sobre el desarrollo militar colombiano. La cultura militar colombiana se analiza verificando algunos aspectos como la disciplina, la moral de las tropas, su educación, las relaciones civiles militares y el desarrollo del derecho de la guerra. En cuanto a la moral de la tropa, se puede definir como "Aquellos principios de orden espiritual -no jurídico- que deben regular la actividad de los miembros de la Institución Militar para el mejor cumplimiento de los fines de esta última que son la defensa militar del país". El general Montgomery da una definición que en últimas nos aclara que es la moral militar: "El factor individual más importante para la obtención del triunfo es el espíritu del combatiente".

Encontramos dos afectaciones graves en la moral militar colombiana, una en los años ochenta durante el gobierno del presidente Belisario Betancur y otra, tal vez la más importante, durante el gobierno de Ernesto Samper, cuando se vivió una de las mayores crisis institucionales desde los años cuarenta, que afectó notablemente a las Fuerzas Militares. Así mismo, constató la presencia de una moral alta en los años sesenta y setenta, y una moral muy alta entre 2001 y 2015, producto de la exigencia y la definición clara de los objetivos de las Fuerzas Militares y un crecimiento institucional en nuestro país.

La disciplina militar va muy emparejada con la moral, que igualmente tiene su mayor afectación en los años noventa, por la falta de definir claramente los roles y misiones de las Fuerzas Militares ante una creciente escalada terrorista y de narcotráfico en medio de la crisis política que se estaba viviendo. Ante el vacío de poder estatal y la falta de voluntad política para definir la política de seguridad y defensa, los particulares y las mafias narcotraficantes crearon grupos armados que complicaron aún más la situación y que terminaron afectando esta moral y disciplina militar. La disciplina tuvo su mejor desempeño entre los años sesenta y setenta, y mejoró notablemente a partir del 2001, con su mejor calificación entre 2012 y 2013.

La educación es una variable muy importante en el desempeño militar y en la configuración de la cultura. Hay dos hitos importantes: uno, la profesionalización del oficial, que se inicia en los años noventa con la implementación de las carreras profesionales liberales dentro de las Escuelas Militares, la educación tecnológica de los suboficiales, la creación en el año 2000 de los soldados profesionales y sus escuelas, y dos, la incorporación de las especializaciones y maestrías en las Escuelas de postgrados y la Escuela Superior de Guerra. La educación ha venido siempre en un proceso de mejoramiento continuo, y en particular a partir de 2006, cuando se dio un especial énfasis y seguimiento por parte del Ministerio de Defensa y del Comando General de las Fuerzas Militares.

Las relaciones civiles-militares, conocidas como la confianza institucional entre el gobierno, el Estado y los civiles con sus Fuerzas Militares, tienen su 
mayor crisis durante el gobierno de Samper, y en segundo término con Betancur, por la falta de confianza de los militares en especial en su Comandante en Jefe, a quien en el primer caso no ven con la autoridad moral requerida para dirigir el país ni las Fuerzas, y en el segundo por su falta de apoyo y respaldo institucional. Encontramos las mejores relaciones en los años sesenta y setenta y posteriormente empiezan a mejorar a partir del 2000 hasta llegar a su mejor época después de 2005.

En cuanto al derecho de la guerra, fue afectado enormemente por los acontecimientos del país en una conjugación de los fenómenos delictivos de terrorismo y narcotráfico y la ausencia de políticas claras de gobierno sobre la seguridad interior en nuestro país. Siempre en las escuelas se educó al oficial y al suboficial y se entrenó al soldado en un marco de cumplimiento legal y normativo. Sin embargo, a partir del año 2001 se enfatiza en la educación y entrenamiento en derechos humanos y el Derecho Internacional Humanitario, se definen las reglas de encuentro donde la Fuerza Aérea es pionera en su aplicación, y hay un desarrollo muy importante en la creación de los oficiales de derecho operacional y los comités jurídicos operacionales que asesoran y apoyan a los comandantes en la toma de decisiones.

\section{La Operación Colombia}

La Operación Colombia, iniciada el 9 de diciembre de 1990, constituye un hecho histórico, que se enmarca en una multiplicidad de interpretaciones y que para algunos fue un acto que cerró de frente el diálogo y la posibilidad de paz con las FARC. Para otros, fue un acto que frenó la capacidad estratégica y las dinámicas de crecimiento de las FARC y el ELN, en el marco de una Coordinadora Guerrillera "Simón Bolívar". Pero en lo que todos coinciden es en que esta acción planteó un antes y un después para la dinámica del conflicto armado en Colombia.

"El 9 de diciembre de 1990 tropas de la Séptima Brigada del Ejército de Colombia, comandadas por el general Luis Humberto Correa, realizaron la primera gran operación aeroterrestre contra un complejo narcoterrorista que constituía la sede del Secretariado de las FARC, conocida con el mítico nombre de Casa Verde, en la zona rural Uribe-Meta sobre las estribaciones surorientales del Páramo del Sumapaz. Al decir de Jacobo Arenas ideólogo fundador del grupo terrorista, "Casa verde, era el símbolo de la construcción de un movimiento revolucionario que orientaba guerrillas comunistas, como un estímulo a la subversión para la toma del poder". Golpear al Secretariado de las FARC en su sede era asunto de máxima trascendencia estratégica para el Ejército Nacional y de singular importancia política para el país. En ese orden de ideas, la Operación Colombia, se planeó en detalle con base en testimonios de desertores de las FARC, aerofotografías de la Fuerza Aérea, análisis meteorológicos y selección de tropas de asalto, cierres sobre el terreno, fuegos aerotácticos y maniobras sobre los objetivos concretos. El asalto aeroterrestre después de los fuegos de ablandamiento aerotácticos, fue conducido por 
las Fuerzas Especiales. Los comandos desembarcaron sobre los objetivos principales:

Casa de Tirofijo, casa de Jacobo, Aulas, Escuela de Cuadros y depósitos logísticos ${ }^{33}$ ".

Esta es una de las descripciones sobre la Operación Colombia que se pueden encontrar tanto en revistas académicas como en la prensa en general, en la que se sigue hablando del tema luego de más de 20 años no solo por la importancia que tuvo en el ámbito nacional de seguridad, sino por la importancia que generó en los temas del pensamiento estratégico operacional. La Operación Colombia ha sido analizada en distintas publicaciones periodísticas y académicas en las que se ha reflexionado sobre su pertinencia y su necesidad en el contexto constituyente que vivía el país en los inicios de la década del noventa.

Una de las múltiples voces frente a este hecho es justamente la de los militares. Recuperar sus vivencias y memorias constituye un aporte para nutrir el pensamiento estratégico operacional, y una reflexión sobre una de las operaciones militares más importantes en la historia del conflicto armado colombiano, como quiera que se inició un proceso de debilitamiento del Bloque Oriental de las FARC.

Para el caso específico de la Fuerza Aérea Colombiana, tuvimos que operar en un contexto geográfico específico como fue el departamento del Meta, en el cañón del río Duda y la Serranía de la Macarena, y determinar y conocer el territorio en el que se iba a operar era sumamente importante para nuestro éxito, teniendo en cuenta las limitaciones tecnológicas de la década de los noventa del siglo XX.

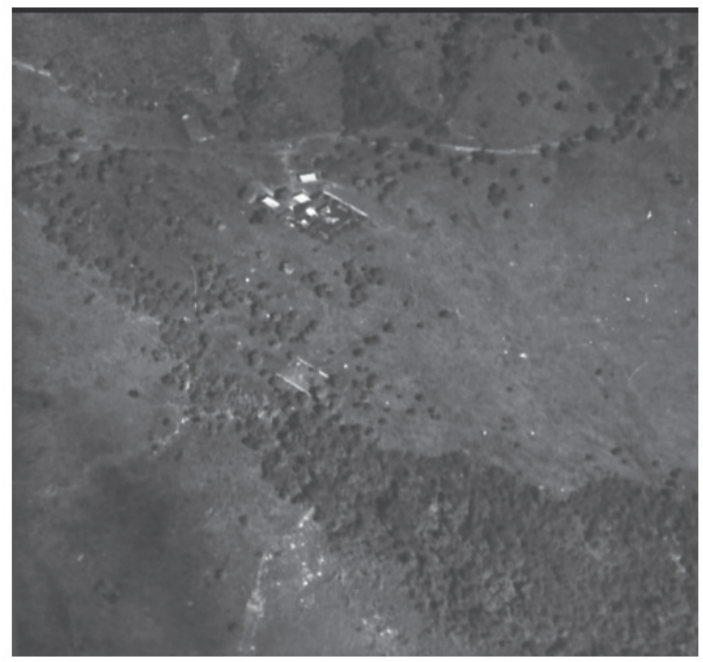

Foto 1. Campamento Casa Verde. Archivo personal

Recuperado el 11 de enero de 2018. https://dialogo-americas.com/es/articles/veinte-anos-despues-dela-operacion-colombia-contra-casa-verde 
Para las FARC, la ubicación de Casa Verde constituía un elemento estratégico de su defensa, ya que ese era el punto destinado para recibir las visitas de políticos y miembros de la sociedad civil durante el proceso de diálogo que este grupo guerrillero estableció con el gobierno de Belisario Betancur. Casa Verde estaba sumida en la vasta geografía del páramo de Sumapaz, con el fin estratégico de no ser detectados fácilmente por los helicópteros que entraban y sacaban al personal civil a sus instalaciones, lo que no representaba una amenaza para la guerrilla puesto que se encontraba a las afueras del cañón, retirada de los campamentos y era utilizada como punto de control.

Casa Verde, más que una pequeña casa en las estribaciones de la Cordillera Oriental, en el municipio de La Uribe (Meta), era un lugar simbólico para la guerrilla de las FARC. Este territorio se consolidó como su retaguardia estratégica y en centro emblemático de su lucha. Casa Verde era el nombre con que se conoció una amplia zona bajo el control de las FARC, en la región montañosa del Meta, integrada por La Gaucha, Casa Verde, la Escuela de Cuadros y El Rincón de los Viejitos.

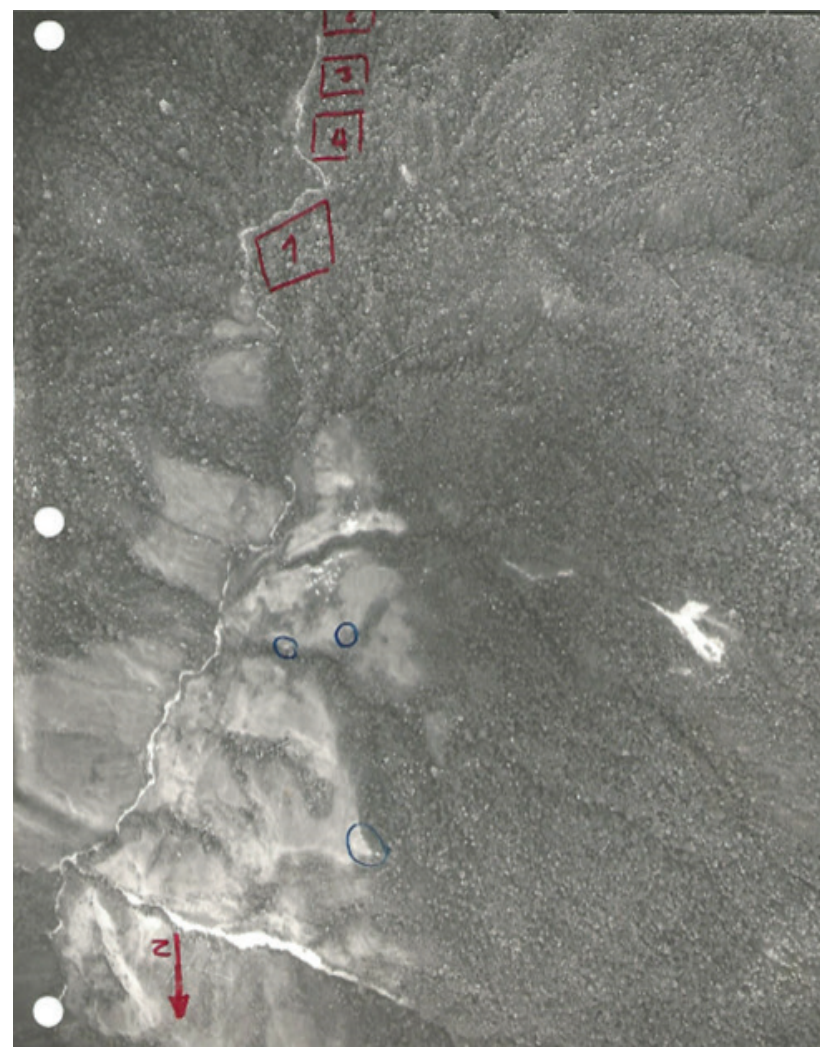

Foto 2. Campamento Casa Verde y objetivos focalizados. Archivo personal

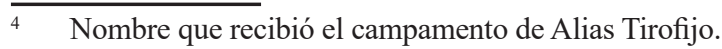


Una escuela de entrenamiento, el campamento de Tirofijo y el campamento de Reyes, entre otros, fueron los objetivos militares que se habían establecido para dar inicio a la Operación Colombia. Por los fenómenos meteorológicos y las características del territorio tales puntos eran poco visibles, pero a pesar de ello podíamos prever el lugar donde los helicópteros tenían que aterrizar, razón por la cual la orden era que primero se debía bombardear esa zona en caso de que hubiera minas antipersona. Debíamos dejar limpia esa zona para poder entrar y efectuar en su totalidad la Operación.

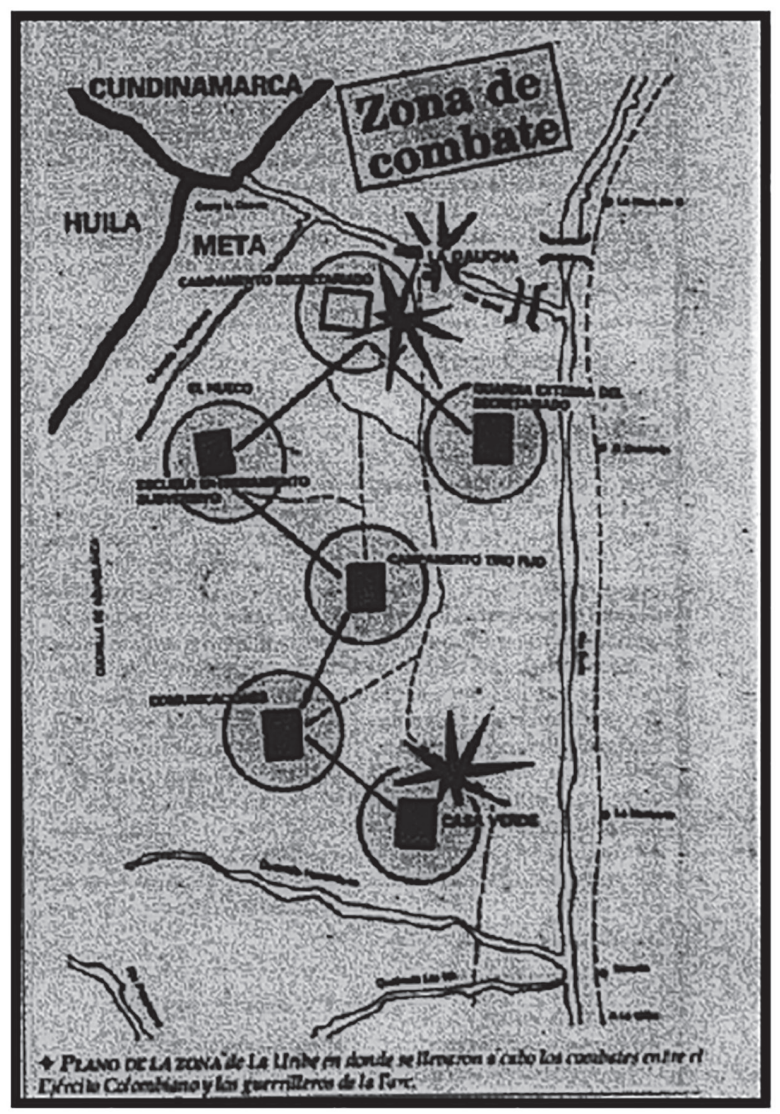

Foto 3 Mapa sobre puntos estratégicos de la Operación Colombia. Tomado de El Nuevo Siglo el 14 de diciembre de 1990.

Para las FARC, esta zona tenía una importancia simbólica ya que en ella se encontraba la tumba de Jacobo Arenas, uno de sus máximos dirigentes históricos. Es así como se entiende que el sector de Casa Verde tenía una importancia central para la guerrilla, y su control sobre el territorio permanecía incuestionado. 


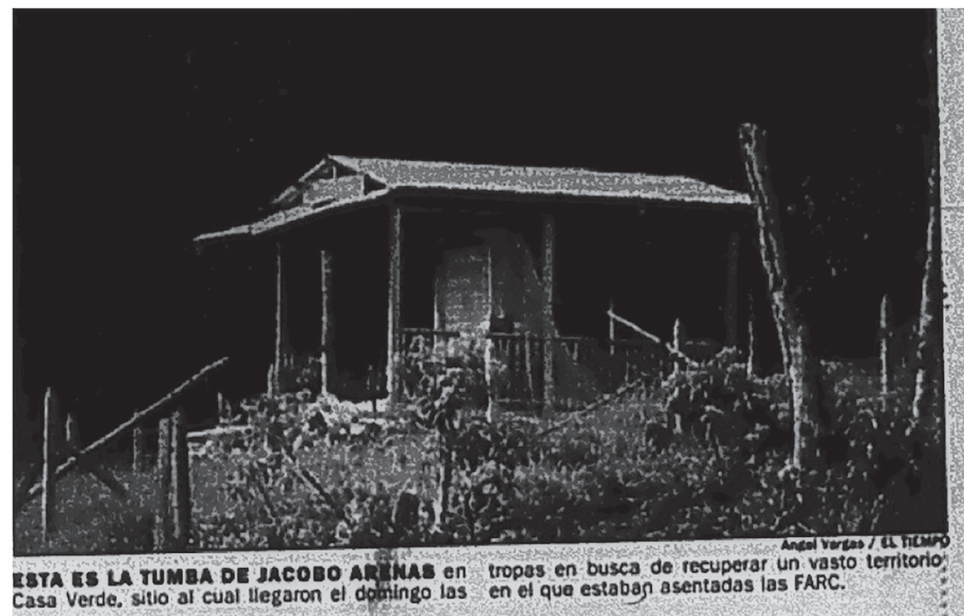

Foto 4. Tumba de Jacobo Arenas en Casa Verde. Tomado: El Tiempo, 13 de diciembre de 1990.

En ese entonces, el líder de la escuadrilla de KFIR era el general Morales, que en aquel momento era Teniente Coronel y segundo comandante de la Base; como Jefe de Operaciones del Grupo de Combate, y bajo ese cargo estuve liderando todo el planeamiento y la ejecución de la tarea. Si bien en la escuadrilla el general Morales era el líder, en la Operación Colombia tuve un liderazgo importante dentro de la base. Por eso para mí esta fue una operación de mucha importancia en mi vida profesional como oficial de la Fuerza Aérea Colombiana. Me permitió dar una conferencia en la Escuela de Guerra sobre la Operación Colombia, y guardo conmigo mucho material que fue trascendental para el éxito de esta operación.

\section{LA INTELIGENCIA MILITAR HUMANA Y EL DESARROLLO TECNOLÓGICO DE LA GUERRA}

En el caso específico de la Operación Colombia, debido a la falta de inteligencia técnica se desarrolló la inteligencia humana, para poder obtener el éxito de la Operación. El reconocimiento de los grupos guerrilleros y de los puntos de guardia y de control de la zona de Casa Verde, fue la clave para que nosotros pudiéramos reconocer el territorio y saber con claridad en dónde debíamos entregar las armas y tener el impacto que se había planeado con anterioridad. El nivel de detalle del conocimiento del territorio fue fundamental para tener todo tipo de información como las curvas de los ríos y las quebradas, y el punto de vulnerabilidad que teníamos por las cimas tan altas que componen esa geografía. En ese entonces no se hablaba de coordenadas, ni de GPS, sino del conocimiento de la inteligencia humana de haber caminado por mucho tiempo toda esa zona. 
Es importante aclarar que los generales tomamos decisiones con un margen de incertidumbre muy grande, tal y como lo señala Clausewitz. A mayor tecnología menor incertidumbre, pero la incertidumbre siempre estará presente. La inteligencia humana fue poniendo poco a poco estaciones a lo largo del territorio para que la información fuera lo menos imprecisa posible. Las fotos aéreas también fueron de gran ayuda para poder tener la ubicación precisa sobre el lugar que se buscaba impactar. En la Operación Colombia se actuó bajo la incertidumbre de saber con claridad dónde estaban las ametralladoras, porque nadie en la inteligencia había podido establecer que había nidos de ametralladoras ubicadas en ciertos puntos. La incertidumbre siempre va a existir, pero el papel de un comandante es aplicar todas las estrategias posibles para reducirla.

La inteligencia humana del territorio fue sumamente importante para que las operaciones de esa época, y la Operación Colombia específicamente, tuvieran éxito, ya que lo que ofrecían las aeronaves no era suficiente para asegurar la eficiencia de la operación. La inteligencia más la precisión fue lo que nos ayudó a tener buenos resultados; una inteligencia de última generación. El problema frente a este tema radica en que en el imaginario colectivo, cuando se habla de entrega de armas por parte de la Fuerza Aérea Colombiana, se piensa que siempre se ha tenido la misma tecnología del GPS y de la precisión con que hoy en día cuentan las aeronaves, y no se cuestiona lo difícil y riesgoso que era operar con la tecnología de hace 20 años o inclusive más. A nosotros nos tocó depender del tiempo, del rumbo y de un mapa.

Bajo este entorno, considero que se debe ahondar en lo que yo denomino la cultura de la guerra ${ }^{5}$, para hacer referencia a la manera en la que se operaba en cada uno de los contextos de la historia colombiana contemporánea. Los hechos y las operaciones ejecutadas antes de 1991 estaban regidos bajo la Constitución de 1886, en la que los parámetros del Derecho Internacional Humanitario eran distintos. Por esta razón el contexto operacional debe partir de todos los ámbitos posibles para dar cuenta de su función y de la manera estratégica del pensamiento militar que ejercía en cada momento histórico.

El caso de la Operación Colombia debe ser leído desde la tecnología y la manera de operar bajo una cultura de la guerra propia de 1990, muy diferente a la evolución y al desarrollo que ha tenido hasta hoy, para garantizar la efectividad de las operaciones y el cumplimiento de las leyes bajo el marco del DIH. Existe una concepción del DIH que el soldado actual tiene muy clara, y que hace 20 años era diferente debido a la forma como se enseñaba la doctrina militar.

Este concepto hace parte de una lista de elementos que se van a desarrollar más adelante con mayor profundidad en una publicación que saldrá en el año 2019. 


\section{DeSARROLlO TECNOLÓGICO, DISCIPLINA MILITAR Y CULTURA DE GUERRA}

La disciplina militar de los años sesenta y setenta era distinta a la que se vive hoy en día. La cultura de guerra de los ejércitos de la antigua Rusia, Yugoslavia o Alemania era muy diferente en un contexto claro de guerra internacional, de lo que puede ser en la actualidad. Es decir, si la Operación Colombia se hubiera ejecutado con la tecnología actual, habría sido mucho más eficiente, evitando errores que en aquel momento era imposible no cometer.

A pesar de que el desarrollo tecnológico iba de la mano tanto de la Fuerza Pública como de los grupos armados ilegales, fue solo hasta los primeros años del siglo XXI cuando la Fuerza Aérea tomó la delantera al adoptar una mejor tecnología y condiciones más favorables para posicionarse de una forma ventajosa sobre los grupos guerrilleros y de autodefensa ilegal. Se registró entonces la adopción de importantes avances tecnológicos por parte de la Fuerza Aérea Colombiana; aunque a la vez la contraparte consiguió en el mercado negro armas y municiones y atacó intensamente a la Fuerza Pública y a la población civil ${ }^{6}$.

Sumado a todo lo anterior, cabe señalar que para la cultura militar de la época era normal, e inclusive representaba un honor, darles a los medios de comunicación explicaciones operativas cuando se tenía éxito en alguna operación. Aspecto negativo, sin embargo, en tanto esa información era aprovechada por los enemigos para entender las dinámicas y estrategias que estaba utilizando la Fuerza Aérea Colombiana.

Es importante entender que el Plan Colombia y las acciones del Estado fueron claves para que crear cultura militar y desarrollo estratégico. De ahí que dicho progreso estuviera por encima del enemigo y hubiera sido posible llegar al Plan Victoria, que hoy en día enorgullece a toda la Fuerza Pública y en especial a la Fuerza Aérea, por disponer de un poder aéreo que determina un desequilibrio en un campo de batalla en el cual las aeronaves de la FAC tuvieron y cumplieron con lo necesario para garantizar y ejercer la soberanía. La Operación Colombia fue entonces una operación que dio cuenta de la adaptación constante de la Fuerza Pública a cada contexto y de la capacidad del poder aéreo empleado por la Institución en ese momento.

Antes de 2006 nosotros operábamos con unas aeronaves con las que se combatía mucho, como los T27, A37, Mirage y el KFIR. No obstante, con este tipo de aviones teníamos que volar con un mapa en la mano para poder ubicar

Un ejemplo de ello son las tomas y ataques guerrilleros a las cabeceras municipales durante la década de los años noventa; fenómeno histórico de gran barbarie y atrocidad, que exigió una respuesta integral por parte de la Fuerza Pública. En particular la Fuerza Aérea Colombiana desarrolló un mecanismo de diagnóstico, monitoreo y acción que fue muy efectivo en contrarrestar dicha amenaza. Este esfuerzo institucional será documentado en un libro que publicaré en el año 2019. 
el blanco militar. Aun cuando los dos últimos tenían un sistema inercial de navegación, este no era tan preciso como los sistemas de última generación. Afortunadamente, todo eso ha venido cambiado, ya que nuestra precisión no se podía calcular inequívocamente y teníamos que lidiar con los recursos e infraestructura de ese entonces. En 2006 llegan a Colombia los aviones Súper Tucano y empiezan a reemplazar a muchas de las aeronaves antiguas para este tipo de operaciones. Esto nos permitió atacar a 20.000 pies sin ser detectados, ni tener el riesgo de que nos pudieran impactar desde la tierra. No se puede decir que el nivel de tecnología con el que se contaba en ese entonces se debía a negligencia del Estado para invertir en el gasto militar, sino que tal era la tecnología con la que se contaba en el mundo militar de la época.

En la medida en que fue llegando mejor tecnología, mejores fueron los resultados. La demora de poder poner la coordenada correcta en una operación con despliegue de armamento en el sistema de cada avión, se debía al trabajo de insertar la coordenada en el sistema, porque la bomba era guiada por GPS. Solo hasta el año 2006 pudimos contar con un tipo de tecnologías de precisión con aviones como el Súper Tucano, que en términos prácticos hace lo mismo que el KFIR.

Ya en 2010 se contaba con los KFIR C10 con el sistema de navegación con un GPS que genera información mucho más precisa. La precisión pasó de ser de millas a metros. Desde la época de 1990 hasta 2008 se utilizaba el sistema inercial en los KFIR, que determinaba la posición geográfica a medida que iba avanzando la aeronave, razón por la cual la operatividad de la época en la que se ejecutó la Operación Colombia, no era tan precisa como la que se obtiene con los aviones de hoy en día.

\section{A MOdo DE CONCluSión: TransformaCiOnes EN EL CONTEXTO OPERACIONAL}

Así como en el contexto de la Operación Colombia la constante era la incertidumbre y la imposibilidad de garantizar un control absoluto del devenir operacional, las décadas del noventa y del 2000 van a estar caracterizadas por el desarrollo del proceso de inteligencia militar, de la tecnología (en el caso de la Fuerza Aérea Colombiana va a darse una inversión y adecuación de las aeronaves fundamental para confrontar a los grupos armados ilegales), del entrenamiento militar contraguerrillero y de la voluntad política de los gobiernos centrales, que incidieron directamente en la capacidad de transformar las dinámicas del conflicto, generando éxitos militares y cambios en las dinámicas de seguridad.

Todas estas transformaciones en el terreno del contexto operacional incidieron de manera positiva en el fortalecimiento de una cultura militar, ahondando en la disciplina y la mística, y elevando la moral al interior de las 
instituciones castrenses. Este cambio es fundamental, ya que potenció el capital humano, desarrolló las posibilidades y capacidades del personal adscrito a las Fuerzas Militares, convenciéndoles de que la victoria era factible y accesible, y fortaleciendo las relaciones con la sociedad y con el poder político, elementos claves para garantizar y potenciar la legitimidad histórica de su actuar.

La forma de operar de las Fuerzas Militares, y en particular de la Fuerza Aérea Colombiana, van a evidenciar su capacidad de incidir en las dinámicas del conflicto de manera plena en contextos operacionales como los de la Zona de Distensión o en la Operación Vuelo del Ángel, contextos en los que se puso de presente que la nueva estructura organizacional iba a garantizar la victoria para el Estado colombiano, teniendo una fuerte influencia las capacidades operacionales del poder aéreo.

Este proceso de racionalización del uso del poder aéreo quedó plasmado formalmente en el documento Manual de Estado Mayor Fuerza Aérea, en el que se evidencia que el proceso de cualificación no fue solamente en la parte tecnológica, sino en la planeación y estrategia interna: "El Macro proceso de Planeación, Programación y Presupuestación de la Fuerza Aérea Colombiana (PPBS), se lidera y desarrolla a través del Sistema Integrado de Planeación que corresponde a la integración y articulación de los Estados Mayores de Planeamiento y Coordinación para los diferentes niveles de planeamiento de la Fuerza" (2003, p. 11).

Otro aspecto esencial en el fortalecimiento de la Fuerza Aérea fue el de implementar el principio del poder aéreo de "control centralizado y ejecución descentralizada" mediante la organización del Sistema de Comando y Control de la Fuerza Aérea. Este sistema integró todas las actividades de inteligencia, planeación, ejecución y control operacional, y además todos los elementos tecnológicos de comunicaciones, tecnologías de la información, señales de radar, sensores y plataformas de inteligencia, bajo el Centro de Comando y Control de la Fuerza Aérea y sus organizaciones subalternas en los Comandos y Grupos Aéreos, los Centros de Comando y Control de las Bases Aéreas. Esto le permitió al Comandante de la FAC tener un control de todas las operaciones, explotar adecuadamente la flexibilidad, velocidad, precisión y versatilidad del poder aéreo e incorporar el DIH en toda la estructura operacional, mediante la definición de las reglas de encuentro, los informes de misión cumplida, el control cerrado de las operaciones de interdicción del narcotráfico y el sistema de información operacional.

En este proceso de desarrollo de las capacidades institucionales, cumple un papel fundamental -más no exclusivo- el Plan Colombia, en la medida en que permite que todas las variables enunciadas al inicio de este documento se potencien y desarrollen, de forma sistemática para lograr la victoria sobre los grupos armados ilegales que tenían amenazada a la sociedad colombiana y a la infraestructura del Estado. 
Esta afirmación no es particular del autor de este trabajo; se encuentra transversalizada en la mentalidad de los miembros de las Fuerzas Militares, tal y como lo reconoce el siguiente testimonio: "La Fuerza Aérea es una antes del Plan Colombia, y otra después del mismo; ganamos en capacidad militar y operativa; fortalecimos la inteligencia propia y conjunta; recibimos asesoría especializada que nos permitió comprender el mejor uso que podíamos hacer de nuestros recursos... Cuando nos pidieron retomar la Zona de Distensión teníamos la capacidad real de hacerlo, atacando ordenada, sistemática y simultáneamente en varios puntos estratégicos... Las FARC no esperaban esa capacidad de respuesta, por eso los tomamos por sorpresa y les golpeamos en esa medida" (MARÍn et al. 2016, p. 238).

Este proceso de transformación y modernización permitió que la Fuerza Aérea Colombiana desarrollara exitosas operaciones aéreas en contra de los grupos armados ilegales, llevando a la desmovilización de las estructuras armadas de las AUC y de las FARC, y al debilitamiento estratégico de otras organizaciones.

Entre 1999 y 2006 se presentan las operaciones aéreas más importantes y significativas en la historia del país, desarrollando una estrategia ofensiva que va a garantizar una mayor capacidad de control efectivo del territorio, y que va a impedir que grupos ilegales consoliden una "guerra de movimientos", con la cual se habrían podido apoderar de vastas zonas del territorio, afectando la calidad de vida de la población que allí habitaba. Al contrario, como se ha mostrado con los trabajos de Echandía (2013) y SALAS (2014), las dinámicas de seguridad del país cambian significativamente después del año 2006.

Pero no solo hay un cambio en el contexto social; también hay una transformación poderosa al interior de las Fuerzas Militares, proceso que no ha sido abordado por la academia, y que es fundamental para comprender la profesionalización, modernización y tecnificación que estas instituciones desarrollaron, y que permitieron que alcanzaran la victoria.

\section{REFERENCIAS}

Alvarado, Y. P. (2006). Operación Vuelo de Ángel la retoma de Mitú. En Osorio Martínez, G. (Comp.), Hablan los generales las grandes batallas del conflicto colombiano contadas por sus protagonistas. Bogotá: Norma.

Comisión Nacional de Reparación y Reconciliación -CNRR (2009). Recordar y narrar el conflicto. Herramientas para reconstruir memoria histórica. Bogotá: CNRR.

DÁvila, A. et al. (2016). El conflicto en contexto. Análisis de 5 regiones. Bogotá: Pontificia Universidad Javeriana. 
ECHANDÍA, Camilo (2013). Punto de partida del debilitamiento de las FARC. En Revista Zero, Bogotá: Universidad Externado de Colombia.

Fundación Ideas para la Paz (2013). Hoy y ayer del Bloque Oriental de las FARC. Bogotá: FIP.

MARÍn et al. (2016). Victorias desde el aire: La Fuerza Aérea Colombiana y el término del conflicto armado. Bogotá: Editorial Ibáñez.

RuEdA, R. P. (2004). La transformación de la Guerra. En La Historia de las Guerras. Bogotá: Ediciones B.

SALAS, Luis Gabriel. (2014) Lógicas territoriales y relaciones de poder en el espacio de los actores armados: un aporte desde la geografía política al estudio de la violencia y el conflicto armado en Colombia, 1990-2012 En Cuadernos de Geografía, Bogotá, Universidad Nacional de Colombia.

SÁnchez SuÁrez, Pedro Arnulfo. (CR). (2014). Poder aéreo en la seguridad y defensa nacional. En Revista Taktika $\mathrm{N}^{\circ}$ 5. Colombia, Fuerza Aérea Colombiana.

SAnTos, María Alejandra. (2014). El poder de la Fuerza Aérea Colombiana: la Operación Vuelo de Ángel y el cambio en la asimetría de poder entre las FF.MM y las FARC-EP. Bogotá, Universidad Colegio Mayor de Nuestra Señora del Rosario, Facultad de Ciencia Política y Gobierno. 
MEMORIA 



\title{
OPERACIÓN COLOMbIa: CRÓNICAS Y NARRATIVÁ, DE DOS PILOTOS DE HELICÓPTERO DE LA FUERZA AÉREA COLOMBIANA
}

\author{
Mayor General (RA) LUIS IGNACIO BARÓN
}

La Operación Colombia ha sido analizada en distintas publicaciones periodísticas y académicas en las que se ha reflexionado sobre la pertinencia y necesidad de ésta, en el contexto constituyente que vivía el país en los inicios de la década del noventa. Todos estos relatos se caracterizan por tres elementos comunes: la inmediatez de las reflexiones, en las que no se pensó la naturaleza estratégica de esta operación; el no vincular como fuente de consulta a los miembros de las Fuerzas Militares que participaron en el desarrollo de la misma; y el desconocimiento por las particularidades y vicisitudes propias de esta operación militar.

Estos tres vacíos expuestos hacen que los documentos históricos con los que se documenta este momento sean incompletos y poco integrales, lo que se traduce en una valoración y apreciación histórica poco objetiva sobre lo que allí ocurrió. En función de esto último, la Fuerza Aérea Colombiana, en razón de su deber de memoria, ofrece dos testimonios vivenciales de pilotos que participaron directamente en esta operación, y que recuerdan elementos contextuales, operacionales y estratégicos que estuvieron alrededor de ésta. Información que sin lugar a dudas será un insumo fundamental para los futuros trabajos que se realicen sobre una de las principales operaciones militares desarrolladas en Colombia.

Los pilotos de helicóptero Luis Ignacio Barón ${ }^{1}$ y Jorge Tadeo Borbón Fernández ${ }^{2}$ recuerdan y narran los acontecimientos más relevantes acerca de la Operación Colombia; generando una reflexión, desde la experiencia, de las incidencias y aportes que ésta le generaron a la seguridad del país y al desarrollo de la región del Meta y el Caquetá. Sin embargo, lejos de ser un recuento frío y operacional, es un recuerdo humano, vivencial y emocionante de dos pilotos que recuerdan a sus compañeros, amigos y a las emociones y sentimientos que tuvieron durante esta operación.

Mayor General. (RA) Ex Segundo Comandante y Ex Jefe de Estado Mayor de la Fuerza Aérea Colombiana.

Mayor General. Segundo Comandante y Jefe de Estado Mayor de la Fuerza Aérea Colombiana. 


\section{NINGÚN TERRITORIO ESTÁ VEDADO PARA LA FUERZA AÉREA COLOMBIANA}

Narrativa del Mayor General Luis Ignacio Barón

Cuando el actual Segundo Comandante de la Fuerza Aérea Colombiana se desempeñaba como Capitán, Piloto de Helicóptero, la situación del país y de las Fuerzas Militares era completamente distinta. Primero, se contaba con limitantes tecnológicas y económicas que hacían que la misión de proteger la soberanía del país fuese más compleja y difícil para los miembros de la Institución; segundo, porque reinaba en la opinión pública la sensación de que persistían "Repúblicas Independientes"3 en donde no podía llegar el Estado, y menos la Fuerza Pública.

Así, recuerda que se decía que había unos santuarios de las FARC, en donde era imposible entrar a desarrollar operaciones militares o tener un acercamiento positivo con la población civil. Entre estos se tenía a zonas estratégicas como el Cañón de las Hermosas en el Tolima, o las regiones de la Macanera, la Uribe y el Caguán en el Meta y el Caquetá; regiones en los que actuaron los Frentes Occidental y Oriental de esta organización.

Con esta reflexión sobre la historia del país, el Mayor General Barón justifica la importancia institucional e histórica que tuvo la Operación Colombia, desplegada por el conjunto de las Fuerzas Militares en el año de 1990, y que llevó a que se hiciera presencia efectiva en una vasta región del país, que había estado ocupada por este grupo armado ilegal. Una Operación que maximizó la confianza en las instituciones militares del Estado, y que empoderó a los policías y militares de Colombia.

El relato del General no se centra en los elementos tácticos de esta Operación, ni en los resultados militares alcanzados; ya que para él lo realmente importante está en el proceso que inició a partir de este momento histórico; proceso que va a finalizar con el debilitamiento de esta organización armada, y la posibilidad de que ésta se encuentre en un proceso de paz con el gobierno nacional y con la sociedad colombiana. De hecho, señala que al leer las repercusiones inmediatas que generó se concibieron tras el desarrollo de la Operación, los columnistas, políticos y académicos no fueron conscientes de la trascendencia e importancia de esta acción militar.

Para estos no se justificaba que se estuviesen invirtiendo recursos humanos y económicos tan valiosos en una operación que no traería réditos militares significativos; y tampoco era un mensaje político adecuado en un momento de convivencia como el que estaba trayendo consigo el triunfo de la "Séptima

Término acuñado por Darío Echandía, cuando era candidato a la Presidencia de la República en 1950, aludiendo a territorios en donde ejercían control político y social grupos irregulares como los Pájaros conservadores o las guerrillas liberales. 
Papeleta" y las elecciones para decidir a los constituyentes que formularían la Constitución de 1991. Así mismo, se señalaba que había que profundizar los procesos de negociación para llegar a acuerdos y a desmovilizaciones como las alcanzadas con el M-19 o con el EPL ${ }^{4}$.

Pese a lo anterior, el Mayor General Barón señaló que "no existía una voluntad real de negociación por parte de esta organización armada, por el contrario la información de inteligencia mostraba que estaban configurando una estrategia encaminada a fortalecer su presencia en la región oriental del país, estrategia que desafortunadamente saldría a la luz pública con la oleada de violencia que se desataría entre los años 1994 y 1998, y con las acciones que realizaron durante los diálogos de paz con el presidente Andrés Pastrana"; razón por la cual las Fuerzas Militares tuvieron que realizar una Operación Militar sin precedentes, aun sabiendo que no era una decisión popular.

Aun dentro de las Fuerzas fue recibido con gran sorpresa el desarrollo de esta Operación, no conocían nada de este territorio y había gran zozobra por las capacidades armadas que pudiesen tener las FARC para repeler el poder militar del Estado colombiano. Zozobra que se hizo realidad, ya que esta organización tenía planeado un armamento de alto calibre con el cual recibir a las aeronaves que ingresaran.

De hecho, el General recuerda vívidamente lo ocurrido "ingresamos a la zona y nos sorprendimos de ver que inicialmente no sucedía nada y que pudimos llegar al denominado Rincón de los Viejitos, una de las zonas que intuíamos estaría mayormente protegida y resguardada; regresamos por suministros y combustible y en la segunda inmersión todo fue diferente, nos recibieron con fuego cruzado, en esa segunda entrada fue que tuvimos las pérdidas humanas".

Con gran nostalgia recuerda a los compañeros que murieron ese día, advirtiendo que en honor a ellos, y al sacrificio que realizaron, es necesario que la opinión pública conozca la importancia de esta Operación y la enorme dificultad que tuvo en su planeación y ejecución; pero así mismo, señala que lo más importante es que la sociedad comprenda que gracias a esta decisión, empezó un proceso de fortalecimiento de la presencia militar y estatal en esta región del país, lo que a la postre debilitaría definitivamente a las FARC, obligándolas a sentarse a negociar con el gobierno colombiano.

Por ello, detiene su narración para evocar la imagen del Teniente Julio Cesar Sanabria "Chamizo" el piloto del segundo Helicóptero que desafortunadamente

El Grupo de Investigación “Análisis en Contexto”, dirigido por la TC Adriana Lucía Marín, Magister., realizó una revisión minuciosa de prensa en la que monitoreó las columnas y notas de prensa que salieron en los principales periódicos colombianos tras el desarrollo de la Operación Colombia; en estos documentos se puede corroborar y comprobar estas apreciaciones del Mayor General Luis Ignacio Barón. 
fue derribado cuando reingresaron en la zona. Señala que las imágenes aún están vivas en su cabeza, y que recuerda en cámara lenta como se dieron las cosas, y como él fue consiente desde el primer momento que su compañero y sus tripulantes iban a ser derribados. Estas imágenes, y muchas otras que conserva en su mente tras casi tres décadas de participación directa en el conflicto armado colombiano, lo llevan a señalar la importancia de detenerlo y encontrar soluciones negociadas.

"Usted no se imagina lo que es seguir operando después de ver esa imagen, de ver un helicóptero amigo estrellado, de oír por el radio el dolor de los compañeros; no creímos que nos fueran a derribar a ninguno" con estas palabras el Mayor General Barón recuerda que en ese momento los pilotos, aunque eran conscientes del enorme riesgo de su misión, no estaban acostumbrados a ver que una aeronave fuera derribada. El golpe anímico fue enorme, pero también lo fue la capacidad de resiliencia y de salir adelante en nombre de los compañeros caídos "en honor a ellos hemos logrado todas las victorias que hasta entonces la Fuerza Aérea Colombiana ha alcanzado".

Éxitos que no han sido gratuitos y por lo que ha sido necesario poner una alta cuota de sacrificio, la cual no ha sido siempre reconocida y agradecida por parte de la sociedad, pero que igual se hicieron con una alta cuota de compromiso y amor por ésta y por la defensa de la institucionalidad colombiana.

La Operación Colombia debe ser recordada por cuatro cosas puntuales: en primer lugar, porque fue una de las primeras experiencias conjuntas y coordinadas que se desarrollaron al interior de las Fuerzas Militares; allí está la semilla de esta estrategia de trabajo conjunto que tan buenos resultados dio en el siglo XXI, y que le dio un giro definitivo al curso del conflicto armado interno.

En segundo lugar, como el momento histórico en el que las Fuerzas Militares lograron asestar un golpe simbólico y estratégico al Secretariado de las FARC, al mostrarles que no había un solo espacio de la geografía nacional en el que estos pudieran resguardarse del poder de estas Instituciones. Más allá de la caseta con techos de zinc que de lejos le daban una tonalidad verde (por eso se conoce como Casa Verde), o del denominado Rincón de los Viejitos, o de todos los elementos simbólicos y significativos para las FARC que allí se encontraban, lo importante fue decirle a esta organización, al Estado y a toda la sociedad "que no existe ningún punto de la geografía que esté lejos del alcance misional y operacional de la Fuerza Aérea Colombiana y de las Fuerzas Militares; soberanía quiere decir tener pleno control territorial dentro de los límites del Estado". 


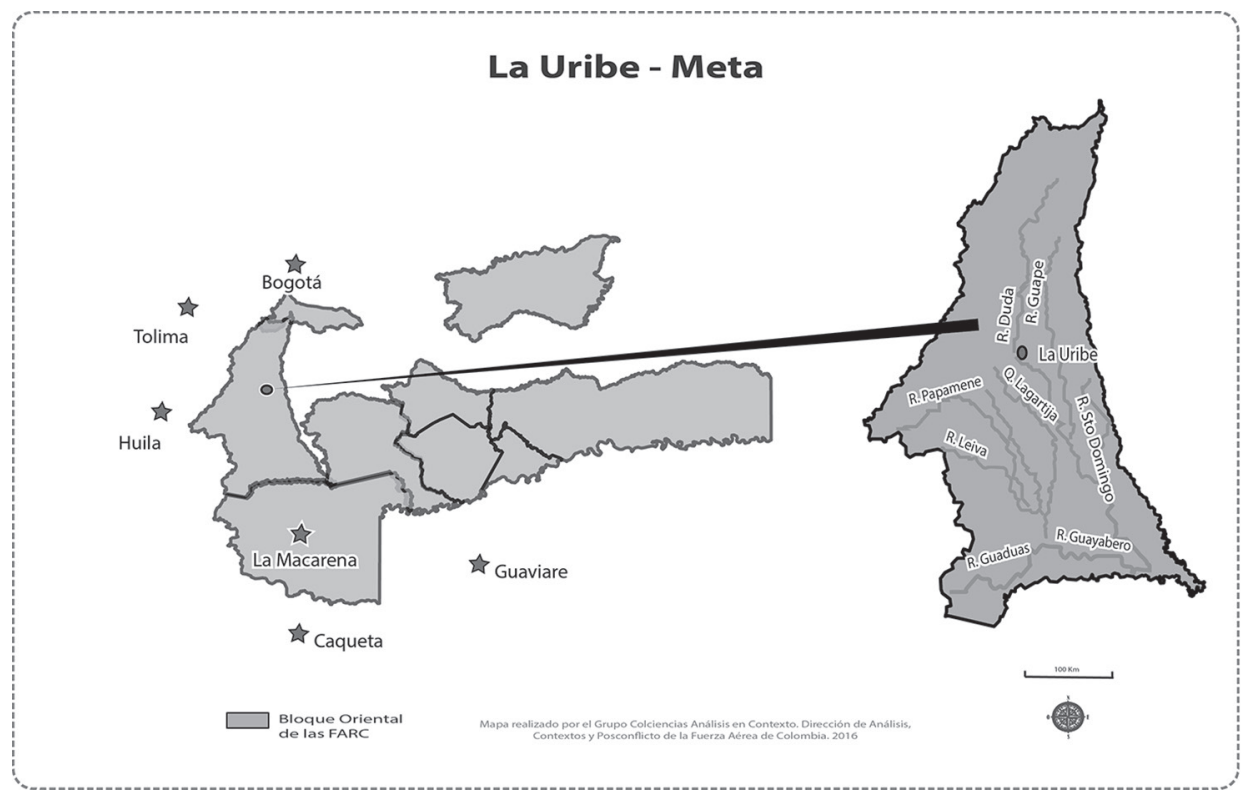

Así mismo, y como tercer corolario, esta Operación dejó claro que sin importar los procesos históricos de las regiones, la Fuerza Pública cumple una misión constitucional, y lo hace bajo el estricto cumplimiento del Derecho Internacional Humanitario y de los Derechos Humanos, por ello cuando llega a una región siempre va a tener la capacidad de desarrollar positivas relaciones con las comunidades asentadas en estos territorios. Por mucho tiempo se pensó que las poblaciones que habitaban en las inmediaciones de la Uribe eran cercanas y proclives a las FARC, pero los años posteriores a esta Operación demostraron lo contrario, se trataba de unas comunidades confinadas, obligadas a soportar las arbitrariedades de este grupo armado, y que reconocieron en las Fuerzas Militares un actor cercano y defensor de sus derechos.

El Mayor General Barón no puede ocultar su tristeza y malestar por el abandonó histórico que el Estado ha cometido con estas regiones apartadas, a donde no han llegado las instituciones públicas "allí no hay salud, no hay educación, no hay acceso a la justicia, allí solo llegamos nosotros. Por ellos intentamos desplegar todas nuestras capacidades vía Acción Integral. Aprendimos que estas comunidades no eran nuestros enemigos, eran unas víctimas del conflicto por las que teníamos que luchar".

Finalmente, señala que esta Operación Colombia fue el inicio de una estrategia militar desarrollada por el Estado Colombiano para neutralizar las acciones violentas desatadas por las FARC en el Suroriente del país, y que estaban orientadas a rodear a la capital del país, a ejercer control sobre zonas de frontera, 
con todos los beneficios que esto trae para el narcotráfico y el tráfico de armas, e intentar instaurar una zona de retaguardia en el sur del país, tal como lo hizo Mao durante la revolución China.

Si bien los analistas que reflexionaron sobre esta Operación de manera inmediata no tenían la posibilidad de vislumbrar todos estos elementos, el Mayor General Barón señala que es fundamental reescribir la historia detrás de la Operación Colombia para que las sociedades futuras sean conocedoras de lo difícil que fue, del enorme sacrificio que puso la Fuerza Aérea Colombiana en ésta; y de los enormes beneficios sociales, económicos de seguridad que iniciaron con esta operación en esta región del país.

\section{LA OPERACIÓN COLOMBIA: MEMORIAS DE UN PILOTO DE COMBATE}

Narrativa del Mayor General Jorge Tadeo Borbón

El Mayor General Jorge Tadeo Borbón Fernández es un hombre que conoce como nadie lo que ocurre en los cielos del país. Desde su puesto como Jefe de Operaciones, es el encargado de velar por todas las operaciones que la Fuerza Aérea desarrolla en toda Colombia. Esta responsabilidad, más una trayectoria de décadas en la institución volando por toda la geografía nacional, hacen que en su memoria se aglutinen una infinidad de operaciones aéreas. Sin embargo, la Operación Colombia no fue una operación cualquiera, y eso claramente se entiende en la forma en que se emociona cuando la narra. Como en otros pilotos, está operación dejó unas huellas imborrables.

La Operación Colombia, oyendo al Mayor General Borbón, son varias historias a la vez. Es la historia sobre cómo las Fuerzas Militares entraron a una zona que consideraban el centro estratégico y simbólico de la guerrilla. Pero también la historia sobre como avezados pilotos lograron superar, en la primera gran operación aérea en el país, algunos de los retos más difíciles abordo de sus aeronaves, y en donde se pagó una gran dosis de sacrificio y sangre para lograrlo.

Esta última, sobre la batalla que se libró en el aire y los hombres que la enfrentaron, es aún una historia por narrar.

El ahora Mayor General Borbón, al momento de la operación Colombia, diciembre de 1990, se desempeñaba como piloto de helicóptero y ostentaba el rango de Teniente.

Recuerda que, en ese entonces, el sitio que se conocía como Casa Verde era uno de esos espacios vedados para las Fuerzas Militares. ¿Y qué era exactamente 
Casa Verde? El Mayor General Borbón explica que Casa Verde toma su nombre a unas instalaciones con techo verde de zinc, a las afueras de un cañón en el municipio de La Uribe (Meta). Eran aulas grandes, en las cuales se recibían las visitas de políticos y miembros de la sociedad civil durante el proceso de diálogo de este grupo guerrillero en los años ochenta.

Pero el verdadero corazón de las FARC se encontraba más adentro del cañón, recuerda el Mayor General Borbón. Penetrando el cañón se encontraban unas zonas que la FARC había bautizado como La Gaucha, El Rincón de los Viejitos y la Escuela de Cuadros. En estos sitios la FARC construyó toda una completa red de campamentos en los cuales se encontraba el Estado Mayor del Bloque Oriental (EMBO), el bloque de las FARC con mayor poderío militar y el principal cabecilla de esta guerrilla, Manuel Marulanda Vélez, alias "Tirofijo". Estas zonas servían para la planificación de la guerra por parte de la guerrilla, eran centros de entrenamientos para sus hombres y el lugar que abrigaba a algunos de sus principales líderes.

Alrededor de Casa Verde existía una especie de mito sobre la "inexpugnabilidad” del mismo. Las FARC se encontraban seguras que una ofensiva contra este territorio sería casi imposible por las mismas condiciones de la geografía que suponía un reto mayúsculo para cualquier tipo de operación militar. Entrar a ese territorio remoto en medio de la cordillera constituía toda una proeza para un piloto.

El Mayor General Borbón recuerda el reto que significaba para un piloto esta zona de Casa Verde, "uno ingresa por un cañón, que se desprende de La Uribe, y vuela por el cañón del Duda, y a medida que va avanzando en el vuelo uno entra a un cañón bien complicado, cada vez más angosto y de mayor altura. Sumado a esto gran parte del año hay nubes perpetuas, por su conformación topográfica piedemonte llanura, los vientos que vienen de los llanos orientales chocan con la cordillera central y ahí es fácil que se conformen estas nubes que permanecen una buena parte del año. Esto hace mucho más complicado la operación aérea por la visibilidad. Ahí no hay otra forma de entrar que teniendo visual todo el terreno".

Pero no solo la geografía era un reto. La forma en que las FARC aprovechaban estas características iban a ser determinantes para la batalla. Y las posiciones altas, que la guerrilla tenía en el cañón, serían el principal dolor de cabeza para las aeronaves y sus tripulaciones, señala el Mayor General Borbón.

Madrugada del 9 de diciembre de 1990. Los pilotos se concentran en un espacio abierto en Mesetas (Meta). Esta era la antesala de una operación cuyas dimensiones no se habían dado en el país. Llegaron todo tipo de aeronaves, de todos los rincones del país: Black Hawks, UH-1H, Bell 212, entre otros. El 
objetivo: Casa Verde. Entre todos estos pilotos se encuentra el entonces Teniente Borbón al mando de un helicóptero. El nombre de la misión: Operación Colombia.

Entre los pilotos de helicópteros, en su mayoría jóvenes tenientes, reinaba una sensación de expectativa e intranquilidad. La noticia que iban a entrar al corazón mismo de las FARC era, sin lugar a dudas, una información que no era fácil de procesar a primera mano. La geografía ofrecía todos los retos posibles: estrechos cañones y nubes perpetuas. Eso, sumado a la incertidumbre sobre la respuesta que encontrarían por parte de las FARC, hacía que la adrenalina corriera por las venas de los presentes.

La falta de información aumentaba un poco la tensión. Viéndolo desde el presente, el Mayor General Borbón, explica como los vacíos de información con los que contaron los pilotos que realizaron este asalto aéreo fueron muy grandes. No existieron mapas ni imágenes de los sitios que las FARC usarían para atacar las aeronaves. El Mayor General Borbón señala que es posible que esa falta de información los hiciera ir un poco más tranquilos, porque aclara, "puede ver el contraste entre esa sensación inicial y cuando entramos. Inmediatamente entramos nos dimos cuenta que la situación iba a estar muy complicada".

Tranquilidad. Esa fue la sensación de la primera entrada de helicópteros. Un día absolutamente despejado y un cielo azul, como recuerda el Mayor General Borbón. Las aeronaves ingresan tranquilamente al cañón, desplazándose entre las altas paredes montañosas y logran dejar al primer grupo de tropas en el terreno. Nada fuera de lo habitual. Sin respuesta de la guerrilla. Las aeronaves retornan a Mesetas a retanquear y recoger más tropas.

El entonces Teniente Borbón se incorpora al grupo en la segunda entrada. Los helicópteros despegaron y por 14 minutos volaron con absoluta tranquilidad. Pero entrando al cañón todo cambio. El factor sorpresa, el cual daban por sentado como un factor decisivo, no existía. Un minuto antes de ingresar empezó el fuego nutrido contra ellos.

Las FARC estaban preparadas para dar la lucha y se plantaron en la defensa de Casa Verde. Estaban empeñadas en sacar todo el provecho al territorio que defendían. El cañón, por el cual necesariamente tenían que ingresar las aeronaves, era parte de la trampa. En la parte alta de la entrada al cañón, nichos de ametralladoras cortaban el paso de las aeronaves. La llamada cortina de fuego se extendía por toda la entrada del cañón. Pero para los pilotos de los helicópteros no había opción: había que volar por medio de esa cortina de fuego.

Las circunstancias no podían ser más compleja para los pilotos. Sin espacio para maniobrar y con un nutrido fuego en contra de ellos, realizaban todo tipo 
de proezas para esquivar y esconderse de las ametralladoras que estaban en las partes altas. La presencia de estas armas, cuenta el Mayor General Borbón, que por su peso requerían de un gran esfuerzo para estar en lo alto de una montaña, eran la mayor certeza que las FARC los estaban esperando.

Los dilemas en medio de esta escena eran grandes: o volar alto y estar a merced de las ametralladoras o volar bajo y arriesgarse a que una cuerda o cable, puesto por las FARC, terminará impactando la aeronave. Eran momentos de gran agitación. Decisiones trascendentales tomadas en segundos. Disposiciones con muchas vidas abordo. Sin embargo, lo único que no estaba bajo cuestionamiento era la idea de seguir volando.

En medio del esfuerzo, múltiples aeronaves y tripulaciones fueron impactadas. Recuerda el Mayor General Borbón que en estas primeras incursiones gran parte de la flotilla quedó fuera de combate. La cortina de fuego cobró su cuota de sangre para todos los que volaron en ese cañón.

"Me dieron y voy de vuelta", recuerda el Mayor General Borbón que escuchó por la frecuencia decir al Teniente Julio Cesar Sanabria, piloto a bordo de un Bell 212, con matrícula de la FAC 4216. La aeronave apenas en su entrada era impactada por el fuego nutrido de los guerrilleros. En este intercambio radial, el Teniente Sanabria explicó que, a pesar que todo en cabina aparentaba estar normal, algo fallaba en la aeronave. El entonces Teniente Borbón le sugirió que aterrizara en La Uribe, ya que Mesetas se encontraba muy lejano.

Pero el helicóptero Bell 212 no logró permanecer en vuelo mucho tiempo. Era una emergencia insalvable. Había sido impactado en la cola, rompiendo el eje impulsor. Con todo el peso del armamento y el combustible, la aeronave se precipitó a tierra. En este hecho murieron el Teniente Sanabria, y su tripulación: el copiloto Subteniente John Mario Alarcón Gómez, el Técnico 3, Jaime Eduardo Ríos Venegas y el Técnico 4. Reinel Gómez Antolinez. Toda la tripulación murió al instante.

El Mayor General Borbón, sobre la caída del FAC-4216, emotivamente recuerda, "yo tuve el momento difícil de ver estrellarse el helicóptero contra el terreno, yo venía detrás de él. Por la frecuencia pude oír el grito. Fue muy difícil. Tratamos de hacer algo, yo aterrice al lado del helicóptero y tratamos de sacar los cuerpos, solo logramos sacar el cuerpo del Teniente Sanabria, con silla y todo. Los otros tres no pudimos sacarlos". Los ojos del Mayor General Borbón, mientras narra esta escena, por segundos se ponen vidriosos. A pesar del uniforme y el rango nadie se acostumbra al dolor de la guerra. Nadie.

El impacto que tuvo la caída del helicóptero entre los pilotos fue grande. El Mayor General Borbón señala que una gran zozobra se posó en el campo de operaciones en Mesetas, en el cual un número de pilotos ante las condiciones 
extremas se negaban a continuar. Muchos eran compañeros y amigos del Teniente Sanabria y su tripulación. Temían que los próximos en caer fueran ellos.

Esta pequeña rebelión fue saldada con la puesta a un costado de unos pocos pilotos. El resto volvió a sus aeronaves seguros de que su compromiso estaba con los hombres que se habían podido desembarcar al interior del cañón, y que sin la llegada de refuerzos iban a ser arrasados. Las cosas en tierra al interior del cañón eran, a la vez que en aire, inciertas. Había que seguir volando y llevando hombres. No había discusión sobre eso.

Para los pilotos, la apuesta por seguir entrando al cañón era extremadamente incierta. El Mayor General Borbón es claro en señalar que, "son momentos en que casi que tenemos que desprendernos de nuestras vidas para seguir con la operación". Una mirada desde un espectador externo podría sugerir que esta era una misión que rayaba en la locura. A los ojos de los pilotos y sus tripulaciones, en ese momento, era simplemente la responsabilidad que se exige cuando se porta un uniforme. En sus mentes estaban esos hombres del Ejército dentro del cañón que por ningún motivo se podían olvidar. Los helicópteros seguirían volando, sin importar lo que viniera.

Cuando todo parecía en contra, de repente la suerte empieza a cambiar.

Con cada entrada los pilotos empezaron a identificar de dónde provenía el fuego. El Mayor General Borbón comenta como fueron los tripulantes de un helicóptero los que, entre la montaña, pudieron dar con la localización de un nido de ametralladora que estaba haciendo estragos entre las aeronaves. Esta localización la recibió un piloto de Mirage que pudo impedir que este nicho continuara haciendo daño a las aeronaves.

A partir de ahí, una a una, empezaron a caer todas las defensas que desde los puntos altos tenían la guerrilla. El fuego ya no tan nutrido, daba pistas para detectar estas amenazas. Las aeronaves seguían entrandoy saliendo. Algunos comoel MayorGeneral Borbón pudieron hacer unas 7 u 8 entradas con tropas.

En unas horas se consolida la entrada aérea por el cañón y las operaciones en tierra pudieron avanzar. El asalto aéreo se había completado.

La Operación Colombia, el Mayor General Borbón la define como "una operación con mucha intensidad en un rango de tiempo muy breve". Todos estos eventos transcurrieron aproximadamente entre las 6:30 y 10:00 am., de ese 9 de diciembre de 1990.

Mirando hacia atrás, el Mayor General Borbón señala, hay muchas enseñanzas sobre la Operación Colombia. A pesar que reconoce que existieron cosas muy 
positivas, indica que los modelos de planificación de las operaciones no eran tan exactos y que los pilotos, en muchos casos, operaban sin toda la información necesaria.

Y es que el Mayor General Borbón es claro en indicar que, a su juicio, el escenario al cual se enfrentaron los pilotos era de una desventaja estratégica grandísima. La operación puso fuera a un número significativo de la flotilla aérea. Así mismo la cuota de sangre y sacrificio por parte de los pilotos y sus tripulaciones fue altísima.

Sin embargo, la operación pudo salir adelante por cuenta de todos esos pilotos que, a pesar de las circunstancias adversas, seguían volando, por medio de ese cañón intransitable, acompañados de una cortina de fuego y con el dolor por los compañeros heridos y caídos. Pero no pararon de volar. Eso es lo que hace un piloto de combate. Volar, cuando para todos parece imposible.

\section{REFLEXIONES FINALES}

La Operación Colombia permanece en el imaginario de los colombianos como uno de los hitos históricos más importantes dentro del conflicto armado del país. Por el mismo impacto que tuvo esta operación, la capacidad de reconstruirla desde la memoria de quienes hicieron parte primordial en el mismo, es un elemento que enriquece el proceso de construcción de memoria histórica. La dimensión del rol que desarrollaron los pilotos y sus tripulaciones en el éxito de la Operación Colombia es un elemento que no puede escapar en el análisis de este hito histórico.

El sacrificio y las capacidades que supuso la Operación Colombia es un elemento que, sin duda, se debe exaltar en lo referente al desarrollo de la misma. Los retos a los cuales se enfrentaron los pilotos para operar en un entorno en donde las condiciones topográficas y la misma respuesta de la FARC, hacían pensar en que cualquier intento de ingreso de una aeronave era imposible, el operativo muestra la capacidad y tenacidad de las tripulaciones. Las capacidades de los pilotos que desde los aviones militares y los helicópteros de la Fuerza Aérea Colombiana permitieron que las Fuerzas Militares llegaran hasta uno de los puntos más emblemáticos de las FARC es un hecho que quedará marcado en la historia.

\section{AGRADECIMIENTOS}

El equipo del grupo de investigación Análisis en Contexto agradece al señor Mayor General Luis Ignacio Barón Segundo Comandante y Jefe de Estado Mayor de la Fuerza Aérea Colombiana y al señor Mayor General Jorge Tadeo Borbón Fernández, Comadante del Comando Conjunto N¹. "Caribe", por su colaboración en este ejercicio de memoria. 



\title{
NUESTRA PRESENCIA AÉREA, MARCó LA DIFERENCIA EN LA RECUPERACIÓN DE MITÚ
}

\author{
Crónica del General (RA) ÉDGAR A. LESMES ABAD
}

La Operación Vuelo de Ángel (O.V.A) como se le conoce a la recuperación de Mitú por parte de las Fuerzas Militares de Colombia, en cabeza de la Fuerza Aérea Colombiana (FAC), fue una operación que alteró la dinámica del conflicto armado colombiano, considerándose un hito en desarrollo de las operaciones contra la organización ilegal FARC y en favor del Estado. El poder aéreo fue factor decisivo durante la O.V.A ya que se potencializaron las capacidades aéreas que tenía la FAC y con ello se cambió favorablemente la correlación de fuerzas.

La operación se convirtió en un precedente doctrinal y operacional, ya que mediante las lecciones aprendidas se produjo una evolución de la Doctrina y las capacidades operacionales. La tecnología de los visores nocturnos, el sistema FLIR (infrarrojo) y la experiencia operacional de los pilotos fueron determinantes para modificar la estrategia armada de las FARC, quienes se encontraban para el año 1998 en una guerra de posiciones pero gracias al poder aéreo de la FAC regresaron a la guerra de guerrillas. Así pues, Mitú fue la última población que las FARC intentaron tomar y establecerse.

En la década de los años noventa, particularmente desde 1996, las FF.MM sufrieron duros golpes, sobre todo contra el Ejército Nacional. Ejemplo de esto fueron las Delicias, la Carpa, Patascoy, el Billar, Miraflores, etc. Estas acciones violentas generaron un efecto político-militar negativo contra el Estado y la población civil, por la utilización indiscriminada de armamento no convencional que iba dirigido contra unidades militares y policiales, afectando de manera sustancial a la población civil inerme y ajena al conflicto. Dichos ataques forjaron un sentimiento de victoria en los miembros de las FARC porque la toma de pueblos y la consecución de la estrategia armada estaba generando resultados positivos para la organización ilegal.

"Los ataques a las Delicias, el Billar, la Toma de Miraflores y la Toma de Mitú, demostraron la debilidad estatal y constituyeron duros golpes a las FF.MM. Estos

Ex comandante de la Fuerza Aérea Colombiana, Jefe de Operaciones de la Fuerza Aérea Colombiana cuando sucedió la Toma de Mitú el 1 de noviembre de 1998. 
ataques correspondieron a una estrategia política y armada de la guerrilla para consolidar su poder territorial en el sur del país, con el propósito de crear un corredor estratégico de movilidad hacia las fronteras con Brasil y Venezuela. Sin embargo, con la respuesta de las FF.MM. en cabeza de la Fuerza Aérea bajo la Operación Vuelo de Ángel, se logró frenar la estrategia armada de la organización ilegal.' (MARín et al, 2017).

Los ataques llevados a cabo por las FARC contra la población civil y las FF.MM, evidenciaron además la debilidad y la incapacidad institucional del Estado para hacerle frente y contrarrestarlos.

"Las FARC entre 1996 y 1998 en zonas del Sur del país demostraron que aprendieron a luchar con un entorno adverso e incierto. Así mismo, pusieron a prueba su capacidad de maniobra, libertad y rapidez de acción. Entre los cambios más significativos observados en la dinámica del conflicto se destaca también la manifiesta prioridad que las FARC dieron entre 1997 y 2001 a los ataques a las poblaciones para destruir los puestos de Policía y debilitar la presencia estatal en los sitios donde buscaban ampliar su influencia." (CASTILla, 2004).

La pérdida de la iniciativa estratégica y operacional del Estado Colombiano entre los años 1994 y 1998 estuvo ligada a las malas relaciones entre el poder Ejecutivo y la Institución militar. Mientras el país requería con urgencia de una estrategia para la seguridad y la defensa, el gobierno se dedicaba a defenderse de los señalamientos de escándalos de corrupción, ilegitimidad, incapacidad gubernamental y el más grave, financiación ilícita de la campaña presidencial con dineros del narcotráfico.

"Para cualquier República contemporánea, el balance de poder entre las autoridades civiles y el estamento militar es un factor crucial, pues tiene incidencia directa sobre la forma del régimen político, el modelo de desarrollo, la relación del Estado con la ciudadanía e incluso sobre las relaciones internacionales". (BECERRA, 2016).

De otra parte, las relaciones exteriores con los Estados Unidos llegaron al nivel más bajo, Colombia fue desertificada, situación que afectó a los militares colombianos en la medida en que la ayuda militar disminuyó notoriamente de 96 millones de dólares en 1994 a 51 millones en 1995 (LoBE, 1998).

"La crisis moral y política del gobierno le resta legitimidad para imponer las condiciones a los militares y ofrecer suficientes garantías para el desarrollo de las negociaciones. La relación de tensión con los Estados Unidos en torno a la extradición de nacionales y las investigaciones adelantadas por la fiscalía a miembros de la campaña y del partido oficialista, derivó en una coyuntura de crisis política y baja credibilidad en el gobierno de turno.” (Lopez, 1999, p. 12).

Para esa época la Fuerza Aérea operaba con recursos y equipos que eran escasos y obsoletos, la inversión en el gasto de seguridad y defensa para el período de 1994-1998 según lo señala el Departamento Nacional de Planeación: 
“...la distribución prevista para inversión en el período se dio prelación a los programas de mantenimiento mayor y adquisición de material y equipo complementario, buscando el mayor grado de alistamiento y operatividad de lo existente, en lugar de la adquisición de nuevos equipos con tecnología de punta. Consecuentemente, el actual Gobierno no emprendió mega proyectos militares de inversión." (DNP, 1991).

De esta manera se evidencia que para esos años la inversión en el gasto de seguridad y defensa no fue la adecuada pese a las amenazas que representaban los grupos armados ilegales.

Teniendo en cuenta el escenario de seguridad de la década de los años noventa en Colombia se puede afirmar que este país no ha sido militarista, es decir, que históricamente no se ha invertido mucho en el gasto de seguridad y defensa como se puede ver reflejado en los años 1994-1996, donde el presupuesto al sector no superó $3 \%$ del PIB.

Para el funcionamiento o la puesta en marcha de operaciones los recursos eran escasos, faltaba liderazgo político y las herramientas militares que se tenían, así como el equipo aéreo no era suficiente para contener la amenaza que representaron los grupos armados ilegales como las FARC.

Por otro lado, había un gran desconocimiento del poder civil sobre la capacidad militar, especialmente sobre el poder aéreo que era la gran ventaja que tenía el Estado sobre dichos grupos. En gran parte se debe eso a la demora en aplicar la fuerza efectivamente.

Con el gobierno de Andrés Pastrana la situación cambió, el mandatario reunió a la cúpula en Cartagena con el fin de analizar la situación de orden público del país y conocer la capacidad militar y los medios que se disponían para enfrentar la amenaza.

En dicha reunión se le explicó al señor Presidente que el presupuesto era escaso y faltaban medios. Para el caso de la Fuerza Aérea se le manifestó que las aeronaves de ala rotatoria, de transporte y de combate del inventario aeronáutico eran insuficientes y obsoletas para la amenaza que se estaba enfrentando, faltaban recursos adecuados para operar eficiente y efectivamente, esa era la situación que se vivía en esa época.

De esa reunión salió la iniciativa del Plan Colombia, algo parecido, guardadas proporciones al Plan Marshall de los Estados Unidos en Europa después de la Segunda Guerra Mundial.

El Plan Colombia fue una política exterior que logró articular la Estrategia Política del Estado con la Estrategia Militar. Con esta articulación las relaciones cívico militares entre el Ejecutivo y la Fuerza Pública mejoraron significativamente y el Plan permitió la consecución de recursos y medios para operar. 
El apoyo de los Estados Unidos de Norteamérica mediante el Plan Colombia propició un proceso de reingeniería y reestructuración de las FFMM, adecuándolas para la guerra irregular. Además, se fortaleció la inteligencia tecnológica, especialmente satelital.

El Presidente Andrés Pastrana se había comprometido con las FARC a realizar la paz, despejando algunas zonas en los departamentos de Caquetá y Meta que comúnmente se le conoció como la zona de distensión. Dentro de las exigencias que hicieron las FARC, solicitaron al Presidente de la República el despeje del Batallón Cazadores en San Vicente del Caguán. Para las FFMM esta decisión fue difícil porque para nosotros era ceder y perder una unidad militar y todo lo que ella representaba.

\title{
La OPeración Vuelo de Ángel
}

Para la década de los años noventa las FARC venían implementando la llamada guerra popular prolongada, la cual consistía en tres etapas, estas son: Guerra de guerrillas, guerra de movimientos y guerra de posiciones.

\begin{abstract}
"Para 1996 las FARC ya se encontraban en la etapa de guerra de movimientos, los ataques perpetrados durante este año y hasta 1998, son el reflejo del paso de la guerra de guerrillas a la guerra de movimientos. Esto se debe a la estrategia armada de la guerrilla de propiciar golpes a unidades militares, durante un tiempo prolongado, con armamento pesado y utilizando una cantidad alta de combatientes. Así dejan las emboscadas, y los ataques de repliegue, para pasar a un enfrentamiento prolongado con las Fuerzas Militares. Los ataques a las Delicias, El Billar, Miraflores reflejan precisamente ese cambio de estrategia." (MARÍn et al, 2017).
\end{abstract}

El primero de noviembre de 1998 cuando inicia la toma de Mitú, yo era el Jefe de Operaciones de la Fuerza Aérea, ese día había un evento deportivo con la Policía. A las 4 a.m. sonó el teléfono, era el Centro de Operaciones de la Fuerza Aérea, y se informó que estaban arremetiendo contra Mitú. Para esa época, con cierta frecuencia las FARC atacaban poblaciones pequeñas, la Fuerza Aérea reaccionaba y los guerrilleros huían al sentir la presencia de las aeronaves.

La Fuerza Aérea tiene prohibido emplear las armas sobre las poblaciones o cuando se presume que hay personal civil en el área, esto con el fin de evitar daños colaterales, o causar la muerte a personal inocente.

Geográficamente me ubiqué y pensé en Miraflores, y supuse que en Mitú iban a hacer lo mismo que habían hecho en Miraflores meses atrás, es decir, se estarían ahí por un tiempo prolongado. Mitú, capital de un departamento en poder de las FARC, sería una noticia muy favorable para la guerrilla y muy desfavorable para el Estado colombiano, su gobierno y Fuerza Pública. 
Cuando sucedió lo de Miraflores, sorprendió el factor sorpresa y la reacción de la Fuerza Pública fue débil, pero la FAC venía implementando su Doctrina Operacional, adquiriendo nuevos equipos, sobre todo nocturnos, ya existía la experiencia de Miraflores, por consiguiente, en Mitú la reacción de la Fuerza Aérea fue contundente.

En la Operación Vuelo de Ángel se utilizó el principio de Masa y Concentración de Medios, se utilizaron diversos tipos de aeronaves para cada una de las misiones asignadas, ala rotatoria y ala fija, y se aprovecharon todas las características de la Fuerza Aérea: velocidad, alcance, flexibilidad y versatilidad.

Todo esto permitió dar una respuesta muy rápida, con lo cual se sorprendió a las FARC. La capacidad tecnológica y operacional demostrada en Mitú permitió que la Fuerza Aérea potencializara sus aeronaves para frenar y contener los ataques de los grupos armados ilegales.

Sin temor a equivocarme, Mitú fue la última población que las FARC trataron de tomarse pues allí sufrieron una pérdida considerable de guerrilleros. Las FARC se vieron obligadas a regresar de la guerra de posiciones a la cual querían llegar a la guerra de guerrillas. Allí el Estado cambió la ecuación a su favor y las FARC que se consideraban victoriosos iniciaron su declive.

\section{Planeamiento de la OPeración}

Para iniciar el apoyo aéreo ordené la salida de dos aviones: Un AC -47 que se encontraba en CACOM 6 "Tres Esquinas", y una hora después otro AC-47 en CACOM 2- "Apiay".

Con los recursos disponibles de la aeronave AC-47 conocida como el "Fantasma", se realizó un primer apoyo aéreo a la Estación de Policía en Mitú. En ese momento, la inteligencia y la información operacional recibida era que las FARC se estaban tomando la capital del departamento del Vaupés.

A las 6 de la mañana, en el evento de la Policía con mi hija, y cuando ya iba a comenzar la maratón se me acercaron dos generales de la Policía entre ellos el General Alfredo Salgado, me dijeron que la situación en Mitú se estaba complicando.

Prácticamente, las FARC estaban copando la Policía, su intención era permanecer en la capital del departamento del Vaupés por un largo tiempo. Se calculó que la correlación de fuerzas era de 5 guerrilleros por 1 Policía, y estos tenían a su favor que disponían de toda el área de la población para maniobrar a su conveniencia, mientras la Policía se encontraba recluida en su cuartel a merced del diferente tipo de armamento de las FARC (granadas, fusiles, ametralladoras, cilindros, lanza cohetes). 
Igualmente, el objetivo fue bien seleccionado, puesto que se dificultaba el apoyo: las únicas vías de comunicación eran el río Vaupés, el cual se encontraba controlado por las FARC a varios días de navegación y la vía aérea.

En el caso de la pista aérea que es la calle principal de Mitú estaba bloqueada, y en cercanías no existía ninguna otra pista aérea que se pudiera utilizar. Me fui con los generales, para el Centro de Operaciones de la Policía, nos comunicamos con la Policía de Mitú y la situación era desesperante, ellos se defendían, pero no era mucho lo que podían hacer con los aviones la comunicación no era fluida por la distancia y la baja altura en la cual estaban operando. Ordené al Comandante del CACOM 2 que despegara un T- 27 Tucano para que se ubicara a la altura de San José del Guaviare y nos sirviera de repetidora con los AC-47 que se encontraban operando sobre Mitú.

En ese sentido, se estaba poniendo en práctica uno de los principios del poder aéreo, el Control Centralizado y la Ejecución Descentralizada, con el cual se debía tener comunicación permanente con todos los actores de la operación. Ya comunicados con la Policía y con los AC-47 que apoyaban donde podían, se tenía información completa sobre la ubicación de las FARC en la población, pero era poco lo que podían hacer pues estos se encontraban con las personas que eran utilizadas como escudos humanos.

Analizando que era inminente que iban a copar a la Policía, inicié un plan para recuperar Mitú, reuniendo las aeronaves que teníamos disponibles de ala fija y rotatoria para llevar tropa a Mitú en el menor tiempo posible.

Para poder realizar la operación se requería de una pista base aérea adelantada desde la cual pudieran operar los helicópteros despegando de San José del Guaviare para desembarcar la tropa y regresar para reaprovisionarse de combustible y llevar más tropa. La autonomía de los helicópteros no les alcanzaba para ir a Mitú o en cercanías y regresar a San José.

De esta manera se buscó en toda el área y no se encontró una pista que sirviera para nuestro propósito, la única pista que servía estaba en territorio de Brasil cerca de la frontera, Querari, un puesto militar del Ejército Brasilero. 


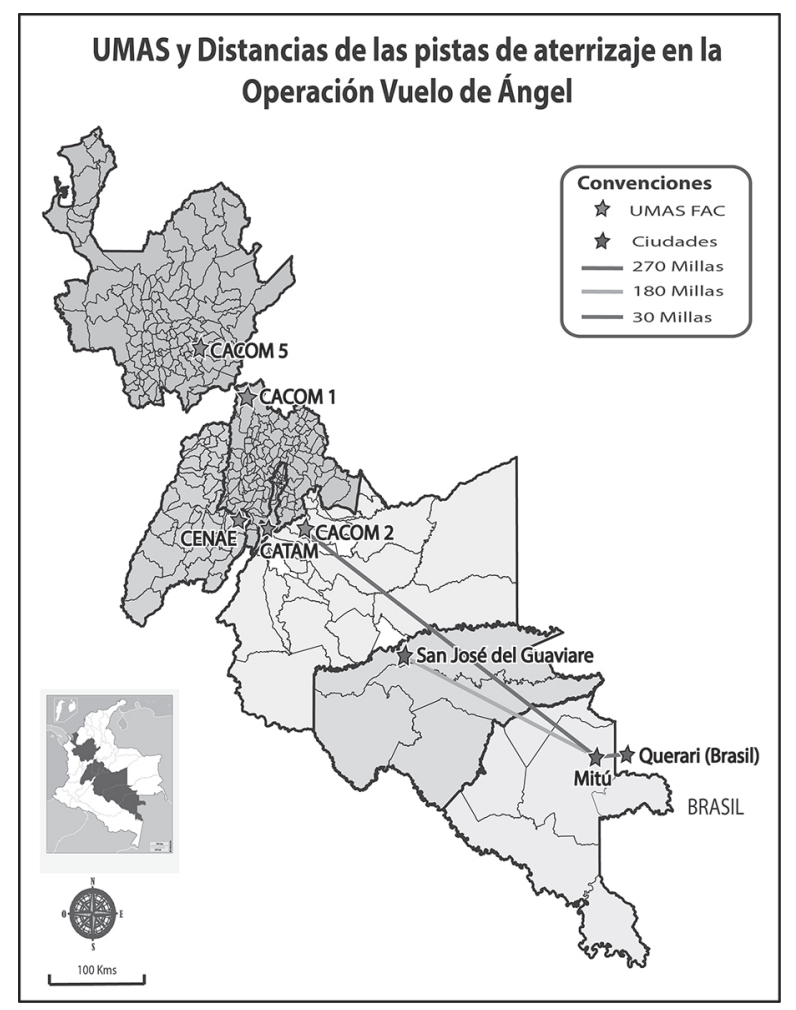

Mapa 1. UMAS y Distancias de las pistas de Aterrizaje en la Operación Vuelo de Ángel Fuente: (GARZÓN, 2018) $)^{2}$

Teniendo en cuenta que para retomar Mitú era imprescindible utilizar la pista de Querari en territorio del Brasil, había que tener autorización del hermano país. Ese primero de noviembre de 1998 era un día festivo en Colombia y también en el Brasil, a las 10:00 hrs aproximadamente hora de Colombia se procedió a llamar a la casa del Coronel Carlos Barrero F., quien era el Agregado de la Fuerza Aérea. Lamentablemente el Coronel Barrero estaba en vacaciones y no se encontraba en la casa. Llamé al suboficial de la Fuerza Aérea Adjunto a la Embajada y le informé de la gravedad de la situación que teníamos en Mitú, Colombia, nosotros requeríamos con urgencia que la Fuerza Aérea Brasilera nos autorizara para utilizar la pista de Querari como base aérea adelantada logística para transportar combustible armamento y tropa, para que desde allí se pudieran lanzar operaciones aéreas y recuperar Mitú.

2 Mapa elaborado por el investigador Daniel Garzón, miembro del grupo de investigación “Análisis en Contexto" registrado ante Colciencias. 
Dos horas más tarde, recibí una llamada del suboficial con la noticia de que la Fuerza Aérea del Brasil autorizaba la utilización de la pista de Querari para nuestras aeronaves de ala fija y rotatoria.

Mientras esto ocurría, se estaban alistando los aviones Hércules C-130 y C-235 para transportar combustible y tropa a Querari y San José del Guaviare, los helicópteros UH-60 Black Hawks para concentrarlos en la Base Aérea de Apiay y desde allí proceder a San José, y los T-27 y OV-10 con armamento para operar cuando las FARC iniciaran a salir de la población.

Por otro lado, el Comandante del Ejército ya se encontraba enterado de la situación y estaba alistando las tropas en Tolemaida y en Apiay para ser recogidas por las aeronaves de transporte y llevarlas a San José y Querari. El Coronel Director de Operaciones Aéreas se encontraba en el Centro de Operaciones de la Fuerza Aérea y yo en el Centro de Operaciones de la Policía, desde allí coordinábamos todo lo necesario con los Comandantes de los Comandos Aéreos comprometidos.

Hacia las 14:00 horas, recibí una llamada del suboficial de la Fuerza Aérea, informándome que la Fuerza Aérea del Brasil no autorizaba la utilización de la pista. Con esta contraorden se perjudicaba la operación, pero era la única opción que se tenía para poder llegar a Mitú. Ahora bien, tomé la decisión y se le dijo al suboficial que le informara a la Fuerza Aérea Brasilera que ya las aeronaves habían despegado para Querari y no tenía comunicación con ellas para hacerlas regresar.

En vista de este impase de última hora y en el cual estaba involucrado un país vecino y amigo, me comunique con el ministerio de Relaciones Exteriores y se le informó lo que se podía presentar. Los helicópteros ya se encontraban en San José y eran las 16:00 cuando despegaron con tropas para Querari.

El único que en ese momento disponía de visores nocturnos (NVG) era el líder, puesto que se estaba en el momento de transición hacia las operaciones nocturnas, y no se disponía de más.

Lo anterior, porque durante el gobierno del presidente Ernesto Samper, los Estados Unidos restringieron el suministro de equipos para la Fuerza Aérea. Los helicópteros debían aterrizar prácticamente de noche y debían guiarse por el líder que sí tenía visión nocturna, además el AC-47 los estaba esperando sobre la pista para iluminarla con el lanzamiento de bengalas (las cuales convertían la noche en día).

Posteriormente, los helicópteros llegaron a su destino con la tropa abordo sin novedad (todos sentimos un gran alivio y satisfacción pues la misión se estaba cumpliendo de acuerdo a lo planeado). La Fuerza Aérea estaba en proceso de modernización y adaptando su Doctrina a la nueva situación que se estaba viviendo porque era el momento de ser proactivos y dinámicos. 
El piloto del primer C-130 que aterrizó en Querari era el Coronel Alfredo González M, hoy Mayor General (r), él sobrevoló la pista y vio que no era una pista muy larga pero que no se era apta para el C-130. Sin embargo, debido a la premura del tiempo, tomó la decisión de aterrizar y gracias a su experiencia el aterrizaje fue exitoso, efectivamente la pista no estaba diseñada para ese tipo de aeronave y por el peso del avión se dañó una parte de la superficie en una de las cabeceras.

La tecnología que se estaba adquiriendo fue determinante para alterar la dinámica por parte de las FARC, el uso del FLIR para ubicar la guerrilla, las bengalas para facilitarle a las tropas su movilidad en la noche, los tiradores de alta precisión desde las aeronaves y los visores para la operación nocturna de los helicópteros, esto le permitió a la Fuerza Aérea operar 24 horas de día y noche facilitándole a las fuerzas de superficie su accionar en el terreno.

La guerra de guerrillas en la cual el enemigo operaba en pequeños grupos dispersos no ofrece objetivos lucrativos para el poder aéreo. En Mitú donde las FARC operaron en gran cantidad y trataron de pasar a la guerra de posiciones, quedaron expuestas al fuego del poder aéreo cuando la Fuerza Pública los obligó a desalojar Mitú, por eso la gran cantidad de bajas que sufrieron.

En Querari, estaba de noche ya teníamos tropa, helicópteros, combustible, para empezar al día siguiente el desembarco. Mientras tanto, el Avión Fantasma seguía sobrevolando el pueblo, mirando, observando y tratando de hacer lo que podían. La FAC tiene una norma y es que en áreas pobladas no se puede disparar. Para esa época, se diseñaron los famosos tiradores de plataforma (aeronave), estos son un grupo de francotiradores entrenados y equipados con fusiles .50 de alta precisión.

Como era imposible utilizar las armas dentro del poblado, se lanzaron bengalas, se utilizó el perifoneo en una operación psicológica para mantener a los guerrilleros despiertos y así estuvimos toda la noche.

Al día siguiente los helicópteros salieron con la tropa, ya se había seleccionado el área de desembarco que no podía ser dentro del pueblo porque estaban los guerrilleros. En las afueras del pueblo había unas áreas apropiadas para el desembarco, lo cual ocurrió.

Los helicópteros llegaron, la tropa desembarcó hubo combates y allí murieron varios soldados. Los helicópteros despegaron para una segunda oleada la cual se cumplió.

Al ver que se estaban desembarcando y que ya les era difícil mantenerse en la población las FARC empezaron a evacuar el pueblo, saliendo por trochas, caminos y por el río Vaupés, las aeronaves de ala rotatoria y fija comenzaron a utilizar sus armas en contra de los guerrilleros que huían en desbandada y sorprendidos por la efectividad del poder aéreo. 
Con el plan concebido y ejecutado a la perfección por la Fuerza Aérea, se evitó lo que había sucedido en Miraflores, se recuperó Mitú en menos de dos días. Las FARC habían planeado permanecer allí varios meses, pero no contaron con la operación rápida de la Fuerza Pública. (Algo parecido a lo que sucedió en la Línea Maginot en la Segunda Guerra Mundial).

Mitú es un pueblo en la mitad de la selva, su calle principal es la pista aterrizaje, no había torre de control, era una pista de tierra, en esa pista aterrizó el Hércules. Esas eran las condiciones del terreno, pero la Fuerza Aérea Colombiana gracias a las ventajas del poder aéreo como la flexibilidad, la maniobrabilidad tiene las capacidades para cumplir con su misión. En esa pista como no había torre de control había un señor que era "el controlador aéreo" cuando iban a aterrizar los aviones, él salía con su carro y avisaba a la población. Hasta ahí fue mi participación en cuanto al planeamiento de la operación.

\section{CONCLUSIONES}

La Operación Vuelo de Ángel dejó grandes enseñanzas para la Fuerza Pública, especialmente para la Fuerza Aérea. Se aplicó la Doctrina Aérea que se tenía en el momento y sirvió de base para actualizar y mejorar dicha Doctrina, en la cual se realizaron las misiones típicas del Poder Aéreo con éxito.

Igualmente, se concluyó una vez más que el Poder Aéreo es definitivo en cualquier tipo de conflagración. El operar y dominar la tercera dimensión le da una ventaja a las propias tropas sobre el adversario. De ahí el slogan que acuño la Fuerza Aérea "nuestra presencia en el combate marca la diferencia".

La Operación Vuelo de Ángel marcó un hito en el desarrollo de los ataques terroristas de los grupos al margen de la ley. Al haber incursionado en la guerra de posiciones se le obligó a las FARC a regresar a la guerra de guerrillas. Mitú fue la última población que intentó tomarse y permanecer, el grupo terrorista.

Por otro lado, en esta Operación se utilizó y puso a prueba la última tecnología incorporada por la Fuerza Aérea como los visores nocturnos (NVG), el sistema FLIR (Forward looking infra-red), el perifoneo y los Tiradores de Precisión desde aeronaves (Teplas).

Estos nuevos elementos puestos al servicio de las operaciones, más el excelente entrenamiento y compromiso de nuestros pilotos y personal logístico permitió tener el éxito obtenido en la Operación Vuelo de Ángel y subsiguientes operaciones. Lo cual doblegó el espíritu de lucha de las FARC y los obligó a dialogar con el Gobierno.

La Operación Vuelo de Ángel permitió que el poder aéreo se potencializara en el conflicto armado interno. 
Pese a que con la toma de Mitú fuimos reactivos, las FFMM y en particular la Fuerza Aérea utilizaron satisfactoriamente sus capacidades militares con el objetivo de recuperar la capital del Vaupés. Así mismo, se demostró que las capacidades aéreas le permitían hacer presencia efectiva y controlar no solo el espacio aéreo sino también el territorio nacional, lo cual generó que se privilegiara y potencializara el poder aéreo en el conflicto armado interno colombiano.

Posteriormente, estas lecciones aprendidas fueron fundamentales para mejorar el modo de operar, se fortaleció y mejoró la Doctrina Aérea, pero quizá lo más importante fue que la Fuerza Aérea Colombiana se potencializó y se convirtió en una herramienta fundamental del Poder Nacional, para contrarrestar diferentes amenazas a la seguridad nacional.

Como lo señaló el presidente Andrés Pastrana, "tan solo habían transcurrido 90 días de gobierno y ya comenzaban a sentirse los primeros resultados de los cambios en la estrategia militar. Las Fuerzas habían adquirido una importante capacidad de reacción y la operación fue considerada como un modelo para otros ejércitos en el mundo, pues se demostró cómo se podían alcanzar objetivos esenciales con escasos recursos." (PASTRANA, 2005).

Por otro lado, gracias a las características del poder aéreo, la Operación Vuelo de Ángel es considerada como un punto de inflexión del conflicto armado colombiano:

"Igualmente, esta operación sirvió para que las FF.MM se dieran cuenta que el poder aéreo, es una ventaja que el Estado colombiano debe explotar al máximo, ya que el poder aéreo produce una asimetría que debe ser utilizada." (MARín et al, 2017).

Gracias a las capacidades aéreas en la Operación Vuelo de Ángel y el poder aéreo demostrado, esta operación ha sido reconocida por el Centro Nacional de Memoria Histórica, por su importancia estratégica. Al respecto en su informe "Tomas y Ataques guerrilleros" se estableció que "una medida fundamental para contener la avanzada guerrillera fue el fortalecimiento del poder aéreo, (...) El poder aéreo se convirtió para las FFMM (Fuerzas Militares) en una ventaja táctica que transformó la correlación de fuerzas entre el Estado y la guerrilla." (CNMH, 2017, p. 102).

Nuestra presencia en Mitú marcó la diferencia en el combate, la Fuerza Aérea Colombiana logró lo que en un principio parecía imposible para el Estado, revertir la estrategia armada de las FARC y gestar uno de los golpes más estratégicos contra el grupo ilegal de las FARC. Pese a una serie de dificultades geográficas, políticas, operacionales, la FAC logró maximizar su poderío aéreo y adaptarse a las condiciones en el teatro de operaciones, lo que género que hoy en día esta Institución cuente con altos y precisos procedimientos operacionales, así como la evolución doctrinaria que permitió que la FAC siempre esté a la vanguardia y respetuosa del Derecho Internacional Humanitario (DIH). 


\section{REFERENCIAS}

Capítulos de libro

CNMH. (2017). Tomas y ataques guerrilleros. Centro Nacional de Memoria Histórica. Bogotá.

MARÍN et al. (2017). La operacion Vuelo de Ángel: punto de inflexión del conflicto armado colombiano. En M. e. al, Victorias desde el aire: La Fuerza Aérea Colombiana y el término del conflicto armado colombiano. Bogotá: Editorial Ibáñez.

MARín et al. (2017). Reflexiones operacionales a partir de la experiencia de las tomas de Puerto Rico y Puerto Lleras. En M. e. al, Victorias desde el aire: La Fuerza Aérea Colombiana y el término del conflicto armado colombiano. Bogotá: Editorial Ibáñez.

PASTRANA. (2005). El día que cambio la guerra. En Pastrana, La palabra bajo fuego. Bogotá.

\section{Publicaciones Periódicas Académicas}

BeCERRA, O. D. (2016). Relaciones cívico-militares en Colombia: apuntes para un estado del arte. Revista Análisis Internacional(6).

Castilla, C. E. (2004). La Guerra por el Control Estratégico en el Suroccidente Colombiano. Revista Sociedad y Economía.(7), 65-89.

Santos, M., (2014).La Operación Vuelo de Ángel, el poder de la Fuerza Aérea Colombiana y el cambio en la asimetría de poder entre las FFMM y las FARC: Repositorio Universidad del Rosario Disponible en http://repository. urosario.edu.co/bitstream/ handle/10336/8913/1020765037-2014.pdf?sequence $=7$

Tokatlian, J. (2008). La Construcción De Un "Estado Fallido" En La Política Mundial: El caso de las relaciones entre Estados Unidos y Colombia. Análisis Político, 21(64), 67-104.

\section{Otros documentos}

DNP. (1991). Plan quinquenal para la fuerza pública 1992-1996. Obtenido de Departamento Nacional de Planeacion, Ministerio de Defensa Nacional.

LoBE (1998) Drogas y narcotráfico/ Estados Unidos: Certificación antidroga pierde partidarios. Disponible en http://www.ipsnoticias.net/1998/03/drogas-y-narcotrafico-estados-unidos-certificacion-antidroga-pierde-partidarios/

Fuerza Aérea Colombiana. (s.f.). Manual de Doctrina Aérea. 


\title{
Abriendo Caminos para Colombia: La función SOCIAL DE SATENA EN UN ESCENARIO DE POSCONFLICTO
}

\author{
ADRIANA LUCÍA MARÍN RAMÍREZ \\ DANIEL GARZÓN MORENO ${ }^{2}$ \\ CAMILO ANDRÉS CASTIBLANCO ${ }^{3}$
}

\section{INTRODUCCIÓN}

La responsabilidad y función social de una aerolínea como Satena va más allá de cumplir satisfactoriamente con el traslado de los pasajeros de un destino a otro. Satena lleva cumpliendo por más de cincuenta años una labor social de abrir caminos para el desarrollo de las zonas periféricas, menos favorecidas y más afectadas por el conflicto armado de Colombia. Satena ha sufrido las consecuencias de la crisi económica, de la competencia comercial y del alza del dólar, no por eso ha dejado de buscar la manera de poder comunicar el centro del país con los territorios más alejados del país, para dar apoyo a la población más necesitada.

Este artículo busca realizar un breve recorrido histórico de la aerolínea enmarcando y enfatizando la función social que ha desempeñado en Colombia a lo largo de su trayectoria. De igual manera, se proyecta hacer una descripción social de la población que habita en las tres regiones donde Satena tiene mayor presencia y cobertura. Las regiones Pacífico, Orinoquia y Amazónica están caracterizadas por ser habitadas por la mayoría de la población étnica de Colombia y por tener los porcentajes más altos de las Necesidades Básicas Insatisfechas, de ahí que el apoyo otorgado por la aerolínea ha sido fundamental durante el conflicto armado y se esté preparando para un escenario de posconflicto y los desafíos que esto conlleva. 
Para el desarrollo de los temas mencionados, el grupo de investigación de la Dirección de Análisis de Contexto y Posconflicto (DICOP) de la Fuerza Aérea le realizó una entrevista al Mayor General de la Fuerza Aérea Pedro Ignacio Lozano Quinche, actual presidente de la aerolínea Satena, quien explicó en breves pero contundentes palabras cuál ha sido la función social de la aerolínea desde su nacimiento en 1962, y la importancia que ha tenido para el desarrollo de las regiones más alejadas del centro del país. Desde el apoyo técnico de la Fuerza Aérea Colombiana con la disposición de aviones, pilotos, técnicos mecánicos y administrativos; y el respaldo financiero del gobierno nacional, Satena surgió con el único propósito de brindar apoyo y unir a los lugares más alejados y periféricos de Colombia con las principales ciudades del centro del país. Dicho propósito ha sido el eje por el cual Satena se ha mantenido hasta la actualidad, no sin antes haber pasado por graves crisis económicas por causa de los cambios de las políticas del gobierno en el acompañamiento financiero a la empresa que tuvo inicio en 1991 al establecer que Satena debería ser una entidad autónoma.

Dicha decisión afectó en diferentes sentidos a la aerolínea, tal vez el más grave de las afectaciones según el Mayor General Lozano, fue el descuido y abandono en el que se vieron inmersas las ciudades periféricas a las que solo llega Satena por tener que cancelar rutas que unían los municipios y veredas con las capitales de los departamentos más alejados, destinos que fueron apropiados por los vuelos chárter incrementando así el valor de cada pasaje lo que impide a los habitantes de dichas zonas con menos recursos poder viajar por vía aérea. Debido a esto, a Satena le tocó empezar a competir por las rutas más concurridas con las demás aerolíneas que por su naturaleza comercial, son más grandes y fuertes económicamente. Esta decisión del gobierno, que para el Mayor General Lozano fue un grave "error", le costó también a Satena por más de quince años un endeudamiento que lo tuvo al borde de la quiebra en el 2010.

Después de llegar a tan críticos momentos financieros, y de mantener viva la aerolínea estable pero sin muchas ganancias, el Banco Interamericano de Desarrollo (BID) realizó un estudio en el año 2015, en el que se estableció que para el debido funcionamiento de la aerolínea y para asegurar el cumplimiento de su función social con el país, el gobierno debía volver a apoyar y a ayudar a Satena otorgándole una subvención para poderse liberar de deudas y apoyar la gestión para cubrir nuevas rutas y llegar cada vez a más destinos. El Mayor General Lozano sabe que con el venir del tiempo y con la nueva ayuda del gobierno, la cobertura a nivel nacional iba a ser mayor y así se podría mantener, recuperar viejas rutas que unieran los pequeños municipios con las capitales de los departamentos, y así, incrementar el impacto social de Satena como una empresa indispensable para el país. 


\section{"Hay muchos lugares de la geografía colombiana que necesitan de nuestro apoyo"}

En la actualidad Satena cubre 34 destinos a nivel nacional (Ver Mapa) de los cuales diez hacen parte de la región Amazónica, ocho de la región Pacífico, seis de la Orinoquia, seis de la Andina y cuatro de la región Caribe. De esos destinos, la mayoría se encuentra en zonas geográficas de difícil acceso en Colombia por lo que la misión social de la aerolínea se enmarca en conectar y apoyar la población que vive en territorios fronterizos y periféricos con las principales ciudades del país, entre ellas Villavicencio, Bucaramanga, Cali, Medellín y Bogotá. En las tres regiones donde Satena tiene mayor cobertura, (Pacífico, Amazónica y Orinoquia), son precisamente las que tienen un mayor índice de población étnica como la indígena y la afrodescendiente. Al mismo tiempo, son regiones en donde el porcentaje de las Necesidades Básicas Insatisfechas (NBI) son muy altas como se va a describir a continuación.

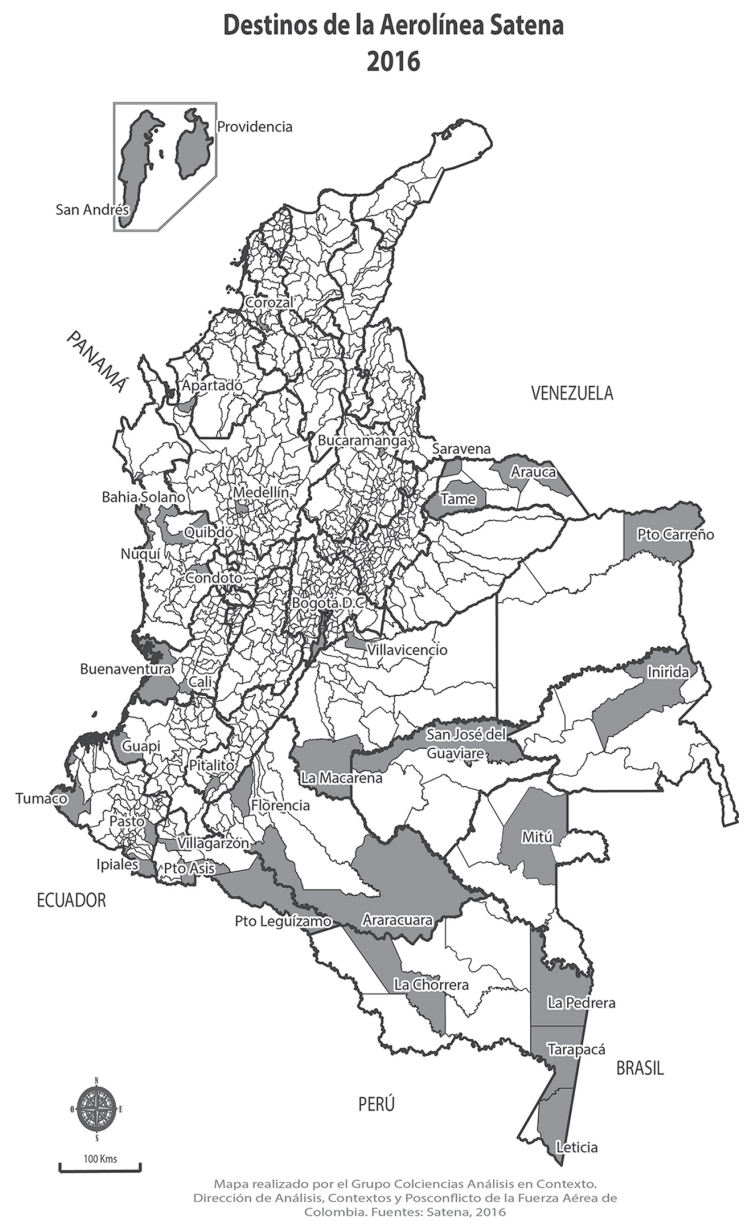




\section{- Región Pacífico}

La región Pacífico es una región de contrastes, en donde claramente los cuatro departamentos que la integran se encuentran en niveles distintos en lo referente a pobreza (DANE, 2016). Los niveles más críticos se encuentran en el departamento de Choco (79,19\%), en donde las NBI son marcadamente críticas, teniendo como vecino a un departamento como el Valle del Cauca (15,68\%), que se encuentra en la franja de desempeño más alto, en el marco nacional. Por el otro lado, departamentos como Cauca (46,62\%) y Nariño (43,79\%) se encuentran en un rango medio alto, constituyéndose bajo el promedio de muchas de las regiones colombianas. Frente a la población étnica, la presencia de comunidades indígenas está repartida en distintos lugares del territorio. Se puede señalar que existe una fuerte presencia en las zonas norte, desde la frontera panameña hasta el Valle del Cauca. En esta zona se encuentran comunidades como Embera Dodiba, Embera Chamí y Waunaan. Un segundo grupo se puede encontrar en el suroriente, en el Cauca, en donde se ubican comunidades como los Tototoe, Guambianos, Guanaca, Kokonukos y Yanaconá, y en el sur de la región, en el departamento de Nariño, se encuentra la comunidad Awa.

Del mismo modo, la región Pacífico es una de las cuales cuenta con la mayor presencia de comunidades afrocolombianas la cual cubre desde el norte hasta el sur del departamento, en la línea costera; en la zona montañosa de estos departamentos su presencia baja significativamente. En esta región existe la mayor concentración de las comunidades afrocolombianas en Colombia. Estos territorios se encuentran, entre los departamentos de Chocó, Valle del Cauca, Cauca y Nariño, y se ubican en la franja occidental.

Por otro lado, el Pacífico colombiano reporta una situación más grave y preocupante en términos de víctimas, configurándose como una de las regiones más violentas del país, en la medida que es la región que presenta mayor número de grupos armados irregulares en disputa de los territorios (Unidad de Víctimas, 2012). La posibilidad de generar conexiones marítimas rápidas con Centro América, las particularidades y complejidades de su topografía, la cantidad de hectáreas sembradas de coca y la presencia histórica de organizaciones armadas ilegales, hicieron de esta región una de las más violentas, y por ende, más generadora de víctimas en Colombia.

La región Pacífica ha sido espacio de confrontación de los distintos grupos armados, especialmente aquellas subregiones en donde hay presencia de cultivos ilícitos, o en aquellas en las que hay corredores de movilidad estratégicos para conectar el centro con el sur del país, o las zonas fronterizas. Para el año 2002, la presencia de las FARC en la región era muy fuerte, especialmente en el norte del departamento del Chocó (zona de frontera con Panamá) y los departamentos del 
Valle Cauca y el Cauca. En el primer caso, buscando el control de las zonas de siembra de coca y marihuana; y en el segundo por la salida fronteriza al Ecuador.

Para el año 2015, el panorama se ha complejizado y agravado, ya que las FARC siguen ocupando los mismos territorios, pero han brotado de forma paulatina grupos armados ilegales asociados con el narcotráfico y con formas de autodefensa ilegal, lo que en definitiva ha traído confrontaciones y hostilidades que han afectado a la población civil, principalmente. El norte del departamento del Chocó se transformó radicalmente, las FARC salieron definitivamente de la zona, y en su lugar emergieron grupos ilegales vinculados al narcotráfico y a la minería ilegal.

\section{- Región Orinoquia}

En el caso de la región de la Orinoquia, en lo que respecta a pobreza se encuentra claramente divida en dos dinámicas territoriales. La subregión que cubre Arauca $(35,91 \%)$, Casanare $(35,55 \%)$ y Meta $(25,03 \%)$ se encuentra entre los niveles departamentales nacionales de presencia media-alta de pobreza. Por el otro lado, departamentos como Vichada (66,95\%) se encuentran en los niveles más altos de presencia de NBI a nivel nacional. Esta región concentra una población de comunidades indígenas entre el norte, centro y oriente, en el sur y occidente del departamento no presenta mayor presencia. En el norte, departamentos de Casanare y Arauca, se pueden encontrar comunidades como los U'wa, Hitnu, Betoye, Chiricoa, Tsiripu, Eduria, Wipijiwi, Yaruro, Misiguare. Ya en el oriente y sur oriente, departamentos de Vichada y Meta, están ubicadas comunidades como los Saliba, Piacopo, Kuiba, Amoruá, Guayabero y Achagua.

Estos pueblos indígenas se encuentran en 96 resguardos (DNP, 2014), en donde se halla una sobreposición de elementos como: pueblos incluidos en el Auto 004 de 2009, pueblos en vía de extinción y al mismo tiempo, tres de los pueblos nómadas que habitan en Colombia, los Guayaberos, Hitnus y Sikuanis, que por sus características culturales, se desplazan a lo largo de un territorio definido según los cambios estacionales y agrícolas. Los pueblos indígenas que componen esta región, se han visto influenciados y determinados por las dinámicas que han traído consigo la extracción de recursos naturales y el conflicto armado en el país. La extracción de petróleo y la concentración en el sector agrícola y pecuario con el cultivo de la palma de aceite, yuca, maíz, plátano, tabaco, entre otros; ha transformado la economía y las dinámicas de intercambio en las comunidades indígenas de la región.

Partiendo de lo anterior, la Orinoquia colombiana ha sido el escenario de los momentos de mayor tensión en la historia del país, por cuenta del auge que tuvo el Bloque Oriental de las FARC en la década de los años 90, y por la proliferación de estructuras armadas vinculadas a las AUC. De allí que en zonas específicas reporte altos índices de hechos victimizantes, huellas claras del paso del conflicto 
armado interno por esa zona del país. La situación en la subregión cercana a la ciudad de Villavicencio es completamente distinta, reportando unos indicadores cercanos a los que se presentan en la región Andina, y con zonas que incluso no reportan víctimas reconocidas.

\section{- Región Amazónica}

Finalmente, la Región Amazónica ofrece un panorama heterogéneo frente a la forma de reparto de pobreza en el territorio, a nivel departamental. Se encuentra en el primer grupo, departamentos como Putumayo (36,01\%) y Guaviare (39,89\%), con mejores niveles en cuanto a NBI. Por el otro lado, se en un segundo grupo está Caquetá (41,72\%), Amazonas (44,41\%) y Vaupés (54,77\%), con niveles un poco inferiores y ubicándose en un índice medio-alto de NBI. Finalmente se encuentra Guainía $(60,62 \%)$ la cual se localiza entre los departamentos a nivel nacional con mayor presencia de pobreza.

La Región Amazonia es la que mayor cantidad de pueblos indígenas integra y al mismo tiempo, la que mayor extensión de tierra tiene en resguardos indígenas, sumando en total 190 resguardos (DNP, 2014). El 17\% de la población amazónica (CEPAL, 2013) corresponde a los más de 50 diferentes pueblos. Al igual que en la región de Orinoquia, la Amazonia colombiana es el escenario en el que habitan otras dos poblaciones nómadas del país, los Ingas, y los Nukak Makú. Al igual que los otros tres, éstos hacen parte de la lista de los 34 pueblos incluidos en el Auto 004, ya que ambos se han visto seriamente afectados por el conflicto armado y las intervenciones empresariales que han interrumpido sus dinámicas ancestrales y culturales.

Distintas comunidades hacen presencia a lo largo y ancho del territorio amazónico. En la parte nororiental, departamentos de Vaupés y Guainía, hay comunidades como los Nukak Makú, Puinave, Curripaco, Carapana, Cubeo, Yurutí, Taiwano, Pisamira, Carapana, Tatuyo, Piratapuyo, Jupda, Bara y Tuyaca. En la parte Occidental, departamentos de Caquetá y Putumayo, comunidades como los Inga, Kofan, Coreguaje, Kichwa, Siona y Kamentza. Y finalmente, en el sur, departamento de Amazonas, se encuentran la amplia cantidad de comunidades como los Miraña, Andoque, Huitoto, Nonuva, Muinane, Carijona, Ocaina, Yauna, Letuama, Yucuma, Matapí, Tanimuca, Barasana, Tariano, Desana, Macuna, Kawiyavi, Yuri y Tucano.

La región podría prestarse para lecturas territorialmente incorrectas, ya que hay amplias zonas con bajos niveles de víctimas, pero que a su vez son zonas con unos niveles de poblamiento muy bajos, e incluso inexistentes (especialmente en zonas selváticas), lo que significa que la lectura de esta región debe hacerse a partir de esta especificidad. La Orinoquia y la Amazonia colombiana, reportan 
unas situaciones muy similares en lo que tiene que ver con el conflicto armado colombiano; las dos regiones están determinadas por la historia del Frente Oriental de las FARC, y la estrategia desarrollada por esta organización para controlar los entramados territoriales que conectan a Colombia con Brasil, Perú y Venezuela (Fundación Ideas para la Paz, 2012).

Esta zona fronteriza ha sido el escenario de unas dinámicas de criminalidad transnacional, debido a la configuración de corredores estratégicos por lo que entraban armas de fuego, y se comercializaban narcóticos (década de los años 90) e insumos y contrabando de minería ilegal (en la actualidad). Así mismo, en esta zona, especialmente en la Orinoquia, se armaron grupos de autodefensas ilegales en las regiones en las que existían yacimientos petrolíferos, o en las zonas ganaderas (Fuerza Aérea Colombiana, 2016).

\section{"Satena es la punta de lanza de todas esas regiones"}

Teniendo en cuenta todos los aspectos mencionados en las tres regiones señaladas, el rol que desempeña Satena es fundamental no solo por brindarle apoyo y presencia a las poblaciones étnicas y económicamente más necesitadas con labores como transportar medicinas y alimentos a estas regiones, sino por inspirar la gestión de la mejora de la infraestructura aeroportuaria para que puedan llegar aviones más grandes y se puedan realizar circuitos de rutas a varias horas del día para aumentar su cobertura. El Mayor General Lozano asegura que la ayuda del gobierno y la Aerocivil y los convenios a los que se llega con las alcaldías y gobernaciones, ha sido fundamental para este proceso de mejora, ya que se entiende que a medida que la infraestructura sea mejor, pueden tener más opciones de ingresos económicos que ayuden a mejorar la situación económica y social de cada uno de los destinos a los que llega Satena.

De igual manera, el presidente de la aerolínea asegura que entre más personas, tanto turistas como habitantes de los diferentes destinos, viajen por Satena, mayor va a ser el interés de las grandes aerolíneas comerciales en cubrir los diferentes municipios y pequeñas ciudades y así incrementar y fomentar el desarrollo interno de estas regiones. Frente a esto, el Mayor General Lozano explica que Satena fue la primera aerolínea en llegar a Yopal, Casanare cuando "aún era un potrero y tocaba ahuyentar a las vacas para poder aterrizar" y que fue gracias al crecimiento de los pasajeros que entraban y salían del municipio que Avianca y otras grandes aerolíneas entraron en ese mercado para competir con ellos, acto que generó que Satena se hiciera a un lado no sin antes sentirse orgullosos, que fue gracias a ellos, que los habitantes de esta ciudad pudieran tener el contacto directo con otras ciudades capitales.

Sumado a lo anterior, y como parte esencial del trabajo social al que responde Satena, hay un gran porcentaje de la población ya descrita que habita en estas 
regiones, que ha hecho uso de esta aerolínea como una solución a emergencias médicas como graves accidentes o incluso embarazos críticos. Sin embargo, a esta población también la ha tenido que asistir directamente la Fuerza Aérea Colombiana debido a que los pobladores consideran que el precio de los pasajes es muy alto y no pueden acceder a los servicios de la aerolínea.

El Mayor General Lozano explica que ese tipo de operaciones en donde los helicópteros de la FAC entran a hacer ese servicio social, sale sumamente costoso y que por lo tanto es Satena la que debe cerciorarse de cumplir también ese tipo de acción social. Para eso, la aerolínea está interesada en realizar convenios con las alcaldías y gobernaciones para crear subsidios a las personas que por motivos críticos de salud necesiten salir de sus regiones y poder llevarlas a un costo mucho más accesible a las principales ciudades del país. Actualmente la única población que cuenta con dicho subsidio son los habitantes y oriundos de San Andrés y Providencia para que puedan realizar el vuelo entre las dos islas a mitad del precio que se vende para el turismo en general.

"Servir, planear y desarrollar" son los tres aspectos que señala el Mayor General Lozano como bases del servició social que cumple Satena para el desarrollo del país y asegura que se está trabajando para que dentro poco tiempo se pueda incrementar la cantidad de destinos y seguir apoyando a la población que se encuentra más alejada del centro del país con acciones fundamentales como el hecho de no haber subido los precios de los pasajes aún incluso con la fuerte subida del dólar en el año 2015. Esto con el fin de que la población que más necesita llegar a estos destinos pueda hacer uso de la infraestructura aérea de Satena.

\section{Satena y su papel en el posconflicto}

Durante el conflicto armado en el país, Satena se ha encargado de continuar su labor social de acercar a las personas a los lugares que se han visto afectados por la violencia. Las regiones afectadas se beneficiaban con el arribo de la aerolínea durante el conflicto por la afluencia de medicamentos y comida para toda la población. Ahora, a puerto de entrar en un escenario de posconflicto se planea que se pueda incrementar el número de vuelos y de destinos para que el turismo pueda tener más acogida, como lo anhela el Mayor General Lozano quien se ha encargado de recorrer cada uno de los lugares a los que llega Satena para deleitarse del paisaje que pocos han tenido acceso, hasta ahora.

"Hay una función social de dar a conocer el país a todas las personas que no lo han podido hacer por causas del orden público" agrega el Mayor General de la Fuerza Aérea Colombiana. Uno de los ejemplos de esto es Villa Garzón en el Putumayo, una de las zonas más afectadas por el conflicto armado en el país, es ahora un lugar que se está promocionando como un destino turístico y que por medio de la publicidad de Satena se busca que se conozca a profundidad el país. 
En el marco de estos escenarios de posconflicto, y adicionalmente a los conflictos sociales que puedan emerger en cuanto a la sobreposición de actividades extractivas y áreas de reserva ambiental, estos territorios periféricos sufren dos tipos de amenazas. Por un lado, la presencia de economías ilícitas como la explotación maderera y minera ilegal, que constituyen dos graves amenazas en cuanto a la preservación ambiental. El avance de la minería ilegal de coltán y tungsteno en PNN como el Puinawai y Amacayacu es una amenaza considerable que deber ser enfrentada contundentemente.

Por el otro lado, y en clave de posconflicto, una posible migración de la producción de coca de las zonas históricas (Macarena, Catatumbo, Putumayo, entre otras) -por cuenta de los incentivos que puedan ofrecerse para los cultivadores tradicionales en el marco del posconflicto- a zonas como la fronteras amazónica donde por cuenta de características como zonas de difícil acceso, presencia de parques naturales y acceso a la frontera facilitarían el cultivo y transporte de narcóticos.

En un escenario de posconflicto, los desafíos se darán en cuanto a la llegada de nuevos actores con capacidad de copar los espacios que dejen las FARC en los territorios. Los riesgos de fragmentación en la desmovilización de las FARC es un escenario posible (McDermott, 2013), ante el cual también hay que contar con la criminalización de elementos de las FARC que continúen en el territorio delinquiendo. Este elemento de fragmentación y la transformación de la amenaza más allá del proceso de desmovilización tienen antecedentes en procesos como los del Ejército Popular de Liberación (EPL), las Autodefensas de Colombia (AUC).

Así mismo, se ha señalado el riesgo de la mimetización total de las estructuras armadas de las FARC con el narcotráfico, invisibilizando el accionar de sus hombres detrás de las fachadas construidas por los cárteles de la droga, y evadiendo las lecturas de macrocriminalidad que hoy se efectúan. Esto implicará una labor de inteligencia policial y militar muy fuerte, que supere fenómenos como el que vivió el San Salvador luego de la desmovilización del FMNL, en donde esta organización siguió operando a través de pequeños grupos criminales (BENíteZ, 1993, p. 8). Este fenómeno de invisibilización es muy similar al que se produjo con la desmovilización de las AUC en el año 2005, con una aparición de innumerables bandas criminales, de las se desconocía su estructura y zonas de operación (ACNUR, 2006).

Ante esta situación, Rettberg (2002) ha señalado que se debe generar una transformación completa del concepto de seguridad, trasladándolo de la seguridad nacional a la seguridad ciudadana; este cambio no es un problema meramente semántico o conceptual, ya que reestructura los roles de las Fuerzas Militares, y pone en una situación protagónica a la Policía Nacional. Por ello, se ha tornado fundamental reflexionar sobre el futuro de una Fuerza Militar en un escenario de posconflicto, señalando que su legitimidad y continuidad va más allá del conflicto mismo. 


\section{CONSIDERACIONES FINALES}

En el contexto específico de los municipios a los que tiene como destino Satena, el reto de la capacidad de llevar desarrollo y bienestar a las comunidades se ve incrementado por obstáculos como la geografía y la dispersión. Con unas comunidades viviendo en 15 de los 16 municipios/corregimientos departamentales dentro de la categoría de "rural remoto" (DNP y Misión Rural, 2015), todo tipo de inversión se incrementa en tiempo y recursos, agravado por fenómenos de corrupción. Sin embargo, este reto social de Satena sigue siendo vital ya que el bienestar de las comunidades redundara en la posibilidad de cerrarle espacio a grupos armados y economías ilegales, construyendo legitimidad en el Estado y sus instituciones en el territorio. El cómo se puede avanzar en este tipo de desafíos y el rol que distintos actores (Sector Público, Sector Privado, Fuerzas Armadas, Academia, entre otros) puedan tener en este proyecto de llevar bienestar a estas zonas, constituye un reto al trabajo conjunto y la innovación de Satena.

Desde otro punto de vista, el desarrollo de los lugares acá mencionados no puede depender únicamente de la aerolínea que con su esfuerzo ha tratado de llegar cada vez a más lugares del país. Hay una serie de retos institucionales, los cuales se manifiestan por las necesidades de fortalecer todo el entramado de instituciones estatales que constituyen la presencia del Estado en el territorio. En el entramado de retos sociales y ambientales que surgen en estos territorios de frontera, la necesidad de una respuesta completa y coherente por parte del Estado constituye una necesidad. En este caso, los retos institucionales pasan desde la atención del Gobierno central, el fortalecimiento de los distintos actores gubernamentales regionales y locales, y el combate frontal contra la corrupción. En cuanto a la atención por parte del gobierno central, la capacidad de destinar recursos para este territorio continúa siendo prioritario por cuenta de la crítica situación en que se encuentra solo viendo indicadores como NBI en los municipios/corregimientos.

La necesidad del fortalecimiento de las entidades gubernamentales a nivel regional y local. En este caso se requiere mejorar las capacidades y recursos con que cuentan funcionarios e instituciones para el cumplimiento de su misión. En un ejemplo, como el combate frontal contra la minería ilegal, en el escenario actual, la asimetría entre los recursos y capacidades de organizaciones criminales hacen imposible que el Estado pueda estar vigilante sobre el daño a los ecosistemas. Se requiere de una gran articulación entre autoridades locales, organismos de control, autoridades ambientales (Corporaciones Autónomas Regionales) y Fuerza Pública, en donde las autoridades a nivel local y regional tengan la capacidad de estar a la cabeza de estos hechos.

Por último, el reto institucional se refiere a la corrupción como uno de las amenazas más grandes en cuanto a la capacidad de fortalecer institucionalmente 
al Estado en los territorios, pero también de fortalecer la misma legitimidad para toda la intervención del mismo. Respecto a la corrupción como un obstáculo en el fortalecimiento institucional, es claro que las innumerables necesidades de estos territorios no van a encontrar solución si la destinación de los recursos nunca llega a las comunidades sino en el enriquecimiento de unos pocos funcionarios y particulares. En el escenario de posconflicto, y en el marco de la inversión territorial que conlleva, se corre el mismo riesgo.

\section{REFERENCIAS}

ACNUR (2005) Algunos indicadores sobre la situación de los Derechos Humanos en Antioquia. Bogotá, ACNUR y Observatorio del programa presidencial para los Derechos Humanos y el DIH.

ACNUR (2006) Diagnóstico del Departamento del Meta. Colombia, Naciones Unidas-ACNUR.

Benítez, R (1993) Condiciones de seguridad en San Salvador tras los acuerdos de paz. San Salvador, Nueva Sociedad.

DANE (2016) Necesidades Básicas Insatisfechas. Tomado de: https://www.dane. gov.co/index.php/estadisticas-por-tema/pobreza-y-condiciones-de-vida/ necesidades-basicas-insatisfechas-nbi

DNP, Departamento Nacional de Planeación. (2014). Aplicativo de Consulta de Resguardos. Disponible en la página web: http://sige.dane.gov.co:81/ resguardos/map.phtml

Fuerza Aérea Colombiana (2016). La Fuerza Aérea Colombiana y el cese del conflicto armado: Victorias desde el aire. Bogotá, Fuerza Aérea Colombiana.

McDermont, J. (2013). "Posibles escenarios de una fragmentación o criminalización de las FARC”. Insight Crime. Centro de Investigación de Crimen Organizado.

Unidad de Víctimas. (2012). Informe nacional de desplazamiento forzado en Colombia 1985 a 2012. Colombia, Unidad de Víctimas. 



\title{
LA DISPUTA POR LOS CORREDORES DE MOVILIDAD EN LA DÉCADA DE LOS NOVENTA: REFLEXIONES SOBRE EL CONFLICTO ARMADO INTERNO COLOMBIANO
}

\author{
Mayor General. (RA) LUIS IGNACIO BARÓN CASAS ${ }^{l}$
}

\section{INTRODUCCIÓN}

Después de tantas experiencias vividas como piloto de la Fuerza Aérea Colombiana surgen reflexiones sobre las dinámicas del conflicto armado interno, y de los planes violentos desarrollados por los grupos armados ilegales para obtener sus propósitos. En este documento, presento una reflexión sobre el conflicto armado que se vivió en el país en la década de los años noventa, centrando la atención en dos variables que, a mi parecer, resultan totalmente explicativas en la transformación del contexto de seguridad que el país experimentó.

Con la primera variable se indilga a las dinámicas desarrolladas por las FARC para cercar a Bogotá y tomarse el poder; se tratan de unas dinámicas territoriales en las que esta organización desplegó una guerra de movimientos, encaminada a concentrar gran número de hombres en puntos clave de la geografía nacional. Por supuesto, esto implicó una respuesta contundente de las Fuerzas Militares, quienes contrarrestaron la ofensiva, y transformaron completamente los indicadores de seguridad del país.

La segunda variable que me interesa desarrollar centra su atención en las transformaciones de las políticas, agendas y compromisos de seguridad en las 4 figuras presidenciales que tuvo el país en esa década. La tesis es muy sencilla: las Fuerzas Militares no podían dar importantes avances en el terreno militar, si no contaban con el apoyo claro y contundente del aparato gubernamental, es decir, que el problema de seguridad no obedece exclusivamente a las instituciones militares, sino que debe ser entendida como una política de Estado, que comprometa a distintas instituciones del mismo.

Los criterios para seleccionar la década de los años noventa como período de estudio obedece a dos criterios puntuales: en primer lugar, porque es la década

Mayor General. Ex segundo Comandante y Ex Jefe de Estado Mayor de la Fuerza Aérea Colombiana. 
en la que se presentan los más altos índices de violencia por cuenta del actual conflicto armado, tal y como lo documentan las estadísticas oficiales o diferentes informes académicos que se reseñarán más adelante.

La segunda, porque en esta década hay unas transformaciones operacionales muy importantes al interior de la Fuerza Aérea Colombiana, que le llevan a asumir progresivamente mayor contundencia y precisión en sus operaciones, y mayor incidencia en la disminución de la intensidad del conflicto. En este período de tiempo la Institución arroja resultados operacionales óptimos, y genera operaciones decisivas y fundamentales para truncar los planes trazados por las FARC (MARÍn et al., 2016).

Estas dos variables que sustentan y guían esta reflexión, permiten esbozar una serie de conclusiones sobre por qué se intensificó el conflicto en unos años específicos (expresado en un aumento de las tomas violentas a municipios, o el incremento del secuestro, entre otros); pero también, porque se lograron configurar mejores estadísticas en materia de seguridad al final de la década de los años noventa (EcHANDÍA, Camilo, 2011).

\section{Dinámicas territoriales del conflicto armado}

En un reciente libro publicado por la Fuerza Aérea Colombiana fui consultado sobre las dinámicas de seguridad en el departamento de Antioquia (Marín et al. 2016), allí señalé que la concentración de la violencia en unos municipios estaba relacionada con el interes de las FARC por asegurarse un corredor de movilidad que le permitiera conectar al norte con el sur del país, en inmediaciones de la capital de la República.

\footnotetext{
"crear corredores que permitian la comunicación efectiva entre el sur y el norte del pais, y entre el occidente y el oriente. Por su posición, Antioquia conectaba al Atlántico con la antigua 'zona de distención'; a través de las vías que nacen en las bocas del Atrato y en Vigía del Fuerte. Por la vía a Urrao conectaba al Bloque Noroccidental. Por el sur, vía Bagado e Ismina se conectaba con Caldas y el Tolima (Rovira, Ronsesvalles, Planadas y/o Marquetalia), por allímismo se salía al Valle por Pradera y Florida o hacia el sur del país por Dolores, Alpujarra o Colombia (Huila), conectando con la Uribe y con el Meta. Asíse conectaban el Bloque Noroccidental, Bloque Central, Bloque Oriental y Bloque Sur entre si'”(MARÍN et al. 2016, pp. 75-76).
}

De allí que la historia del conflicto armado interno pueda contarse a través de estos corredores, y de las intencionalidades y apuestas que los grupos armados han desarrollado, ya que por medio de estos se comprende las particularidades y especificidades de cada región del país, dimensionando los recursos naturales en disputa, las posiciones estratégicas que se pretendían alcanzar, y las posibles relaciones de estos actores con otros sectores sociales, económicos y políticos. 
En las siguientes páginas me propongo explorar esta relación territorial del conflicto armado colombiano, focalizando en las tres regiones que fueron centrales para el propósito de las FARC que sustenta la tesis central de este documento.

Mapa 1. Corredor occidental

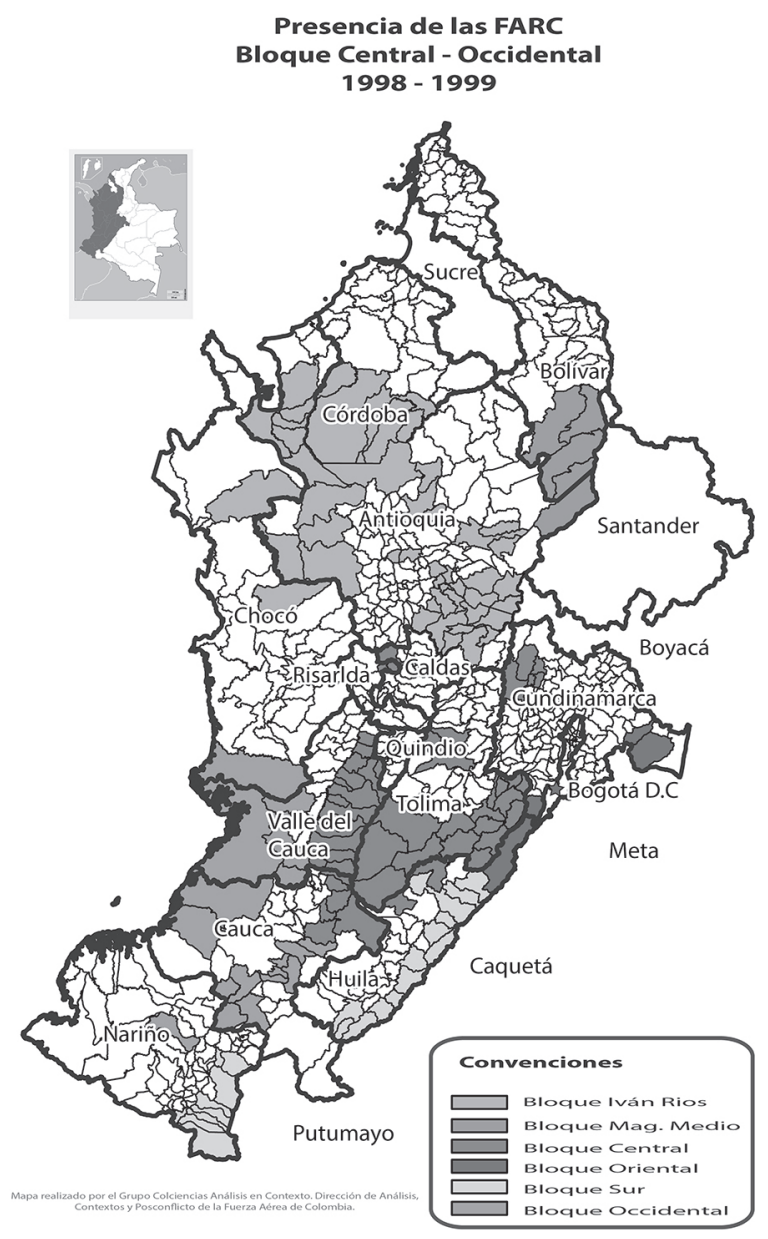

Fuente: Garzón, Daniel (2016)

El Mapa 1, sustenta la cita realizada en el libro de la DICOP; mostrando cómo la posición que asumen los Frentes de esta organización, en alineación con el Bloque Occidental, permitieron crear un corredor de movilidad que conectaba desde el departamento de Córdoba con los departamentos de Huila y Nariño, atravesando zona ricas en cultivos ilícitos y en recursos naturales.

Es sumamente enriquecedor para la comprensión de las acciones violentas que han asotado al sur del país, entender cómo los Bloques Central y Occidental de 
las FARC se estructuraron para generar una gran barrera de contención ubicada en el sur del departamento del Cauca. La detección de esta estrategia por parte del gobierno y de la Fuerza Pública, fue central para disminuir la presencia de esta organización en esta región (mayoritariamente indígena) y para liberar a la vía Panamericana del accionar irregular de este grupo armado (DAVILA, Gomis, \& SALAZAR, 2016).

Este movimiento, se sincroniza con las acciones que intentó desarrollar el grupo armado en el suroriente del país, en donde también despliega una ofensiva que buscaba conectar todos los Frentes y Bloques que operaban entre los departamentos que componen la Orinoquia colombiana:

“Así, para 1993, las FARC desarrollaron una serie de Frentes en la región: el 7, 42, 43, 26, 40 y el 31 se van a asentar en los municipios de Mesetas, Uribe, Puerto Rico, Vistahermosa, La Macarena, Puerto Lleras y San Juan de Arama; los frentes 22, 27 y 32 en la región del Sumapaz, al oriente del departamento de Cundinamarca; los frentes 31, 27, 38, 28, 10 y 45 se van a ubicar en el departamento de Arauca, abriendo una frontera con Venezuela, estratégica para sus fines económicos; los frentes 1, 7, 16, 39 y 44; se apoderaron de zonas tácticas en los departamentos del Guaviare, Vichada y Guainía” (Marín, et al. 2016, p. 101).

\section{Mapa 2. Corredor suroriental}

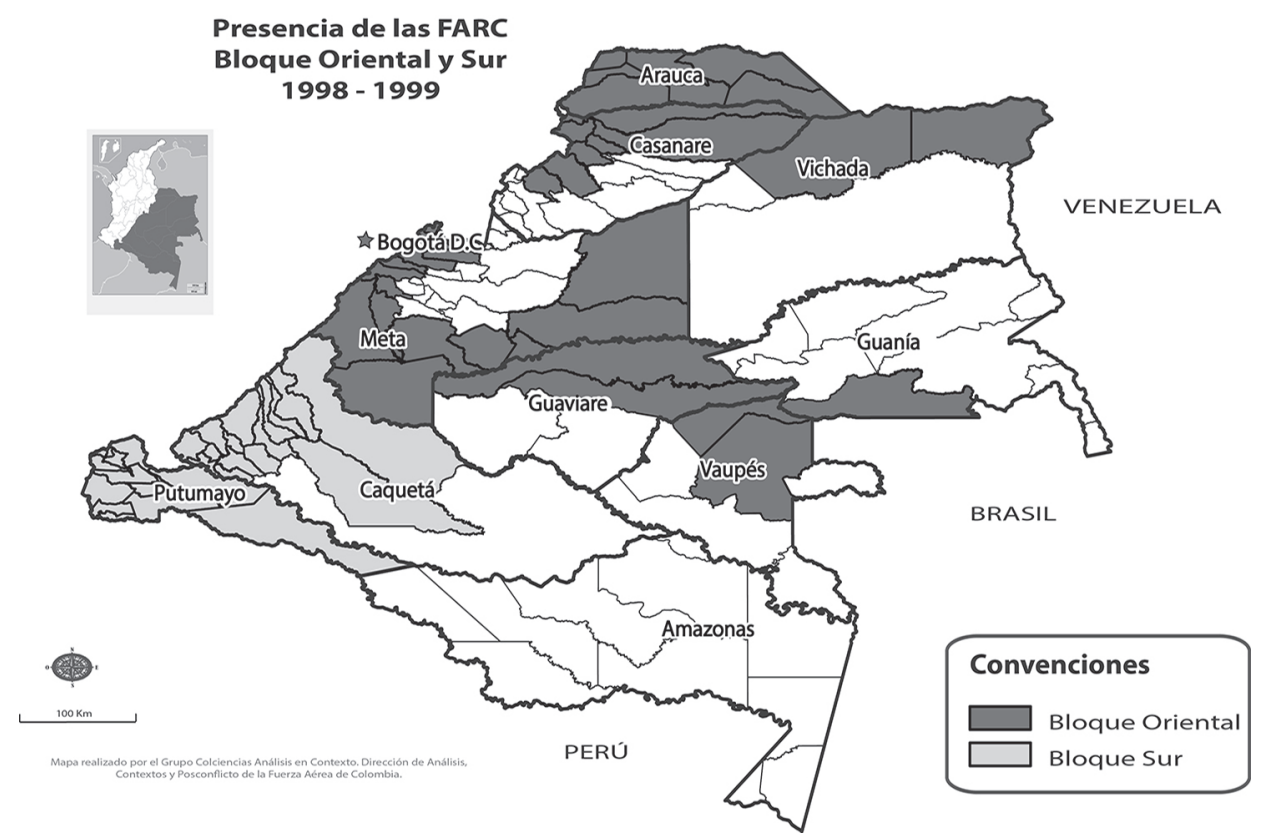

Fuente: Garzón, Daniel (2016) 
Si se sobreponen los dos mapas, se encontrará que había una clara intención por controlar una buena parte del territorio nacional, dividiendo a Colombia en dos, y aislando la zona sur del país, ganándose el control de las más grandes concentraciones de cultivos ilícitos del país, y teniendo acceso a las fronteras con Ecuador, Perú, Brasil y Venezuela, fundamentales para la entrada de armas y contrabando; y para la salida de narcóticos (ECHANDía \& BECHARA, 2006).

De hecho, el período en el que se desmilitarizó la región del Caguán (la Zona de Distensión), tiene que ser entendido bajo esta lógica; las FARC intentaron aprovechar ese territorio para ampliar su presencia en la región, apoderándose de una zona neurálgica de la Orinoquia, en inmediaciones de la capital de la República.

La intención de dar un uso táctico a la Zona de Distensión se evidenció con la escalada de acciones que las FARC realizaron en julio de 1999, con antelación al inicio de las negociaciones. En este momento, la ZD se utilizó como plataforma de los ataques hechos a los municipios ubicados en los alrededores. Estos ataques pusieron al descubierto el propósito de las FARC de avanzar en su «plan estratégico» mientras se llevaban a cabo las conversaciones con el gobierno. La escalada de la guerrilla buscaba, en primer lugar, ampliar el dominio territorial a partir de la ZD, donde concentró un componente de importancia histórica, y en segundo término, contribuir al desgaste del gobierno, que era blanco de fuertes críticas a causa del uso que las FARC le daban al escenario de las negociaciones. (ECHANDÍA, 2013, p. 55).

Así, la intervención oportuna de la Fuerza Aérea Colombiana y de las otras instituciones militares, tuvo que ser cortante y efectiva, para contrarrestar estos intentos irregulares que se dieron en el marco de un proceso de paz. La efectividad fue innegable, sobretodo si se tienen en cuenta diversos informes académicos que muestran que para los primeros años del Siglo XXI la presencia e influencia de las FARC era menor, y que habían perdido la capacidad de afectación a la población y a la infraestructura del Estado que otrora habían logrado desarrollar.

Así lo pone de presente la siguiente tabla construida por la Fundación Ideas para la Paz (2011) en la que se hace un análisis del Bloque Oriental de las FARC y de su presencia efectiva en la región:

Gráfico 1: Municipios con influencia de las FARC: 1992 - 2011

\begin{tabular}{|l|r|r|r|r|r|}
\hline & 1992 & 2002 & 2011 & 92 a 02 & 02 a 11 \\
\hline Número de municipios & 97 & 192 & 32 & $97,9 \%$ & $-83,3 \%$ \\
\hline Efectivos por municipio & 16,9 & 36,4 & 133,6 & 1,2 & 2,7 \\
\hline
\end{tabular}

Fuente: Fundación Ideas para la Paz (2013)

Para analistas como Camilo Echandía (2013) o el Observatorio de Derechos Humanos y DIH de la Presidencia de la República (2013), las FARC exedieron el límite de sus posibilidades al creer que podían mantener este control territorial por 
un largo período de tiempo; pero a su vez, reconocen que la intervención de la Fueza Pública fue fundamental para trastocar el ritmo que asumió el conflicto colombiano.

Es fundamental señalar en este punto, junto a Echandía (2013) y Esquivel (2016), que las posibilidades que le dio el poder aéreo a las Fuerzas Militares fue clave para llegar a las zonas más apartadas de la geografía nacional, en donde las FARC creyeron tener unos territorios propios, a los que no podría llegar nunca el Estado.

Desde que se desarrolló la Operación Colombia (1990) hasta Operaciones claves como la de Sodoma (2010) se lanzó un mensaje contundente a la opinión pública y a las organizaciones armadas: ningún territorio estaba vedado para la intervención de las Fuerzas Militares, y no existía ningún "santuario" de las FARC, o ninguna "República independiente", tal y como esta organización hacía querer suponer.

Pero lo más interesante de la intervención militar desarrollada, es que se impidió el plan final de esta organización: rodear a la ciudad de Bogotá, con el fin de intentar tomarse el poder por la vía armada, en un intento por destruir el Estado de derecho y la democracia colombiana (VALENCIA \& INSUASTY, 2011).

En el siguiente mapa, trato de mostrar esta tendencia, por medio de la presentación del movimiento que desarrolló las FARC, para ubicar Frentes en las inmediaciones de la capital, especialmente en la región del Sumapaz, en municipios de Cundinamarca y en las vías que comunicaban a Bogotá con Villavicencio.

\section{Mapa 3. Desplazamientos de las FARC (1998 a 1999)}

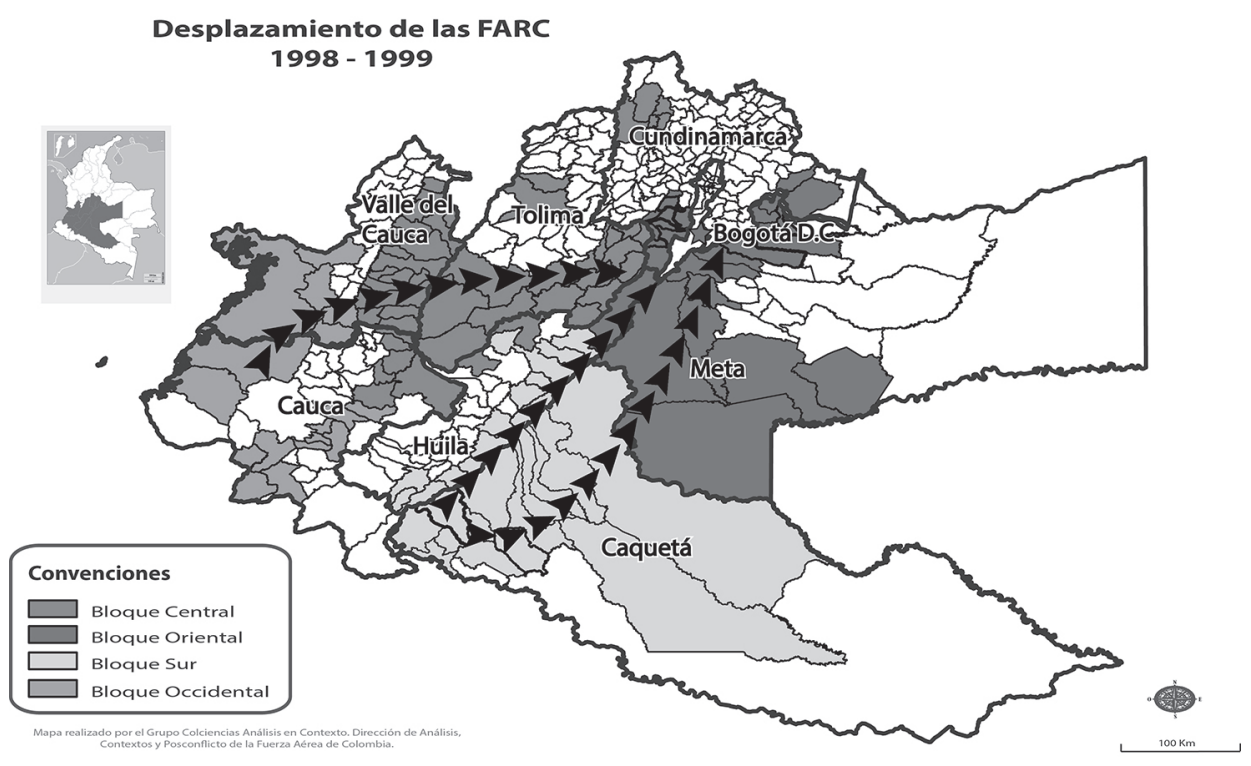

Fuente: Garzón, Daniel (2016) 
Sobra decir lo importante que fue impedir este movimiento de las FARC, y conmemorar el esfuerzo y sacrificio que significó repeler estas ofensivas violentas por parte de esta organización; pero también señalar que los indicadores de seguridad sobre el Sumapaz relevan que para el año 2005 ya no había una presencia significativa de hombres de este grupo en la región en mención, y que de hecho la presencia de las FARC en el departamento de Cundinamarca es muy baja, siendo éste uno de los cinco departamentos con menos número de acciones violentas por cuenta del conflicto armado interno (Observatorio del Programa Presidencial de Derechos Humanos y DIH, 2015).

\section{Transformaciones en las políticas de seguridad en Colombia en la década del noventa}

En la decada de los años ochenta, con la puesta en marcha de la Séptima Conferencia de las FARC (1983), se definen los lineamientos políticos y militares de la organización ilegal, según PIZARro "esta le da al movimiento una clara concepción operacional y estratégica como ejército revolucionario, lo que marcó un reajuste de todos sus mecanismos de dirección y mando." (PIZARRo, s.p, p. 188) Así mismo, es bajo este contexto que las FARC deciden cambiar su modo de operar, bajo el Plan Cisne 3 el cual consistía en la ubicación, asedio, asalto y copamiento de unidades militares. De esta manera, las FARC empiezan a proyectar desde los años ochenta su guerra irregular, bajo la concepción de la guerra popular prolongada.

Para entender la estrategia de las FARC, es necesario partir de la premisa que sus objetivos militares y políticos están alineados y funcionan bajo una lógica de inter acciones que apuntan a un solo fín. Esto según la premisa de Vicente Torrijos quien afirma que:

"La sincronización que hacen las FARC entre lo político y lo militar es la clave para entender cómo es que pretenden hacerse al poder o influir decididamente en él. Esa sincronización conduce a la idea de que lo político y lo militar no van en paralelo,como dos líneas cercanas pero que nunca se tocan. No. En realidad, lo político y lo militar se hallan fundidos en una lógica de interacciones sirviendo al mismo fin que no es otro que acceder al poder mediante un proceso revolucionario." (ToRRIJOS, 2009, p. 176).

En el contexto de las Fuerzas Militares, a finales de los años ochenta, se produce un cambio en la estrategia y la doctrina de las instituciones castrantes, en donde estas van a prepararse para la guerra irregular. De esta manera, en el año 1987 se "propició la creación y activación de los llamados Batallones de Contraguerrilla y el cambio de la preparación de los oficiales con un marcado énfasis al combate irregular, la nueva estrategia de las FARC volvería a señalar el cambio tanto en la conformación del Ejército..." (Del Valle, 2015, p. 9). Así mismo, es bajo este contexto que nace la 
Brigada Móvil No. 1, en donde se evidencia cómo las Fuerzas Militares cambian su estrategia militar para adecuarse al nuevo ambiente operacional. Sin embargo, cuando se produce este cambio, y siguiendo los lineamientos de la Séptima Conferencia, "se inicia un vertiginoso crecimiento de las FARC" (PIZARro, s.p) Por otro lado, "a mediados de la década y para enfrentar las acciones guerrilleras poco a poco fue surgiendo el concepto de apoyo mutuo entre el Ejército, la Armada y la Fuerza Aérea" (Río, 2008, p. 346). Esto porque anteriormente, no había un trabajo conjunto entre las Fuerzas Militares.

Ahora bien, con el gobierno de Cesar Gaviria, la situación de seguridad y defensa cambió, ya que durante este gobierno se evidenció una voluntad política para acabar con los grupos armados ilegales. El contexto político durante esta época estuvo caracterizado por una maniobra política y militar que estaba enfocada en la estrategia nacional contra la violencia y la política de negociación. Dentro de estas estrategias dos hechos marcaron la dinámica del conflicto armado colombiano, los cuales fueron el ataque a Casa Verde mediante la Operación Colombia, y la elección de los miembros de la Asamblea Constituyente; lo cual indicaba que el sistema político colombiano se estaba transformando.

\begin{abstract}
"Durante el primer semestre de gobierno ocurrieron dos acontecimientos que marcaron una coyuntura que permite descifrar la lógica subyacente en la evolución del conflicto armado colombiano al comienzo de la última década del siglo pasado. En efecto, en la madrugada del 9 de diciembre de 1990, se inició la operación militar sobre Casa Verde, sitio donde estuvo ubicado el cerebro dirigente de las FARC, desde 1983, ejerciendo un status político de hecho y al mismo tiempo se abrieron las urnas para elegir popularmente a los miembros de la ANC (Asamblea Nacional Constituyente)". (VELASQUeZ, 2006).
\end{abstract}

De esta manera, el Gobierno Nacional mostró la voluntad política de atacar al Secretariado de las FARC, utilizando sus capacidades militares tanto aéreas como terrestres. Este hecho generó un precedente ya que el Estado Colombiano mostró una iniciativa estratégica al atacar un centro de gravedad de la guerrilla, que en este caso era el Secretariado. "Por medio de inteligencia se prepara para un plan maestro que pretendía acabar con el corazón de las guerrillas como lo fue la operación Colombia con el fin de atacar la Uribe y el secretariado de las FARC (...) dicho ataque se preparó con antelación y se utilizó por primera vez un contingente de todas las aéreas, infantería, fuerza aérea, helicópteros helicoportados, y contrainsurgencia." (VALENCiA \& InSUASTY, 2011). Otro hecho generado a partir de la Operación Colombia, radica en que después de la operación, las FARC solicitan iniciar las conversaciones de paz con el Gobierno, lo cual demuestra como una operación militar altera el contexto político del Estado. "Es necesario generar previamente un entorno o contexto político militar que induzca la merma en la intensidad del conflicto, para hacer más viable la negociación." (VelasqueZ, 2006, p. 159). Sin embargo, cuando solicitan esta 
petición al Gobierno en el transcurso de 72 horas después de ese 9 de diciembre de 1990, las FARC se repliegan. De esta manera, si la ofensiva de las Fuerzas Militares hubiera continuado, muy seguramente la organización hubiera quedado aún más debilitada. Empero, como las Fuerzas Militares siguen las directrices y las instrucciones del Presidente de la República, quien tiene la responsabilidad de mando como comandante en jefe de las Fuerzas Militares, para ese momento no se tenía permitido ni siquiera prender los helicópteros.

Después de Casa Verde, Según Echandía “la organización insurgente logró avanzar en el proceso de especialización de sus frentes y la creación de grupos de choque, como las columnas móviles." (Echandía \& BECHARA, 2006).

Así mismo, "la administración de Gaviria, buscó marcar un cambio en relación con las Fuerzas Armadas: "Inicia su gobierno con unas políticas más claras y parece apuntar a un control civil del orden público, por primera vez en el país, asumiendo la responsabilidad que le compete al Estado en el manejo de estos asuntos." (VARGAS, 2002, p. 73). Como política de seguridad del Gobierno, Gaviria creó la Estrategia Nacional de Violencia, según Francisco Leal "la estrategia reconoció la multiplicidad de formas de violencia, incluida la producida por el Estado". Hizo un importante esfuerzo por identificar las principales relaciones sociales de este fenómeno y formuló un tratamiento para cada una de sus manifestaciones, que involucraba al conjunto del Estado." (LEAL, 2002). Esto refuerza la tesis de la voluntad política del Gobierno para mejorar las condiciones de seguridad del país, en donde primero se constituye una política de seguridad, se mejoran las relaciones cívico-militares, y se genera un contexto político para un proceso de paz. "Según la Estrategia, para erradicar el flagelo de la violencia era indispensable hacer compatibles los objetivos generales con las particularidades regionales. Para ello era necesario comprometer a los gobernadores, los alcaldes y los consejos seccionales y departamentales de seguridad, y contar con la opinión de todos los sectores de la población." (Leal, 2002, p. 82). En ese sentido se evidencia como el Gobierno Nacional quería articular la política de seguridad con las políticas económicas y sociales teniendo en cuenta el enfoque territorial, como manera de enfrentar los factores que causaban violencia en el país.

Así mismo, según lo señala CRUZ se produjo un "crecimiento de la guerrilla, derrotando la concepción de guerra integral, sirvió para que Gaviria acentuase la visión militar, se dieron todas las garantías, recursos y manos libres a las Fuerzas Armadas." (CRUZ, 2001, p. 227).

Por otro lado, Gaviria implementó una política de paz, "En este período culminaron las negociaciones con el EPL, el Quintín Lame y el PRT. (...). En este mismo contexto se inició un proceso de conversaciones con los alzados en armas que formaron parte de la coordinadora guerrillera Simón Bolívar y que se llevó a cabo en Caracas, Venezuela y Tlaxcala, México. El modelo de negociación 
que propuso el gobierno de Gaviria a las FARC y el ELN es el mismo esquema que se adoptó con el M19. A pesar de emplear la acción militar como una forma de ganar peso en las negociaciones, la FARC y el ELN discutirían, en su seno, la validez de la lucha armada" (LoPEZ, 1999, p. 253).

Ahora bien en cuanto a la dinámica del conflicto armado, "los combates por iniciativa de las Fuerzas Militares incrementaron en virtud de la llamada "guerra integral contra la guerrilla" lanzada tras el fracaso de los diálogos de paz con la Coordinadora Guerrillera Simón Bolívar (CGSB). La proporción entre los combates iniciados por las Fuerzas Militares y las acciones de las FARC aunque siguió siendo desfavorable al Estado, mejoró ostensiblemente.” (EchANDÍA, 2011, p. 8).

En ese sentido, el Gobierno de Gaviria implementó una táctica de seguridad mediante la implementacion de la Estrategia Nacional contra la Violencia, la cual se constituyó como la política de seguridad del Gobierno. Así mismo, con la Operación Colombia demostró la voluntad política y la iniciativa estratégica para atacar a la organización ilegal, hecho que se marcó como un punto de inflexión del conflicto armado colombiano, por la alteración de las dinámicas propias del conflicto. Esto porque demostró que el Estado es quien debe ostentar el monopolio legítimo de la violencia, el cual tiene unas instituciones militares encargadas de la seguridad y defensa del Estado y la Nación. Así mismo, esta operación demostró que las Fuerzas Militares pueden trabajar conjuntamente, generando precedentes posteriores.

Durante la presidencia de Ernesto Samper, la situación de orden público en el país se ve fuertemente afectada por el incremento de los ataques de los actores armados ilegales, como los efectuados por las FARC con Las Delicias, El Billar, Miraflores,Patascoy y Mitú. "las FARC durante el gobierno de Ernesto Samper (1994-1998) buscaron mediante la ejecución de una serie de acciones contundentes desbordar la capacidad de reacción y contención de la Fuerza Pública." (Echandía, Camilo, 2011, p. 8). Estos ataques tuvieron un antecedente que fue la Octava Conferencia de las FARC, en donde las "FARC comienzan a concentrar un número enorme de su fuerza en el país." (PizARro, s.p, p. 188). Esto responde a la estrategia militar para descartar al Estado y las Fuerzas Militares tratando de dispersarlas. Así mismo las FARC empiezan a implementar una estrategia centrípeta, la cual consistía en "la creación de unidades militares capaces de cercar y aniquilar bases y tropas de élite del Ejército oficial, (...) la doctrina militar va a encontrar en este contexto un terreno apropiado para desplegar plenamente sus potenciales." (PIzARro, s.p, p. 188).

Según Echandía, "El balance de fuerza, que es desfavorable al Estado, tuvo el agravante de que la tendencia ascendente en los combates de las Fuerzas Militares con las FARC a partir del fracaso de las negociaciones en el Gobierno Gaviria, se invirtió a partir de mediados de 1997 cuando comienzan a caer en picada hasta julio de 1998." (2011). 
Así mismo, bajo este contexto y con la creación de las empresas de seguridad privada, las Convivir, las autodefensas ilegales empiezan a enfrentarse con la guerrilla "Los cambios experimentados recientemente también muestran cómo los grupos paramilitares (sic) se involucraron a partir de 1996 en la dinámica de la guerra y logran romper la retaguardia del ELN, que pierde hegemonía en una franja del territorio que abarca desde el nordeste antioqueño hasta Norte de Santander." (ECHANDÍA, 2004, p. 5).

De esta manera, el Gobierno Nacional demostró que no tenía la capacidad política y militar para enfrentar la amenaza que representaban las FARC para ese entonces, así como otros actores armados ilegales como eran las autodefensas. Esto también se vio perjudicado por el ambiente internacional, en donde la comunidad internacional veía el contexto colombiano con preocupación, hasta el punto de llegar a declarar a Colombia como Estado Fallido. "Uno de los ejemplos en el que un elemento exógeno aportó a la identificación de que Colombia estaba ad portas de constituirse en un "Estado fallido" fue el proceso anual de certificación de Estados Unidos en materia de lucha contra las drogas" (Tokatlian, 2008). Esto porque además durante el gobierno de Samper, con el proceso 8.000 el Estado Colombiano perdió credibilidad y legitimidad, afectando la seguridad y defensa, ya que por ejemplo los recursos en materia de cooperación militar disminuyeron. Esto perjudicó la acción de las Fuerzas Militares ya que no contaban con los recursos económicos para poder enfrentar la amenaza.

"La crisis moral y política del gobierno le resta legitimidad para imponer las condiciones a los militares y ofrecer suficientes garantías para el desarrollo de las negociaciones. La relación de tensión con los Estados Unidos en torno a la extradición de nacionales y las investigaciones adelantadas por la fiscalía a miembros de la campaña y del partido oficialista, derivó en una coyuntura de crisis política y baja credibilidad en el gobierno de turno." (LopEZ, 1999, p. 12).

Cuando inició el período presidencial de Andrés Pastrana (1998-2002), la dinámica del conflicto armado estaba caracterizada por los enfrentamientos que se realizaron entre la Fuerza Pública y la organización ilegal. Es, bajo este contexto, que en 1998 se produce la Toma de Mitú, la cual estaba enfocada a demostrar la capacidad militar y política de las FARC. Sin embargo, bajo la Operación Vuelo de Ángel las Fuerzas Militares recuperan la iniciativa estratégica, ya que demuestran que mediante la utilización del poder aéreo, estas pueden obtener la ventaja estratégica por las capacidades de reacción y apoyo aéreo.

Además, esta operación logró alterar la estrategia de las FARC, ya que las obligó a retroceder a la guerra de guerrillas, esto porque con los ataques al Billar y Mitú implicaba la concentración de guerrilleros en unidades de masa, las cuales quedaban expuestas al poder aéreo. "La Operación Vuelo de Ángel marcó un punto de quiebre en el conflicto colombiano, porque esta operación 
frenó la avanzada guerrillera. Gracias al poder aéreo demostrado, se dieron de baja a muchos guerrilleros, lo cual permitió inclinar la balanza hacia el Estado Colombiano. Así mismo, con esta operación se alteró la correlación de fuerzas entre las FFMM y las FARC-EP.” (SANTOS, 2016, p. 136).

Por otro lado, el contexto político durante el Gobierno de Andrés Pastrana estuvo caracterizado por la transformación de las Fuerzas Militares, la cual se vio fortalecida por la implementación y consolidación del Plan Colombia. Esto porque el Plan le otorgó a las Fuerzas Militares mejores recursos tecnológicos para poder operar. Por ejemplo, "los fondos destinados para la asistencia militar 328 millones (63,2 \%) son para comprar helicópteros (208 para Black Hawks y 120 para Hueys)" (LeAL, 2002, p. 181). Esto alteró la dinámica del conflicto armado y le otorgó a las Fuerzas Militares la capacidad militar ofensiva. De igual forma, el Plan Colombia fue la reacción del Estado frente a una amenaza, en donde la política exterior sirvió para la seguridad del Estado. "El PC estableció el marco institucional de cooperación bilateral entre el Gobierno de los Estados Unidos y el Gobierno de Colombia para: i) fortalecer las capacidades operacionales de la Fuerza Pública contra la cadena de producción del narcotráfico y la lucha contra los Grupos Armados al Margen de la Ley (GAML)." (DNP, s.p) En ese sentido, el Plan Colombia estaba enfocado en atacar las dos principales amenazas para el Estado representadas en el narcotráfico y los grupos armados al margen de la ley, mediante la repotenciación de las capacidades militares.

\begin{abstract}
"Adicional a la profesionalización, tres aspectos permiten visibilizar la modernización de la Fuerza Pública. En primer lugar, se presentó una mejor coordinación entre las FF.MM., a través de las fuerzas de tarea conjunta. En segundo lugar, el sector de Seguridad y Defensa sustituyó el armamento y material de guerra, fortaleció los sistemas de comunicaciones, planeación, investigación criminal, inteligencia y de equipo logístico. Y por último, la Fuerza Pública adquirió nuevas tecnologías ofensivas que permitieron neutralizar grandes concentraciones guerrilleras y mejorar los tiempos de respuesta ante acciones unilaterales de los GAML.” (DNP, s.p)
\end{abstract}

Este plan modificó las estructuras orgánicas de las Fuerzas Militares, ya que permitió la creación de nuevas estructuras militares, según el Departamento Nacional de Planeación en un documento realizado como balance del Plan después de 15 años , "Colombia pasó de tener menos de 35 helicópteros en 1999 a más de 200 en 2014; en el mismo período de tiempo, las brigadas móviles pasaron de 3 a 36 ; se crearon 8 batallones de alta montaña y 52 escuadrones móviles; el 100\% de sus miembros han sido capacitados en derechos humanos y Derecho Internacional Humanitario.” (DNP, s.p). Esto marcó y alteró la dinámica de confrontación del conflicto armado colombiano, ya que le dio a las Fuerzas Militares, mayor 
capacidad y maniobrabilidad, recuperando así la iniciativa estratégica ${ }^{2}$. Por otro lado, el Plan Colombio le otorgó mayor versatilidad a las Fuerzas Militares, ya que les permitió operar y tener "disponibilidad 24/7 con cambios significativos en la capacidad de operación aérea y de combate" (DÁvila, Gomis, \& SALAZAR, 2016, p. 109). Esto porque con la adquisición de los visores nocturnos, se aumentó la capacidad para combatir a los actores armados ilegales durante la noche.

Según ECHANDía una de las consecuencias de la transformación de las Fuerzas Militares es que, "la reforma militar le dio al Estado nuevas capacidades para combatir a los grupos irregulares, impidió que las FARC avanzaran en su "plan estratégico" y utilizaran de manera táctica el escenario de las conversaciones como lo había propuesto el grupo guerrillero desde el momento en que creó la Zona de Distensión (ZD) en el área correspondiente a los municipios de San Vicente del Caguán en Caquetá y Uribe, Mesetas, Vistahermosa y La Macarena en Meta." (ECHANDía, 2011, p. 15).

De esta manera, mientras que se producía la transformación de las Fuerzas Militares, el Presidente Pastrana también optó por una negociación de paz con las FARC. "El pedido hecho por las FARC a comienzos de 1998, de desmilitarizar los municipios de San Vicente del Caguán, La Uribe, Mesetas, la Macarena, y Vista Hermosa, como requisito para iniciar conversaciones de paz, fue ratificado a mediados del año y aceptado por Pastrana" (LeAL, 2002). De esta manera, se estableció la zona de distensión, la cual tenía como objetivo facilitar las conversaciones. Sin embargo, las FARC aprovecharon la situación política para seguir violando los Derechos Humanos de la población civil, así como mantener y asegurar su estrategia de la toma del poder.

\begin{abstract}
"Al efecto la inteligencia aérea jugó un gran papel en la obtención de información confiable que llevaron al Ejecutivo a decidir la suspensión del diálogo de paz y recuperar la zona de distensión (Comando Aéreo de Combate No. 1-CACOM-1, 2002). Información que constató las vías terrestres de acceso, pistas de aterrizaje ilegales, infraestructuras para mantenimiento y resguardo de transporte vehicular, crecimiento de los cultivos de coca, relaciones con terroristas internacionales en la zona despejada y, además, la continuación de atentados terroristas, secuestros y ataques a poblaciones." (Marín, Castiblanco, Castrillon, y Cotrina, 2016, p. 105).
\end{abstract}

En ese sentido, con la retoma de la Zona de Distensión, con la transformación militar y el Plan Colombia, las Fuerzas Militares demostraron que el Estado Colombiano tenía las capacidades militares para recuperar los municipios de la Zona de Distension, al igual que se evidenció la iniciativa estratégica del Alto Gobierno.

Por otro lado, dentro de las adquisiciones del Plan Colombia se encuentran la compra de "H-1N Huey Helicópteros,50 UH-II Huey-II Helicópteros,20 UH-60 Black Hawk Helicópteros, Un número no determinado de misiles dirigidos (bombas inteligentes), 13 AT-802 aeronaves de fumigación 11 OV10, aeronaves de fumigación • 1 T-65 aeronave de fumigación, Caravan (transporte aéreo), Aviones no tripulados." (DNP, s.p). 
Con el Gobierno del Presidente Uribe, se creó la Política de Seguridad Democrática, la cual establecía que "La Fuerza Pública iniciará el proceso de consolidación del control estatal sobre el territorio, asegurando su presencia permanente y definitiva en todas las cabeceras municipales, con el apoyo de brigadas móviles y demás unidades de las Fuerzas Militares y de la Policía Nacional.” (Presidencia de la República, 2003, p. 16).

Producto de la conduccion estratégica del Estado en materia de seguridad y defensa, durante el Gobierno de Uribe, como lo evidencia ECHANDÍA, se alteró nuevamente la estrategia de la guerrilla:

\begin{abstract}
"A partir de 2002 es posible observar un cambio en las estrategias y los movimientos tácticos de los alzados en armas, en función de las modificaciones en la dinámica de la confrontación. La decisión del gobierno de Álvaro Uribe de enfrentar el desafío de la guerrilla con un mayor esfuerzo militar sobre las estructuras armadas ha hecho que retomen de su experiencia anterior los comportamientos propios de la guerra de guerrillas y opten por el repliegue táctico hacia sus zonas de refugio, lo cual se expresa en una disminución operativa a nivel nacional." (ECHANDÍA \& BECHARA, 2006, p. 37).
\end{abstract}

Igualmente, dentro de la política de seguridad democrática se establecieron como amenazas el terrorismo, las drogas ilícitas, las finanzas ilícitas, el tráfico de armas, municiones y explosivo, el secuestro y la extorsión, el homicidio. (Presidencia de la República, 2003).

Teniendo en cuenta las dinámicas del conflicto, en el 2004 se crean las Fuerzas de Tarea Conjunta,como respuesta para afrontar el problema de seguridad y defensa que representaban en ese momento las organizaciones ilegales como las FARC. "Fue así como en el año 2004 se produce una de las mayores trasformaciones en la historia de las Fuerzas Militares de Colombia, creando unidades conjuntas que hoy, aunque con modificaciones de enfoque, siguen expandiéndose en el país y dando resultados valiosos para la recuperación de la seguridad en puntos críticos de la geografía nacional.” (FLóREz, 2012, p. 54). Estas Fuerzas de Tarea Conjunta buscaban articular las capacidades del Ejército Nacional, la Armada y la Fuerza Aérea, mediante la focalización y la acción conjunta.

Se da entonces como premisa de la Política de Seguridad, como lo afirmó Marta Lucía Ramírez en la carta de presentación de la política, "La Fuerza Pública dará el primer paso en este esfuerzo de articular una respuesta integral a los retos de seguridad. El segundo lo debe dar el Estado en su conjunto y el tercero, toda la sociedad." (Presidencia de la República, 2003, p. 8). Esto significaba que la concepción de seguridad iba más allá de tratar el problema con la organización ilegal FARC y otros actores armados, la seguridad debía consolidarse también con otras instituciones del Estado y contar con la participación y apoyo de la población civil. De esta manera, es bajo el Gobierno del Presidente Uribe que se 
puede afirmar que el famoso tríangulo de Clausewits, Estado, Población y Fuerzas Militares se completa, ${ }^{3}$ esto porque por la política de seguridad y los resultados operacionales, la población civil se da cuenta que las Fuerzas Militares estaban recuperando el territorio.

Esto se demuestra con la implementación de diferentes planes como el Plan Patriota, el cual tenía como objetivo la recuperación territorial de unos departamentos:

“La favorabilidad militar del Estado (...) se acentúa durante este período en el marco de la Política de Seguridad Democrática del ex presidente Álvaro Uribe (2002-2010) gracias a la implementación de planes de recuperación territorial como el Plan Patriota en 2004 con énfasis en Meta, Guaviare y Putumayo, los Planes Libertad I y II (en 2003 y 2005) en Cundinamarca y Tolima; la operación Marcial en el Oriente antioqueño y otras operaciones en las zonas de Montes de María y Arauca." (Prieto, Rocha, \& Marín, Seis tesis sobre la evolución reciente del conflicto armado en Colombia, 2014).

De esta manera, puede afirmarse que la Política de Seguridad Democrática, "se construyó sobre un conjunto integral de estrategias que incluían el control del territorio y la defensa de la soberanía, la desarticulación de los GAI y de las organizaciones dedicadas a la producción y tráfico de drogas, el fortalecimiento del servicio de justicia y la atención del Estado en zonas deprimidas y de violencia." (RENTERÍA, 2008, p. 4). Dentro de los logros obtenidos de la Política se encuentra "la neutralización de los frentes guerrilleros que rodeaban a Bogotá, la desarticulación de las milicias que operaban en la capital antioqueña y, en general, el profundo debilitamiento de las estructuras armadas de la insurgencia." (RENTERÍA, 2008, p. 5). Durante el período 2003-2009 hubo una disminución del conflicto por la política de seguridad del Gobierno Uribe, esto según una investigación realizada por la Universidad del Norte. (Universidad del Norte, 2016, p. 2).

Ahora bien, después de la reelección del Presidente Álvaro Uribe, se establece la Política de consolidación de Seguridad Democrática, la cual "se fundamenta en la articulación institucional de las diferentes entidades del Estado, en el esfuerzo militar y policial, el apoyo de la población civil y la cooperación internacional." (RENTERÍA, 2008). Esta buscaba reforzar y articular las acciones de las instituciones del Estado, para solucionar el problema de seguridad integralmente, y no solo bajo el liderazgo de las Fuerzas Militares. De aquí que "para alcanzar el objetivo de consolidación, el Plan Nacional de Desarrollo 2006-2010 plantea tres estrategias fundamentales: el control del territorio y defensa de la soberanía nacional, el combate al problema de las drogas ilícitas y al crimen organizado, y el fortalecimiento de las políticas de convivencia y seguridad ciudadana." (RENTERÍA, 2008, p. 7).

Según Clausewits, la trinidad de la guerra está compuesta por el pueblo, el segundo, al comandante en jefe y a su ejército, y el tercero, solamente al gobierno (2003). 
Por otro lado, con las Políticas de Seguridad del Gobierno Uribe, la dinámica del conflicto armado interno cambió y trajo como resultado que:

“1) En 2007 se llegó al pico en los combates por iniciativa del Ejército de los 25 años estudiados; 2) En 2008 el accionar armado de las FARC disminuyó significativamente en comparación con la situación de 2003; 3) las FARC, debilitadas, se replegaron hacia zonas fronterizas como Putumayo, Nariño, Cauca, Catatumbo en Norte de Santander y Arauca, y 4) las FARC perdieron su capacidad para cometer grandes ataques a poblaciones e instalaciones militares, por lo que enfocan su accionar en eventos que requieren de poca movilización de personal y recursos.” (Prieto, Rocha, \& Marín, 2014, p. 10).

Durante el 2008-2010, "las ofensivas desarrolladas por la fuerza pública continuaron siendo superiores a la actividad armada de las FARC, a lo que se suman los esfuerzos del Estado por dar con el paradero de los comandantes de bloques y frentes más importantes de la agrupación (PRIETO, RochA, \& MARÍN, 2014). Desde el Ejecutivo se evidenciaba una política dirigida contra las FARC, y la focalización de la estrategia de seguridad, mediante los objetivos transcendentales de alto valor, que dieron como resultado bajo la operación Sodoma, la muerte de Jorge Briceño, alias el Mono Jojoy; esto va a alterar la táctica de las FARC, en la medida en que se impacta un objetivo de alto valor. Por otro lado, las FARC, "para contrarrestar su debilitamiento, en 2008 (...) ponen en marcha el Plan Renacer que bajo un principio de economía de la fuerza, logra aumentar levemente su iniciativa armada con la activación de artefactos explosivos, hostigamientos, ataques con francotirador y contra la infraestructura económica." (Prieto, Rocha, \& MARÍn, 2014, p. 11).

\section{CONCLUSIONES}

Este documento evidencia las transformaciones en el terreno de la seguridad que experimentó Colombia en la década de los años noventa, gracias al desarrollo de políticas de seguridad de Estado, integrales y con el apoyo de la cooperación internacional; y al enorme sacrificio que los miembros de la Fuerza Pública desplegaron para garantizar la tranquilidad de la sociedad.

Así, en la primera parte del documento, quedó evidenciado que el conflicto colombiano debe ser entendido y dimensionado de forma territorial, entendiendo las particularidades de cada región del país, y la de los grupos específicos que operan en cada uno de estos territorios. Ello podría llevar a señalar que aunque los actores armados tienen una estructa jerárquica que impone unos lineamientos comúnes (por ejemplo alinear a las FARC para acercarse a la capital), en el fondo cada región experimenta el conflicto de una forma específica y diferenciada. 
Durante todos los años de servicio, evidencié los cambios que se presentaron en el conflicto colombiano, y fui testigo de los momentos más cruentos de la violencia que azotó al país; pero también tuve la suerte de hacer parte de la Fuerza Aérea Colombiana, y de experimentar las transformaciones de seguridad que el actuar de las instituciones militares le dieron al país.

Estas transformaciones están ampliamente documentadas en cifras oficiales y en reportes académicos, así que el plusvalor (uno de ellos) de esta investigación está en detallar las estrategias de movilidad que quiso desarrollar las FARC, y en evidenciar cómo fueron repelidas y desbaratadas todas ellas.

El lector encontrará una cartografía del conflicto armado colombiano, en la que se representan los corredores estratégicos que se quisieron configurar durante la década del noventa; corredores que desembocaban en Bogotá, pero que a la vez eran utilizados como rutas para la entrada de armas y la salida de drogas.

En ese contexto, también se experimentaron oscilaciones en las políticas de seguridad que cada gobierno desarrolló, con directas consecuencias sobre la dinámica del conflicto armado colombiano. Estas políticas, a su vez, estuvieron alineadas con las doctrinas de seguridad que emanaron del ambito internacional, y lograron que en un momento particular se configuraran armoniosamente, a través, por ejemplo, del Plan Colombia, y de los valiosos recursos de inversión que con éste entraron al país.

Así se teje la última conclusión de este documento: no es posible lograr victorias decisivas en el marco del conflicto armado interno, si no hay una plena articulación entre el poder político (Ejecutivo) y el poder militar. Para las Fuerzas Militares es fundamental y gratificante, trabajar de la mano con gobiernos que son dolientes del tema de la seguridad y que apoyan irrestrictamente a sus Fuerzas en el camino por labrar la paz del país.

\section{REFERENCIAS}

\section{Capítulos de libro}

Dávila, A., Gomis, M., \& Salazar, G. (2016). el Conflicto en Contexto 19982014. En A. Dávila, G. SAlazAR, \& A. GonzÁlez, El conflicto en contexto: un análisis en cinco regiones colombianas 1998-2014. Bogotá: Editorial Universidad Pontificia Javeriana.

LEAL, F. (2002). Nuevos temas para la agenda de seguridad nacional gobierno de Cesar Gaviria Trujillo, 1990-1994. En F. L. BuITRAGo, La seguridad nacional a la deriva: del Frente Nacional a la posguerra fría. Bogotá: Alfaomega.

Marín, A., Castiblanco, C., CAstrillon, J., \& Cotrina, A. (2016). La zona de distensión y su recuperación por la Fuerza Aérea Colombiana. En R. 
Esquivel, A. Marín, C. Castiblanco, J. Castrillón, A. Cotrina, M. SanTOS, . . J. GARCÍA, La Fuerza Aérea Colombiana y el término del conflicto armado:Victorias desde el aire. Bogotá: Impress Colombia.

Clausewits, K. (2003). De la guerra. Obtenido de El Cid Editor : http://lahaine. org/amauta/b2-img/Clausewitz\%20Karl\%20von\%20-\%20De\%20la\%20 guerra.pdf

Cruz, A. (2001). El dilema de la paz: renuncia a las armas o reformas estructurales. En J. M. Manuel Alcántara, Colombia ante los retos del siglo XXI: desarrollo, democracia y paz. Salamanca: Universidad de Salamanca.

Del VAlLe, W. (2015). Perfil del oficial del ejército en el postconflicto. Obtenido de Universidad Militar Nueva Granada: http://repository.unimilitar.edu.co/ bitstream/10654/13563/1/PERFIL\%20DEL\%20OFICIAL\%20DEL\%20 EJ\%C3\%89RCITO\%20NACIONAL\%20EN\%20EL\%20POSTCONFLICTO.pdf

DNP. (s.p). Departamento Nacional de Planeación. Obtenido de Plan Colombia: Balance de los 15 años: https://colaboracion.dnp.gov.co/CDT/Sinergia/ Documentos/PLAN_COLOMBIA_Boletin_180216.pdf

ECHANDÍA, C., \& BeChARA, E. (2006). Conducta de la guerrilla durante el gobierno Uribe Vélez: de las lógicas de control territorial a las lógicas de control estratégico. Análisis Político(57).

ECHANDÍA, C. (2004). La Guerra por el Control Estratégico en el Suroccidente Colombiano. En Revista Sociedad y Economía(7).

ECHANDÍA, Camilo. (2011). Situación actual de las FARC: Un análisis de los cambios en las estrategias y la territorialidad (1990-2011). Obtenido de Fundación Ideas para la Paz: www.ideaspaz.org/publications/posts/78

Flórez, J. (2012). La doctrina conjunta en Colombia: análisis de la fuerza de tarea conjunta omega. Obtenido de Universidad Nacional de Colombia: http://www.bdigital.unal.edu.co/7724/1/699243.2012.pdf

LEAL, F. (2002). Nuevos temas para la agenda de seguridad nacional gobierno de Cesar Gaviria Trujillo, 1990-1994. En F. L. Buitrago, La seguridad nacional a la deriva: del Frente Nacional a la posguerra fría. Bogotá: Alfaomega.

LóPez, W. (1999). Las políticas de paz y los procesos de negociación en colombia. breve balance y perspectivas. En: Revista Convergencia.

PizARRo, E. (s.p). Las FARC-EP ¿Repliegue estrategico, debilitamiento o punto de inflexión? . En E. Pizarro, Las FARC-EP ¿Repliegue estratégico, debilitamiento o punto de inflexión? Bogotá. 
Presidencia de la República . (2003). Politica de Defensa y Seguridad Nacional. Obtenido de Organizacion de Estados Americanos: www.oas.org/csh/spanish/documentos/colombia.pd

Prieto, C., Rocha, C., \& Marín, I. (2014). Fundacion Ideas para la Paz. Recuperado el 13 de julio de 2016, de Seis tesis sobre la evolución reciente del conflicto armado en Colombia: http://cdn.ideaspaz.org/media/website/ document/5436b8cdbf6e1.pdf

Prieto, C., Rocha, C., \& Marín, I. (2014). Seis tesis sobre la evolución reciente del conflicto armado en Colombia. Obtenido de Fundación ideas para la paz: cdn.ideaspaz.org/media/website/document/5421e84004722.pdf

ReNTERÍA, C. (2008). La Consolidación de la Política de Seguridad Democrática en el Plan Nacional de Desarrollo 2006- 2010. En: Revista Fuerzas Armadas Escuela Superior de Guerra: http://www.cgfm.mil.co/documents/10184/24774/ edicion+205.pdf/68c91 add-7eae-4a1d-8e32-643fca307ddc

Río, C. T. (2008). Conflicto interno y Fuerzas Armadas Colombianas 1982-2002. En

C. T. Río, De milicias reales a militares contrainsurgentes la institución militar en Colombia del siglo XVIII al XXI . Bogotá: Editorial Pontificia Javeriana.

Santos, M. A. (2016). La operación Vuelo de Ángel,punto de inflexión del conflicto armado colombiano. En Esquivel, C. Castiblanco, A. Marín, J. Castrillón, A. Cotrina, M. Santos, . . . J. García. La insistencia de las FARC en los ataques contra las instalaciones de la Policía Nacional a partir de 1997 se convirtió en todo un propósito estratégico inscrito en el desarrollo de planes de guerra dispuestos a lograr el control de zonas especificas cada. Bogotá: Impress Colombia.

Tokatlian, J. (2008). La Construcción de un "Estado Fallido" En La Política Mundial: El caso de las relaciones entre Estados Unidos y Colombia. Análisis Político, 21(64).

Torrijos, V. (2009). El poder y la Fuerza.En la unidad político-militar está la verdadera capacidad estratégica de la organización armada. En V. Torrijos, Crisis, Paz y Conflictos. Bogotá: Editorial Universidad del Rosario.

Valencia, J., \& Insuasty, A. (2011). Evolución de las estrategias de guerra en Colombia: ¿Cómo han evolucionado las estrategias de guerra utilizadas por el ejército colombiano en la historia de Colombia, 1 desde 1930 hasta 2006. El Ágora USB, , 11(1).

VArgas, A. (2002). Las Fuerzas Armadas colombianas y las concepciones de seguridad y defensa. En A. VARgas. Las Fuerzas Armadas en el conflicto colombiano: antecedentes y perspectivas. Bogotá: Intermedio. 
Velásquez, C. A. (2006). El ambito político en el conflicto armado con las FARC:1990-2006. En: Revista de Relaciones Internacionales, Estrategia y Seguridad, 1(2). 


\title{
LAS FRONTERAS NO ADYACENTES, COMO SOLUCIÓN AL TRÁFICO AÉREO ILEGAL
}

\author{
Brigadier General HENRY QUINTERO BARRIOS ${ }^{l}$
}

El propósito de este documento es interpretar qué se puede entender por fronteras no adyacentes y evidenciar cómo están presentes en el fenómeno del movimiento aéreo ilegal, y la forma en que se ha logrado controlar esta actividad por parte de la Fuerza Aérea Colombiana, por medio de diferentes estrategias que involucran a otras entidades, agencias, organizaciones y países, a través de la metodología de seis sigma, y su impacto en el tema fronterizo, entre el año 2003 y 2013, como un programa efectivo.

En primer término es necesario enfocarse en qué se entiende por frontera, y su planteamiento desde diferentes perspectivas, tanto históricas, como realistas o ideológicas y culturales con el fin de poder entender el desarrollo de esta área y cómo impacta el devenir de una nación, así mismo el origen, no solamente del término mismo, sino de su realidad geográfica y cuál es el papel que cumple en la actualidad.

La definición de frontera tal como se le conoce hoy en día ha sido una evolución que viene desde la antigüedad, aunque el término convencional de demarcación de un país con respecto a otro en la antigüedad partía de la consideración del propio país como centro de poder y civilización y al resto se le consideraban pueblos bárbaros, obviamente desde la óptica de superioridad cultural, política y militar del país en cuestión, y desde entonces se denomina límite (o marca) a la localización geográfica de "tierra de nadie" u "otra tierra", que separa dos realidades, con una connotación política sobre una realidad geográfica contrastable. Tanto en la antigüedad, como en el medioevo (FERNÁNDEZ-CARrión, 2010, p. 3), con diferentes conceptualizaciones y en muchos casos adaptada a las necesidades de los gobernantes de turno.

Inicialmente, hay que considerar las diferencias entre frontera y límite, y etimológicamente Julio Casares en el diccionario ideológico de la lengua española indica que por límite, se entiende el término o lindero de reinos, posesiones, etc.,

Jefe de la Jefatura Tecnologías de la Información JETIC. Administrador Aeronáutico, Magíster en Estrategia y Geopolítica de la Escuela Superior de Guerra; especialista en telecomunicaciones. 
e incluso figuradamente como el fin, o término. Mientras que, frontera, es el límite o confín de un Estado (CASARES, J., 1995), dentro de este contexto se ve como una definición se ajusta a un significado geográfico, mientras la otra hace referencia a un contexto político.

Por otra parte, es Frederick Jackson Turner quien inventa el término frontera, en 1893, en "El significado de la frontera en la historia americana", "la frontera es el borde exterior de la ola, el punto de contacto entre la barbarie y la civilización" (TURNER, 1893, p. 188), y la hace sinónima del espíritu nacional norteamericano. Posteriormente, Michel Foucher en L'Invention des frontières, se cuestiona la frontera desde una doble perspectiva, como estrategia política interna o nacional o como poder geopolítico a nivel internacional (1987).

En la actualidad el término frontera reúne la concepción geográfica y política, cultural, étnica, económica, etc. que existe entre dos o más países. Por esto, se puede hablar de frontera nacional, regional, continental, religiosa hasta personal, de un individuo o colectivo con respecto al conjunto del que se pretende diferenciar. Por ello, la frontera puede hacer mención a un colectivo, como a un individuo, a un país como a una región, a una localización geográfica, como una realidad política hasta una diferenciación cultural, religiosa o económica. Aunque, normalmente predominará la concepción de frontera como sinónima de una realidad política, localizada dentro de unas coordenadas geográficas determinadas por encima del resto de las demás consideraciones etimológicas del término indicadas. (FERNÁNDEZ-CARRIón, 2010, p. 4).

En 1980, Jean Gottmann, se cuestiona la frontera indistintamente como línea o zona ("la frontière est une ligne ou une zone"), mientras que, ese mismo año, John House entiende como frontera ('frontier') la zona que se extiende a los dos lados de una línea que marca una frontera ('boundary')...En este mismo sentido, Michael Foucher en L'Invention des frontières resalta que por una cuestión semántica, y añadiré personalmente que política, a partir de Turner, los norteamericanos consideran la frontera como la conjunción de "the frontier" (frontera) y "boundary" (límite), y por ello el autor defiende la diferenciación lingüística propuesta por otros investigadores franceses que consideran como "frontières" el término geopolítico por excelencia, en el que se diferencia entre "ligne et zone correspondent" (entre línea y zona de frontera). (FouCHER, 1987, p. 38), así se plantea la diferencia de manera expresa entre límite y zona de frontera, una concepción geográfica y una política.

Para el caso de Hispanoamérica existe una unidad política, jurídica, económica, social, religiosa, lingüística, etc. que es establecida por la corona castellana, como lo expresa Alfredo Jiménez Núñez en "The Spanish Colonial Model'. ( 1994, pp. 66-95). 
En el libro de Historiografía metodología y tipología de fronteras, se hace una diferenciación desde varios puntos de vista de las fronteras, y expresada inicialmente desde la perspectiva del tiempo y el espacio.

Así mismo, plantea como a través de la historia las fronteras se han definido de manera preferencial por las referencias geográficas, con lo cual establece las fronteras naturales y por concomitancia las fronteras artificiales como herencia del proceso de descolonización principalmente.

Por otra parte, la combinación de las dos categorías anteriores da origen a las fronteras mixtas, que en la actualidad se pueden ver a lo largo de frontera colombo venezolana, y que por sustracción de materia son preponderantes en la definición de límites marítimos.

Igualmente, se establece una subdivisión en las fronteras naturales referenciando fronteras territoriales e insulares, donde las insulares por antonomasia definen una relación de los países insulares con su entorno debido a la falta de relación directa y de contacto visual y físico con el país vecino.

El Doctor Miguel Héctor Fernández Carrión Director del Instituto de Estudios Históricos y Económicos en Madrid España, autor del mismo libro plantea otra diferenciación entre fronteras urbanas y rurales, pues en general en las fronteras hay espacios vacíos que se pueden definir como rurales y las que hacen referencia a centros poblados donde conviven las comunidades de dos o más Estados, como es el caso de Leticia (Colombia), Tabatinga (Brasil) y Santa Rosa (Perú), y que en la actualidad tienen libre tránsito de bienes y personas.

Por otra parte, Hartshorne en the nature of geography, entiende la existencia de "límites políticos", pero al mismo tiempo considera la formación de las fronteras políticas en relación con los procesos de poblamiento, por lo que distingue seis tipos o etapas: "fronteras totalmente anteriores o pioneras; anteriores; subsiguientes (...); sobrepuestas (...); sobrepuesta de modo excavación y reliquias (...)”(1939).

Sin embargo, las fronteras no adyacentes no se han expuesto y se plantea dicha definición como las líneas de comunicación directas que permiten el intercambio de bienes y servicios que impactan en los intereses nacionales sin la intermediación de terceros estados.

Partiendo de esta definición, se puede ver que existen acuerdos, tratados, convenios que permiten el intercambio de mercancías, personas, bienes, tanto de manera directa en forma legal, como es el caso de exportaciones, importaciones, que a su vez establecen rutas que permiten el actuar de las organizaciones que operan cometiendo delitos transnacionales y establecen a su vez líneas directas de comunicación para el tráfico de drogas, armas, trata de personas, migración ilegal, dumping, lavado de activos, etc. 
En el primer caso ingresan categorías que van desde el turismo, con la promoción de los diferentes atractivos de cada país, con excepciones de requisitos legales, y barreras comerciales, hasta el intercambio de bienes y mercancías con aranceles preferenciales, reducción de trámites y facilidades logísticas y legales que incentivan dicho intercambio, adicionalmente, se encuentran los servicios que no necesariamente requieren una presencia física en los Estados no adyacentes, sino que pueden ser provistos de manera remota y para lo cual es necesario establecer canales que permitan dicha actividad, todas estas conllevan a su reconocimiento en temas como tributación, cumplimiento de requisitos y normatividad, respeto del entorno cultural y social, idioma, costumbres etc., para ajustarse a las necesidades particulares de dicho Estado no adyacente y de las preferencias de sus habitantes con el fin de garantizar el poder competir en dichos mercados, pero desde la perspectiva política también se puede observar como un estado no adyacente es limítrofe con otro. El solo hecho de establecer una misión diplomática recorta los canales comunicacionales y de relaciones con este estado, de tal suerte que se pueden adelantar en dicha misión tareas que de otra forma involucrarían o a terceros estados o requerirían un esfuerzo adicional, así mismo la presencia de actores diplomáticos permite la participación directa de sus conciudadanos en la actividad electoral como una extensión de los derechos de los connacionales y no solamente en lo político, también en lo administrativo y en lo económico con lo cual se establecen relaciones que naturalmente están circunscritas a países adyacentes, validando nuevamente que no es geográficamente necesario ser países vecinos para tener una frontera común.

Por otra parte, desde la perspectiva geopolítica cabe anotar la relación entre estados que define Kautilya en Arthasastra, los estados vecinos son los enemigos naturales, mientras que los estados no colindantes son los aliados naturales, basado en que dicha premisa igualmente aplica para los estados vecinos quienes por su naturaleza tendrán como enemigos naturales a dichos estados y a terceros estados no colindantes como aliados naturales.

En lo referente al movimiento ilegal aéreo en Colombia, este se inició con la bonanza marimbera en la Guajira Colombiana en los años 70, fenómeno que fue migrando hacia la producción de narcóticos, y desde la producción de hoja de coca inicialmente en los 80 y en los 90 a la producción de pasta base de coca y Clorhidrato de cocaína, aumentando exponencialmente las utilidades de los grupos al margen de la ley, aprovechando que las facilidades que genera el movimiento aéreo y las debilidades existentes para el control del mismo por parte de las autoridades (KaUtiLYA, 2008).

"Los delincuentes dedicados al negocio del narcotráfico han diseñado diferentes estrategias para lograr movilizar sus mercancías a los puntos estratégicos de distribución y comercialización, logrando así continuar con la cadena de esta estructura criminal; el medio más usado en la década de los 80's (inicios del 
auge del narcotráfico) fue el terrestre, pero al ser el más controlado por la fuerza pública en esa época, tener la limitante de cobertura internacional y el tiempo excesivo de movilización, los narcotraficantes incursionaron en los medios marítimo y aéreo para efectuar sus movimientos ilegales, siendo este último el más rápido y de mayor cobertura. En consecuencia nace la preocupación de realizar un estudio de los movimientos aéreos ilegales concentrados en la región Caribe" (Devia, Iván, \& Ferreira Cardenas, 2015, p. 3).

En Colombia la administración del espacio Aéreo nacional está regida por la Unidad Administrativa Especial de Aeronáutica Civil (UAEAC), quien se encarga de hacer cumplir los convenios establecidos con la Organización de Aviación Civil Internacional (OACI), que es un organismo creado por la Organización de Naciones Unidas (ONU) en 1944, y cuya misión es "En la Aerocivil trabajamos por el desarrollo ordenado de la aviación civil, de la industria aérea y la utilización segura del espacio aéreo colombiano, facilitando el transporte intermodal y contribuyendo al mejoramiento de la competitividad del país.", que en la práctica se traduce en la gestión del espacio aéreo para que las aeronaves legales vuelen con seguridad.

Por otra parte, "La Fuerza Aérea Colombiana ejerce y mantiene el dominio del espacio aéreo, conduce operaciones aéreas, para la defensa de la soberanía, la independencia, la integridad del territorio nacional, el orden constitucional y el logro de los fines del Estado." como se puede ver es la Fuerza Aérea Colombiana la encargada de mantener bajo control que no se efectúen vuelos ilegales en el Espacio Aéreo Nacional.

Partiendo de aquí, se inicia la lucha contra el narcotráfico por vía aérea como una necesidad del gobierno Colombiano a través de la Fuerza Aérea Colombiana y se establecen las primeras actividades en 1990 con el apoyo frontal del gobierno de los EEUU, iniciando los sobrevuelos de aeronaves AWAC de la USAF, P-3B y C-550 de USCUSTOMS, con operadores de Defensa Aérea Colombianos, Peruanos y Ecuatorianos abordo, en un esfuerzo por lograr una sinergia en la interdicción de aeronaves y embarcaciones que cruzaran el Gran Caribe con rumbo norte, sin embargo dicho esfuerzo estaba muy por debajo de las necesidades de vigilancia y monitoreo de dicha zona, como se puede ver con esta simple iniciativa los intereses del Gobierno de los EEUU de mantener su territorio libre del flagelo de las drogas, lo lleva a trabajar con países limítrofes no colindantes para establecer una acción directa sobre una actividad que afecta su seguridad y en la cual no intervenían terceros estados que podían servir de área de amortiguación para tratar de controlar la entrada de narcóticos, pues la práctica de la época era el arrojar los cargamentos de droga al mar o en zonas despobladas del territorio para ser recuperadas por las organizaciones al margen de la ley.

Por lo anterior, en 1987 se inicia el programa Caribean Basin Radar Network (CBRN), que tenía como objetivo establecer una red de radares que cubriera una zona desde los países desde donde salían los vuelos ilegales cargados con droga y se implementan radares en Colombia en Puerto Salgar en 1989, Villavicencio 
y Barranquilla en 1990, los cuales iniciaron como equipos tácticos móviles, TPS 43 y TPS 47, en donde todo el trabajo logístico, de soporte y de mantenimiento estaba a cargo de los EEUU y la operación de vigilancia y seguimiento a cargo de personal de las fuerzas aéreas de los países anfitriones, una vez más dejando entrever la frontera existente entre países no colindantes, con intereses comunes desde dos ópticas diferentes, por una parte los EEUU interesados en que no ingresaran narcóticos a su país y por otra parte los países productores tratando de reducir y someter a las organizaciones al margen de la ley que afectan la seguridad y convivencia de sus ciudadanos.

En 1991 se implementa la operación andina "Plan Águila", cuyo propósito primordial era el control de vuelos ilegales desde Ecuador, Perú y el sur de Colombia, áreas de producción y procesamiento de pasta de base de coca, por lo tanto se instalan radares en Colombia en Tres Esquinas, Larandia y Araracuara (Caquetá), Leticia (Amazonas), Iquitos (Perú) y Lago Agrio (Ecuador), igualmente con el apoyo de los EEUU y cuya señal era explotada por cada país y los EEUU, quienes tenían interés en efectuar la interdicción de los vuelos ilegales, con lo cual se deja ver otro aspecto de las fronteras no adyacentes, pero de intereses comunes.

Por otra parte, está la situación de vuelos ilegales en Colombia para el año 2003 "En la Figura 1, se observa el número de vuelos ilegales despegando y aterrizando en territorio colombiano en el año 2003. Se registró un promedio de casi dos vuelos diarios (para un total de 639) en los cuales traficaban estupefacientes movilizándolos a los países fronterizos, convirtiendo el fenómeno en un crimen transnacional." (DEviA et al., 2015, p. 5),

Figura 1. Trazas de vuelos ilegales en Colombia en el año 2003

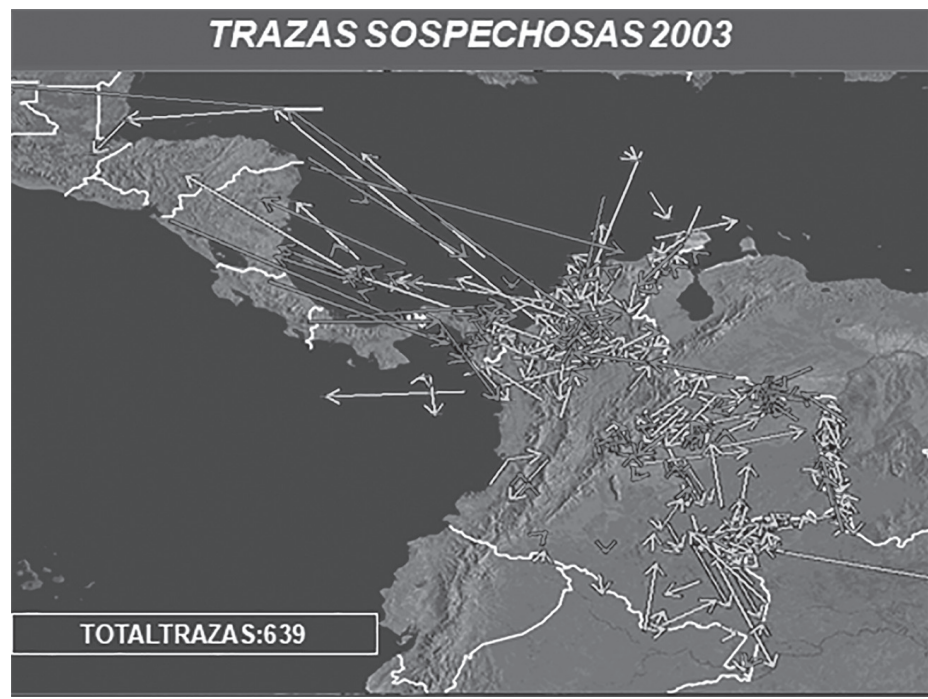

Fuente: Dirección Defensa Aérea de la FAC. 
Adicionalmente, si se considera que cada vuelo tenía en promedio una capacidad de carga de una Tonelada métrica de clorhidrato de cocaína (HCL), se puede inferir que se transportaron 639 toneladas durante el año 2003, por vía aérea solamente, y el valor del kilo de HCL en las calles de los EEUU era de USD 25.000,oo, se puede concluir que por el tráfico de HCL por esta vía las organizaciones al margen de la ley recibieron USD 15.975.000.000,oo, sin considerar que cada kilo de HCL puede convertirse hasta en 4 kilos con la adición de otros productos, como harinas, cementos, "La cocaína, entonces se vende en las calles como hidrocloruro de cocaína, no apta para fumar, o como formas intermedias menos costosas, como el crack o el bazuco, aptas para fumar. Los vendedores en las calles la diluyen para reducir sus costes, con sustancias inertes de apariencia similar como talco, azúcar, suero, o con drogas activas como procaína y benzocaína u otros estimulantes del sistema nervioso como anfetaminas. La pureza de la cocaína es variable" (GONZÁLEZ \& VilLASENÍN, 2010, p. 5).

Como se puede ver, los ingresos de los carteles son cuantiosos y les permiten a través de las mismas rutas mover hacia los EEUU, narcóticos, pero en sentido contrario armas y dinero, con lo cual el ciclo comercial para estas organizaciones era completo, según el banco mundial para el año 2003 el PIB de Colombia correspondía a USD 94.680.000.000, con lo cual se puede observar que las organizaciones al margen de la ley recibieron el 16.87\% del PIB de Colombia, lo que fácilmente coloca en riesgo la capacidad del Estado, especialmente en lo referente a su legitimidad y actuación en la sociedad, ya que estas organizaciones terminan llenando los espacios que los entes gubernamentales no son capaces de llenar y el mismo estado reconoce a través de sus entidades que es un problema, como lo expresa el Departamento Administrativo Nacional de Estadísticas (DANE) en su boletín del cuarto trimestre del año 2003 "El PIB sin cultivos ilícitos registró una tasa de crecimiento de 3,96\%"(DANE, 2003, p. 1).

"Las nuevas rutas movilizan las drogas ilícitas desde territorios aledaños a las fronteras colombianas hacia el Caribe, afectando el territorio Nacional de los países fronterizos, sin embargo las aeronaves que realizan esa actividad logran sobrevolar parte del espacio aéreo colombiano, al cruzar el Mar Caribe, atravesando parte del mar patrimonial ${ }^{2}$, Dado que por normas internacionales no se puede hacer uso de las armas en aguas patrimoniales ${ }^{3}$, el Estado colombiano soporta su lucha contra el Narcotráfico con la implementación de convenios ${ }^{4}$ para combatir este delito de manera conjunta con los demás países de la región que se ven afectados por este delito.'(Devia et al., 2015, p. 6).

Franja de mar desde el mar territorial hasta las 200 Millas Náuticas.

Franja de mar que va más allá del mar territorial hasta el límite de las aguas jurisdiccionales.

Procedimientos operacionales Vigentes. Fuerza Aérea Colombiana en convenios con EE.UU, Honduras,

República Dominicana, Guatemala, Perú, Brasil, Venezuela, Ecuador y Panamá. 
El profesor Rubén Darío López en su trabajo sobre mar territorial y mar patrimonial define como:

"Mar patrimonial

1. El Estado ribereño tiene el deber de promover y el derecho de reglamentar las investigaciones científicas que se adelantan en el mar patrimonial, así como el de aportar las medidas necesarias para evitar la contaminación del medio marino y asegurar su soberanía sobre los recursos.

2. El Estado ribereño ejerce derechos de soberanía sobre los recursos tanto renovables como no renovables que se encuentran en las aguas, en el lecho y el subsuelo de una zona adyacente al mar territorial, denominada mar patrimonial.

3. La anchura del mar patrimonial debe ser objeto de acuerdo internacional preferentemente de ámbito mundial. La suma de esta zona y la del mar territorial, teniendo en cuenta las circunstancias geográficas, no deberá exceder en total de 200 millas náuticas.

4. La delimitación de esta zona entre dos o más estados se hará con arreglo a los procedimientos pacíficos previstos en la Carta de las Naciones Unidas.

5. En el mar patrimonial, las naves y aeronaves de todos los Estados con litoral marítimo o sin él, tienen el derecho de libre navegación y sobrevuelo sin otras restricciones que las que pueden resultar del ejercicio, por parte del estado ribereño, de sus derechos en el mismo mar. Con estas únicas limitaciones, habrá también libertad para tender cables y tuberías submarinas.'(López, 1981, p. 154).

Con lo anterior quedan perfectamente claro los derechos del Estado a ser ejercidos en su mar territorial y mar patrimonial, así mismo, como se puede observar en la figura 1, estas rutas cruzan en algún momento el mar territorial y el mar patrimonial, de por lo menos tres estados antes de llegar a su destino, varios de ellos no adyacentes, pero limítrofes en lo que se refiere a esta vulnerabilidad y al interés común de interdictar dichos vuelos, de este interés nace la necesidad de establecer acuerdos como los Procedimientos Vigentes Operacionales (POV ), que se han firmado con varios países de la región, donde se estandarizan los procedimientos a ejecutar cuando se tiene una aeronave ilegal cruzando el espacio aéreo de un Estado hacia otro sin cumplir con los requisitos establecidos por la OACI, con lo cual se generan dos riesgos, el primero, en lo que hace referencia al tráfico de drogas, un delito transnacional, y el segundo, al que se genera en contra de la aviación comercial que está volando sin saber de la posición y altura de dichas aeronaves que pueden llegar a confluir con el tráfico ilegal sin preservar ni las distancias o alturas mínimas de seguridad.

En lo que respecta a Colombia, se definieron los procedimientos de interdicción de aeronaves con el gobierno de los EEUU en agreement between the government 
of the united states of america and the government of the republic of Colombia concerning the program for the suppression of illicit aerial traffic in narcotic drugs and psychotropic substances ("air bridge denial agreement") del 2004 y actualizado en el 2010, basados en el documento de naciones unidas, uso de las armas por las autoridades encargadas de hacer cumplir la ley, con el fin de garantizar que se preservara el respeto de los Derechos Humanos, así mismo para avalar su cumplimiento se encuentra un programa de entrenamiento para las tripulaciones de la FAC, con el fin de certificar su estandarización, de otra parte no solamente siguen el procedimiento quienes se encuentran en vuelo, sino que el mismo es monitoreado, seguido y aprobado por un oficial supervisor en tierra, quien escucha el procedimiento y aprueba sus pasos sucedáneos, y de forma similar otro supervisor en tierra en Joint Interagency Task Force of South (JIATF of South), con el fin de atestiguar el respeto de los procedimientos y de los Derechos Humanos, así mismo, el Programa Air Bridge Denied (ABD), es sometido a varias etapas de control, en primera instancia reuniones periódicas durante el año con JIATF of south para verificación de los eventos transcurridos entre cada revisión, en segunda instancia la evaluación anual por parte del congreso de los EEUU y autorizado previa revisión, por el presidente de los EEUU, lo que en la práctica se convierte en un garante de la correcta aplicación de procedimientos, alto nivel de entrenamiento y respeto de los Derechos Humanos.

En todo el proceso y estas revisiones se tienen en cuenta el respeto de los DDHH bajo la premisa establecida en la convención de Naciones Unidas de 1988 contra el tráfico ilícito de narcóticos y sustancias psicotrópicas, así mismo, los compromisos establecidos ante la OACI, para garantizar la seguridad de la operación aérea por parte de los estados contratantes.

El programa $\mathrm{ABD}$, es un modelo exitoso en lo referente a interdicción, y no solamente por el hecho de cumplir con los procedimientos establecidos, sino por el respeto a los DDHH, y a la reducción del tráfico aéreo ilegal, pero este resultado no obedece solamente al programa en sí, sino a una serie de iniciativas nacidas en la Dirección de Defensa Aérea de la Fuerza Aérea Colombiana, gestadas desde la perspectiva de la metodología seis sigmas.

Bajo el enfoque de seis sigma ${ }^{5}$ en el año 2005 se definió el problema como:

"En el proceso ABD, la reacción a trazas sospechosas es punto de medición para el indicador de efectividad de la Fuerza. Este valor se mide bajo el índice $\%$ de trazas sospechosas inutilizadas o inmovilizadas y se calcula como: (trazas inmovilizadas + trazas inutilizadas) / Total trazas sospechosas. De acuerdo a la RAE el valor ideal de este índice es de 85\%. Para el año 2003 el índice estaba en promedio en $1.89 \%$ basado en un total de 639 Trazas Sospechosas y una efectividad de solo 28 resultados exitosos y el impacto que generó es el transporte de 1 tonelada por vuelo

Metodología de optimización de procesos inventada por Motorola en los años 80 . 
a 25.000 dólares cada tonelada con unos ingresos promedio de U\$15.975.000.000 anuales, para los grupos al margen de la ley.” (Quintero, 2009b).

Para ese año el proceso se encontraba en -0,58 Sigma, lo que significa que se tenía la oportunidad de mejorar el proceso ya que cada millón de veces que se ejecutaba el mismo solamente se acertaba en 18.900 veces, en términos porcentuales representaba que el $98 \%$ de las veces se fallaba en la interdicción aérea, por lo tanto fue mandatorio tomar medidas para lograr mejorar el proceso y lograr reducir este movimiento.

Partiendo de este escenario se establecieron varias líneas de acción, donde se efectuó un planeamiento y estableció una estrategia de cómo abordar el problema.

Se inicia con el cruce de información existente y a establecer qué datos no se poseían, como la ubicación de pistas ilegales, matrículas de aeronaves, empresas, funcionarios de aviación, rutas principales, cultivos ilícitos, zonas de producción, organizaciones involucradas, y de qué manera se podía atacar este flagelo, con lo que se definió una hoja de ruta para aunar esfuerzos y lograr el objetivo de garantizar la seguridad del espacio aéreo nacional.

En primera instancia, se inician los trabajos para tomar las acciones necesarias a nivel nacional, involucrando a las agencias competentes que podían ayudar en la interdicción y es como se logra establecer acuerdos de servicio con entidades como la Policía Antinarcóticos, Grupo Control de Aviación Civil, Fiscalía General de la Nación, UAEAC, en razón a que la estrategia nacional para la lucha contra las drogas define diferentes roles, y la Fuerza Aérea Colombiana, necesitaba articular los esfuerzos para obtener un resultado contundente.

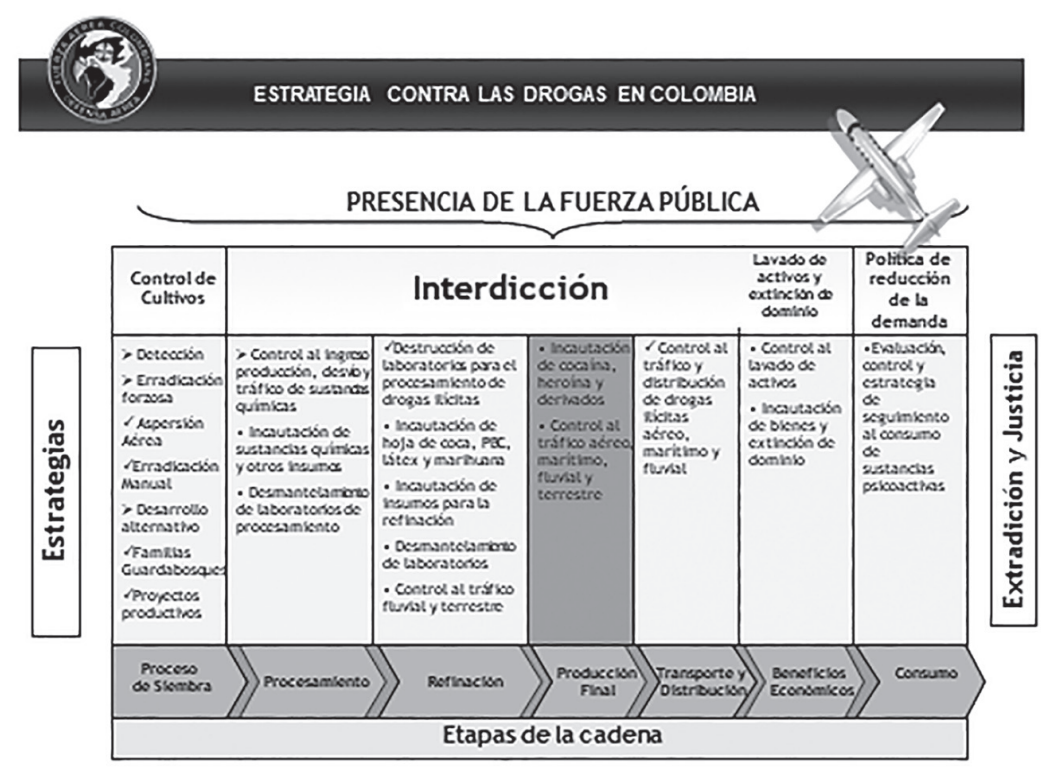

Fuente: Dirección de Defensa Aérea FAC(Quintero, 2013) 
Como se puede observar en dicha estrategia la Fuerza Aérea solamente estaba inmersa en la etapa de producción final y Transporte y distribución, pero la cantidad de actores que intervienen en dicho negocio hizo necesario ampliar el espectro y establecer varias actividades orientadas a controlar el problema raíz.

Las aeronaves por su naturaleza requieren de todo el soporte en tierra, talleres, mantenimiento, cargue, despegue, aterrizaje, personal entrenado, descargue, licencias, permisos, planes de vuelo, información meteorológica, tripulantes, etc, por lo tanto, parte del esfuerzo se focalizó en estos temas y se definieron cuáles eran las principales actividades en las cuales se debía enfocar el esfuerzo.

Fue así, como se priorizaron las rutas, pistas ilegales y aeronaves, estableciendo patrones de conducta que permitieron incrementar la efectividad de la interdicción, con lo que se dieron los primeros pasos hacia una estrategia que garantizara, el control del espacio aéreo, para llegar inicialmente a lograr el control del espacio aéreo nacional y posteriormente empezar a establecer alianzas, no solamente con países limítrofes sino con países con fronteras no adyacentes.

De esta manera es, como la Fuerza Aérea definió el Blanco Aéreo: "Son todos aquellos medios aéreos y su infraestructura de apoyo, que en alguna medida son empleados por el enemigo para controlar su espacio aéreo o que utiliza para vulnerar el nuestro. Siendo así, se puede determinar cómo componentes del blanco aéreo los siguientes: Aviones, Pilotos y Personal Aeronáutico, Pistas, Rutas, Infraestructura aeronáutica, Empresas, Espectro electromagnético, Sistemas de Comando y control" (Quintero, 2009), de igual manera se define una estrategia puntual sobre el tema: "Desarrollar las actividades necesarias para obtener el conocimiento del enemigo aéreo, con el fin de descifrarlo en su funcionamiento como en su ubicación, a fin de proceder a su neutralización física o legal mediante la realización de alianzas estratégicas interinstitucionales e internacionales"(QUINTERO, 2009), dándole vida a la integración con países tanto limítrofes geográficamente como con fronteras no adyacentes, al perseguir el mismo fin.

Igualmente, se define como objetivo principal "Minimizar, controlar o neutralizar la amenaza aérea actual o inminente, mediante el empleo de los medios de la Defensa Aérea" (Buelvas et al., 2016) (Quintero, 2009a), donde se deja en claro la problemática para el país y por ende la decisión del estado de enfrentar dicha amenaza a través de las siguientes acciones:

1. "Conocimiento claro de la amenaza.

2. Alianzas Estratégicas Interinstitucionales.

3. Fortalecimiento Normativo.

4. Control de ejes del enemigo.'(Quintero, 2009)

Partiendo de este enfoque, se inicia la búsqueda de información en varios frentes, en lo referente al primer punto se definieron las siguientes actividades: 
antecedentes, análisis de movimientos aéreos, análisis de movimientos legales, información de otras agencias, proyectos y blancos de defensa aérea, análisis operacional, gestión operacional, control de pistas ilegales. (QUINTERO, 2009).

En segundo término, se establecieron alianzas interinstitucionales con: Dirección Nacional de Estupefacientes, Policía antinarcóticos, Fiscalía General de la Nación, Armada Nacional de Colombia, Ejército Nacional, Departamento Administrativo de Seguridad, y Acuerdos y convenios de cooperación transnacional con: DEA, ICE,NAS,JIATF-South, por parte de EEUU con el convenio ABD (2003), y con Brasil (1997), Perú(2004), República Dominicana (2010), Venezuela(2011), Honduras (2011), Panamá (2012), Guatemala (2010) y Ecuador (2013), donde se definían procedimientos de cooperación para aunar esfuerzos en la lucha contra el delito transnacional aéreo.

En el tercer aspecto, se trabajó sobre la alineación de los procedimientos bajo la normatividad de DDHH, y se transversalizó sobre los definidos en los de operación con otros países estableciéndose controles administrativos y operacionales.

Finalmente, en el control de los ejes del enemigo se fortaleció la interdicción aérea, se aumentó el control sobre los campos de operación, se establecieron controles sobre empresas, aeronaves y personal.

Esta estrategia fue efectiva al lograr la integración de diferentes dependencias, no solo al interior de la Fuerza Aérea Colombiana, sino del país, y aún más allá, al involucrar a las fuerzas aéreas de otros países, con quienes se lograron estandarizar procedimientos y establecer canales de comunicación que permitían la sinergia entre estados limítrofes no adyacentes, logrando impactar el movimiento aéreo ilegal, se resume en el siguiente gráfico:

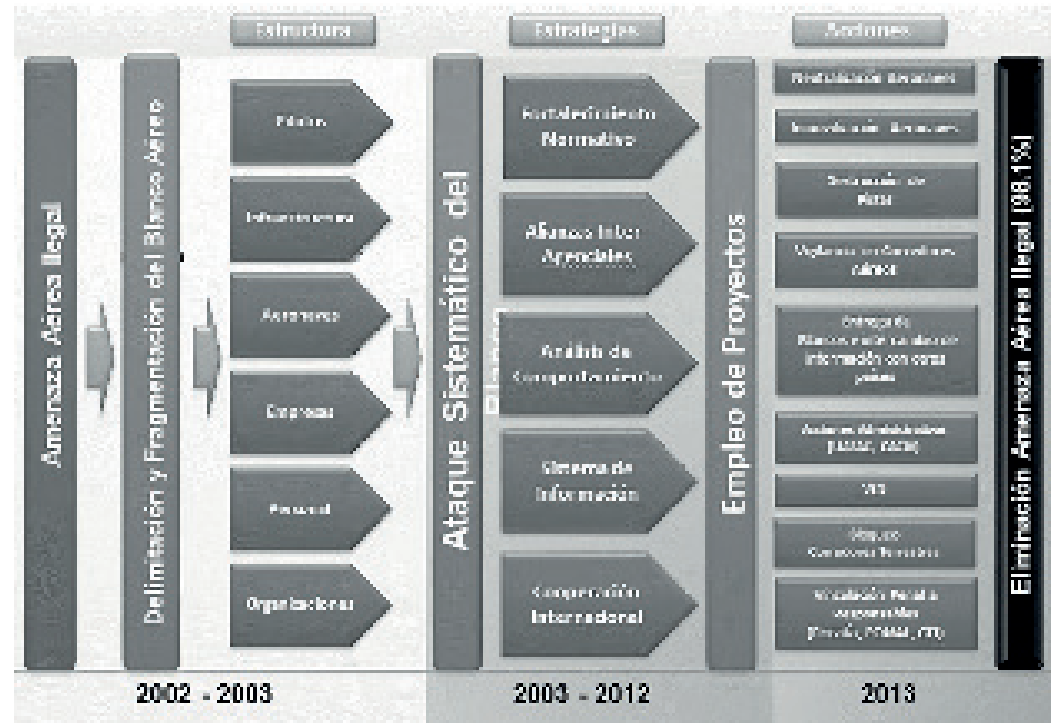

Fuente: Dirección de Defensa Aérea FAC(Quintero, 2013) 
Todos estos aspectos se tuvieron en cuenta en los procedimientos de control definidos con los países que establecieron acuerdos, lo que permitió aunar esfuerzos y ser mucho más eficientes en los resultados, donde no solamente se estandarizaron procedimientos, sino que se logró transferir conocimientos, experiencia y ayuda en la manera de efectuar el levantamiento de la información, sistematizarla, analizarla, distribuirla y emplearla de manera efectiva, de tal suerte que sirviera no solamente para el desarrollo operacional sino para allegar como elementos probatorios ante las autoridades judiciales y sirviera para consolidar casos que permitieran contrarrestar el actuar de los diferentes carteles, de esta forma se logró una reducción de los movimientos aéreos ilegales del espacio aéreo nacional, logrando una reducción del 96.8\% del año 2003 al 2013.

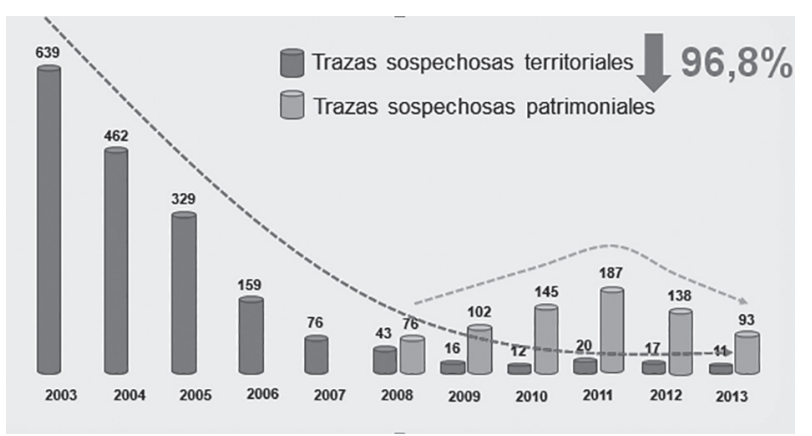

Fuente: Dirección de Defensa Aérea FAC(Quintero, 2013)

Para el 2008 el proceso se encontraba en 1.37 sigma lo que refleja una mejora significativa, en razón a que se logró una efectividad del $45 \%$ y a partir de este momento el proceso se estabiliza con unas reducciones mínimas, que no han podido ser mejoradas por la falta de aeronaves, radares, plataformas de alerta temprana y bases de lanzamiento, ya que estas medidas requieren inversiones cuantiosas de las que se tienen los proyectos de inversión pero no la asignación de recursos, sin embargo el panorama de sobrevuelo de aeronaves ilegales por el espacio aéreo nacional es completamente diferente a la del año 2003. 


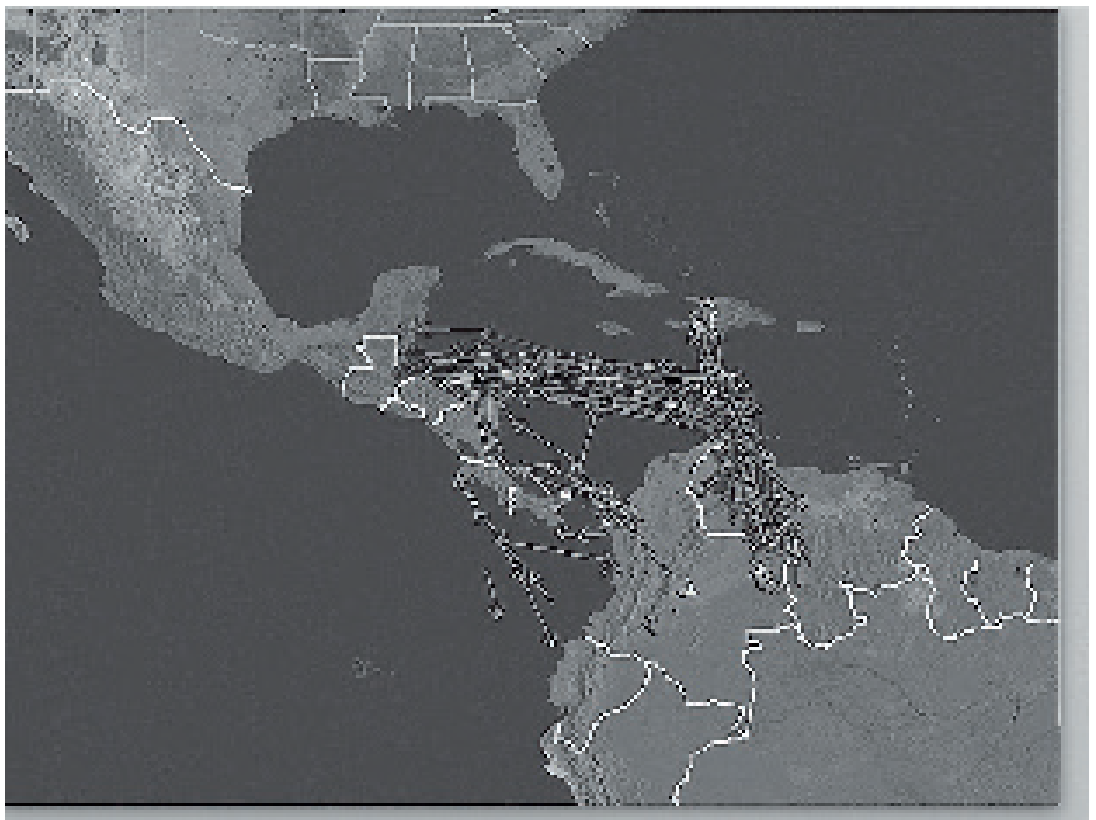

Fuente: Dirección de Defensa Aérea FAC (Quintero, 2013)

Como puede observarse esta estrategia ha sido efectiva desde la perspectiva aérea, sin embargo el fenómeno de los movimientos ilegales migró del ámbito aéreo al marítimo por varias razones, en primer término debido a que los movimientos marítimos permiten mover mayores cantidades de alcaloides, en segundo término las instalaciones requeridas como puerto para el zarpe de las embarcaciones no requieren mayores exigencias técnicas y dificultan enormemente su ubicación, en tercera instancia los medios técnicos de detección de estos movimientos son mínimos frente a la amenaza y su ubicación en tierra limita el alcance de los mismos y los instalados a bordo de aeronaves no permiten mantener una vigilancia de los mares de manera permanente, lo que dificulta su interdicción, así mismo el tiempo de permanencia de dichas embarcaciones es mucho mayor donde dos de los principales enemigos de las autoridades es el tiempo y el alcance, si no se tienen los medios suficientes para lograr transferir los blancos de un país a otro se pierden los esfuerzos y en segundo término si no se poseen las unidades capaces de llegar hasta las rutas que estas embarcaciones usan se hace imposible su interdicción, y no todos los países de la región poseen dicha capacidad, a excepción de EEUU, México y Colombia, quienes no alcanzan a cubrir las necesidades de vigilancia de estos corredores, lo que ha permitido el incremento de movimientos marítimos, su evolución tecnológica, su capacidad de carga y su alcance, tema que amerita un estudio aparte por sí mismo. 


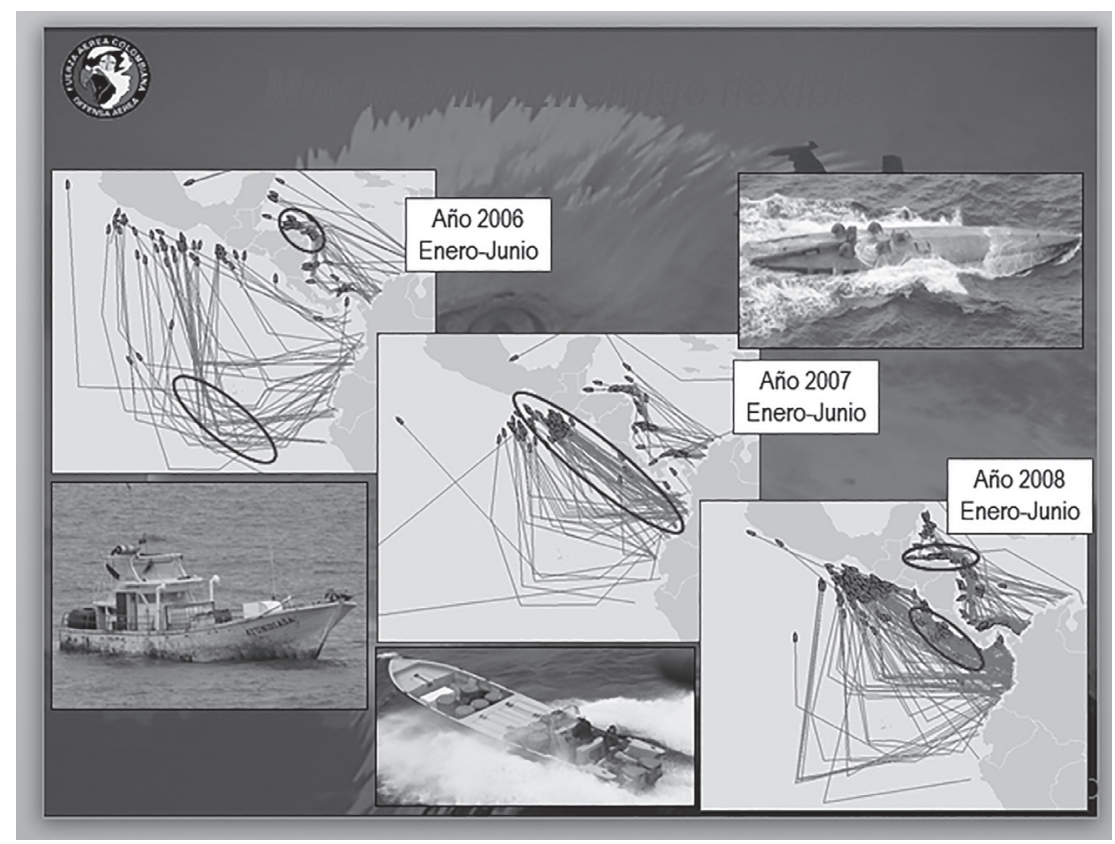

Fuente: Dirección de Defensa Aérea FAC(Quintero, 2009)

Del ejemplo anterior, se demuestra que los países no adyacentes pueden ser limítrofes y llegar a compartir varios intereses sobre un mismo tema, convirtiéndolos en países limítrofes en lo referente a estos intereses, de la misma manera se pueden plantear intereses de diferente índole, pero se va a encontrar siempre la misma situación, la unión de actividades orientadas a alcanzar el mismo interés, como se puede ver en los acuerdos comerciales, judiciales, aduaneros, migratorios o inclusive coaliciones con fines de efectuar operaciones militares, a nivel táctico se convierten en países limítrofes aunque sus jurisdicciones geográficas no se toquen.

Hoy en día con el advenimiento de no solamente rutas comerciales más cortas y directas, se establecen nuevos límites entre los Estados sino que se dan nuevas relaciones que van más allá de la capacidad estatal, cuando por ejemplo hay adeptos del DAESH alrededor del mundo, con lo cual se puede configurar lo que en la práctica podría llamarse un Estado Virtual, cuya influencia llega hasta donde tiene sus seguidores y hace de estos, países con fronteras no adyacentes, de manera similar se puede observar grupos como los que apoyan la independencia de diferentes estados, que de acuerdo a la ONU son 16 territorios en el mundo que aún no consiguen su independencia, y que Naciones Unidas define como territorios no autónomos, sin embargo se encuentran casos en Europa que por el momento no hacen parte de este inventario, como Gibraltar, Groenlandia, Irlanda 
del norte, Cataluña, El país Vasco, Escocia, Baviera, Flandes, Galicia, Islas Feroe, Padania, Tirol del sur, Córcega y Trentino,) por otra parte en Asia se encuentra el Tíbet, el Kurdistán, Hong Kong, Guam, Chechenia, Macao, Cachemira, Transnitria y Gagauzia, , así mismo en África se encuentra Somalilandia, Nueva Caledonia, Sahara Occidental y Tokelau, en América Bermudas, Islas Caimán, Islas Malvinas, Islas Turcas y Caicos, región Mapuche, islas Falklands, Quebec (el tiempo) y la lista continúa, así mismo los adeptos y detractores existen en todas partes y por diferentes motivos, que van desde lo económico, político, religioso, étnico, cultural, geopolítico, a continuación se puede ver la lista que Naciones Unidas tiene como territorios no autónomos, como puede verse con un sesgo político ya que no incluye una gran cantidad de territorios alrededor del mundo.

\begin{tabular}{|c|c|c|c|c|}
\hline Territorio & Incluidos en la lista & Administración & $\begin{array}{c}\text { Superficie } \\
(\mathrm{km} 2)^{1}\end{array}$ & Población 1 \\
\hline \multicolumn{5}{|l|}{ ÁFRICA } \\
\hline Sảhara Occidental 図面 & Descle 1963 & $\underline{2}$ & 266,000 & 584,000 \\
\hline \multicolumn{5}{|l|}{ ATLÁNTICO Y EL CARIBE } \\
\hline Anguila 저메 & Desde 1946 & Reino Unido & 96 & 15,700 \\
\hline Bermuda 図四 & Desde 1946 & Reino Unido & 53.35 & 61,695 \\
\hline 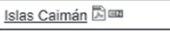 & Desde 1946 & Reino Unido & 264 & 60,413 \\
\hline 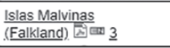 & Desde 1946 & Reino Unido & 12,173 & 2,500 \\
\hline $\begin{array}{l}\text { Islas Turcas y } \\
\text { Caicos 젖aㅔ }\end{array}$ & Desde 1946 & Reino Unido & 948.2 & 37,910 \\
\hline 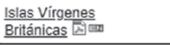 & Desde 1946 & Reino Unido & 153 & 28,200 \\
\hline $\begin{array}{l}\text { Islas Virgenes de los } \\
\text { Estados Unidos 젓 }\end{array}$ & Desde 1946 & Estados Unidos & 352 & 103,700 \\
\hline Monserrat 四四 & Desde 1946 & Reino Unido & 103 & 5,000 \\
\hline Santa Elena & Desde 1946 & Reino Unido & 310 & 5,691 \\
\hline \multicolumn{5}{|l|}{ EUROPA } \\
\hline Gibraltar & Descle 1946 & Reino Unido & 5.8 & 33,140 \\
\hline \multicolumn{5}{|l|}{ PACIFICO } \\
\hline Guam 중.m & Desde 1946 & Estados Unidos & 540 & 159,358 \\
\hline Nueva Caledonia & $1946-1947$ y desde 1986 & Francia & 18,575 & 268,767 \\
\hline Pitcaim 중 & Desde 1946 & Reino Unido & 35.5 & 39 \\
\hline Polinesia Francesa 펑미 & 1946-1947 y desde 2013 & Francia & 3,600 & 271,800 \\
\hline Samoa Americana 저시 & Desde 1946 & Estados Unidos & 200 & 60.200 \\
\hline Tokelau & Desde 1946 & Nueva Zelandia & 12.2 & 1,499 \\
\hline
\end{tabular}

Fuente: Las Naciones Unidas y la Descolonización. http://www.un.org/es/decolonization/ nonselfgovterritories.shtml

Como puede verse cada una de estas causas tiene adeptos y detractores que no solamente sientan sus puntos de vista desde lo ideológico, sino que cubre aspectos publicitarios, hasta actividades en las redes sociales que buscan apoyo alredor del mundo, pero así mismo encuentran detractores, todo esto en detrimento de los límites geográficos de los estados comprometidos y donde terceros países con intereses específicos apoyan y facilitan dichas actividades, mientras que contrapartes bloquean y desmotivan estos procesos y cada caso tiene ejemplos, inclusive podría hacerse referencia a los casos más relevantes de los últimos años, como el Brexit, donde siempre existió la duda sobre la intervención de Rusia en dicha consulta, o las elecciones presidenciales de los EEUU, donde nuevamente 
Rusia deja un manto de duda sobre su intervención en las mismas, nuevamente permitiendo ver que las fronteras no adyacentes son una realidad en la actualidad y que en lo que se puede preveer va a terminar cobrando una mayor relevancia, debido a que los intereses de los Estados van más allá de sus fronteras que serán cambiantes pero siempre existirán.

\section{REFERENCIAS}

¿En qué regiones europeas quieren la independencia?|Europa |DW |29.09.2017. (n.d.). Retrieved March 19, 2018, from http://www.dw.com/es/en-qué-regiones-europeas-quieren-la-independencia/a-40751717

Buelvas, E. P., Gehring, H., Eduardo, E., Buelvas, P., Mauricio, A., Camilo, V., ... García, R. (2016). Política exterior colombiana: escenarios y desafíos en el posconflicto. Retrieved from https://s3.amazonaws.com/academia.edu. documents/46571501/la politica exterios colombiana en el marco del posconflicto.pdf?AWSAccessKeyId=AKIĀIWOWYY $\overline{\mathrm{G} Z} \overline{2} \overline{\mathrm{Y}} \overline{\mathrm{B}} \mathrm{UL} 3 \overline{\mathrm{A}} \& \overline{\mathrm{Ex}}$ pires $=1512315720 \&$ Signature $=\mathrm{CU} \% 2 \mathrm{BtsDX3nCd1NGxYnOG65 \textrm {cErDqg }}$ $\% 3 \mathrm{D} \&$ response-content-disposition=inline

DANE. (2003). comunicado dane 4 trim 2003.

Devia, H. R., Iván, D., \& Ferreira Cardenas, M. (2015). Modelamiento estadístico del tráfico aéreo ilegal en Colombia.

FERNÁNDEZ-CARrión, M.-H. (2010). Historiografía, metodología y tipología de fronteras.

Foucher, Michael. (1946-... . ). A. du texte. (1987). L'invention des frontières. Retrieved from http://gallica.bnf.fr/ark:/12148/bpt6k3322804w

González, L., \& Villasenín, Y. (2010). Cocaína. Udc.es, 21.

HARTSHORne, R. (1939). The nature of geography. Retrieved from https:// ia800309.us.archive.org/31/items/natureofgeograph010994mbp/natureofgeograph010994mbp.pdf

JimÉNEZ, A. (1994). Handbook of Hispanic cultures in the United States.

KaUtiLyA. (2008). Arthasastra La ciencia politica de la adquisición y el mantenimiento de la tierra. (O. Guerrero, Ed.) (Universida). México.

LóPEZ, R. D. (1981). El mar territorial y el patrimonial. Retrieved from file://C:/ Users/Henry/Downloads/5422-10995-1-SM.pdf

Quintero, H. (2009a). Cumbre de presidentes Colombia. México: Guatemala y Panamá. 
Quintero, H. (2009b). Reunión jefes de operaciones.

Quintero, H. (2013). Cómo se controló el blanco aeronáutico.

Ranking de Estados que aspiran a su independencia-Listas en 20minutos.es. (n.d.). Retrieved March 19, 2018, from https://listas.20minutos.es/lista/ estados-que-aspiran-a-su-independencia-347871/

Según la ONU, en el mundo todavía hay 16 territorios no autónomos colonias que no pueden ser países-Archivo Digital de Noticias de Colombia y el Mundo desde 1990-eltiempo.com. (n.d.). Retrieved March 19, 2018, from http://www.eltiempo.com/archivo/documento/MAM-4017672

TURNER, F. J. (1893). El significado de la frontera en la historia americana. 


\title{
REFLEXIONES OPERACIONALES A PARTIR DE LA experiencia de las tomas de Puerto Rico y Puerto LLERAS
}

\author{
Coronel (RA) ALEX EDWIN TIUSO MALAGÓN ${ }^{1}$
}

\section{INTRODUCCIÓN}

El presente documento surge de las reflexiones vivenciales y operacionales de más de 20 años como piloto de la Fuerza Aérea Colombiana, experiencia que permite ofrecer algunas ideas sobre el devenir del conflicto armado que ha vivido el país, sobre las profundas transformaciones que este ha tenido, y las adaptaciones que la institución ha desarrollado para ser más operativa y efectiva.

El análisis centra su atención en los acontecimientos sucedidos en la segunda mitad de la década de los años noventa, uno de los períodos históricos de mayor confrontación, y en la región comprendida por los departamentos del Meta y el Caquetá, dos de los departamentos más comprometidos con la violencia desatada por las FARC para conseguir los propósitos que se trazaron en ese período histórico del país. La gravedad de ese contexto sociohistórico, exigió una reacción contundente por parte de la Fuerza Pública, y en particular un uso más efectivo del poder aéreo que, como se verá durante el documento, fue decisivo para transformar y alterar las dinámicas del conflicto armado.

Entre la década de los años noventa y los primeros años del siglo XXI, la institución adecuó y racionalizó su forma de operar y proceder, haciéndose cada vez más incidente y decisiva en la transformación asimétrica del conflicto, y de la configuración de fuerzas de las partes en confrontación. Esto permitió que en el decurso de una década, las condiciones del país cambiaran diametralmente, con todos los beneficios sociales y económicos que la seguridad trae consigo.

Estas victorias no fueron gratuitas ni fáciles, implicaron unos sacrificios y compromisos gigantescos por parte de los hombres y mujeres adscritos a las

Coronel (RA) Se desempeñó como Jefe del Comando y Control-CCOFA de la Jefatura de Operaciones Aéreas de la Fuerza Aérea Colombiana. 
Fuerzas; sacrificios que no siempre fueron reconocidos por la sociedad, y que por ende deben ser expuestos a la luz pública para que se dignifique y se reconozca el valeroso papel desempeñado.

Así mismo, todas estas reflexiones y experiencias permiten generar conclusiones de las que emanan recomendaciones y valoraciones sobre algunas transformaciones que aun deben darse, y que permitirían que la efectividad de la Institución fuese mayor, para beneficio de todos los colombianos.

\section{Contexto Puerto Rico y Puerto Lleras}

Durante la década de los años noventa, la dinámica del conflicto armado se caracterizó por los enfrentamientos entre la Fuerza Pública y diferentes actores armados ilegales como las FARC. De esta manera, durante los años 1996-1999 las FARC asestaron diferentes golpes estratégicos contra unidades militares en los departamentos de Caquetá, Meta, Putumayo, Nariño, Vaupés, entre otros. Los ataques más emblemáticos fueron el Billar, Miraflores, Patascoy, Mitú, Puerto Rico y Puerto Lleras. Todo esto se enmarcó durante el Gobierno del Presidente Andrés Pastrana, quien para potencializar la política de Seguridad del Gobierno, articuló y reforzó a las Fuerzas Militares con el Plan Colombia, mientras que se llevaban a cabo las negociaciones de paz.

Ahora bien, durante los años 1996 y 1999, la intensidad del conflicto aumentó por los ataques realizados en el Suroccidente y Suroriente del país.

\footnotetext{
"Entre 1996 y 1998, en zonas del sur del país, las FARC demostraron su elevada capacidad de aprendizaje en medio de un entorno adverso e incierto. Así mismo, pusieron a prueba su capacidad de maniobra, libertad y rapidez de acción. Entre los cambios más significativos observados en la dinámica del conflicto, se destaca la prioridad manifiesta que las FARC dieron entre 1997 y 2001 a los ataques a las poblaciones para destruir los puestos de policía y debilitar la presencia estatal en los sitios donde buscaban ampliar su influencia.” (ECHANDÍA y BECHARA, 2006, p. 33).
}

Para poder comprender plenamente la importancia territorial de estos municipios y los motivos que llevaron a que las FARC se ensañaran contra la Fuerza Pública y la sociedad de estos municipios, es necesario mirar la ubicación geográfica de los mismos, y las posibilidades de comunicación, movilidad y tráfico que estos le daban al actor que lograse ejercer control sobre ellos (Ver Gráfico 1). 


\section{Gráfico 1. Puerto Rico, Puerto Lleras y EI Billar}

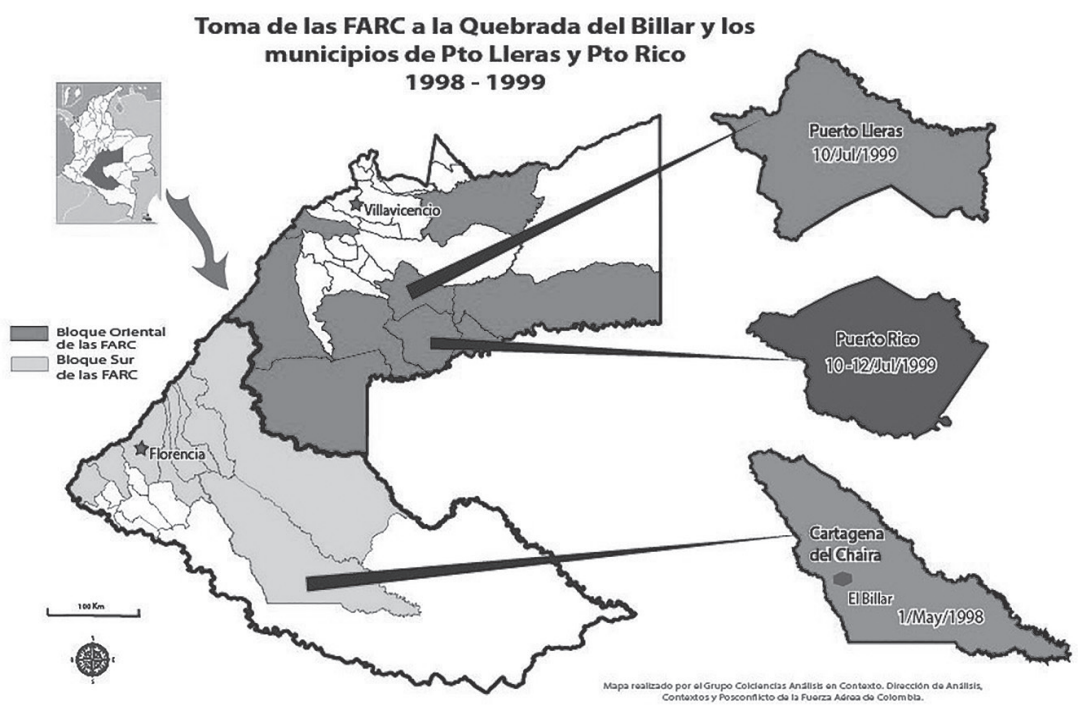

Fuente: FAC-DICOP (2016)

Esta dinámica de la guerrilla responde a los lineamientos políticos y militares de la organización ilegal, trazados por la Séptima y Octava Conferencia, en donde se evidencia un cambio en el modo de operar, mediante la puesta en marcha de las estrategias centrifuga y centrípeta. Para la década de los años noventa, la estrategia centrifuga consistía "en la creación de unidades militares capaces de cercar y aniquilar bases y tropas de élite del Ejército oficial, (...) la doctrina militar va a encontrar en este contexto un terreno apropiado para desplegar plenamente sus potenciales." (Pizarro, s.p, p. 188).

Dentro de ese contexto, es que las FARC realizan los ataques contra unidades militares de la Fuerza Pública de manera prolongada con tácticas y armamento no convencional. "La insistencia de las FARC en los ataques contra las instalaciones de la Policía Nacional a partir de 1997 se convirtió en todo un propósito estratégico inscrito en el desarrollo de planes de guerra dispuestos a lograr el control de zonas específicas cada vez más amplias que se constituyen en núcleos de expansión de control militar." (ECHANDÍA y BECHARA, 2006). Por eso la ubicación geográfica de los ataques realizados durante el período de 1996 y 1998 correspondía a la intención política y militar de la organización de crear corredores de movilidad en el sur del país.

El año 1998 las FARC realizaron los golpes más contundentes contra la Fuerza Pública, entre esos se encuentra el Billar y Mitú. En la quebrada "el Billar" en la 
zona rural de Cartagena del Chairá (Caquetá), en el mes de marzo, fue el primer enfrentamiento contra una unidad militar que tenía las capacidades militares para enfrentar un ataque de una organización ilegal. Este ataque fue contra el Batallón de contraguerrillas 52 que hacía parte de la Brigada Móvil No. 3 y tenía la "misión de realizar actividades ofensivas contra el Bloque Sur de las FARC. Tenía responsabilidad en la zona ubicada entre la quebrada el Toche y la Vereda el Águila.' (PARDO, 2008, p. 634). El golpe estuvo enfocado en atacar las diferentes estructuras del Batallón Contraguerrillas, así lo señala Rafael PARDO:

"El 2 de marzo a las cuatro de la tarde, la Compañía D desprendió una patrulla para registrar una zona selvática y esta fue recibida con fuego de ametralladora y mortero. De inmediato fue apoyada por la Compañía C y por el resto de la Unidad $\mathrm{D}$, refuerzos que también fueron atacados (...) el comandante del batallón pidió por radio apoyo aéreo y a las seis de la tarde un avión fantasma AC-47 sobrevoló el sector, lanzó granadas de iluminación y realizó varios ametrallamientos a blancos dirigidos por radio desde tierra." (PARdo, 2008, p. 634).

La importancia del ataque al Billar radica en la demostración de las capacidades bélicas de la Guerrilla, al enfrentarse a un batallón contraguerrillas, "que era la unidad mejor dotada y entrenada del Ejército Colombiano para hacer frente a estos grupos, nunca había ocurrido un combate abierto con una situación tan desfavorable para las tropas" (PARDO, 2008, p. 635). Con este ataque las FARC querían demostrar su poderío militar al embestir contra un Batallón contraguerrillas, que por su connotación militar representaba enfrentarse a una fuerza que tenía unas capacidades militares superiores.

Pese a que hubo apoyo aéreo de la Fuerza Aérea mediante los aviones fantasma AC-47,K-fir, Mirage M-5, aviones OV-10 y helicópteros pesados como los Black Hawk y MI-17, por autonomía de vuelo los aviones fantasma AC-47 tardaron en prestar su apoyo aéreo. No obstante, este soporte fue clave para disminuir la intensidad del enfrentamiento.

Sin embargo, durante la toma del Billar según la sentencia en donde se juzga al Estado Colombiano, se señala que se presentaron unas fallas en el planeamiento de las operaciones.

\footnotetext{
"Las diferentes Subsecciones de la Sección Tercera del Consejo de Estado al juzgar la responsabilidad estatal por tomas guerrilleras han fijado unos lineamientos claros frente a un mismo punto de derecho cuando se ha definido su responsabilidad bajo el título jurídico de imputación de falla del servicio por la muerte de oficiales, suboficiales y soldados, que con ocasión de su vinculación a la fuerza pública, murieron por acción de la insurgencia armada en el curso de operaciones militares, responsabilidad fundamentada en fallas estructurales de planeamiento y desarrollo de las actividades militares, lo que ha facilitado que el enemigo pudiera atestarle derrotas militares al Ejército Nacional, siendo las más graves la pérdida de vidas humanas de los integrantes de las unidades militares que han sucumbido en el contexto del ataque guerrillero." (Consejo de Estado, 2014).
} 
De esta manera, el Billar se configuró como una de las apuestas estratégicas de la organización ilegal, en donde les demostraron al Estado Colombiano y a las Fuerzas Militares, que ya tenían la capacidad militar para atacar las unidades élites del Ejército de Colombia. Esta arremetida también va ligada a la estrategia política y militar de la organización, y responde a esa lógica de desgastar al Estado. Así mismo, esta ofensiva también está conectada con el ataque que posteriormente realizarían en el Mitú, ya que si en la toma del Billar demostraban su capacidad bélica, eran capaces de tomarse una capital de departamento y obtener control territorial en el sur del país.

Igualmente, otro de los golpes más estratégicos durante los años noventa, fue en 1998 con la toma de Mitú, en donde las FARC pretendían demostrar su capacidad bélica y política. Con esta acción armadala organización tenía diferentes objetivos, el político estaba enfocado a fortalecer su posición con miras en la mesa de negociación con el Gobierno de Andrés Pastrana (1998-2002), así como obtener el reconocimiento del estatus de beligerancia. En cuanto al objetivo militar, la Toma de Mitú representaba el paso de la guerra de movimientos, a la guerra de posiciones, en donde se demostró que las FARC tenían la capacidad militar de tomarse una capital de departamento, con una ubicación geoestratégica importante. Así mismo, esto generó un impacto internacional ya que las FARC dictaron un mensaje político a la comunidad internacional enfocado a la capacidad bélica que tenían para tomarse una capital de departamento, aunque esto también respondía a su intención política de obtener el estatus de beligerancia. Por otro lado según Marco Palacios, con el canje de presos estos convirtieron y fortalecieron su estrategia política enfocada en obtener el estatus de beligerancia, "pensaron, quizás, que así se acercaban al ansiado reconocimiento internacional de fuerza beligerante establecido en los Protocolos de Ginebra." (PALACIOS, 2012, p. 162).

Pese a que la Toma de Mitú tomó connotaciones políticas, durante esta, las FFMM demostraron tener las capacidades militares para contrarrestar la amenaza, esto se dio bajo la Operación Vuelo de Ángel, en donde por la reacción y capacidad aérea, se recuperó la capital del Vaupés. "Uno de los factores de éxito de la Operación Vuelo de Ángel, radica en la utilización de las capacidades inherentemente estratégicas del poder aéreo como lo son la velocidad, la flexibilidad, la maniobrabilidad para atacar los centros de gravedad del enemigo." (SANTos, 2016, p. 136). Así mismo, dado que las FARC demostraron con este ataque su paso a la guerra de movimientos, esto los dejos expuestos, por la concentración de los guerrilleros, a los ataques aéreos, por ejemplo con el avión fantasma se "ubicó una columna de guerrilla y fue en este ataque donde se hizo un mayor número de bajas. Para el académico español de la Universidad de los Andes (...) este bombardeo acabó todo el frente 37 de las FARC, aproximadamente 80 guerrilleros." (PeRdomo, 2006, p. 306). 
A partir de la Operación Vuelo de Ángel, las Fuerzas Militares recuperaron la iniciativa estratégica en el conflicto armado colombiano, "la Operación Vuelo de Ángel marcó un punto de quiebre en el conflicto colombiano, porque esta operación frenó la avanzada guerrillera. Gracias al poder aéreo demostrado, se dieron de baja a muchos guerrilleros, lo cual permitió inclinar la balanza hacia el Estado Colombiano. Así mismo, con esta operación se alteró la correlación de fuerzas entre las FFMM y las FARC-EP." (SANTOS, 2016, p. 136). De esta manera, Vuelo de Ángel se convirtió en un precedente exitoso para las Fuerzas Militares, en especial para la Fuerza Aérea Colombiana, ya que mediante la capacidad aérea se logró alterar la estrategia de las FARC.

En términos de la dinámica del conflicto armado colombiano esta se alteró, porque las FARC no pudieron volver a realizar estos golpes estratégicos, como lo señala PIZARRo "desde 1998, las FARC no pudieron volver a realizar acciones militares de un real valor estratégico, pues se vieron obligados a retornar a la guerra de guerrillas y a evitar la concentración de amplias unidades militares ante el avance de la Fuerza Aérea." (Pizarro, s.p, p. 194). Con estos ataques durante 1996, 1998,1999 las FARC querían demostrar su poderío.

Estos hechos ocurrieron en el contexto del gobierno del Presidente Andrés Pastrana, el cual estuvo caracterizado por la reestructuración y modernización de las Fuerzas Militares, el proceso de paz que conllevó a la zona de distensión, y el Plan Colombia. Estos hechos políticos fueron determinantes en el conflicto armado colombiano, ya que se alteraron las dinámicas y se produjo un reacomodamiento de los actores.

En cuanto a la reestructuración, "las Fuerzas armadas no podían permanecer a la defensiva en especial con los golpes que las FARC les habían propinado entre 1996 y 1998. A partir de este último año, desde el Ministerio de Defensa y el Comando General de las Fuerzas Militares, contando con la ayuda norteamericana, se emprendió su más profunda transformación recuperando su iniciativa táctica y obligando a las FARC a retroceder.” (Río, 2008). La reestructuración conllevó cambios institucionales, adquirir nuevas tecnologías y una nueva doctrina. De esta manera la nueva restructuración de las Fuerzas Militares estuvo enfocada en crear instituciones que se adaptaran a una nueva situación de seguridad y defensa, y para contrarrestar la amenaza que representaban las FARC para los años noventa, se necesitó de un reacomodamiento institucional. Esto supuso la creación de las siguientes instituciones:

1. Comando Conjunto Operaciones Especiales

2. Coordinación Nacional de Inteligencia

3. Comando Conjunto Caribe

4. Fuerza de Tarea Conjunta 
5. Agrupacion Fuerzas Especiales Antiterrostias Urbanas-AFEAUR (14)

6. Batallones de Alta Montaña (7)

7. Brigadas Moviles( 15)

8. Grupos Gaula (32)

9. Soldados Campesinos (27.000)

10. Infanteria de Marina (4.355)

11. Escuadrones Moviles (54)

12. Seis divisiones

13. Unidades Especiales (FUDRA, Brigada contra el Narcotráfico, Brigada de Aviación del Ejercito, Brigada de Fuerzas Especiales) ${ }^{2}$

14. FUDRA, Brigada contra el Narcotráfico, Brigada de Aviación del Ejército, Brigada de Fuerzas Especiales)

Por otra parte, el Plan Colombia se constituyó como un proyecto de cooperación militar,económico y político que le permitió al Estado Colombiano adquirir recursos económicos para fortalecer las Fuerzas Militares. "La mayor parte de la ayuda está destinada a fines militares y policivos. Aparte de las altas cifras para el equipo aéreo, son importantes las destinadas a capacitación y entrenamiento. Los nuevos recursos se sumaron a los 330 millones que habían sido asignados para los años 2000 y 2001, que también corresponden principalmente a ayuda militar y policiva." (BuITRAGO, 2002).

Así "se puede entender el Plan Colombia como el conjunto de disposiciones legales y fondos presupuestarios del Gobierno de los Estados Unidos, ejecutado en Colombia por distintas agencias estadounidenses, pasó rápidamente de la guerra de las drogas al de la sinergia de la guerra unificada a narcotraficantes y terroristasmetiendo a las guerrillas en la clasificación.” (PALACiOs, 2012, p. 165) En términos de resultados cuantitativos según Palacios "no cabe de que fue decisivo en debilitar a las FARC, pues un 80 \% se destinó al campo militar." (PALACiOS, 2012). Así mismo, el Plan Colombia fue exitoso ya que le dio a las FFMM capacidad operativa y tecnológica para combatir a los actores armados ilegales, prueba de ello fue por ejemplo la adquisición de visores nocturnos, lo cual le dio una nueva capacidad a la Fuerza Aérea de aumentar la autonomía de vuelo.

Con el inicio del proceso de paz, bajo el Gobierno del Presidente Pastrana, el 7 de noviembre 1998, se decretó el inicio de la zona de distensión, "esta requirió once prórrogas presidenciales, objeto de negociaciones, a veces ardua, desgastadoras y traumáticas que reflejaban la dificultad de la negociación.” 
(Palacios, 2012). Por otro lado, esta zona suponía la concesión de territorio en La Uribe, La Macarena, Vista Hermosa. Mesetas y San Vicente del Caguán. Este tenía el propósito de realizar las conversaciones de paz entre el Gobierno Nacional y las FARC-EP, para facilitar la negociación.

Las implicaciones políticas de la Zona de Distensión radican en que el gobierno concedió un territorio a una organización ilegal, reforzando la idea de que el Estado Colombiano no era capaz de ejercer el monopolio legítimo de la violencia, ya que durante los años noventa con las acciones contra la Fuerza Pública, esta capacidad estatal se vio perjudicada.

Pese a que la Zona de Distensión buscaba generar unas condiciones políticas para la negociación, las FARC aprovecharon para mantener un control territorial sobre sus zonas de influencia y se violaron los Derechos Humanos de la población civil así lo señala el grupo ilegal "fraguó, la mayoría de las acciones armadas que desarrollaron durante este período en las regiones del Suroriente y Suroccidente del país, organizando secuestros, extorsiones, tomas violentas a municipios y estaciones de Policía, amenazas y asesinatos selectivos contra sectores sociales que no compartían sus ideas, entre muchas acciones contra la población civil y contra las autoridades estatales." (MARÍN, et al, 2016, p. 105).

Ahora bien, después de Mitú, las FARC intentaron realizar ataques a diferentes municipios como Puerto Lleras y Puerto Rico. "Sin embargo, la rápida y exitosa acción de las Fuerzas Armadas, que estaba poniendo a prueba su nuevo instrumental tecnólogico y táctico (uso masivo de helicópteros, tropas aerotransportadas, visores infrarrojos para el combate nocturno, misiles airetierra) fue el inicio de una serie de exitosos militares en cadena como Puerto Rico (Caquetá) Puerto Lleras (Meta).” (Pizarro, s.p). Al igual que Mitú, las tomas de Puerto Lleras y Puerto Rico, por la concentración de los guerrilleros, hace que estos estuvieran expuestos al poder aéreo. "Las FARC no pudieron volver a realizar acciones militares de un real valor estratégico,pues se vieron obligadas a retornar a la guerra de guerillas y a evitar la concentración de unidades militares ante el avance de la Fuerza Aérea." (PizArro, s.p) Según el CNMH , "en un enfrentamiento en Puerto Lleras, el Ejército calcula que murieron 183 guerrilleros al ser detectado un campamento del Frente 15.” (CNMH, 2014, p. 205).

Para el Programa Presidencial de Derechos Humanos y Derecho Internacional Humanitario, "las Farc siguieron intentando dar un salto en su proceder militar, pero esta vez se puso de presente su desventaja aérea y fue así como en el Meta fallaron los ataques a Puerto Lleras, Puerto Rico y San Juan de Arama en donde la guerrilla puso muchas víctimas después de que sus hombres fueron bombardeados por la Fuerza Aérea Colombiana. Después de la ruptura de las conversaciones entre el Gobierno y las FARC las Fuerzas Militares hicieron esfuerzos por disminuir la influencia de las Farc en esa vasta zona." (Observatorio 
del Programa Presidencial de Derechos Humanos y Derecho Internacional Humanitario, 2002, p. 7).

Esto marcó la dinámica del conflicto armado interno ya que las FFMM recuperaron la iniciativa estratégica, porque lideraron enfrentamientos contra los actores armados. "Entre 1999 y el año 2000 los combates por iniciativa de las FF.MM. presentan un crecimiento sostenido que se acelera de forma significativa a partir del año 2001, hasta llegar en 2002 a superar ampliamente las acciones de los grupos irregulares. Entre 2003 y 2004, esta tendencia creciente se estabiliza y alcanza su mayor nivel.” (ECHANDÍA y BECHARA, 2006, p. 36).

Por la ubicación de los municipios de Puerto Lleras, Puerto Rico y los municipios de la zona de distensión se puede afirmar que los ataques a estos dos municipios tenían como propósito mantener el control territorial de las zonas de influencia cerca a la zona de distensión. Este propósito no es ajeno a las estrategias de creación de corredores de movilidad de las FARC que mostraron durante los años noventa con sus golpes estratégicos contra el Billar, Las Delicias, Miraflores y Mitú. Asi una vez más, las FARC querían demostrar su capacidad militar y política mediante el ataque a las poblaciones. Sin embargo, "su proyecto abortó en buena medida por la desventaja aérea. Sus intentos por ampliar su poder en el entorno de la zona de distensión fallaron por este factor, y no fueron pocas las bajas que les produjeron los intentos por tomarse Puerto Lleras, Puerto Rico y San Juan de Arama." (Observatorio del Programa Presidencial de Derechos Humanos y Derecho Internacional Humanitario, 2002).

El avión fantasma durante los ataques a Puerto Lleras y Puerto Rico fue clave ya que con los ametrallamientos y diferente entrega de armamento, y por la concentración de los guerrilleros en unidades grandes, permitió dar de baja a diferentes estructuras guerrilleras. De esta manera, en este caso se demostró una vez más que el poder aéreo por sus ventajas inheremente estratégicas como la flexibilidad, versatilidad, movilidad y por la condición de atacar directamente centros de gravedad, es clave para maximizar una debilidad de la organización ilegal. Teniendo en cuenta "los estudios de caso de la guerra irregular se demuestra la necesidad que el poder aéreo sea utilizado en misiones de apoyo a uno de los siguientes roles definidos en términos generales de ataque, movilidad, o de reconocimiento. Un aspecto crítico de la aplicación del poder aéreo es la capacidad de precisión." (HUEBERT, 2009, p. 41)3.

Precisamente esta fue una de las debilidades que se presentó durante el apoyo aéreo prestado por el Avión Fantasma, ya que para evitar los daños colaterales y evitar impactar a los policías que se encontraban en la Estación, el piloto del AC-47 mantenía constante comunicación con uno de los policías, para así ser preciso cuando se bombardeaba.

Traducción libre del autor 
Después del apoyo aéreo prestado en Puerto Rico y Puerto Lleras, estos territorios no volvieron a dominio de las FARC, porque la organización ilegal se dio cuenta lo expuestas que estaban al poder aéreo. Así mismo, con el golpe, la guerrilla empezó a disminuir sus ataques a los pueblos por el cambio en la dinámica del conflicto y no podian realizar ataques en masa (ECHANDíA, 2011).

En cuanto al cambio de la dinámica en el conflicto armado interno, producida por el éxito de las Fuerzas Militares en Puerto Rico (Caquetá) y Puerto Lleras (Meta), las FFMM demostraron la capacidad estratégica de retomar la iniciativa. Así lo señala Echandía, "las acciones en Caquetá tuvieron como escenario principal los municipios de El Doncello y Puerto Rico,donde luego de retomar la iniciativa, las Fuerzas Militares causaron 40 bajas en las filas de las FARC, mientras que un número aproximado de 37 agentes de la Policía fueron registrados como desaparecidos.” (2011,p. 15).

Por otro lado, en cuanto a la estrategia política para fortalecer su posición política en las conversaciones de paz, según lo afirma Echandía: "Estas acciones pusieron al descubierto el propósito de las FARC de avanzar en su "plan estratégico" mientras se llevaban a cabo las conversaciones con el gobierno en el Caguán.” (2011, p. 15). Lo cual evidencia que sus estrategias políticas y militares siempre van encaminadas y se articulan entre sí.

De esta manera, con las operaciones en Puerto Rico y Puerto Lleras, "las Fuerzas Militares van recuperando la iniciativa en la confrontación gracias al incremento en la movilidad y la mayor capacidad de reacción aérea para contrarrestar los ataques de las FARC. A los reveses sufridos por las FARC en julio de 1999 en Puerto Rico (Caquetá) y Puerto Lleras (Meta) se sumó en agosto, una operación de la Fuerza Aérea en Hato Corozal (Casanare), en la que fueron dados de baja 45 guerrilleros." (EchANDÍA, 2011).

En la medida que se incrementaban las operaciones de las Fuerzas Militares, se iba acumulando mayor experiencia operacional, teniendo en cuenta la dinámica de confrontación que propusieron las FARC durante los años noventa. El factor que alteró la correlación de fuerzas y la estrategia de la organización ilegal, fue el poder aéreo que se convirtio en la herramienta del Estado Colombiano, para repeler los ataques en Mitú, Puerto Rico, Puerto Lleras, posteriomente en Hato Corozal y en la operación Gato Negro. Este factor se vio potencializado por los recursos adquiridos bajo el Plan Colombia, que fueron claves para darle la iniciativa estratégica a las Fuerzas Militares.

\section{REFLEXIONES FINALES}

Cuando se evalúa el accionar de la Fuerza Aérea Colombiana, desde el año 2006 hasta el presente, se encuentra que esta Institución ha avanzado tecnológica y 
humanamente en una dirección adecuada para enfrentar positivamente a los actores armados ilegales, desarrollando operaciones aéreas que permitieron desactivar las estrategias territoriales de estos grupos y diezmando significativamente a estas organizaciones. Esto se ve reflejado claramente en las conclusiones a las que llegan diversos investigadores del conflicto armado colombiano, quienes señalan de forma clara que desde este período, organizaciones como las FARC, por ejemplo, no pudieron volver a desarrollar ofensivas de alto impacto contra la sociedad y contra el Estado (ECHANDÍA \& BECHARA, 2006).

Cuando desarrollé operaciones aéreas en la región de Arauca en el año 2006, constaté todos estos fenómenos expuestos, dimensionando que pese a la peligrosidad de las organizaciones armadas, nunca tendrían la posibilidad de desarrollar acciones irregulares como las que se hicieron en el Billar, Puerto Rico o Puerto Lleras. ¿A qué se debe esta transformación estratégica?, sintetizo la respuesta en tres temas puntuales:

En primer lugar, a la decisión y compromiso político del Gobierno Nacional, brindando recursos e infraestructura suficiente para que las FFMM pudieran desarrollar su misionalidad de forma expedita. Esto significó entender que la seguridad era un problema de Estado, y no podía depender del diagnóstico y posición de los gobiernos de turno.

En segundo lugar, a la cooperación internacional que brindaron los recursos necesarios y suficientes para modernizar el equipo técnico de las FFMM. Pero sobre todo, porque estos recursos permitieron que la Fuerza Aérea Colombiana se fortaleciera institucionalmente, y asumiera una posición estratégica ofensiva y decisiva. Varias operaciones áereas ponen de presente que estos cambios operacionales fueron importantísimos para dar un viro significativo del conflicto.

En ese mismo sentido, debe entenderse que el poder aéreo permitió superar la práctica irregular desarrollada por las FARC de utilizar artefactos explosivos no convencionados para impedir que las tropas de tierra avanzaran con celeridad por distintos corredores del país; esto fue un factor decisivo porque contrarrestó una apuesta macabra desarrollada por esta organización armada (Observatorio del Programa Presidencial de Derechos Humanos y Derecho Internacional Humanitario, 2002).

Finalmente, la articulación y coordinación entre las Fuerzas fue fundamental porque permitió triangular y complementar la información de inteligencia disponible, teniendo cada vez más claridad sobre las ubicaciones de los cabecillas y hombres claves de los Frentes de las FARC y los planes y propósitos que la organización tenía, lo que a la postre fue fundamental para dar los más duros golpes militares.

Además se articularon las distintas ventajas comparativas y poderes de cada Fuerza, maximizando y racionalizando el poder final que se desprendía 
de tal combinación, en beneficio de la seguridad, y de la articulación con las regulaciones de la normatividad nacional e internacional (MARÍn, et al, 2016).

Fue tan efectivo este período, y tan útil la combinación de esos tres factores que se hace necesario institucionalizar y perpetuarlos, como una forma permanente de operar de las FFMM, generando una cultura institucional en donde estos principios emerguen como máximas interiorizadas en la mentalidad de los comandantes y de todos los hombres adscritos a las mismas.

Ello implica superar los celos y egos institucionales, avanzar en el apoyo del poder político del país y la permanente tecnificación y modernización del proceder de la FFMM. Pero también significa seguir comprendiendo las ventajas estratégicas que ofrece el poder aéreo, y las mejores formas de sacar todo el provecho que éste puede ofrecer.

\section{REFERENCIAS}

Observatorio del Programa Presidencial de Derechos Humanos y Derecho Internacional Humanitario. (2002). Obtenido de Panorama actual del Meta: historico.derechoshumanos.gov.co/Observatorio/Publicaciones/.../meta/meta.pdf

Buitrago, F. L. (2002). Seguridad Nacional,Regional o de Estados Unidos. En F. L. Buitrago, La seguridad nacional a la deriva del frente nacional a la posguerra fría. Bogotá: Alfaomega.

CNMH. (2014). Centro Nacional de Memoria Histórica. Obtenido de Guerrilla y población civil trayectoria de las FARC 1949-2013.

Consejo de Estado. (2014). Sentencia 2075012: http://190.24.134.114:8080/ WebRelatoria/ce/index.xhtml

ECHANDÍA, C., \& BeChaRA, E. (2006). Conducta de la guerrilla el gobierno Uribe Vélez: las lógicas de control territorial a las lógicas de control estratégico. Análisis Político.

ECHANDÍA, Camilo. (2011). Situación actual de las FARC: un análisis de los cambios en las estrategias y la territorialidad. Obtenido de Fundacion Ideas para la Paz: www.ideaspaz.org/publications/posts/78

HUEBERT, K. D. (2009). The role of airpower in irregular warfare. Obtenido de Naval Postgraduate School: http://www.dtic.mil/dtic/tr/fulltext/u2/a514119.pdf

Marín, A., Castiblanco, C., Castrillon, J., \& Cotrina, A. (2016). La zona de distensión y su recuperación por la Fuerza Aérea Colombiana. En R. Esquivel, A. Marín, C. Castiblanco, J. Castrillón, A. Cotrina, M. Santos, y otros, La Fuerza Aérea Colombiana y el término del conflicto armado:Victorias desde el aire. Bogotá: Impress Colombia. 
Palacios, M. (2012). Paz Cuatrienal. En M. Palacios, Violencia pública en Colombia 1958 -2010. Bogotá: Federación de Cultura económica.

PARDo, R. (2008). La transformación de la guerra. En R. Pardo, Historia de las guerras. Bogotá: Norma.

Perdomo, Y. (2006). La operación Vuelo de Ángel: la retoma de Mitú. En G. Osorio. Hablan los generales las grandes batallas del conflicto colombiano contadas por sus protagonistas. Bogotá: Norma.

PizARRo, E. (s.p). Las FARC-EP ¿Repliegue estratégico, debilitamiento o punto de inflexión?. Bogotá.

Río, C. T. (2008). Conflicto interno y Fuerzas Armadas Colombianas 1982-2002. En C. T. Río. De milicias reales a militares contrainsurgentes la institución militar en Colombia del siglo XVIII al XXI. Bogotá: Editorial Pontificia Javeriana.

Santos, M. A. (2016). La operación Vuelo de Ángel,punto de inflexión del conflicto armado colombiano. En Esquivel, C. Castiblanco, A. Marin, J. Castrillón, A. Cotrina, M. SAntos, y otros. La insistencia de las FARC en los ataques contra las instalaciones de la Policía Nacional a partir de 1997 se convirtió en todo un propósito estratégico inscrito en el desarrollo de planes de guerra dispuestos a lograr el control de zonas especificas. Bogotá: Impress Colombia.

Torrijos, V. (2009). El poder y la Fuerza. En la unidad político-militar está la verdadera capacidad estratégica de la organización armada. En V. TORRIJOS. Crisis, Paz y Conflictos. Bogotá: Editorial Universidad del Rosario. 



\title{
LA OPERACIÓN VUELO DE ÁNGEL, PUNTO DE INFLEXIÓN EN EL CONFLICTO ARMADO COLOMBIANO
}

\author{
María ALEJANDRA SANTOS BARÓN ${ }^{l}$
}

\section{INTRODUCCIÓN}

El conflicto armado colombiano ha estado caracterizado por los enfrentamientos entre las Fuerzas Militares y grupos al margen de la ley como las FARC, ELN y grupos de autodefensas. De esta manera, durante este conflicto se han producido diferentes puntos de inflexión. Estos puntos se pueden entender como momentos de quiebre históricos, en donde se producen cambios en las dinámicas políticas, militares, económicas y sociales; que se ven alteradas por fenómenos externos o internos. "La noción de turning point -o punto de inflexión- hace referencia a momentos especialmente significativos de cambio; se trata de eventos o transiciones que provocan fuertes modificaciones." (ROBERTI, 2012). Como lo señala James A. RAWLEY, los puntos de inflexión, "sugieren coyunturas importantes en el curso de la historia, cuando la fuerza se encuentra con otra contra fuerza con tal intensidad, como para hacer posible un cambio.” (RAWLEY, 1967, p. 1) Igualmente, en los años noventa, se produjeron diferentes puntos de inflexión como los ataques de las Delicias, El Billar, la toma de Miraflores y la toma de Mitú.

Durante la década de los años noventa, Colombia vivió una época de violencia, caracterizada por los enfrentamientos violentos entre las Fuerzas Militares y los grupos al margen de la ley. Igualmente, en el transcurso de esta época el Estado colombiano tuvo problemas para consolidar su aparato estatal, ya que, al disputarse y enfrentarse con grupos al margen de la ley, el monopolio de la violencia legítima estaba debilitado.

\footnotetext{
Magister en Seguridad y Defensa Nacional de la Escuela Superior de Guerra, Politóloga del Colegio Mayor de Nuestra Señora del Rosario. Actualmente trabaja en la Fuerza Aérea Colombiana, en el Departamento Estratégico de Asuntos Jurídicos y Derechos Humanos. Es miembro del grupo de investigación "Análisis en Contexto". Este capítulo se basó en el trabajo de grado de la autora, para obtener su título profesional como politóloga. Agradecimientos especiales para el General Yair Perdomo, quien colaboró en la investigación.
} 
Los ataques a las Delicias, el Billar, la Toma de Miraflores y la Toma de Mitú, demostraron la debilidad estatal y constituyeron duros golpes a las FF.MM. Estos ataques corresponden a una estrategia política militar de la guerrilla para consolidar su poder territorial en el sur del país, con el propósito de crear un corredor estratégico de movilidad hacia las fronteras con Brasil y Venezuela. Sin embargo, con la respuesta de las FF.MM, en cabeza de la Fuerza Aérea bajo la Operación Vuelo de Ángel, se logró frenar la estrategia militar de la organización ilegal.

De esta manera, la Operación Vuelo de Ángel (O.V.A) realizada por la Fuerza Aérea Colombiana fue uno de los puntos de inflexión en el conflicto armado colombiano, esto por el poder aéreo utilizado que logró alterar las asimetrías entre las FF.MM y la organización ilegal. Esta operación frenó el paso de la guerra de guerrillas a la guerra de movimientos, siendo esta una asimetría que favorecía a la guerrilla. Así, el presente artículo pretende analizar por qué la Operación Vuelo de Ángel, puede considerarse como uno de los puntos de inflexión del conflicto armado colombiano.

El capítulo está divido en los siguientes apartados: en la primera parte, se explicarán los años noventa en el conflicto armado; y en la segunda parte, se analizará en qué consistió la Operación Vuelo de Ángel. Esta última parte consta de tres subpartes: la primera, la toma de Mitú; la segunda, la O.V.A y la tercera, después de la Operación.

La pregunta planteada para la investigación fue, ¿Por qué puede considerarse la Operación Vuelo de Ángel como el punto de inflexión del conflicto armado colombiano, teniendo en cuenta que esta operación cambio la asimetría de poder entre las FFMM y las FARC?

El presente capítulo cuenta con una investigación claramente cualitativa, en donde se escogió la tipología de estudio de caso. Esta metodología permite el estudio y análisis de un caso específico, encontrando las particularidades del mismo. Igualmente se manejará este método de investigación, en donde "se utilizan las descripciones interpretativas (palabras) más que estadísticas (números) para analizar los significados subyacentes y patrones de relaciones sociales." (Universidad de Valencia, s.p.).

El enfoque que se va a privilegiar en la investigación, es el enfoque neo institucionalista ya que este permite entender los fenómenos políticos mediante el estudio de las instituciones, así "la investigación de los fenómenos políticos parte de las instituciones, como rasgo estructural de la sociedad, o de la forma de gobierno. Sin embargo, se postula que este análisis debe estar también informado por un escrutinio del comportamiento individual, las ideas y los intereses en juego, tanto individuales, como grupales." (LosAda y CASAS, 2008, p. 179). En ese sentido, en el artículo se analizarán las instituciones y las relaciones de poder 
del Estado, las Fuerzas Militares, y la organización ilegal FARC, entendida como una organización al margen de la ley.

En este marco, "El resultado de la investigación podrá ser pertinente para el Estado Colombiano, especialmente para las Fuerzas Militares ya que este estudio les permitirá tener una investigación académica sobre el poder aéreo y su influencia en la alteración de la asimetría. Así mismo, esta investigación es relevante porque permite analizar una operación militar que resulta exitosa para el Estado Colombiano. Igualmente, este trabajo resulta pertinente para la ciencia política en la medida en que permite relacionar un concepto militar con un concepto académico, y permite entender las relaciones de poder que se presentaron entre la organización ilegal y el Estado colombiano." (SANTOS, 2014, p. 10).

Teniendo en cuenta la coyuntura actual de Colombia, en donde se presenta un proceso de paz con la guerrilla, es necesario evaluar las operaciones más relevantes del conflicto armado interno colombiano, ya que se pueden identificar los escenarios disuasorios, en donde por medio de la acción militar se logra hacer retroceder a la guerrilla.

\section{LOS AÑOS NOVENTA EN EL CONFLICTO ARMADO COLOMBIANO}

La época de los años noventa presentó una dinámica violenta dentro del contexto del conflicto armado colombiano, por los fuertes enfrentamientos que se presentaron entre las FFMM, las organizaciones ilegales como las FARC, ELN y las autodefensas. Igualmente, es en este tiempo que la guerrilla FARC, logra ejecutar ataques estratégicos en el sur del país.

Durante los años noventa, las Fuerzas Militares recibieron duros golpes contra sus Batallones, Brigadas, Puestos de Control, Puestos de Policía, entre otros. Los ataques militares a las Delicias, el Billar, Miraflores fueron parte de un planeamiento estratégico de la organización ilegal para crear un corredor hacia la frontera de Venezuela y Brasil. Esto con el propósito de mantener un control territorial en el suroriente del país.

Un factor fundamental en el incremento de los ataques militares perpetuados por las guerrilla en los noventa, fue el aumento de los cultivos de coca. "Colombia (...) paso a tener más de 100 mil hectáreas en 1995 y 150 mil hectáreas en 1996. Esta nueva actividad, que transformó el papel de Colombia en el negocio de la coca, también modificó la guerra de guerrillas (...) Las áreas de expansión de la coca fueron las selvas del sur, donde los grupos más significativos de las FARC tenían asiento." (PARDO, 2008, p. 626) De esta forma, se puede evidenciar la relación entre los cultivos de coca y la presencia de las FARC, en el sur de país. "La nueva fuente de recursos les dio a las FARC un nuevo horizonte 
político-militar y una nueva base social. La financiación le permitió a este grupo armado, en particular a los llamados bloques de frentes Oriental y Sur, aumentar numéricamente e incrementar sustancialmente su capacidad militar." (PARDO, 2008, p. 626) Con el crecimiento de las finanzas de la guerrilla impulsadas por el narcotráfico, fortalecen su capacidad económica para planear los ataques y movilizar su pie de fuerza en el sur del país.

Por iniciativa de la Fuerza Pública, en el Gobierno de Cesar Gaviria, se lanza el ataque contra Casa Verde, uno de los "santuarios de las FARC" y donde se encontraban los miembros del Estado Mayor de la organización ilegal. "Los combates por iniciativa de las Fuerzas Militares se incrementaron en virtud de la llamada "guerra integral contra la guerrilla" lanzada tras el fracaso de los diálogos de paz con la Coordinado Guerrillera Simón Bolívar(CGSB).” (EchANDía, 2008, p. 6). En el ataque contra Casa Verde se utilizaron diferentes recursos militares como helicópteros, aeronaves K-fir entre otros. "Al cabo de intensos bombardeos con aviones de guerra, tropas del Ejército asumieron ayer el control del área de influencia guerrillera en La Uribe y avanzaban ayer hacia Casa Verde, cuartel general de las Fuerzas Armadas Revolucionarias de Colombia (FARC)" (El Tiempo, 1990).

Más adelante, "durante el gobierno de Ernesto Samper (1994-1998), las FARC, que ya contaban con una mayor capacidad ofensiva derivada de la acumulación de experiencia en la preparación y conducción de ataques, escalaron su accionar con el propósito de dar el salto de la guerra de guerrillas a la guerra de movimientos." (EChANDÍA, 2008, p. 6). Un ejemplo de esto fueron los ataques de las Delicias, el Billar, y la Toma de Miraflores.

De esta forma, en 1996 se produce el ataque en las Delicias (Caquetá), contra una base militar del Ejército. "Era la primera vez que una compañía, establecida en una base previamente fortificada, con armamento y equipo completo, con adecuado entrenamiento general era totalmente destruida."(PARDO,2004, p. 632)2. Este ataque de la organización ilegal era con "fuego nutrido de ametralladoras, granadas de fusil y de mortero. Decía el operador de radio que el ataque principal lo estaban dirigiendo con artillería pesada, probablemente se refería a cilindros de gas, rellenos de explosivos y metralla." (PARDO, 2004, p. 628). Con este ataque las FARC demostraron a las Fuerzas Militares sus capacidades bélicas ${ }^{3}$.

Por otra parte, el éxito de esta operación de la guerrilla, radica "en el dominio de la zona, tanto de los ríos como de los caminos en la selva, del conocimiento de la situación y de los movimientos de las unidades militares, de su capacidad de reunir cuatrocientos hombres, sin ser detectados por la inteligencia militar, y de esperar el momento adecuado para realizar el golpe de mano." (Pardo, 2008 , p. 631). Esta operación, refleja el paso de las guerras de guerrillas a la guerra de posiciones, en la medida en que las FARC, realizan un ataque prologando, con un pie de fuerza relativamente alto, y el enfrentamiento contra la Compañía del Ejército fue con artillería pesada.

3 Como lo menciona Rafael Pardo, "las operaciones desplegadas por estos dos bloques de frente de las Farc, tuvieron desde 1996 una característica novedosa: eran propiamente militares, con grandes unidades y teniendo como objetivos bases militares y policiales fuertemente defendidas, muy distintas a los hostigamientos, 
Otro ataque estratégico para la guerrilla fue el ataque conocido como El Billar. Éste fue realizado el $1^{\circ}$ de Marzo de 1998, en el municipio de Cartagena del Chairá (Caquetá), contra el Batallón Contraguerrillas No 52. "Esta era la primera vez que una unidad especializada en la lucha contra la insurgencia perfectamente entrenada y con mejor dotación de las FF.MM, era atacada por un actor irregular." (PARDO, 2004, p. 636).

Después del ataque de El Billar, el 3 de agosto de 1998, se produce lo que se conoce como la Toma de Miraflores, contra la Base de Policía Antidrogas, en el municipio de Miraflores (Guaviare). Este "enfrentamiento, que duró más de 20 horas, dejó como saldo 9 muertos, 10 heridos y 22 militares desaparecidos." ( El Espectador, 2008).

Así mismo, como lo señala Camilo Echadía, "el Ejército sufrió un duro revés en su empeño por debilitar la retaguardia estratégica del bloque sur (...) las FARC atacaron las bases de la Policía en Miraflores (Guaviare) y Uribe (Meta), así como las instalaciones del Ejército en Pavarandó (Urabá); en desarrollo de estas acciones murieron cerca de 100 personas entre uniformados y civiles y fue secuestrado un centenar de miembros de la Fuerza Pública." (Echandía, 2011, p. 13). Estos ataques debilitaron a las Fuerzas Militares. Igualmente, el Estado Colombiano estaba atenuado por su poca eficiencia en el control del monopolio legítimo de la violencia. Así, "el Estado colombiano, debido a la falta de presencia en todo el territorio nacional y a la pérdida del monopolio legítimo de la fuerza, no integra ni cohesiona la población y el territorio y ha reducido su capacidad para mediar y canalizar los conflictos y tensiones sociales. Estos son resueltos al margen de las instituciones públicas, lo cual es la causa del surgimiento de diversas expresiones de "parainstitucionalidad", tales como los grupos privados de justicia y defensa, las mafias de narcotráfico y los movimientos guerrilleros.” (EsCOBAR, 1998).

Ahora bien, como lo muestra la siguiente gráfica, para 1996 las FARC ya se encontraban en la etapa de guerra de movimientos, los ataques perpetrados durante este año y hasta 1998, son el reflejo del paso de la guerra de guerrillas a la guerra de movimientos. Esto se debe a la estrategia militar de la guerrilla de propiciar golpes a unidades militares, durante un tiempo prolongado,con armamento pesado y utilizando una cantidad alta de combatientes. Así, dejan las emboscadas, y los ataques de repliege, para pasar a un enfrentamiento prolongado con las Fuerzas Militares. Los casos mencionados anteriomente, de los ataques a las Delicias, El Billar, Miraflores reflejan precisamente ese cambio de estrategia.

emboscadas o asaltos a pequeñas unidades, que había predominado en las tres décadas anteriores." (Pardo, 2008, p. 626). En este orden de ideas, a partir del año 1996, las FARC ponen en práctica, su modo de operar, (ubicación, detección, asedio y copamiento) para atacar unidades militares. 
Gráfico 1. Etapas de la Guerra Popular Prolongada de las FARC-EP.

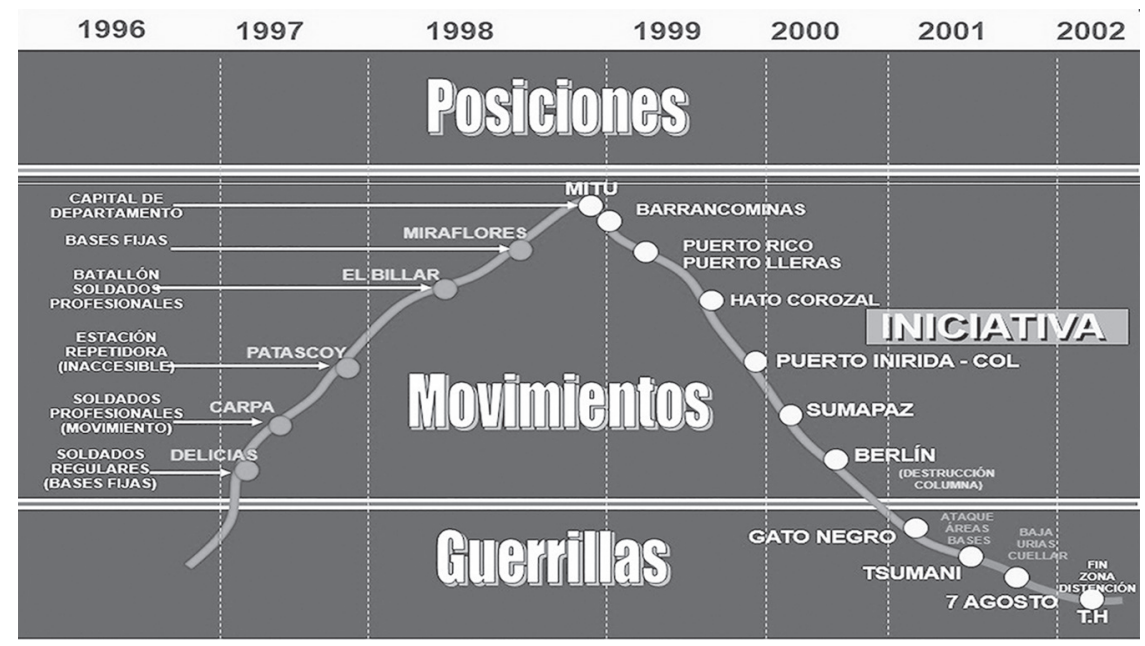

Fuente: (Santos, 2014, p. 19)

El Bloque Oriental de las FARC en "1993 se le asignó un área de injerencia que comprendía nueve departamentos: Cundinamarca, Boyacá, Arauca, Casanare, Vichada, Meta, Guaviare, Guainía y Vaupés.” (Paz, 2015, p. 5). Teniendo en cuenta que este Bloque fue el que lideró los ataques de las Delicias, El Billar,Miraflores y Mitú, se puede deducir que su apuesta de control territorial estaba enfocada a la creación de un corredor de movilidad hacia las fronteras de Brasil y Venezuela. Respecto a esto, el Gr Perdomo menciona que "de esta forma todos esos puntos (Miraflores, Carurú, las Delicias, el Billar) eran lanzas que estaban dirigidos, hacia la frontera con Brasil y Venezuela". (SANTOS, 2014, p. 65).

Prueba de ello es la ubicación geográfica de los municipios de Puerto Leguizamón, Putumayo (Delicias), Cartagena del Chaira, Caquetá (El Billar), Miraflores, Guaviare, y Mitú, Vaupés. Al trazar una línea entre estos municipios se puede deducir que el control territorial de éstas, era fundamental para la organización ilegal, para así tener un corredor de movilidad. Si lograban mantener esos territorios, tenían controlado una parte importante del sur del país, el siguiente mapa muestra el trazo de "la línea estratégica de control de las FARC"

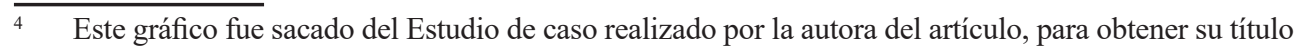
como Politóloga, con base a una entrevista que se le realizó al General Perdomo. 


\section{Mapa 1. Corredor Estratégico de las FARC 1996-1998}

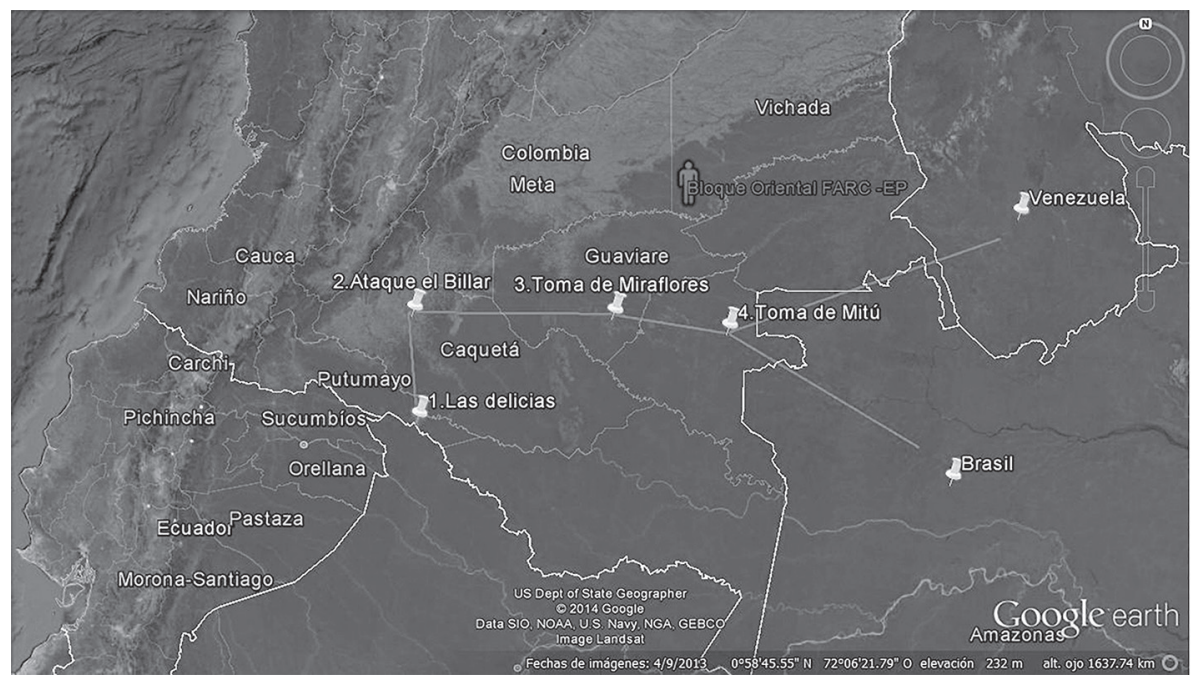

Fuente: (Santos,2014, p. 23).

Por otra parte, mientras por la vía militar se apoderaban de esos territorios, por la vía política conseguían otros. Cuando se inicia el proceso de paz del Gobierno del Presidente Andrés Pastrana, las FARC solicitan el despegue de varios territorios en el departamento del Metá. "El pedido hecho por las Farc a comienzos de 1998, de desmilitarizar los municipios de San Vicente del Caguán, la Uribe, Mesetas, La Macarena y Vista Hermosa, como requisito para iniciar conversaciones de paz, fue ratificado a mediados del año y aceptado por Pastrana, como presidente electo.” (LeAL, 2002, p. 150). Vale la pena aclarar que más adelante se va a retomar este punto.

En conclusión, la década de los años noventa fue violenta por los ataques producidos por la organización ilegal en diferentes zonas del país, sobre todo en el sur, con los ataques a las Delicias, El Billar, y Miraflores. Estos son otros puntos de inflexión que marcaron la época de los años noventa. Ahora bien, la guerrilla siguiendo los planteamientos estratégicos de las Conferencias, y bajo la tesis de la guerra popular prolongada se encuentran en la etapa de la guerra de movimientos, los ataques en esta época son precisamente un reflejo de este ciclo. Para 1998, Colombia vivía uno de los períodos más violentos de su historia. Con los ataques producidos, la organización ilegal pretendió crear un corredor de movilidad en el sur del país, con salida hacia las fronteras, para tener un control territorial que le aseguraba el tránsito de tropas, y el tráfico de drogas ilícitas. 


\section{LA OPERACIÓN VUELO DE ÁNGEL}

El siguiente apartado se enfoca en analizar la Operación Vuelo de Ángel (O.V.A), entendida como la operación militar que logró alterar las asimetrías entre la Fuerza Pública, y la organización ilegal, por el poder aéreo utilizado. De esta forma, este apartado tiene tres subpartes, la primera describe la toma de Mitú, en donde se explicará en qué consistió la toma; la segunda analiza la Operación Vuelo de Ángel; y la tercera pretende explicar qué pasó después de la O.V.A, ya que esta operación se convirtió en un precedente militar para las Fuerza Pública y el Estado Colombiano.

\subsection{LA TOMA DE Mitú}

La apuesta más estrátegica de la organización ilegal, durante los años noventa, fue la Toma de Mitú. Este ataque se produjo el $1^{\circ}$ de noviembre de 1998, en la capital del Vaupés. "Con 1.200 de sus hombres, las FARC iban tras el último lugar de la amazonia cubierto por presencia policial: apostados en el puesto de policía de Mitú, 75 policías, entre oficiales, suboficiales y agentes, intentaban defenderse sin posibilidad de recibir apoyo inmediato, a pesar de estar en una capital de departamento." (Perdomo, 2006, p. 288).

Por una parte, este ataque de la organización ilegal tenía tres propósitos, el primero relacionado con línea estratégica de control territorial, mencionada anteriormente. De esta forma, controlar Mitú, era demostrarle al país que eran capaces de tomarse una capital de departamento, y dada la posición geográfica de Mitú (cercanía con la frontera de Brasil) asegurar ese territorio, era tener controlado un punto estratégico con la frontera, creando así el corredor de movilidad. El segundo propósito, era fortalecer su posición política en la mesa de conversación con el gobierno del Presidente Andrés Pastrana."Con miras a maximizar su posición negociadora con Pastrana, las Farc se tomaron la población de Mitú, capital de departamento" (PAlacios, 2012, p. 159). Por último, el tercer propósito estaba relacionado con el reconocimiento internacional del estatus de beligerancia al demostrar el control del territorio.

"La intención de la guerrilla no era solo dar un golpe efectista y salir, sino quedarse definitivamente -o por lo menos algunas semanas- en esta población, reclamando de la comunidad internacional un reconocimiento de su estatus de beligernacia, algo que quizás algunos pocos países hubieran hecho, basandose en precedentes históricos y en la terminología internacional, que se aplica a movimientos insurgentes que llegan a dominar una parte importante del territorio. Inclusive,llegamos a tener información de que allí pensaban lanzar una especie de gobierno autónomo sobre una porción de territorio para generar un hecho político.” (Pastrana, 2005, p. 93). 
En este orden de ideas, las estrategias militares y políticas de la organización ilegal, para 1998, le estaban dando resultados contundentes. Además, con la estrategia militar de la guerra popular prolongada, les permitió realizar ataques, para así fortalecer su estrategia política de la "toma del poder." Igualmente, bajo el contexto del proceso de paz con Pastrana, la guerrilla logró demostrar su poderío militar con la toma de Mitú.

"El Bloque Oriental de las FARC, integrado por los frentes 1, 7, 17, 44 y por la Columna Móvil Juan José Rondón, que sumaban no menos de mil trescientos hombres atacaron a Mitú.” (PARDO, 2008, p. 639). Esta toma, estaba liderada por Henry Castellanos, alias Romaña, y como comandante del Bloque estaba Jorge Briceño Suárez, alias Mono Jojoy. "Los guerrilleros atacaron el cuartel de Policía, y sus alrededores, en un radio de tres manzanas, que quedaron prácticamente arrasadas, utilizando armas no convencionales, como cilindros de gas rellenos con gasolina, pegante inflamable, y pentolita, además de gradanas, que lanzaban desde las mismas viviendas de los atemorizados pobladores." (Pastrana, 2005, p. 94). Las FARC eligieron Mitú porque les representaba una ventaja asimétrica ${ }^{5}$ favorable respecto a las Fuerzas Militares. "Mitú era en ese momento el punto más alejado de la geografía colombiana con una concentración importante de Fuerza Pública. Era el lugar al que podían atacar con ventaja porque los refuerzos tardarían mucho tiempo en llegar." (Perdomo, 2006, p. 289). Igualmente, otro factor que favoreció la Toma fue que "el sitio más cercano para lanzar la operación aérea era San José del Guaviare, ubicado a 180 millas de Mitú.” (Perdomo, 2006, p. 293). Por tanto, el radio de alcance de los helicópteros (200 millas) no alcanzaba para regresar a San JosÉ del Guaviare. (Perdomo, 2006, p. 293).

En Mitú la presencia estatal estaba liderada por la Policía, como lo relata John Frank Pinchao, "nosotros éramos un grupo aproximadamente de 75 policías, en su mayoría patrulleros recién egresados de las escuelas de formación policial, quienes, al contrario de lo que comúnmente se piensa -que son inexpertos y no aptos para el combate- se defendieron como tigres. Fuimos atacados por unos 1500 guerrilleros al mando del Mono Jojoy, quien delegó funciones en comandantes guerrilleros como Urías, Romana, Patesopa, y otros. La verdad no esperaba que emplearan tantos guerrilleros para esta toma, pues como lo dije, era prácticamente un pueblo tranquilo y esto no tenía antecedentes." (MARTíN y JARAMILLO, 2014).

Para efectos del concepto de asimetría se trae a colación, el concepto de Steven Metz, el cual define que la asimetría es "actuar, organizar y pensar diferente al oponente con el fin de maximizar las ventajas, explotar las debilidades del adversario, obtener la iniciativa, o alcanzar una mayor libertad de acción. Ésta puede ser estrategia-política, estrategia militar o una combinación de ambas." (Metz y Johnson II, 2001). 


\title{
2.2. La Operación Vuelo de Ángel
}

Ahora bien, para contrarrestar la Toma de Mitú, las Fuerzas Militares lanzan la Operación Vuelo de Ángel (O.V.A). Ésta consistió en el apoyo aéreo a los Policías y el ataque aéreo a posiciones de la organización ilegal. El poder aéreo ${ }^{6}$ se vio reflejado en la utilización de aeronaves de ala fija (AC-47 Fantasma, C130 Hércules, OV -10 Bronco, T 27 Super Tucano, C235) y aeronaves de ala rotatoria (Helicópteros Black Hawk y Arpia). En ese sentido "la primera decisión que tomaron las FF.MM, fue enviar un avión fantasma AC-47 y 2 aviones OV -10 Bronco, para que estos realizaran los primeros bombardeos, y sirvieran como apoyo aéreo para los policías que estaban en Mitú." (SANTOS, 2014, p. 37). Igualmente, para retomar Mitú, los Generales Freddy Padilla de León, Comandante de la VII Brigada del Ejército, el General Jaime Humberto Cortés Parada, Comandante de la Cuarta División, junto con el entonces Coronel Perdomo, Comandante de CACOM 4, empezaron a planear la operación.

En el momento en que la organización ilegal se tomá Mitú, las FFMM realizan un cálculo estratégico de la importancia de recuperar la capital.Respecto a esto el Gr (r) Perdomo comenta:

\begin{abstract}
"Cuando comenzamos a valorar todo y a realizar el análisis durante el ataque a Mitú nos dimos cuenta que ellos ya tenían todo preparado, atacaron La Uribe, el Billar, y las Delicias, hicimos la flecha trazando estos puntos y nos preguntamos esta gente para donde va. Cuando atacan Miraflores, usted mira la cronología y se da cuenta que ellos estaban caminando y nosotros no nos dimos cuenta. Entonces cuando dicen Mitú, nos dimos cuenta que o vamos por Mitú o perdemos media Colombia, que era parte del plan de las FARC. Cuando se presentó esta situación, nos dimos cuenta que teníamos que salvarle la vida a la gente y al Estado.” (SANTOS, 2014, p. 65).
\end{abstract}

Por parte de la Fuerza Aérea Colombiana (FAC), "el Comando de la Fuerza Aérea dispusó de cuatro Black Hawn, dos UH-60 de transporte y dos tipo Arpía de ataque, tres aviones fantasma, tres OV -10, un Tucano T-27, y dos Hércules c-130" (RUEDA, 2008, p. 640). El apoyo aéreo prestado por el Avión Fantasma fue fundamental, para disminuir la intensidad del ataque, sin embargo, para el $1^{\circ}$ de noviembre en la tarde, los policías "que resistian en el puesto se entregaron ante la superioridad de los atacantes" (PARDO, 2008, p. 640). Un factor que disminuyó la efectividad del poder aéreo fue que para ese entonces, las Fuerzas Militares no tenían cartografía de Mitú, por tanto al momento de lanzar los bombardeos, no había mucha precisión, y se podía afectar a la población civil. "Habíamos olvidado a Mitú, no teníamos mapas discriminados por cuadrantes, ni grillas del terreno para que los policías en tierra pudieran darnos instrucciones precisas."' (PERDOMO, 2006, p. 294).

El poder aéreo es "el uso militar de recursos aeroespaciales para defensa de la nación y apoyar su política extranjera. Más aún, es la aplicación de instrumentos aeroespaciales para el logro de los objetivos del liderazgo nacional." (Ogan, 1991). 
Sin embargo, ese problema se resolvió cuando por instrucciones del General Perdomo, se realizó un mapa con indicaciones de personas que conocían la capital y lo complementaban cuando las tripulaciones regresaban. (Perdomo, 2006, p. 295). "Para contrarrestar esta dificultad, el entonces Coronel Perdomo, quien dirigió la operación, mandó llamar a un agente de la policía que había estado en Mitú y por esta razón conocía la capital. Así, éste le hizo un mapa de Mitú, ubicando el Hospital, el colegio, el puesto de policía, entre otros." (SANTOS, 2014, p. 37).

Estos mapas se crearon bajo la denominación de grillas, como lo menciona el Gr Perdomo:

"Se nos presentó un problema relacionado con la precisión de los ataques. Así,
cuando la Policía nos pedía apoyo, mire que nos estaban disparando desde la
Iglesia, pero uno alcanzaba a ver la punta de la Iglesia, pero no sabíamos cuál
era. Entonces qué nos tocó hacer, nos inventamos en Apiay, una cosa que se
llama las grillas, entonces tomábamos las fotos de los pueblos y lo dividíamos
en cuadros. Así, a cada puesto de Policía, le entregamos una foto con las grillas,
y nosotros teníamos otra. Por ejemplo, cuando atacaban un pueblo, la Policía
decía me están atacando el Cuadro C, y nosotros cuadriculamos las fotos. Ellos
nos decían el cuadro y nosotros aquí lo dibujamos, entonces sabíamos a donde
mandar el ataque exactamente. Así, todos teníamos esos mapas y cuando nos
pedían el apoyo, nosotros sabíamos dónde actuar". (SANTos, 2014, p. 65).

Sin embargo, para el caso de Mitú no tenían estas grillas al iniciar la Operación, ya después se fue configurando el mapa, como se muestra en el siguiente mapa que realizaron policías y pilotos para la retoma de Mitú.

\section{Mapa 2. Mapa de Mitú en Grillas}

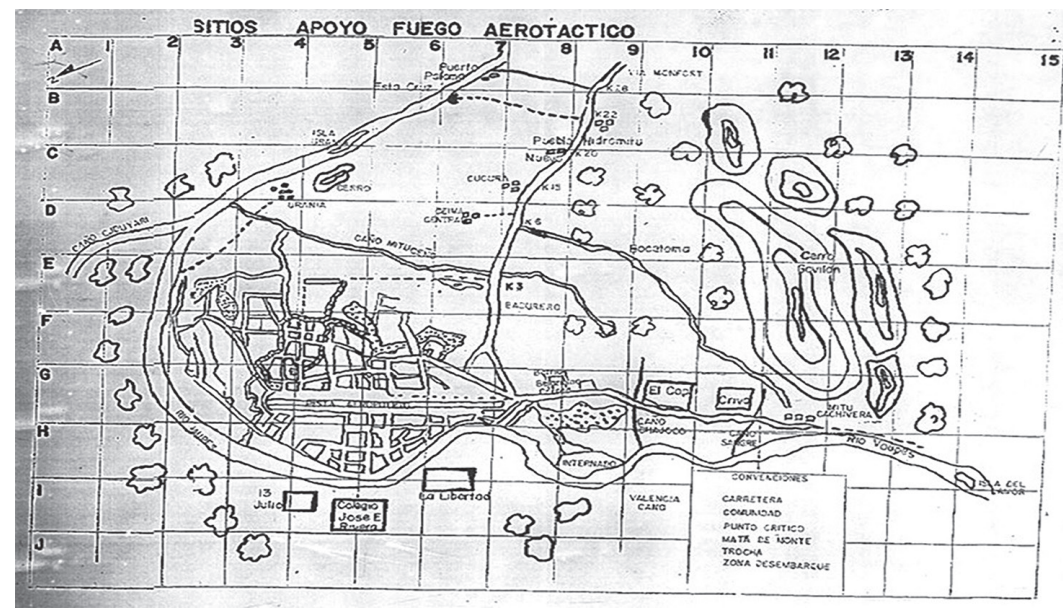

Fuente: (Perdomo, 2013, p. 23) ${ }^{7}$

\footnotetext{
7 Gráfica proporcionada por el General Yair Perdomo.
} 
Como no había una pista aérea cercana a Mitú, las Fuerzas Militares, utilizaron una pista en la frontera de Brasil. "Era una pista construida por el gobierno brasilero para ejercer soberanía de frontera y que tenía unos ochocientos o mil metros de largo. Pensaba que allí podríamos aterrizar aviones Hércules C 130, aviones Caza 235 y los helicópteros uh-60 de transporte y de combate." (Perdomo, 2006, p. 296). Esta pista fue una ventaja para las FFMM en la medida en que les permitió desplegar todo el poderio aéreo, resbastecerse y pernoctar, fue desde allí que los Hércules, los Helicópteros Black Hawk, y los OV 10 lanzaron la Operación. Respecto a esto el Gr Perdomo comenta que "no teníamos una pista entre San José del Guaviare y Mitú para transportar los aviones, entonces tuvimos que tramitar un permiso para utilizar una pista que hay en la frontera en Brasil. Una de estas pistas era Itibare esta quedaba a 70 millas a distancia al Sur, quedaría a 280 millas, entonces no podíamos llegar. Igualmente, ellos nos estaban haciendo un monitoreo y estaban escuchando nuestra frecuencia y cuando nos dimos cuenta el operador de radio de las FARC-EP, nos dice jaquí nos vamos a quedar! Eso nos motivó más." (SANTOS, 2014, p. 68).

"Las FARC-EP realizaron un cálculo estratégico basado en las distancias entre Mitú, y los lugares en los cuales se podría lanzar una operación. Sin embargo, no contaron con que las FF.MM encontrarían una pista en Brasil, en donde pudieron aprovisionar a los aviones y helicópteros. Entonces, el cálculo estratégico se convirtió en una asimetría de poder que era una ventaja para las FARC-EP y una debilidad para las FF.MM.” (SANTOS, 2014, p. 42). Sin embargo, cuando se utilizó la pista en Brasil, este asimetría se alteró terminando por favorecer a la Fuerza Aérea. De esta manera, se puede evidenciar que cuando el Estado combina su poder nacional, en este caso la diplomacia, con el poder militar, puede alterar las asimetrías y así maximizar una debilidad de la organización guerrillera.

Mientras la tropa de Ejército se transportaba hacia la pista en Querari, Brasil, "El avión Fantasma detectó a los guerrilleros de las FARC que se reagrupaban, organizaban cordones de seguridad y se movian por río y por tierra. Bajo un incesante bombardeo, la Fuerza Aérea dio de baja un número importante de subversivos, la retoma apenas comenzaba" (PERDOMO, 2006, p. 302). Uno de los instrumentos aeroespaciales que fue clave en la Operación Vuelo de Ángel, fue el avión fanstasma este "era el más importante, porque era el que tenía mayor duración de tiempo, y en ese avión podíamos meter a gente para que hiciera monitoreo de comunicación. Ellos escuchaban todo lo que pasaba y nos ayudaban a orientar, porque no teníamos equipos de interceptaciones de comunicaciones. El fantasma tenía un sistema que se llamaba FLIR, y con este sistema podíamos ver los movimientos de la guerrilla." (SANTOS, 2014, p. 70).

Uno de los factores de éxito de la Operación Vuelo de Ángel, radica en la utilización de las capacidades inherentemente estratégicas del poder aéreo como lo son la velocidad, la flexibilidad, la maniobrabilidad para atacar los 
centros de gravedad del enemigo. Esto se ve reflejado en O.V.A en la medida en que el avión fantasma pudo bombardear posiciones de la guerrilla.También con la utilización de la pista en aérea en Brasil, esto les permitío tener mayor flexibilidad y maniobrabilidad. En ese sentido, "el poder aéreo tiene una serie de ventajas asimétricas (capacidades a las que el enemigo no se puede enfrentar con paridad ni contrarrestar de ninguna forma). Por ejemplo, la capacidad del poder aéreo de llevar a cabo ataques de precisión en todo el mundo puede desempeñar una función importante en las operaciones de contrainsurgencia." (PECK, 2007). Igualmente, respecto al poder aéreo, como lo menciona Hayward "sus contribuciones más significativas son, probablemente, en los ámbitos de la movilidad, inteligencia y la conciencia de la situación"8. (HAYWARD, 2009, p. 14).

Así mismo, "cuando la guerrilla pasa a la guerra de movimientos y se agrupa en grandes unidades militares, queda expuesto al poder aéreo. Por tal razón, en esta etapa de la guerra popular prolongada es que el poder aéreo logra ser más efectivo, porque el enemigo está agrupado en grandes unidades y está expuesto a los ataques que el poder aéreo logre efectuar." (SANTOS, 2014, p. 34). De esta forma, en Mitú cuando la organización ilegal se agrupó quedó expuesta a los bombardeos y ametrallamientos que realizó la Fuerza Aérea.

Una de esas ventajas asimétricas es que "cuando se producía un bombardeo del Avión Fantasma, este logra atacar el centro de gravedad de las FARC-EP, porque el poder aéreo demostrado ofrece "la capacidad de perseguir directamente objetivos." (VARGAS 2010, p. 25). Así, cuando se identificaba un objetivo, el avión podía lanzar un bombardeo y generar muchas bajas, porque el enemigo estaba concentrado en un solo lugar. Así mismo, el poder aéreo tiene la capacidad de alterar la asimetría de poder, ya que por sus características particulares tales como la flexibilidad, la versatilidad, la movilidad y la respuesta, logran que exista superioridad aérea y se logra atacar los centros de gravedad." (SANTOS, 2014, p. 43).

Igualmente, esta "asimetría que aprovecharon muy bien las FF.MM, fue el poder aéreo ya que les permitió obtener una ventaja en el teatro de operaciones. En la Operación Vuelo de Ángel, el uso de los helicópteros y aviones de ala fija, fueron vitales para retomar la capital del Vaupés. Así, las FF.MM utilizaron helicópteros Black Hawk UH-60 y helicópteros AH-60 Arpía, que se utilizan para combate. También utilizaron el avión AC-47 Fantasma, que proporcionó apoyo aéreo; el avión C-130 Hércules, y el avión Caza 235 para el transporte de las tropas; aviones OV-10 Bronco para el combate y apoyo aéreo; y un avión Tucano T-27 para la retransmisión de las comunicaciones." (SANTOS, 2014, p. 43).

Para el 2 de noviembre de 1998, con el constante apoyo aéreo del Avión AC-47 Fantasma y los OV-1O, ya se preparaba el desembarco en Mitú para recuperar la

$8 \quad$ Cita traducida del inglés por la autora. 
capital. Así como lo menciona el Gr Perdomo "completamos un contingente de 270 soldados en Querarí (...) le pedí al Capitán Garzón que usará una zona de desembarque a más de cinco millas del pueblo y desplegará la primera oleada de la operación, cerca de Mitú para retomar la población" (PERDOMO, 2006, p. 301). Con el trabajo conjunto y coordinado entre el Ejército Nacional, la Fuerza Aérea y la Policía, las Fuerzas Militares se preparaban para el desembarco. De esta forma, con los helicópteros Arpía se atacó a las FARC con el propósito de ablandarlos, "a las 11:30 de la mañana terminó el desembarcó de 250 soldados, y la 1:20 de la tarde, empezaron los combates entre la guerrilla y el Ejército. Las FARC calcularon las distancias y ubicaron 35 emboscadas" (Perdomo, 2006, p. 303).

Finalmente, el 3 de noviembre, "el AC-47 ubicó, a través del sistema FLIR, (...) un grupo grueso de guerrilleros que huía de Mitú por el río, les hundimos un bongo y dimos de baja a un gran número de ellos." (Perdomo, 2006, p. 305). Igualmente, "el fantasma ubicó otra columna guerrillera y fue en este ataque donde hizo un mayor número de bajas. Para el académico español de la Universidad de los Andes, Román Ortiz, especialista en guerra de guerrillas (...) ese bombardeó acabó todo el frente 37 de las FARC, aproximadamente ochenta guerrilleros." (PERdOMO, 2006, p. 306). El hecho de acabar en un solo bombardeo con casi todo un frente, es un indicador de la efectividad del poder aéreo. Es quizá por esta razón que la guerrilla se percató de las debilidades de concentrarse en grandes unidades, porque quedaban totalmente expuestas.

Respecto a esto, el General Perdomo en una entrevista señala que "la gente que estuvo en Mitú nos contó que la Guerrilla utilizó tres volquetas de obras públicas, para sacar a sus muertos porque ellos no los dejan. Se presentaron tantos muertos, porque yo sabía dónde estaba la guerrilla, yo sabía dónde era el sitio de concentración, desembarco y donde estaban las lanchas. A raíz de eso, simplemente verificamos y mandamos el ataque. Por eso fueron tantos muertos. El impacto mundial fue grandísimo, porque era una capital de departamento, pero la gente no sabía que Mitú era pequeño. Se tomaron el Estado, la cabecera del Vaupés, entonces eso impacta. Tenían ya San José del Guaviare, y se tomaron Mitú, para crear la República independiente de Marquetalia.” (SANTos, 2014, p. 70).

Como bien se sabe, para este año 1998, la guerrilla estaba tratando de demostrar su poderío militar. Con la Operación Vuelo de Ángel se revierte su estrategia militar de pasar a la guerra de movimientos, y las devuelve a la primera etapa de la guerra popular prolongada, la guerra de guerrillas. (ver gráfico 1) Es quizá por esta razón, que la O.V.A se convierte en uno de los puntos de inflexión del conflicto armado colombiano, ya que gracias al poder aéreo utilizado, las FFMM lograron alterar y cambiar la estrategia militar de las FARC. En este sentido, el Gr Perdomo afirma que: 


\begin{abstract}
"Mitú representó el punto de quiebre de la ofensiva guerrillera y el momento en el cual las FARC entendieron que teníamos la voluntad suficiente para enfrentarlos en cualquier lugar de la geografía colombiana, de día o de noche. Después de Mitú ellos tuvieron que volver a su esquema de guerra de guerrillas y al terrorismo, porque su estrategia de juntar muchos guerrilleros los exponía a grandes bajas por cuenta del poder aéreo.” (PERDOMO, 2006, p. 306).
\end{abstract}

Igualmente si se analiza la correlación de fuerzas para esa toma, el uso de las aeronaves de ala fija y de ala rotatoria, ${ }^{9}$ que fueron 23 , con la inexistencia de una capacidad de contrarrestar el poder aéreo por parte de la guerrilla para el año de 1998, esta correlación favorece positivamente a las FFMM. "La subversión desde hace varios años busca revertir la desventaja estratégica en la que quedó cuando la Fuerza Aérea modernizó su flota de aviones y helicópteros de reconocimiento y combate, al tiempo que el Ejército, la Armada y la Policía también fortalecieron sus divisiones de aviación. Todo eso le ha permitido al Estado penetrar en zonas consideradas casi como "santuarios" de la guerrilla y del propio "Secretariado." (Siglo, 2012). Sin embargo, como lo señala el General (r) Héctor Fabio Velasco, ex Comandante de la FAC "En 1999 las FARC adquirieron en un país centroamericano unos misiles de éstos, pero ese armamento requiere una preservación muy especial en un ambiente seco y frío, en la selva o en climas tropicales no se conservan bien, porque se dañan muy fácilmente" (Siglo, 2012). De esta forma, se puede evidenciar como después del 1998, las FARC empiezan a tratar de conseguir misiles tierra-aire para compensar esa debilidad estratégica de la guerrilla.

Una asimetría que benefició a la organización ilegal fue el pie de fuerza, "por una parte las FARC-EP contaban con aproximadamente mil doscientos hombres (Perdomo, 2006, p. 288), que pertenecían al Bloque Oriental compuesto por los Frentes 1, 7, 17, 44, y por la Columna Móvil Juan José Rondón. (PARDO, 2004, p. 639). A diferencia de la Policía que contaba con 75 policías, entre oficiales, suboficiales y agentes. Ahí se puede evidenciar una asimetría que favorece a las FARC-EP pues en la toma, contaban con mayor pie de fuerza que las FF.MM. Ahora bien, cuando las FF.MM lanzan la operación, "la respuesta del Ejército provino de los batallones de contraguerilla 7, 52, 53 y 54 con un total de mil doscientos hombres." (Río 2008, p. 345). Eso sin contar que se alteró la correlación de fuerzas de la organización ilegal, por el uso de los instrumentos aeroespaciales.

Igualmente, otro factor que favoreció a las Fuerzas militares es ese miedo que tiene la organización ilegal hacia los helicópteros y aviones. De esta forma, el General Perdomo comenta que:

$9 \quad$ En total fueron utilizados 23 aeronaves, entre las cuales se encuentra "Helicóptero U-60 Black Hawk, Helicóptero UH60 Arpia, Avión AC-47 “Avión Fantasma, Avión C130 "Hércules”, OV -10 Bronco, Avión C235, y avión T-27 Tucano" Esta información fue rastreada de fuentes bibliográficas, recursos de internet como la página web de la Fuerza Aérea Colombiana y de conversaciones telefónicas y entrevistas con el Gr Yair Perdomo Alvarado. 
"Los próximos ataques los hizo distantes: me atacó la Uribe, me atacó Puerto Lleras, Puerto Rico, y me atacó un puerto por allá que se llama Hato Corozal, entonces comenzó a medirme todas las fuerzas, yo tenía aviones en la base de Marandua, y en Tres esquinas. Posterior a eso, cuando yo oigo "teléfono rojo", pienso que este me va a atacar y yo no tengo ningún avión, entonces se me ocurrió que los aviones de entrenamiento volarán la zona. Así que les dije a unos instructores de entrenamiento, que volarán diferentes zonas, entonces cada uno iba a volar por diferentes zonas. Por allá estaban hablando, porque la triangulación de los radios, daba que estaban allá. Entonces cuando oímos las triangulaciones, nos dimos cuenta que iban a hacer los ataques en esos puntos: en Saravena, Puerto Lleras, Orito, Uribe y Puerto Rico, me iba a hacer cuatro jugadas. Por lo tanto, yo les dije vamos a hacer lo siguiente, váyanse y vuelan sobre estos pueblos, uno tiene que estar en el punto a las siete, el otro a las seis y media, usted a las seis y cuarenta, usted a las cinco, y usted a las cinco y media. Entonces comiencen a hablar entre ustedes, porque él los va a estar escuchando, digan lo que quieran pero digan que van a atacar, que están esperando la autorización para atacar. En la conversación, el "Mono Jojoy" dice cancelamos la situación y nos vamos por estafetas y aplazamos la estrategia.” (SANTOS, 2014, p. 45).

Por otra parte, el uso de los instrumentos aeroespaciales, generó una ventaja positiva para FFMM ya que por los bombardeos y los ametrallamientos, se logró dar de baja a una cantidad considerable de guerrilleros, como se señaló anteriormente. Finalmente, después de los últimos bombardeos realizados por la Fuerza Aérea en Mitú, la organización ilegal se empieza a replegar por el río Vaupés, utilizando diferentes rutas de escape. El siguiente mapa evidencia las rutas de escape de la guerrilla, cuando se estaba finalizando la Operación Vuelo de Ángel.

\section{Mapa 3. Rutas de Escape FARC}

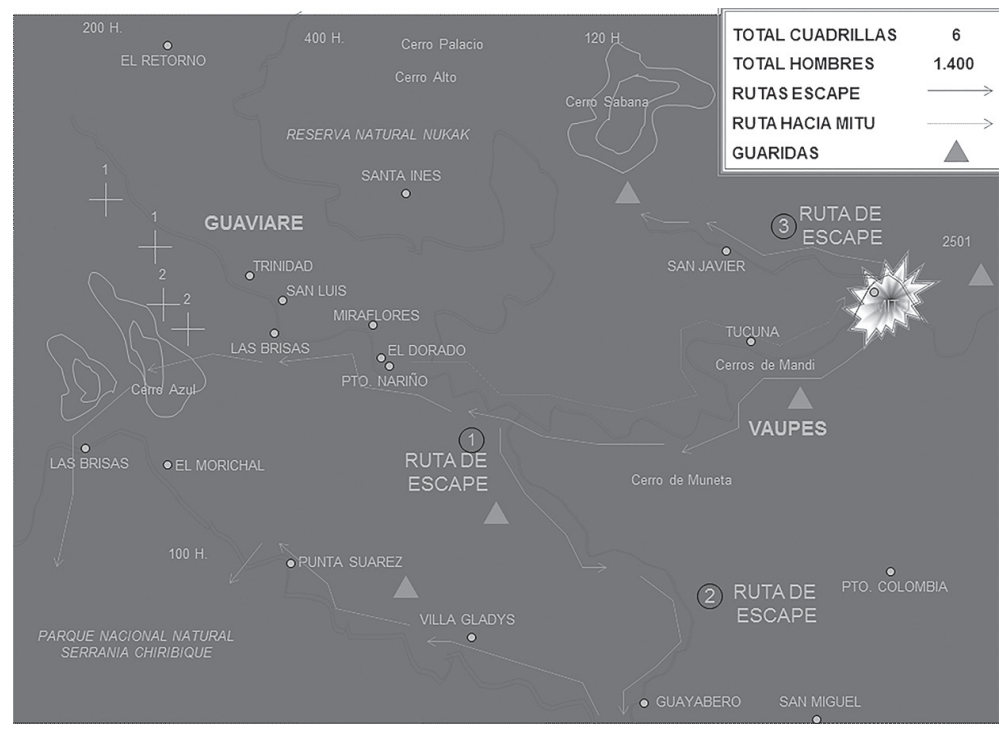

Fuente: (Perdomo, 2013, p. 11)

10 Gráfica proporcionada por el General Yair Perdomo. 
Por otra parte, en Mitú, la organización ilegal utilizando las asimetrís, empleó armamento no convencial, "habían lanzado doscientos cilindros bombas, cargados con metralla y pegamento para, de paso producir intoxicación en la tropa, a causa de la mezcla de gases." (Perdomo, 2006, p. 306). "El uso de armas no convencionales se convierte en una asimetría que utilizan las FARC-EP, para atacar al enemigo. Las FF. MM. como están sujetas al Derecho Internacional Humanitario y a los Protocolos I y II de la Convención de Ginebra, no utilizan armas que no estén reguladas por el Derecho Internacional. Esto supone una ventaja para las FARC-EP ya que al no estar sujetas en estos tratados internacionales, recurren a este tipo de prácticas para generar mayor daño.” (SANTOS, 2014, p. 44).

De esta forma como lo señala Robin GEISs "la parte más débil buscaba obtener una ventaja comparativa frente a un enemigo militarmente superior, asistimos a la reaparición de prácticas prohibidas desde hace tiempo en los conflictos armados, como son los ataques directos contra personas civiles, la toma de rehenes y el uso de escudos humanos, y a la utilización de esas prácticas como estrategia". (GeIss 2006, p. 2).

"Como saldo de la violenta incursión guerrillera, 16 civiles y 12 policías fueron asesinados, 10 policías resultaron heridos y 60 policías fueron secuestrados, incluyendo al Coronel Luis Mendieta." (PATiÑo, 2010). Eso sin contar que Mitú quedó destruida, por los cilindros que utilizó la organización guerrillera.

"La Operación Vuelo de Ángel marcó un punto de quiebre en el conflicto colombiano, porque esta operación frenó la avanzada guerrillera. Gracias al poder aéreo demostrado, se dieron de baja a muchos guerrilleros, lo cual permitió inclinar la balanza hacia el Estado colombiano. Así mismo, con esta operación se alteró la correlación de fuerzas entre las FF.MM y las FARC-EP. Esta operación "supuso un avance estratégico del Estado para materializar un objetivo perseguido desde vieja data: la presencia y el control en cualquier parte del territorio nacional." (FLÓREZ y JARAMILLO, 2014, p. 80). Igualmente, esta operación sirvió para que las FF.MM se dieran cuenta que el poder aéreo, es una ventaja que el Estado colombiano debe explotar al máximo, ya que el poder aéreo produce una asimetría que debe ser utilizada." (SANTOS, 2014, p. 41).

De esta manera,"el intento de toma de Mitú en 1998, fue el final de un período de iniciativa estratégica por parde de las FARC, y fue el fracaso de su intento por pasar a una guerra de posiciones (...) la Fuerza Aérea incrementó su velocidad de respuesta y su poder de fuego, lo que hizo más vulnerable a la guerrilla en este tipo de ataques masivos" (PARDO, 2008, p. 644).

Así mismo Alfredo Rangel, establece que "se puede afirmar que la toma de Mitú marcó un punto de quiebre en la dinámica del conflicto con las FARC. A raíz de este hecho, y en particular de la operación para retomar el control del municipio, las Fuerzas Militares lograron integrar de manera efectiva el poder 
aéreo en apoyo a las fuerzas terrestres. Esta operación también fue pionera en el uso de los medios de combate nocturno." (RANGEL, 2003, p. 23). De esta forma, como lo señala Rangel también "al contar las Fuerzas Militares con medios aéreos para concentrar tropas rápidamente y proveer apoyo de fuego desde el aire, obligaron a las FARC a regresar a sus operaciones de guerra de guerrillas." (RANGEL, 2003, p. 52).

En ese sentido, la Operación Vuelo de Ángel logró frenar la estrategía militar de la organización ilegal, en la medida en que gracias a las caractéristicas inheremente estratégicas del poder aéreo, se debilitó la organización guerrillera, en cuanto a que se produjeron muchas muertes en combate de guerrilleros, y como por la guerra de movimientos, se agrupan en grandes cantidades, esto los expone ante el ataque de helicópteros o aviones como el Fantasma.

El éxito del poder aéreo con la operación Vuelo de Ángel radica en que "el poder aéreo en la guerra irregular se debe adaptar para ser efectivo, esto significa que debe identificar los nuevos centros de gravedad del enemigo y planear estratégicamente cuál es la mejor manera para derrotar al enemigo. Así, logra utilizar correctamente los instrumentos aeroespaciales. Una de las adaptaciones que debe realizar el poder aéreo es preparar a sus pilotos y demás miembros de la Fuerza Aérea, para entender los conflictos asimétricos. Cuando logran entender la forma en la que luchan las guerrillas, podrán dar golpes más efectivos. De esta forma, podrán entender que el poder aéreo en la guerra popular prolongada es más efectivo cuando se está en la guerra de movimientos, ya que en esta, la guerrilla se expone a los ataques estratégicos del poder aéreo." (SANTOS, 2014, p. 52).

Igualmente, "en consonancia con las premisas de la asimetría como estrategia, los Estados que luchan contra irregulares ven como sus ventajas son relativizadas por el enemigo. No obstante, para Colombia el hecho de contar con la supremacía aérea nunca ha dejado de ser una ventaja. Dicho de otro modo, haber alterado las ventajas relativas con las que contaba, la guerrilla por medio de la acción de la Fuerza Aérea, le sirvió al Estado para debilitarla." (JARAMILlO y STRONG, 2014, p. 18). Así se puede evidenciar, que el poder aéreo en la O.V.A. se convirtió en una herramienta militar del Estado, para recuperar el monopolio legítimo de la violencia, y así enviar un mensaje político a otras organizaciones al margen de la ley, en cuanto a que el Estado estaba preparado para repeler cualquier enfrentamiento. También se puede considerar "la Operación Vuelo de Ángel como una operación que permitió dar un salto estratégico operacional que alteró las premisas del conflicto colombiano.” (SANTOS, 2014, p. 41).

En resumen, la O.V.A implicó "misiones típicas de Defensa Aérea, Contrapoder terreste, Transporte aéreo, Asalto aéreo, Reconocimiento, inteligencia y vigilancia, así como de Comando y control." (JARAmiLlo \& STRONG, 2014, p. 16). En ese orden de ideas, la magnitud de la repuperación de Mitú "es un hito 
indispensable para entender la importancia de la superioridad aérea como un elemento clave para la libertad de acción de las Fuerzas Militares." (JARAMILLO y STRONG, 2014, p. 16).

\title{
2.3. Despúes de la Operación Vuelo de Ángel
}

Posteriormente de la Operación Vuelo de Ángel, las FFMM recuperaron su capacidad ofensiva, siendo más proactivas. Esto se ve reflejado en la medida en que después del 1998, las FFMM recuperaron su iniciativa táctica y estratégica, porque lograron proyectar operaciones militares contundentes contra la organización ilegal. Además de la transformación militar que se presentó, generando así las condiciones militares y políticas para el fortalecimiento de las Instituciones Militares.

Por ejemplo, "desde el Ministerio de Defensa, y el Comando General de las Fuerzas Militares, contando con la ayuda norteamericana se emprendió su más profunda transformación recuperando su iniciativa táctica y obligando a las FARC a retroceder (...) Con los golpes recibidos y su impacto en la institución, las Fuerzas Militares comenzaron a trabajar conceptos como los de masa y movilidad para responder a la guerra de guerrillas, lo que implicaba que la situación de confrontación se analizaba como una guerra a la que se tenía que responder con operaciones militares. (TORRES, 2008, p. 351).

Respecto a las operaciones militares relevantes, producto de esta transformación, se destacan la Operación Gato Negro y la Siete de Agosto:

\begin{abstract}
"Dos de las principales operaciones militares llevadas a cabo fueron la "Gato Negro" y "la Siete de Agosto". En la primera operación en marzo y abril de 2001, la Cuarta División, la FUDRA, la Armada y la Fuerza Aérea, en la región de San José de Ocuné, Puerto Principe, Guerima, Puerto Lindo, El Lomo, Chupabe, Cumaribo y San Felipe (Vichada) y Barrancominas (Guanía) capturaron al narcotraficante Fernandinho y tomaron un importante corredor de selva y ríos que utilizaban las farc. En agosto de 2001, aconteció la mayor operación de contrainsurgencia, después del descalabro de fines de los noventa; fue la respuesta al intento de las FARC de tomar la base de Carimagua y de recuperar el corredor que habían perdido en la Operación Gato Negro; participaron cuatro mil soldados de FUDRA, apoyados por veinte helicópteros y aviones de combate contra unos mil trescientos guerrilleros, en esta operación fue dado de baja Urias Cuella, junto con unos seiscientos insurgentes más." (ToRREs, 2008, p. 352).
\end{abstract}

Igualmente, era necesario reconfigurar las estructuras militares de las FFMM, adaptándolas al contexto de la guerra irregular. "El análisis de lo sucedido entre 1996 y 1998 llevó al estudio de la estrategia de las FARC, la que proyecta copar la cordillera oriental y en ella cercar a la capital del país (...) las Fuerzas Militares centraron su plan en la neutralización de los corredores de movilidad 
de la guerrilla, lo que afectó la estructura orgánica de las Fuerzas Militares, en tres niveles de consideración: primero se crearon los batallones de alta monta; segundo al servicio militar ingresaron miles de jóvenes del sector rural bajo la modalidad de-soldados campesinos-, y en tercer lugar, en la medida en que cerca de quinientos municipios de Colombia no había presencia de las Fuerzas militares, la estrategia de defensa proyectó y puso en marcha la actuación combinada de la policía con los militares.” (TORRES, 2008, p. 352).

Ahora bien, la transformación de las Fuerzas Militares, estuvo a cargo del General Fernando Tapias y el General Jorge Mora. "Para que pueda hablarse de transformación militar ella debe comprender tres aspectos complementarios: 1) cambios institucionales, 2) nuevas tegnologías, y 3) una nueva doctrina.' (TorRes, 2008, p. 354). El resultado de la nueva estructura orgánica de las Fuerzas Militares para los primeros cinco años del siglo XX fue el siguiente:

- Comando Conjunto Operaciones Especiales

- Coordinación Nacional de Inteligencia

- Comando Conjunto Caribe

- Fuerza de Tarea Conjunta

- Agrupación Fuerzas Especiales Antiterroristas Urbanas-AFEAUR (14)

- Batallones de Alta Montaña (7)

- Brigadas Móviles( 15)

- Grupos Gaula (32)

- Soldados Campesinos (27.000)

- Infantería de Marina (4.355)

- Escuadrones Móviles (54)

Seis divisiones Unidades Especiales (FUDRA, Brigada contra el Narcotráfico, Brigada de Aviación del Ejército, Brigada de Fuerzas Especiales) ${ }^{11}$

Toda esta restructuración militar, le dio herramientas a las FFMM para combatir a la organización ilegal. De esta manera, lograron focalizar los esfuerzos y transformarse para la guerra irregular que se vivía en Colombia.

Así mismo, "las FARC intenteron despues de Mitú, tres operaciones masivas: Puerto Rico, Meta, Casanare y San Juanito, Cundinamarca, pero fracasaron y tuvieron grandes bajas en todas ellas. A partir de esos fracasos, la guerrilla

11 Esta tabla fue sacada de (TorRes, 2008, p. 354). 
reincidió en sus ataques a pequeñas guarniciones, a pueblos desprotegidos y zonas nubladas o altas para evitar la reacción aérea." (PARDo, 2008, p. 644). Se puede evidenciar, como después de O.V.A la organización ilegal, tuvo que cambiar su modo de operar. Esto se debe a que las FFMM comprendieron las fortalezas de utilizar el poder aéreo, maximizando una debilidad de la guerrilla.

Igualmente, como lo señala Ingrid Bolívar, "desde finales de 1998, la Fuerza Pública comenzaba a mostrar alguna capacidad para neutralizar la cadena de acciones contundentes que le venían propiniando las FARC, gracias a la ventanja representada por el uso de helicópteros y aviones." (GoNZÁLEZ, BoLÍvar, y VÁSQUEZ, 2002, p. 78). En ese orden de ideas, se puede afirmar, que la Operación Vuelo de Ángel se convirtió en un predecente militar, la cual generó que las FFMM se percataran de las ventajas tácticas y estratégicas del poder aéreo.

Así mismó "durante los cuatro años (1998-2002), la relativa ventaja táctica de las FARC fue prácticamente neutralizada por la Fuerza Pública mediante el uso de la ayuda tegnológica del paquete militar incluido en el Plan Colombia y los cambios operados en los mecanismos de inteligencia del Ejército Nacional. Al golpe de Mitú contra las FARC, siguieron las acciones de la Fuerza Pública en Dabeida, en Arauca, y en el Guaviare, en las cuales los muertos de la guerrilla pasaron de 150.” (GoNZÁlez, Bolívar y VÁSQUEZ, 2002, p. 78).

En cuanto al escenario político durante y después de la retoma de Mitú, este estuvo enmarcado por el proceso de paz que se adelantó entre el Gobierno del Presidente Andrés Pastrana y la guerrilla de las FARC. "El 9 de enero de 1999, se instalaron oficialmente los diálogos de paz" (GONZÁlEZ, BolívAR y VÁSQUEZ, 2002, p. 79). Sin embargo, a principios de 1998, ya se habían iniciado los diálogos, en donde una de la exigencias de las FARC fue la desmilitarización "de los municipios de San Vicente del Caguán, La Uribe, Mesetas, la Macarena y Vista hermosa, requisito para iniciar conversaciones.” (BuitraGo, 2002, p. 151). Así, "amparado bajo la ley 418 de 1997, llamada de orden público decretó el despeje de un areá de 42.000 kilometros cuadrados por 90 días, del 7 de noviembre de 1998 al 7 de febrero de 1999." (Buitrago, 2002, p. 152).

Así se estableció después “una zona de despegue en el Caguán, que requirió once prórrogas presidenciales, objeto de negociaciones" (PALACIOS, 2012, p. 159). Esta zona de despegue comprendió los mismos municipios de San Vicente del Caguán, La Uribe, Mesetas, la Macarena y Vista hermosa.

Para la organización ilegal, "el despegue en los cinco municipios contiguos y selváticos para empezar el diálogo era una reinvidación de alto valor simbólico (...). Sin embargo, en el suroriente colombiano, el despeje del Caguán se entendió como un extraordinario triunfo político de las Farc; como un reconocimiento implícito a sus recientes victorias militares y a su poderío, la zona de despegue se convirtió en formidable arma de propaganda fariana." (PALACIOS, 2012, p. 162). 
En este sentido, vale la pena preguntarse ¿Cómo después de Mitú el Gobierno Nacional, fue capaz de entregar territorios para el despeje? Era claro que la toma de Mitú fue una estrategia política y militar de la organización ilegal, para fortalecer su posición en la mesa de negociación.

No obstante, pese a que la toma de Mitú no salió como lo planeaban, después de demostrar su capacidad militar, el gobierno le entregó ese territorio. Respecto a esto, Marco Palacios señala que "el Secretariado transmitió a las bases y simpatizantes la idea que los triunfos militares de los últimos tres años (19961998) marcaban una tendencia irreversible. En ese momento festivo no sacaron ninguna conclusión autocrítica del fiasco de Mitú." (PALACios, 2012, p. 162). Sin embargo, las FFMM mandaron un mensaje fuerte a la organización ilegal con la Operación Vuelo de Ángel, en la medida en que demostraron que estaban preparadas militarmente para repeler cualquier ataque que se presentará en el territorio colombiano.

En conclusión, la Toma de Mitú fue un intento fracasado de la organización ilegal en la guerra de movimientos. Este intento fue un fracaso por la respuesta militar de las Fuerzas Armadas enmarcada en la Operación Vuelo de Ángel. Ésta se configuró como un precedente militar para las Fuerzas Militares, sobretodo para la Fuerza Aérea Colombiana. Esto porque el poder aéreo utilizado en la Operación, maximizó las ventajas interesantemente estratégicas. De esta forma, alteró asimetrías como el pie de fuerza de la organización guerrillera, la estrategia militar de crear un corredor estratégico, entre otros. Igualmente, permitió que las FFMM entendieran la importancia del poder aéreo como una herramienta militar y política para debilitar al enemigo. Después de la Operación Vuelo de Ángel, las Fuerzas Militares fueron más proactivas, porque lograron demostrar su capacidad militar para neutralizar a las organizaciónes ilegales. Esto se ve reflejado en la medida en que las FFMM lograron maximizar la ventaja del uso de aviones de ala rotatoria y ala fija, prueba de ello fueron las acciones militares de la Fuerza Pública en las operaciones Gato Negro, y Siete de Agosto.

\section{CONCLUSIONES}

Este trabajo se propusó analizar porque la operación Vuelo de Ángel fue uno de los puntos de inflexion del conflicto armado. Esto por el poder aéreo demostrado, que logró alterar las asimetrías de poder entre las FFMM y la organización ilegal.

En ese orden de ideas, siguiendo las premisas del conflicto armado colombiano se encontró que éste ha estado caracterizado por los enfrentamientos entre el Estado y grupos al margen de la ley. De esta manera, se presentaron puntos de inflexión históricos, como la violencia bipartidista del siglo XIX, el Bogotazo, la Operación Marquetalia, entre otros. Desde este momento, se empezaron a gestar problemas económicos, inestabilidad política, violencia, y exclusión política. En 
los años sesenta bajo el contexto de la Guerra Fría, y en donde las ideologías marxistas y leninistas estaban en furor, se crearon, grupos al margen de la ley, conocidos como las guerrillas de las FARC, ELN y el EPL. En ese sentido, la organización ilegal FARC se configura como un actor irregular, que bajo la tesis de la guerra popular prolongada y la combinación de todas las formas de lucha, empiezan a gestar ataques contra el Estado Colombiano.

Es así, que durante los años noventa, se presentaron diferentes ataques militares por parte de las FARC, cambiando la dinámica de la violencia. En esa época, el Estado Colombiano tuvo problemas para mantener su monopolio legítimo de la violencia, ya que al tener que enfrentarse con grupos ilegales, estos cuestionaron esa capacidad estatal propia del Estado de Derecho. Igualmente, siguiendo los planteamientos estratégicos de la organización ilegal bajo la Séptima Conferencia y la Octava Conferencia, se estructuraron como grupo armado ilegal, con un modo de operar diferente, y en donde entienden la necesidad estratégica de controlar territorios. Así pues, en los años noventa, realizan diferentes golpes en el sur del país, como los ataques a Las Delicias, El Billar, Miraflores y Mitú. Estos ataques tienen un factor común, fueron enfrentamientos prolongados, con armamento pesado (artillería) y los objetivos militares son estratégicos. Además, en los noventa, la organización ilegal se encuentraban en la guerra de movimientos de la guerra popular prolongada, la cual les permitió agruparse y atacar unidades militares especializadas.

Ahora bien, uno de los resultados del análisis de la década de los años noventa, con los ataques a Las Delicias, el Billar, Miraflores y Mitú, se infiere que la guerrilla quería controlar esos territorios para crear y mantener un corredor de movilidad hacia las fronteras de Venezuela y Brasil. Esa línea estratégica que se traza uniendo los puntos, permite visualizar ese control de territorios. Igualmente, con la desmilitarización y después el despeje de territorio en la zona de distensión, se evidencia que la organización ilegal mediante sus estrategias políticas, pretendía también obtener territorios, pero por vía política.

Otro resultado de la investigación demostró que cuando la organización ilegal lanza la Toma de Mitú, esta tenía un carácter estratégico de alto valor, ya que en primer lugar, es una capital de departamento en una zona estratégica. En segundo lugar, la guerrilla quería fortalecer su posición política en la mesa de negociación con el Gobierno del Presidente Andrés Pastrana y tercero, al controlar el territorio, le demostrarían a la comunidad internacional su capacidad bélica, con el propósito de obtener el estatus de beligerancia. También, le querían demostrar al Estado y a las FFMM su capacidad militar y el control territorial. La organización ilegal estaba desgastando al Estado al propiciar ataques en todo el territorio colombiano, por ende al realizar la toma de Mitú mandaban un mensaje político (estamos en todo el territorio), a comparación del Estado en donde en muchos lugares, no había presencia estatal. 
Sin embargo, las FFMM en cabeza de la Fuerza Aérea Colombiana, lanzan la Operación Vuelo de Ángel, para retomar Mitú. Uno de los resultados más relevantes de la investigación radica en que esta Operación fue clave para recuperar Mitú, ya que gracias a la utilización de los instrumentos aeroespaciales, las FFMM lograron alterar asimetrías de la organización ilegal, como el pie de fuerza, y otros cálculos estratégicos. La Operación Vuelo de Ángel también logró cambiar la estrategia militar de la organización ilegal de pasar de la guerra de guerrillas a la guerra de movimientos, en la medida en que la guerrilla se dio cuenta que al estar agrupadas, quedan expuestas al poder aéreo. Quizá por esta razón, se puede considerar que la O.V.A es uno de los puntos de inflexión en el Conflicto Armado Colombiano, porque al cambiar la estrategia militar de la organización ilegal, estas tuvieron que volver a la guerra de guerrillas para poder realizar ataques contra el Estado. Esta operación cambió las dinámicas del conflicto, obligando a la organización ilegal a realizar emboscadas y otras tácticas propias de guerra de guerrillas. Por estas razones, se puede considerar la Operación Vuelo de Ángel, como un punto de inflexión que logró alterar la estrategia de la organización ilegal, así como cambiar la balanza de poder entre las FFMM y la guerrilla, favoreciendo al Estado Colombiano.

Después de Mitú, pese a que las FARC perdieron en términos militares, ganaron en términos políticos, dicho de otro modo, el ataque a Mitú, les permitió fortalecer su posición política en el proceso de paz con el Gobierno Pastrana y obligaron al Estado a sentarse a dialogar. Sin embargo, las FFMM con la O.V.A tuvieron muchas lecciones aprendidas y se dieron cuenta que la ventaja táctica y estratégica del poder aéreo, podía ser clave para ganar batallas. De esta forma, la Operación Vuelo de Ángel, se convirtío en un precedente histórico y militar que marcó el Conflicto Armado Colombiano. En ese orden de ideas, el poder aéreo se configuró como una herramienta militar para el Estado, para recuperar su monopolio legítimo de la violencia.

\section{REFERENCIAS}

GonzÁlez, F. E. (2002). La dinámica del conflicto . En: F. E. González, Violencia política en Colombia de la nación fragmentada a la construcción del Estado (pp. 41-92). Bogotá: CINEP.

Jaramillo, M., y Strong, J. (2014). La Fuerza Aérea Colombiana, Punta de lanza de la defensa de la nación . En: La Fuerza Aérea Colombiana y sus nuevos retos. Campos de acción en un escenario interno transformado (pp. 9-58). Bogotá: Escuela Superior de Guerra.

LosADA, R. y Casas. Enfoques que privilegian las Instituciones. Enfoques para el análisis político. (pp. 163-178) Bogotá: Pontificia Universidad Javeriana, 2008. 
Leal, Francisco (2002). ¿Seguridad Nacional, Regional o de Estados Unidos? La seguridad nacional a la deriva (pp. 144-188). Bogotá: Alfaomega.

Palacios, M. (2012). Paz cuatrienal, Violencia pública en Colombia, 1985-2010 (p. 220). Bogotá: Fondo de Cultura Económica.

PATIÑo. (2010). Estado y Guerra, Guerra y construcción del Estado en Colombia 1810-2010. (p. 303) Bogotá: Random House.

PARDO, R. (2008). La transformación de la guerra, La historia de las guerras (pp. 625-649). Bogota: Ediciones B.

Pastrana, A. (2005). Capítulo IX el día que cambió la guerra. La palabra bajo fuego (p. 554). Bogotá: Planeta.

Perdomo, Y.(2006). La Operación Vuelo de Ángel: la retoma de Mitú. En G. Osorio Martínez(Comp.) Hablan los generales las grandes batallas del conflicto Colombiano contadas por sus protagonistas (pp. 298-306). Bogotá: Editorial Norma.

Torres ,C. (2008). Conflicto interno y Fuerzas Armadas Colombianas. En C. Torres del Río y S. Hernández (Eds), De milicias reales a milicias contrainsurgentes. (pp. 339-361) Bogotá: Editorial Pontificia Universidad Javeriana.

Artículos en publicaciones periódicas académicas

ECHANDÍA, C. (2008). El fin de la vulnerabilidad de las FARC. El estado actual del conflicto armado en Colombia. Nueva Sociedad, 217, 1-10. Disponible en:http://www.nuso.org/upload/articulos/3543_1.pdf

GeISs, R. (2006). Las estructuras de los conflictos asimétricos. En: International Review of the Red Cross, (864):1-24 Disponible en http://www.icrc.org/spa/ assets/files/other/irrc_864_geiss.pdf

MARTín, JE., Jaramillo-Marín, J. (2014). Las conmemoraciones noticiosas en la prensa colombiana: rememorando la toma a Mitú, Palabra Clave 17(2):378-411. Disponible en http://palabraclave.unisabana.edu.co/index. php/palabraclave/article/view/3561/3504

Rawley. (1967). Turning Points of the Civil War. Review Book. The Journal of Southern History 33 (3) , pp. 411-412 Disponible en http://www.jstor.org/ stable/2204893

Roberti, E. (2012). El enfoque biográfico en el análisis social: claves para un estudio de los aspectos teórico-metodológicos de las trayectorias laborales, En: Revista Colombiana de Sociología. RCS 35 (1) Disponible en http:// www.revistas.unal.edu.co/index.php/recs/article/view/31341/39585

OrJUELA, L. (1998). El Estado colombiano en los noventa: entre la legitimidad y la eficiencia. Revista de Estudios Sociales,(1) :56-60. Disponible en http:// res.uniandes.edu.co/view.php/28/index.php?id=28 
PUBLICACIONES PERIÓDICAS NO ACADÉMICAS

ECHANDÍA, C. (2011). Situación actual de las FARC: Un análisis de los cambios en las estrategias y la territorialidad (1990-2011). Verdad Abierta. Disponible en www.verdadabierta.com/documentos/.../farc-1/270-situacion-farc-web1

Fundación Ideas para la Paz (2015). Hoy y ayer del Bloque oriental de las Farc Áreas Dinámicas del Conflicto y Negociaciones de Paz marzo de 2015, Fundación Ideas para la Paz: Disponible en http://cdn.ideaspaz.org/media/ website/document/552d4149f0d72.pdf

HaYward, J. (2009). Air Power, Insurgency and the War on Terror. Royal Air Force Centre for Air Power Studies: Disponbible en http://www.joelhayward. org/Hayward\%20Insurgency\%20Book\%20\%20A5\%20We b.pdf

METz, S., y Johnson II. (2001). Asymmetry and U.S military strategy: Definition,Background and Strategic concepts.Strategic studies institute. Disponible en http://www.strategicstudiesinstitute.army.mil/pubs/display.cfm?pubID=223

Ogan, A. J. (1991). Reflexionando sobre el poder aéreo. Air and Space Power Journal Disponible en http://www.airpower.maxwell.af.mil/apjinternational/ apjs/1991/1trimes91/ogan.html\#ogan

Peck, A. G. (2007). La Función Crucial del Poder Aéreo en la Guerra Irregular (IW). En: Panzertruppen. Disponible en: http://www.panzertruppen.org/ documentos/poderaereo.html

RANGEL, A. (2003). Fuerzas militares para la guerra. La agenda pendiente de la reforma militar. Fundación Seguridad y Democracia : Disponible en http:// www.aporrea.org/media/2009/11/fuerzas_militares_para_la_guerra.pdf

SAntos, M. (2014). La Operación Vuelo de Ángel, el poder de la Fuerza Aérea Colombiana y el cambio en la asimetría de poder entre las FFMM y las FARC: Repositorio Universidad del Rosario Disponible en http://repository.urosario. edu.co/bitstream/handle/10336/8913/1020765037-2014.pdf?sequence $=7$

\section{Otros documentos}

El Espectador. (2008, julio 19). Así fue la toma de la base de Miraflores. El Espectador: Disponible en http://www.elespectador.com/noticias/nacional/ articulo-asi-fue-toma-de-base-de-miraflores

Perdomo (2013) Operación Vuelo de Ángel. Doctrina y Empleo del Poder Aéreo Aplicación de la Fuerza (Presentación en Power Point) Escuela Superior de Guerra.

Siglo, E. N. (2012, diciembre 12). Misiles en poder de Farc: ¿mito o realidad? Recuperado el 12 de noviembre 2015,El Nuevo Siglo: Disponible en http://www. 
elnuevosiglo.com.co/articulos/12-2012-misiles-en-poder-de-farc-\% $\% 2 \% B-$ Fmito-o-realidad.html

Tiempo, E. (1990, diciembre 10). El Ejército ataca Casa verde. Consultado el noviembre 8, 2015, El Tiempo: Disponible en http://www.eltiempo.com/ archivo/documento/MAM-34015

Universidad de Valencia. (s.p). Método Cualitativo. Recuperado el 21 de noviembre de 2015, de Universidad de Valencia: Disponible en http://www. uv.es/monterdh/researchers/Curso_Master_UJI/(5a)Metodos_de_investigacion_social_Cualitativos.pdf 



\title{
LA DOCTRINA JURÍDICO OPERACIONAL COMO ELEMENTO PREPONDERANTE EN EL ÉXITO OPERACIONAL DE LA FUERZA AÉREA EN EL SIGLO XXI
}

\author{
Brigadier General (RA) JUAN CARLOS GÓMEZ RAMÍREZ
}

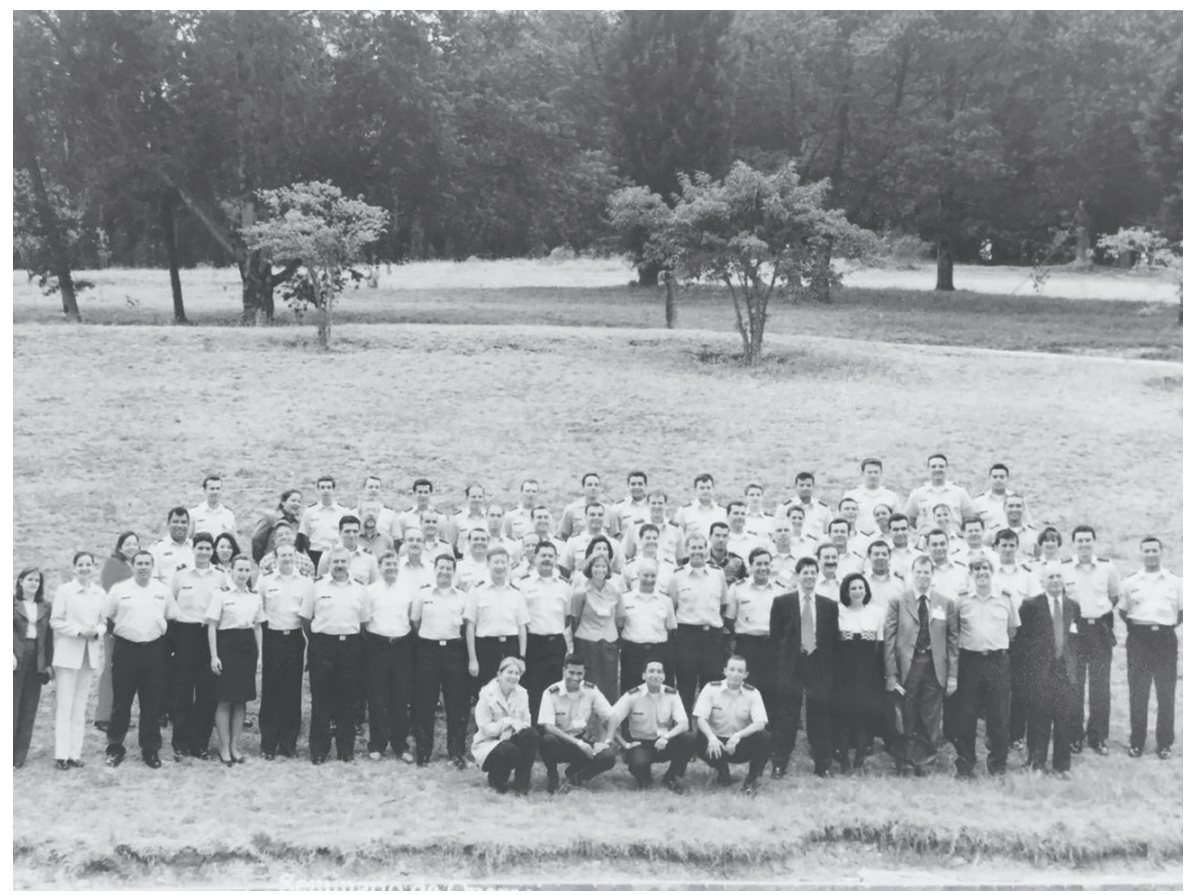

Seminario de operaciones aéreas en el marco del derecho internacional de los conflictos armados. Entre las conclusiones de este evento estuvo la creación de la figura del asesor jurídico operacional y las reglas de enfrentamiento. Paipa, agosto de 2001. Fuente: Archivo señor BGA Juan Carlos Gómez Ramírez, Jefe de la Jefatura Jurídica y Derechos Humanos-FAC.

Magíster en seguridad internacional y relaciones civiles militares, de la escuela de posgrados de la Marina de los Estados Unidos, especialista en derecho administrativo, abogado. Oficial en retiro de la Fuerza Aérea Colombiana en el grado de Brigadier General. Se desempeñó como jefe de la Jefatura Jurídica y Derechos Humanos de la Fuerza Aérea Colombiana. 
Resulta clave en el análisis de lo positivo de la campaña militar aérea contra los grupos armados organizados al margen de la ley (GAOML) ${ }^{2}$, el desarrollo de una doctrina jurídico operacional que ha permitido el ejercicio de la violencia y el uso de la fuerza de manera legal y legítima, con altos estándares de respeto de la normativa internacional (Derecho Internacional Humanitario) y una efectividad propia de las mejores fuerzas aéreas del mundo.

Solo entre el 2007 y lo corrido del 2016, la Fuerza Aérea Colombiana desarrolló 17.964 misiones aéreas en donde se aplicó la fuerza. De estas misiones se constata la realización de 6.121 operaciones dentro de las cuales hubo: ataques estratégicos, interdicciones y apoyos aéreos cercanos. En total, y para lograr este despliegue militar de uso de la fuerza, se volaron un total de 28.433 horas $^{3}$.

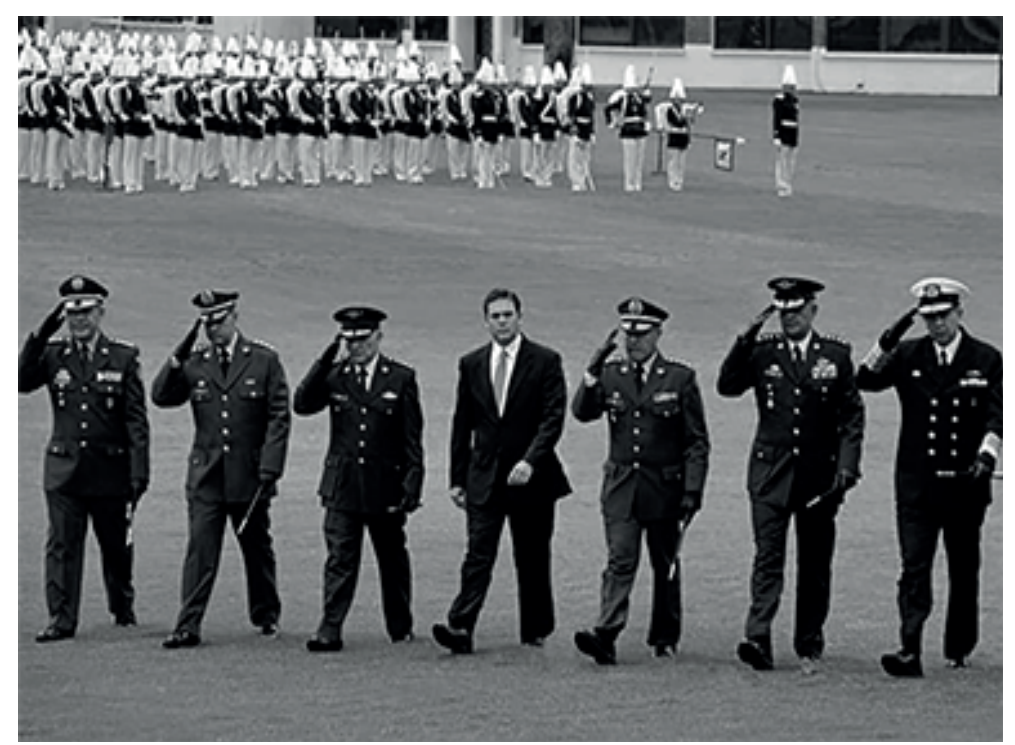

De izquierda a derecha cúpula militar Plan de Guerra Espada de Honor I: Gr. (R) Roberto León Riaño-Director General de la Policía Nacional (2012-2013), Gr. (R) Sergio Mantilla SanmiguelComandante del Ejército Nacional (2011-2013), Gr. (R) Flavio Enrique Ulloa Echeverry-Jefe de Estado Mayor Conjunto (2011-2013), Dr. Juan Carlos Pinzón Barco-Ministro de Defensa (2011-2015), Gr. (R) Alejandro Navas Ramos-Comandante General Fuerzas Militares (2011-2013), Gr. (R) Tito Saúl PinillaComandante Fuerza Aérea Colombiana (2011-2013), Alm. (R) Roberto García Márquez-Comandante Armada Nacional (2011-2013). Fuente: Ministerio de Defensa Nacional, Memorias al Congreso 20122013, en linea: https://www.mindefensa.gov.co/irj/go/km/docs/Mindefensa/Documentos/descargas/ Prensa/Documentos/memorias2012-2013.pdf

2 Concepto GAOML, véase: Ley 975 del 2005 "Por la cual se dictan disposiciones para la reincorporación de miembros de grupos armados organizados al margen de la ley"...Recuperado de: http://www. secretariasenado.gov.co/senado/basedoc/ley_0975_2005.html.

3 Fuerza Aérea Colombiana. Jefatura de Operaciones Aéreas, marzo de 2016. 
La capacidad operacional desplegada por la Fuerza Aérea Colombiana demuestra y explica cómo el grupo Fuerzas Armadas Revolucionarias de Colombia (FARC) ha perdido, en concepto del Ministerio de Defensa, el $26 \%$ de su capacidad armada. El plan de guerra "Espada de Honor", implantado en el 2012, ya para el 2014 arrojaba la neutralización entre desmovilizados, detenidos, heridos y muertos en desarrollo de operaciones 11.727 integrantes de los GAOML. Entre ellos, 57 jefes de la organización terrorista ${ }^{4}$.

Con relación al grupo Ejército de Liberación Nacional (ELN) las cifras eran 1.547 neutralizados en total. Entre ellos se cuentan: 572 desmovilizados, 489 miembros de las redes de apoyo al terrorismo (RAT) entre capturados y desmovilizados. Así mismo, fueron neutralizados 8 cabecillas: 2 de frente de guerra, 5 de frente y 1 de la Dirección Nacional ${ }^{5}$.

La Fuerza Aérea Colombiana sigilosa y discreta ha participado de manera decisiva, contundente y quirúrgica en todas y cada una de las neutralizaciones que tienen debilitado al enemigo y su capacidad terrorista. La mayoría de los cabecillas de los GAOML que han perdido la vida en medio de operaciones militares, lo han hecho gracias a operaciones en donde se ha aplicado la fuerza desde el aire. Entre el $1^{\circ}$ de enero y el 17 de noviembre de 2014, según cifras de la Jefatura de Operaciones Aéreas de la Fuerza Aérea Colombiana, se habrían realizado 641 ataques aéreos. Es decir, un promedio de dos ataques diarios entre estratégicos y de apoyo aéreo cercano ${ }^{6}$.

El poderío militar ejercido en los últimos años ha permitido a muchas regiones del país vivir en condiciones de seguridad propias de un Estado sin conflicto. Entre enero y mayo del 2014, el 96\% del territorio nacional no tuvo ninguna acción terrorista por parte de los grupos FARC o ELN. Es decir, en este período de tiempo, 1059 municipios estuvieron libres de cualquier hecho de violencia atribuido a estas organizaciones?

Las operaciones militares concebidas y planeadas ejemplarmente a lo largo y ancho del territorio nacional, con un control efectivo, eficiente y centralizado; han

$4 \quad$ FARC perdió el 26\% de su capacidad armada: Ministerio de Defensa. Recuperado de: http://www. eltiempo.com/politica/justicia/farc-perdio-el-26-de-su-capacidad-armada-segun-ministerio-dedefensa-/14510762

5 Ministerio de Defensa Nacional (2013). Memorias al Congreso 2012-2013. Bogotá: Imprenta Nacional. Recuperado de: https:/www.mindefensa.gov.co/irj/go/km/docs/mindefensa/documentos/descargas/ prensa/documentos/memorias2012-2013.pdf

6 Las cifras. La Fuerza Aérea Colombiana cumpliendo su misión (2014, julio-diciembre). Revista Taktika, 5 (9), p. 9. Recuperado de: https://www.doctrinafac.mil.co/sites/default/files/revista taktika_2014_ed_no_9ok.pdf

7 Ministerio de Defensa Nacional (2014). Memorias al Congreso 2013-2014. Bogotá: Imprenta Nacional. Recuperado de: https:/www.mindefensa.gov.co/irj/go/km/docs/mindefensa/documentos/descargas/ prensa/documentos/memorias2013-2014.pdf 
sido un ingrediente fundamental en el éxito de la recuperación de la seguridad, en el debilitamiento e incluso la derrota de los GAOML en muchos lugares de Colombia.

\section{EL CONTROL CENTRALIZADO Y LA EJECUCIÓN DESCENTRALIZADA COMO CLAVE EN USO DEL PODER AÉREO}

En enero 13 de 2004 la Fuerza Aérea Colombiana expidió el primer Manual de Comando y Control (FAC 3-57). Este documento es el manual de doctrina operacional que sirvió de guía a los comandantes, a todos los niveles del mando, para la aplicación de uno de los principios más importantes -si no el más sustancial-del poder aéreo: "control centralizado-ejecución descentralizada". Este concepto operacional contribuye en la planeación, dirección, coordinación y control de la guerra desde la perspectiva aérea.

El control centralizado y la ejecución descentralizada se materializan a través de la creación del Centro de Comando y Control de la Fuerza Aérea Colombiana (CCOFA). La filosofía de esta organización radica en integrar las funciones del Centro de Operaciones, la Defensa Aérea y las Comunicaciones Aéreas en un sistema conocido como C3I2 (Comando, Control, Comunicaciones, Inteligencia e Informática). Este sistema permite al Comandante de la Fuerza Aérea Colombiana, quien está investido de la autoridad legal, planear, dirigir, coordinar y controlar los medios aéreos disponibles para el cumplimiento de la misión encomendada. El CCOFA a su vez tiene su enlace directo y en tiempo real con los Centros de Comando y Control de las Bases Aéreas (CCOBAS). La organización, las instalaciones y los medios de la Base Aérea, basados en la estructura del CCOFA, le proveen al Comandante del Grupo Operativo, y por su conducto al Comandante del Comando o Grupo Aéreo, de un medio adecuado para la conducción de las operaciones aéreas encomendadas por el comandante de la Fuerza Aérea.

Las funciones del Comando y del Control se ejecutan a través de personas que se organizan simultáneamente con el equipo, las comunicaciones, las facilidades y los procedimientos. Todo esto permite al Comandante planear, dirigir, coordinar, controlar las fuerzas y las operaciones que se despliegan para el cumplimiento de la misión; a este conjunto se le conoce como Comando y Control.

El Mando y el Control Centralizado de operaciones, que se ejecutan de manera descentralizada, son un principio básico del empleo del poder aéreo. Esta capacidad permite al Comandante Aéreo sacar provecho máximo de las características y posibilidades que da el poder aéreo, y a la vez delegar autoridad en los comandantes subalternos para que estos desplieguen la iniciativa en los detalles tácticos que encierra la maniobra. 
Al centralizar el control hay una sinergia ventajosa: estableciendo prioridades, capitalizando la flexibilidad, asegurando la unidad de propósito de la operación y reduciendo las posibilidades en cuanto a la selección de objetivos que, en otras condiciones, podrían resultar conflictivos. Las operaciones descentralizadas, con los avances tecnológicos adquiridos, aseguran una mejor respuesta operacional, hacen a la Fuerza Aérea más flexible sin afectar el control. Por su parte, la falta de un control centralizado puede influir en la pérdida de velocidad y a la vez afectar la flexibilidad para la concentración de las aeronaves en ataque o defensa en lugares que resulten decisivos.

La ventaja del C3I2 para el Comandante es que puede contar en un solo lugar y en el momento indicado, con las herramientas requeridas para la toma de decisiones en cuanto al uso del poder aéreo. La sistematización del Comando, el Control, las Comunicaciones, la Inteligencia y la Informática en un solo centro son, sin duda alguna, clave en el éxito operacional del uso del poder aéreo.

El control centralizado y el conocimiento aplicado del Derecho Internacional Humanitario han sido la llave perfecta para la efectividad de la Fuerza Aérea en lo corrido del siglo XXI.

\section{EL DERECHO INTERNACIONAL HUMANITARIO COMO HERRAMIENTA CONTUNDENTE EN EL DEBILITAMIENTO DE LA AMENAZA TERRORISTA}

Fue clave para quienes integran la Fuerza Aérea entender el alcance real del Derecho Internacional Humanitario, en el sentido de acotar una norma concebida de manera pragmática para proteger a las personas y los bienes civiles en épocas de conflicto. Así mismo conocer e interpretar que el Derecho Internacional Humanitario no prohíbe la guerra, por cuanto quienes la redactaron en representación de la humanidad entienden que dicha prohibición resultaría inocua. Por el contrario, lo que siempre se pretendió y se logró de manera sencilla, fue regular el uso de la fuerza y poner límites en cuanto a medios y métodos utilizados para el ejercicio legal de la violencia por parte de los estados.

El Derecho Internacional Humanitario fue concebido para proteger a las personas y a los bienes que no participan en hostilidades, pero a la vez, está construida para los Comandantes Militares para que la conozcan y sepan cómo usar la fuerza armada como herramienta necesaria en la neutralización y la afectación de una amenaza que rete la misma existencia del Estado. Este conocimiento y este entendimiento por parte de la Fuerza Aérea resultó determinante en la neutralización y el debilitamiento militar de los GAOML.

La Fuerza Aérea entendió la significancia del DIH y supo de los riesgos de la aplicación del poder aéreo al enfrentar a los GAOML hace muchos años, 
especialmente desde el 12 de diciembre de 1998. Este día fue nefasto para el país debido a que una acción narcotráfico del grupo FARC, que incluyó el aterrizaje ilegal de una aeronave muy cerca del caserío de Santo Domingo (Arauca) para dejar armas y recoger droga, impuso una operación militar en contra del grupo ilegal que se extendió por espacio de tres días. En consecuencia, además de 9 soldados asesinados y 21 heridos, el día 13 de diciembre murieron 17 civiles, entre ellos 7 menores de edad. Este caso 18 años después de ocurrido, no ha podido resolverse del todo en los estrados judiciales.

La Fuerza Aérea ha sostenido, y aun lo sostiene, que la muerte de los civiles obedeció al estallido de un carro bomba, instalado por el grupo FARC en la mitad del casco urbano, para ser detonado al paso de los soldados. En concepto de otras personas, la explosión que generó las muertes se atribuye a un dispositivo cluster consistente en seis bombeletas lanzado desde una aeronave de la FAC en vuelo. Dos sentencias penales se han producido, una en contra del grupo FARC y otra en contra de integrantes de la Fuerza Aérea. La sentencia en contra de Grannobles, cabecilla de ese grupo ilegal, se cayó por decisión de la Corte Constitucional que dijo que en este proceso se violó el debido proceso y se estableció una verdad de espaldas a las víctimas ${ }^{8}$. En el caso de los pilotos de la FAC este proceso se encuentra en casación ante la Corte Suprema de Justicia hace ya varios años. Desde el punto de vista internacional, la Corte Interamericana de DDHH condenó a la Nación por estos hechos.

Independientemente de la verdad procesal que surja una vez se hayan agotado todas las instancias, lo cierto es que el daño a la legitimidad institucional por el posible exceso en el uso de la fuerza, planteado por quienes consideran que fue una aeronave de la FAC la que lanzó un artefacto explosivo sobre los civiles, ha sido devastador.

La comandancia de la Fuerza Aérea concibió, poco después de ocurrida esta situación, que era indispensable realizar ajustes a la doctrina jurídico operacional para garantizar no solo que se minimizaran eventuales daños colaterales, producto de una operación militar aérea, sino que cada vez que el nombre de la FAC se pusiera en entredicho por alguna operación la reacción debería ser inmediata, para atender las posibles y eventuales víctimas del ataque aéreo y determinar de manera exacta las situaciones de modo, tiempo y lugar que se presentaron en el sitio de la operación.

La creación del Comité Jurídico Operacional, es sin duda uno de los aciertos en la atención de las quejas por eventuales daños incidentales o colaterales. Una vez se realiza una operación aérea de aplicación de la fuerza y ante la menor queja

Corte tumbó condena contra 'Grannobles' por masacre de Santo Domingo (2015, noviembre18). Recuperado de: http://www.elcolombiano.com/colombia/corte-tumbo-condena-contra-grannoblespor-masacre-de-santodomingo-KE3143158 
que implique la posible afectación de personas y bienes civiles, la FAC activa el comité, el cual asiste de manera inmediata al sitio de los hechos constata las novedades y asume con las autoridades locales, regionales y nacionales cualquier daño o efecto que vaya más allá de la afectación del objetivo militar9 . Esta lección aprendida de los hechos de Santo Domingo, es sin duda una de las principales garantías de seguridad jurídica para la Fuerza Aérea y las tripulaciones. Poder revisar "in situ" los efectos de un ataque aéreo y asumir administrativamente los posibles resultados dañinos del mismo, más allá del objetivo militar, han sido importantes en la preservación de la legitimidad de la Fuerza Aérea a lo largo que este siglo en la aplicación del poder aéreo.

Adicional al Comité Jurídico, desde el 2001 la Fuerza Aérea emitió instrucciones frente a la aplicación del DIH en sus operaciones. Esto quedó claramente establecido en la Circular No. 701316 IGEFA-IGODH-725, del 8 de junio del 2001, en donde se explican diferentes conceptos dentro de los cuales se destacan: la beligerancia, el artículo 3 común a los convenios de Ginebra, la definición de Objetivo Militar, la importancia de la Información de Inteligencia antes del lanzamiento de un ataque, la distinción de lo que son considerados bienes civiles, combatientes, personal protegido, reglas de combate, etc ${ }^{10}$.

En el mismo 2001, entre el 29 y el 31 de agosto, la Fuerza Aérea desarrolló el primer seminario de Operaciones Aéreas en el Marco del Derecho Internacional de los Conflictos Armados (DICA) ${ }^{11}$. De este evento se extrajeron las conclusiones sobre las cuales hoy, hay absoluta claridad, pero que para la época eran sin duda innovadoras. El concepto de Objetivo Militar y su relación con la Ventaja Militar. Nada que no ofreciera al Comandante Militar una ventaja medible, podría ser considerado Objetivo Militar. Frente al concepto de la Necesidad Militar quedó claro que ésta surge de la misión y que es la potestad que da el derecho de la

9 Circular No. 764 IGEFA-IGODH-725, del 2 de abril de 2001: ..."instrucciones para que dentro de lo posible los distintos Comandos Aéreos, durante el planeamiento de las operaciones conjuntas que se realicen con el Ejército, Armada o Policía y apoyos aéreos cercanos, por intermedio de las tropas de superficie o directamente, se levante un acta inmediatamente se realice una operación aérea, con la firma del mayor número de autoridades civiles, dentro de las cuales se cita al Alcalde, Personero Municipal, Defensor del Pueblo, Fiscal, Juez, Secretario de Gobierno, Concejales etc., y representantes de la sociedad civil como por ejemplo de la Iglesia, maestros, líderes de la comunidad etc., con el fin de que quede constancia que durante la operación aérea realizada ni la población civil, ni sus bienes resultaron afectados o si quedaron quién es el responsable de los mismos...".

10 Fuerza Aérea Colombiana (2001). Doctrina de las Operaciones Aéreas en el marco del DIH y los DH (Documento elaborado por la Inspección General y el Departamento de DH y DIH). Numeral 74, p. 29.

11 Derecho Internacional de los Conflictos Armados, Derecho Internacional Humanitario y Derecho de la Guerra son considerados sinónimos. Estas tres denominaciones recogen la normativa de Ginebra y de La Haya, que en conjunto son las normas de carácter internacional que regulan el uso de la fuerza en los conflictos armados. Mientras la de Ginebra se refiere generalmente a las personas y a los bienes protegidos; la de La Haya trata lo relativo a los medios y métodos permitidos y no permitidos en desarrollo de la confrontación bélica. 
guerra a un Comandante para decidir cuándo un integrante de un GAOML o un bien material se pueden convertir en Objetivos de Ataque y neutralizarse a través del uso de la fuerza incluida la letal, y este hecho no solo será legal sino absolutamente legítimo en el marco de un conflicto armado ${ }^{12}$. En este mismo espacio se concluyó acerca de la necesidad de crear la figura del Asesor Jurídico Operacional, ${ }^{13}$ figura que se creó ese mismo año y que posteriormente gracias al excelente resultado que dio en la Fuerza Aérea se extendió en el 2006 y 2007 al Ejército y la Armada Nacional.

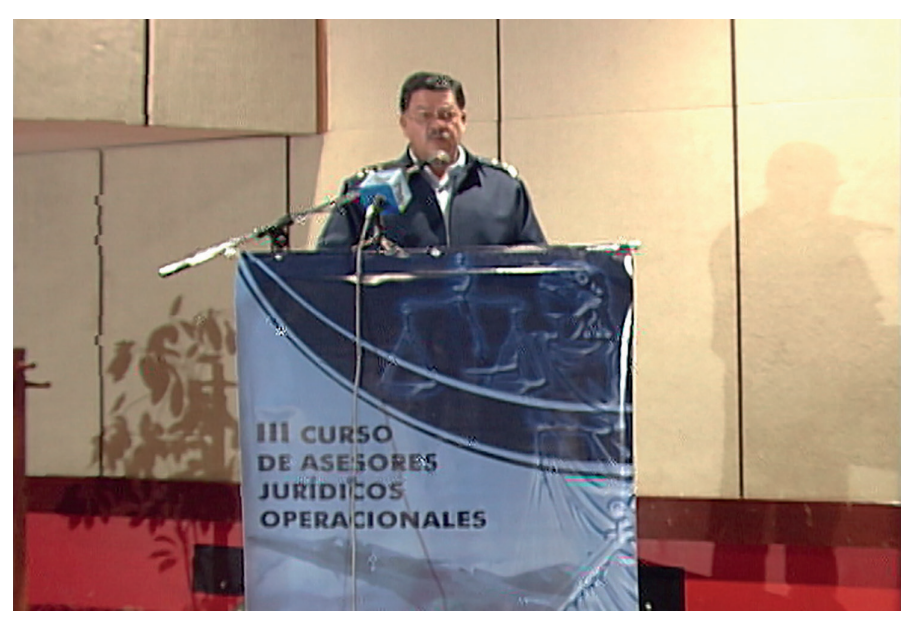

Señor Gr. (R) Édgar Lesmes Abad, Comandante Fuerza Aérea Colombiana (septiembre 8 de 2003-agosto 16 de 2006), en el Seminario Asesor Jurídico Operacional, 2006. Fuente: Ar chivo de Audiovisuales FAC.

Otra de las conclusiones de este seminario estuvo en ratificar la importancia de la Misión de la Fuerza Aérea y su capacidad bélica. Por ello se hizo énfasis en la necesidad de reducir los posibles daños colaterales producto de las operaciones, pero se insistió en el papel decisivo del poder aéreo. "Los militares no queremos la guerra pero, de presentarse, debemos ganarla" fue el planteamiento realizado por el Inspector General de la Fuerza Aérea en su momento señor Mayor General Édgar Alfonso Lesmes Abad ${ }^{14}$.

12 Fuerza Aérea Colombiana (2001). Doctrina de las Operaciones Aéreas en el marco del DIH y los DH (Documento elaborado por la Inspección General y el Departamento de DH y DIH). Numeral 77, pp. 30 y 31.

13 Asesores jurídicos en las fuerzas armadas", véase: Protocolo I adicional a los Convenios de Ginebra de 1949 relativo a la protección de las víctimas de los conflictos armados internacionales, 1977, Artículo 82. Recuperado de: https://www.icrc.org/spa/resources/documents/misc/protocolo-i.htm

14 Fuerza Aérea Colombiana (2001). Doctrina de las Operaciones Aéreas en el marco del DIH y los DH (Documento elaborado por la Inspección General y el Departamento de DH y DIH). Numeral 77, p. 31. 
El literal 4 del numeral 77 que transcribe una de las conclusiones del Primer Seminario de DICA reza: "Integración en las actividades de capacitación en DIH al personal operacional, a los asesores jurídicos militares (fiscales, auditores, jueces y asesores) y a las autoridades civiles, tales como la Procuraduría, la Fiscalía y la Defensoría del Pueblo. Crear mutua confianza" ${ }^{15}$.

Dos puntos más hicieron parte de las conclusiones de este trascendental evento institucional: la obligación de construir Reglas de Enfrentamiento (RDE) y la necesidad de fortalecer la Inteligencia Militar como elemento fundamental en el éxito de la consecución y elección de Objetivos Militares. El seminario resultó exitoso gracias a contar con la participación como instructor principal del entonces Coronel del Ejército del Aire Español Javier Guisandez Gómez, piloto y profesor experto en la materia. Para la fecha, él trabajaba con el Comité Internacional de la Cruz Roja (CICR) y con el Instituto de Derecho Humanitario de San Remo (Italia). Así mismo, los Estados Unidos se hicieron presentes con la participación del Coronel Charles Dunlop, abogado, Asesor Jurídico Operacional de la Fuerza Aérea de los Estados Unidos. Él, años después ascendió hasta el grado de Mayor General y llegó a ser el Jefe de los Asesores Jurídicos Operacionales en la Fuerza Aérea de su país.

Las RDE se redactaron en la Fuerza Aérea y el proceso de Inteligencia se adecuó a las necesidades operacionales de la institución. Estos instrumentos se fueron madurando desde finales del 2001 y se incorporaron en directivas, circulares y otro tipo de instrumentos que finalmente se condensaron en el Manual de Comando y Control FAC 3-57 (Reservado), en su primera edición publicada el 13 de enero de 2004.

El Anexo A del citado Manual enumera seis reglas de enfrentamiento que, aún hoy 2016, continúan de manera incólume siendo las Reglas de Enfrentamiento de la FAC en las Operaciones Aéreas; ellas son:

1. Solo se podrá disparar, si está identificado en el sistema de puntería o sistema de armas, el objetivo militar que se pretende batir.

2. Solo se podrá salir a vuelo si se tiene clara la misión, el objetivo de la misión y el nivel de autorización del uso de las armas.

3. Si existe duda sobre la naturaleza militar del objetivo, se debe cancelar la misión.

4. Ante una agresión actual o inminente se podrá hacer uso de las armas en defensa propia, de un tercero, poblaciones o unidades de la Fuerza Pública.

5. Solo se disparará a una aeronave en aire o en tierra, si ha recibido la autorización correspondiente. 
6. Toda aeronave de la Fuerza Aérea tiene derecho a su propia defensa si alguna aeronave interceptada comete una acción hostil.

La elaboración y puesta en práctica de estas reglas no fue fácil, aunque las instrucciones aquí expuestas se ven claras y concisas. Para la época era revolucionario decir a un piloto que solo podía salir a vuelo en el momento en que la misión fuera clara y los niveles de autorización para uso de las armas ya estuvieran determinados. Para aquel entonces, era frecuente que las aeronaves salieran a vuelo y ya en el aire se daban instrucciones frente a la misión y los niveles de autorización en la entrega de las armas. Otro escenario novedoso era que el piloto tuviera la potestad con base en su criterio y la situación que estuviera viviendo en el momento, de cancelar la misión sin necesidad de recurrir a una autoridad superior. Estas anécdotas hacen parte de lo que poco a poco se ha convertido en toda una doctrina jurídico operacional que ha hecho de la Fuerza Aérea y sus aviadores una fuerza contundente en el uso y ejercicio del poder aéreo pero a la vez ha garantizado que esta fuerza se use con legitimidad y con estricto apego a la constitución y la ley.

La inteligencia aérea colombiana se fortaleció y se convirtió en una garantía en el legítimo y efectivo uso del poder aéreo. El Anexo D del Manual de Comando y Control FAC 3-57, que establece un formato de viabilidad para el desarrollo de operaciones de bombardeo, obliga a quienes entregan la información relacionada con los Objetivos Militares a ser precisos, para garantizar así la no existencia de daños incidentales o su atenuación cuando la ventaja militar es muy grande y se prevean estos daños como factibles. Es el Comandante de la Fuerza Aérea y no otra autoridad quien, con base en su experiencia, conocimiento y análisis de los principios de necesidad, ventaja militar y proporcionalidad, determina si es o no viable realizar cada una de las operaciones concebidas y planeada para el lanzamiento de bombas.

\section{REFLEXIÓN FINAL}

El poder aéreo y su uso en Colombia fue fortalecido de manera singular por el conocimiento y la incorporación del DIH en su doctrina operacional. La doctrina jurídico-operacional en la FAC facilitó el uso de la fuerza dentro del marco constitucional y legal. Nadie podría decir que la implementación de las circulares, directivas y manuales menoscabó la efectividad del poder aéreo. Por el contrario, el conocimiento de la normativa permitió a la Fuerza Aérea y sus pilotos ser decisivos en los momentos que el país y la confrontación armada lo demandaron.

La Constitución de 1991 es amplia en cuanto a derechos y garantías constitucionales y de protección de derechos pero, al mismo tiempo, y taxativa en cuanto a la misión y las responsabilidades de la fuerza pública, en concreto 
de las Fuerzas Militares. La finalidad primordial de la institución militar es la defensa de la soberanía, la independencia, la integridad del territorio nacional y el orden constitucional ${ }^{16}$. Así mismo el artículo 214 de la Constitución Política establece en su inciso segundo el respeto por las reglas del derecho internacional humanitario. ${ }^{17}$ Por su parte el Código Penal colombiano tiene entre sus tipos penales los relacionados con el DIH.

El conocimiento del Derecho Internacional Humanitario en su amalgama con la doctrina de Comando y Control de la Fuerza Aérea, incrementaron el poder de combate y la eficiencia en la utilización del poder aéreo en Colombia. Los comandantes han logrado cumplir la misión concibiendo, planeando y ejecutando operaciones militares exitosas desde el punto de vista de los resultados y a la vez han garantizado la protección de la población civil y sus bienes. Esta combinación asertiva de la operatividad y el derecho son, en gran medida, dos de los factores determinantes en el debilitamiento militar de los GAOML y los que han permitido a los colombianos pensar en un futuro en paz y sin la presencia de organizaciones ilegales que vuelvan a retar la estabilidad y pongan en riesgo la existencia del Estado.

16 Constitución Política de Colombia, Artículo 217. Recuperado de: http://www.secretariasenado.gov. co/senado/basedoc/constitucion_politica_1991.html

17 Ibídem, Artículo 214, inciso 2. 



\title{
The larger lessons of Plan Colombia: a CASE OF INNOVATION AND SUCCESS
}

\author{
Brigadier General ELIOT GERARDO BENAVIDES GONZÁLEZ ${ }^{l}$
}

\section{INTRODUCTION}

Democracy and security concerns have been interests for the U.S. and Colombia and their traditional and long bilateral state relationships. Likewise, democracy and security objectives were addressed to design and implement the strategy under the label of Plan Colombia. By 2000, the United States of America and Colombia implemented Plan Colombia to disrupt, deny, and neutralize illegal drug production and trafficking in Colombia, by providing military aid and strengthening social programs through alternative programs and investment in physical infrastructure (RAmírez, Stanton \& WASH, 2005). Even though the former were the original goals stated by Plan Colombia, in practice this Plan enabled the Colombian government to rebuild the sate-nation while fighting drug-trafficking. In retrospect, the situation in Colombia by the late 1990s was dramatically negative in terms of insecurity, ineffective governance, insecurity, and low-level of rule of law. In all these regards, Colombia was facing hybrid threats in terms of insurgency, terrorism, criminal bands, and kidnapping. Actors such as the leftist Revolutionary Armed Forces of Colombia or FARC, National Liberation Army or ELN, and the right wing United Self-Defense Forces of Colombia or Autodefensas Unidas de Colombia (AUC) were involved in narcotrafficking and caused insecurity and endemic violence (REID, 2007).

As a result, the country faced an economic downturn, social inequality, wide violence, corruption, and low-level education. Likewise, poverty and internally displaced persons (IDPs), increased in rural areas, while environmental degradation reached peak levels. All of these were linked to illegal drug production and trafficking (PIZARRO \& GAITÁN, 2006). In brief, legitimacy was at stake and therefore, the country's stability. 
Today, the strategic environment of Colombia has improved, to the point that now, the former FARC insurgency, the oldest and largest guerrilla of the world, is engage to disarmament, demobilization and reintegration (DDR) process, as integral part of post-conflict peace consolidation. In this sense, Plan Colombia and domestic policies have achieved significant progress in the security environment and therefore, rule of law and governance were regained in Colombia. Along these 17 years in Colombia, the territorial recovery by means of interagency plans, including military actions and alternative social programs, have been implemented and executed in focus areas subjected to coca eradication, under the label of Acción Integral (Integral Action).

In reality, Plan Colombia became an indirect approach to strengthen democracy in Colombia. In 2002, two years after Plan Colombia initiated, President Uribe, labeling his governmental policy as democratic security, integrated civilian and governmental agencies actions in conjunction with the military strategy or Plan Patriota (2002-2006) in key rural areas affected by the insurgency and the AUC, because. By 2006, the new Plan was named Plan de Guerra Consolidación or Plan Consolidation (2006-2010), in order to achieve positive effects in this focus areas, applying more emphasis in social programs and rule of law, in focus areas, while the military action was directed to reduce guerrilla influence in rural areas. (Plan consolidación, 2009).

Similarly, under the President Juan Manuel Santos administration (2010-2014) this approach continued in terms of Plan Bicentenario (2010-2012). (Comando General de las Fuerzas Militares, 2012). Also, Plan Espada de Honor or Sword of Honor, in four versions I/II/II/IV (2012-2016). The latter, the result of 4 strategic revisions, using a new methodology for evaluation purposes and implementing measures of effectiveness at strategic, operational and tactical levels, in order to disable and paralyze the FARC, ELN and criminal organizations, both militarily and financially. (Comando General de las Fuerzas Militares, 2017). In short, Plan Colombia, indirectly, enforced internal political culture changes, such as the democratic security domestic policy (BRUNEAU, 2003).

Thus, this paper will argue that Plan Colombia and its military preeminence have been necessary to achieve military and non-military conditions while rebuilding the nation-state. Therefore, by studying the case of Colombia it is possible to draw its large lessons addressing security and democracy matters. Also, Plan Colombia and its military character and social component have been necessary to disrupt and neutralize the overwhelming and hybrid threat in Colombia. In brief, security was necessarily addressed first to pave the way for rebuilding rule of law and governance. By contrast, unresolved issues and new security challenges present in the strategic environment are noted. 
By assessing Plan Colombia and the narrative of Colombia in the last 17 years, this paper will argue that the Plan has applied key elements of the U.S. military doctrine in terms of joint military planning and counterinsurgency to rebuild the security environment. Thus, this strategy has achieved success in meeting the bulk of the military conditions while it has enabled other non-military conditions to rebuild the nation-state. However, some neighboring countries of Colombia and nongovernmental organizations (NGO) have stated counterarguments against Plan Colombia, criticizing the greater military component along with its lesser social part.

\section{PLAN COLOMBIA}

Briefly and before assessing Plan Colombia, Colombia's geography is addressed to explain the extension of that country, compared to two vivid scenarios for U.S. statesmen and military. Those are Iraq and Afghanistan. Colombia's territorial extension is $1,141,747 \mathrm{~km}^{2}$. It is over the size of Afghanistan $\left(647.500 \mathrm{~km}^{2}\right)$ and Iraq $\left(437.072 \mathrm{~km}^{2}\right)$ together.

In addition, Colombia has territorial limits with Venezuela, Brazil, Peru, Ecuador, and Panama. Also, Colombia has maritime limits with: Venezuela, Ecuador, Panama, Nicaragua, Honduras, Jamaica, Haiti, Dominican Republic, and Costa Rica. In brief, Colombia limits with 11 countries in the Caribbean and South America. Having said so, the Colombia's strategy position is a factor to explain the character of bilateral relations between the U.S. and Colombia. Besides, the reader may see the extent of Colombia while facing security issues in terms of criminal bands, narcotrafficking, insurgency, and terrorism.

In addition to the geography factor, the background of the U.S.-Colombia relations is presented. In 1990 President George H.W. Bush led the first Andean Drug Summit. It was executed in Cartagena-Colombia. The heads of state of the U.S., Colombia, Bolivia and Ecuador signed the Declaration of Cartagena, to address political, military and economic actions related with counternarcotics efforts. In all these regards, the U.S.-Colombia relations have addressed mainly security challenges. At the same time, Colombia was classified by the U.S. Congress as a failed state. (FrechetTe, 2007). As a result, former President Bill Clinton reached a political consensus and proposed the Plan Colombia initiative. It is important to note that the latter was first stated in Colombia by President Andres Pastrana (1998-2002), shaping domestic perceptions before the Plan was implemented. The former was key to favor public support and further success of the strategy. In consequence, for strategists in the U.S. and Colombia, Plan Colombia was a logical step in the light of the long and traditional bilateral relationships for many decades to address security issues (narcotrafficking). 
As a result, from the Colombian's perspective, Plan Colombia was conceived like a domestic initiative to save the country. Originally, the Colombian government saw this Plan as a multinational endeavor not only from the U.S., but also from the European Union (EU) to promote economic and social development in Colombia. That circumstance played a major role for legitimacy in Colombia, as it will be explained below and noted in this paper as a key element. In the meantime, U.S. policymakers were highly concerned to address security in Colombia. According to Thomas R. Pickering, President's Clinton former Undersecretary of State. Pickering "Colombia as a failed state would harm American interests and those of its neighbors on many levels." (PICKERING, 2009, p. 71).

By 2001, President George Bush and the U.S. Congress, the latter under the Andean Counterdrug Initiative (ACI) (Lemus, Stanton \& WASH, 2005) continued supporting Plan Colombia. Specialized programs such as Air Bridge Denial (ABD) were established, by providing air assets, intelligence and funds to interdict illicit flights from the source zones toward the U.S. (FRECHETTE, 2007). Besides, U.S. and Colombian coast guard and navy asses were executing maritime interdiction in the Caribbean Sea and the Pacific. Likewise, Colombian army, marine and national police units were executing drug eradication in country. As noted by Eduardo Pizarro and Pilar Gaitan, by 2003 Colombia became "the third largest recipient, after Israel and Egypt, of the U.S. military aid." (PIZARRO \& GaITAN, 2006, p. 53).

Moreover, counternarcotics operations became essential to deny, disrupt, and undermine the economic leverage achieved by FARC. After Cold War, narcotrafficking became the main means of support for insurgency and terrorist activities. Likewise, insurgents of National Liberation Army or ELN and rightist paramilitaries AUC were involved with narcotrafficking in depth (CORUM \& JoHNSON, 2003). In the late 1990s, those circumstances enabled insurgentsterrorists (FARC, ELN, and AUC) to expand their leverage while increasing violence, illegal activities, and corruption, while the statecraft was unable to contain this overwhelming and hybrid threat. Hence, Plan Colombia was the turning point of the U.S.-Colombia relationships. Crandall (2008) "Plan Colombia was an initiative to rescue Colombia under this bilateral agreement to provide funds and assets to wage the war on drugs." (p. 91). From the Colombia perspective, Plan Colombia was vital to correct the path of democracy in Colombia and necessary to building domestic capacity to recover nation-state. The latter was also true for the U.S. government, while containing drug trade effects on U.S. and region stability were the primary objectives. At the end, it was the beginning of a new chapter of U.S.-Colombia relationships continued after President Clinton and President Pastrana. Ultimately, those circumstances explain the imperative of Plan Colombia and its military character to address the security environment in Colombia and the U.S. 


\subsection{Operational ASSESSMent}

Plan Colombia and the U.S. military doctrine introduced valuable inputs that enhanced the Colombian military, by considering not only equipment, air assets and logistic support, but also professionalization. As a result, Plan Colombia achieved a military transformation in Colombia. For instance, by 2000 the military in Colombia addressed challenges in terms of joint organization to improve the quality of military planning to produce effectiveness at the operational and tactical level while executing defense, offense, and stability operations. In addition, Plan Colombia and its military aid package including equipment and material, strengthened critical capabilities to the military such as command and control, air mobility, sustainability, interoperability, intelligence, surveillance, and reconnaissance (ISR). Also, the extent of training and professionalization was significantly improved in military tactics in terms of special operations, search and rescue (SAR), and psychological operations (PSYOPs). Those core capabilities are essential to execute successfully military actions in the battlefield while increasing the extent of military professionalization in Colombia.

In particular, Plan Colombia on one hand strengthened the professionalism of the military not only in military tactics, but also in knowledge and practice of the Law of Armed Conflicts (LOAC). Another aspect is the focus of the Colombia military on the protection of the population, infrastructure, isolating the insurgents from the populace as a permanent priority. Toward this end, winning the heart and mind of the population became paramount for the military strategy, while providing military conditions to enhance rule of law and governance. Furthermore, for the first time in Colombia, the state is established in all 1,099 municipalities of Colombia, supported by military and national police forces (MARCELLA, 2009). To this end, military and police manpower has increased from 313,406 in 2002 to 437,548 in 2009 (39.61\%). (Ministerio de Defensa, 2009). In consequence, the military and the national police paved the way to reestablish local authority in ungoverned rural areas in Colombia, while isolating the insurgency from the population. The latter became the virtual cycle, by employing the military Instrument of Power (IOP) first to really consolidate control of the entire territory, as a military condition to enable rule of law and economic development. Ultimately, control of the territory is an indicator of success in pursuing governmental legitimacy, contrary to the arguments stated by neighboring countries and NGOs.

Likewise, under the path of military transformation indicated above, conditions were met before to transit into joint military organizations in Colombia. The latter was gradually achieved while facing frictions and challenges, because of services used to plan and operate independently. Afterward, in 2004 Joint Task Force Omega was established to execute military operations in the largest base 
area of the FARC ${ }^{2}$. Then, by 2005 the Joint Command Number 1 or CCON-1 was established in the northern Caribbean region of Colombia. By 2009 Joint Command Number 2 was created, to conduct military operations in the pacific region of Colombia (Fuerzas Militares activan Comando Conjunto Pacífico, 2009). As a result, for the first time in Colombia the military efforts are truly integrated in unified actions to deter, disrupt, and degrade hybrid threats, with close coordination with national police, Fiscalia or law enforcement members. In brief, Plan Colombia has enabled Colombian military transformation equal to the Goldwater-Nichol DOD Reorganization Act of 1986 (Goldwater, 1986). That transformation was necessary to enhance military effectiveness while integrating interagency efforts to promote the rule of law and mitigate human rights violations. Lastly, military professionalization in Law of War, Human Rights have been essential to attain legitimacy in irregular warfare. Similarly, special operations and informational operations have been the paramount in offensive operations while reducing collateral damage. Collateral damage is a factor across the three level of irregular warfare, as it has been learned in Colombia.

With Plan Colombia, the utility of air power in military operations illustrated the effects of both kinetic and non-kinetic operations. The former are executed by precision guided munitions (PGM) against high-value targets and air interdiction, minimizing collateral damage. The latter are carried out by means of airlift, PSYOPS, human-based intelligence and ISR; search and rescue (SAR), and medical evacuation. For instance, military operations have successfully planned and executed, by introducing joint military planning and operations. By 2008 joint Operation Phoenix or Operación Fénix was executed to neutralize the second top leader of FARC. This is the first time in the history of Colombia a Top FARC terrorist was killed as a result of military operations (Comando General de las Fuerzas Militares, 2008). Then, Operation Jaque, a non-kinetic operation, successfully achieved the rescue of three U.S. and twelve Colombian military hostages retained by FARC over six years. The significance of this operation is that its goal was successfully accomplished while no single casualty was produced, whether friendly or insurgent. Likewise, the FARC leaders involved in this operation were captured (Comando General de las Fuerzas Militares, 2008). That illustrated the primacy of rule of law over military annihilation as a condition to strengthen legitimacy. It is a result of long-term and consistent efforts under military transformation in Colombia, which began with Plan Colombia.

By 2002, that area was a safe haven for FARC and the ground for drug trafficking, terrorism, kidnapping, and source for logistics. For decades the state-nation failed to provide effectively governance. As a result, that area became favorable for insurgency by considering vacuum of legitimacy, population support while fertile lands were suitable to cattle as well as both legal and illegal crops. This area is the size of Switzerland. 


\subsection{National Leadership, Legitimacy, and Population}

Alvaro Uribe was elected President of Colombia in May 2002, after Plan Colombia was implemented two years earlier, the latter under the mandate of President Andres Pastrana (1998-2002). Uribe's administration was able to develop a comprehensive domestic policy to integrate Plan Colombia while procuring a political culture change in Colombia. For example, he stated that democracy was vital to Colombia while security and rule of law were prerequisites to achieve, territorial control and governance in country. He successfully experienced that when he was governor of Antioquia, the second largest economic, industrial, and politic state of Colombia (Frechette, 2007).

In particular, this paper will argue that specific conditions in Colombia enabled President Uribe to instituted democratic security policy in 2002. First, the former President Pastrana wore out all his political capital to achieve the peace with the FARC, between 1999 and 2002 ${ }^{3}$. Then, negative outcomes that political peace process convinced the populace in Colombia of the real political objectives of the FARC guerrillas to take the power and establish a Marxist regime, and therefore democracy was at stake. As a result, the population's expectations pointed out strong leadership in person of President Alvaro Uribe. In other words, set of conditions in 2002 were fertile ground to President Uribe, his leadership, and to legitimate his "security democratic" policy (FRECHETTE, 2007). The same was true by 2010 , for President Santos in order to achieve the conditions and results at the strategic level for the peace process developed until today. In other words, political consensus while executing a continuous and institutional effort during 3 administrations.

\subsection{U.S. Military doctrine and Plan Colombia}

Even though Plan Colombia addresses military aid and social component, this paper will assess Plan Colombia from a military perspective. To this end, there are key elements identified in the U.S. military doctrine that were introduced into the strategy. Today the military mission confronts broad and complex challenges that demand knowledge of warfare, analysis of the operational environment, and application of operational art to attain the set of military

President Pastrana dictated the so-called "distension zone" or demilitarized zone requested by the Revolutionary Armed Forces of Colombia (FARC), as a condition to maintain the peace talks for three years, while the FARC used as a safe haven in increasing its terrorists activities, narcotrafficking and kidnapping. 
conditions instituted by the political conductor and to translate the strategy into military actions. In addition, contextual factors such us doctrine, technology, civil-military relations, concepts of Just War traditions, war termination and conflict resolution are contextual factors that today influence the military mission. To this end, those concepts are encapsulated in the U.S. military doctrine and labeled as counterinsurgency COIN and stability operations (Counterinsurgency Operations, 2009).

U.S. military doctrine, introduced by means of Plan Colombia and the military strategy or Plan Patriota, have provided the ground for the Colombian military capability to advance with the strategy, by focusing in governance and the population, while securing the environment in the light of U.S. counterinsurgency and stability operations doctrine. Likewise, Plan Colombia introduced the military concept of unified action. Joint Publication 1 remarks that unified action "is a broad term referring to the synchronization, coordination, and/or integration of the activities of governmental and nongovernmental entities with military operations to achieve unity of effort". (Doctrine for the Armed Forces of the United States, 2007). It was valuable to balance, at the strategic level, the use of all instruments of power to attain a strategic goal. However, this concept has not fully developed by civilians and military at the tactical level in Colombia. Yet local government stewards are reluctant to be involved with military, by considering it may violate the concept of neutrality in light of the Law of Armed Conflicts ${ }^{4}$. Therefore, this is one of the weaknesses of the top-down execution of the strategy.

Furthermore, Counterinsurgency Operations were renewed within the execution of Plan Patriota. Paradoxically and in spite of the professionalism of the military in Colombia and its broad experience, the threshold between the theory and the practice were significant. Military practice was supported by individual experience and skill, rather than military doctrine and integrated civil-military strategy. In the past, Colombian military doctrine and strategy was focus on conventional warfare, with lack of counterinsurgency and stability operations concepts. As a result, the military conducted and executed annihilation warfare. By the 1990s ineffective long-term military solutions were addressed while the rise of human right issues undermined the legitimacy in Colombia ${ }^{5}$. That situation was improved after Plan Colombia was established. The Plan made significant changes

$4 \quad$ I observed that situation in small municipalities in the Caquetá region which was part of the former DMZ in 2008, when I was assigned to Joint Task Force Omega.

5 Those arguments were based on personal contact experience of the author as a Colombian Air Force officer for twenty years. His background in counter-narcotics operations and counterinsurgency operations, provide the authority to assert that the military doctrine In Colombia is focused in conventional warfare rather than irregular warfare. Currently and in spite of the practice of the counterinsurgency operations, there is no current operational doctrine addressing this matter. The military culture relies more in the experience and the skills, and lesser in the formal knowledge regarding counterinsurgency and stability 
in the military strategy, by introducing the U.S. military tenets and elements of counterinsurgency operations (Counterinsurgency Operations, 2009). In addition to counterinsurgency, the U.S. military doctrine addresses Stability Operations and noted as "missions, tasks, and activities conducted outside the United States in coordination with other instruments of power, to maintain or reestablish a safe and secure environment, provide essential governmental services, emergency infrastructure reconstruction, and humanitarian relief.' (Joint Operations, p. GL26). Plan Patriota implicitly has introduced some of those concepts, by assessing the achievements of the set military conditions.

In sum, there is a close and consistent link between the U.S. military doctrine and Plan Colombia. The new military strategy introduced new elements that have been stated in the U.S. military doctrine in terms of COIN and stability operations to establish military objectives and conflict termination criteria, which became vital elements of the strategy. In this specific case and circumstances the U.S. military doctrine in COIN and stability operations was suitable to attain challenges in the security environment. As it was explained before, this strategy has shown significant progress in the security environment for the first time in Colombia. Hence, it is justifiable to assert that Plan Colombia and its military preeminence have been essential to build governance and rule of law in Country in the light of U.S. military doctrine. Nevertheless, COIN is still necessary while further steps should be taken, to strengthen interagency (IA) and stability operations.

\subsection{Civil-Military relations in Colombia}

Plan Colombia has been a key element to strengthen the security democratic policy, by illustrating how appropriate Civil-Military relations are essential and necessary to build security, law or rule and governance. For the first time, at the strategic level, the statesmen in Colombia understood that security is a complex matter that necessitates the integration of civil and military actors to develop a policy to integrate and coordinate efforts to the same end (unified policy). Secondly, this new concept enhanced the military at the operational level to manage simultaneously security issues while enabling governance and rule of law led by the civilian authority. As a result, the primacy of legitimacy has been demonstrated before the eyes and expectations of the population. Nonetheless, during prior experience and before Plan Colombia, civil-military relations were a factor that negatively affected security in Colombia, as explained briefly below.

After the period of military rule in Colombia, between 1953 and 1958, the military were alone fighting the bulk of the security problems in Colombia. The

operations doctrine. On the other hand, this tenets and elements of the U.S. doctrine were introduced in the Colombian national military strategy in the light of the Plan Patriota. 
civilians had assumed for over forty years, and before the implementation of Plan Colombia, that security was not their responsibility. Thus, the misguided policy that the civilian should be apart from national security issues, the latter considered as solely a military matter while civilians conduct politics, the judicially, matters, and legislation. According to Marks (2002) "There, the lack of concern by the ruling elite played a key role. For decades following $L a$ Violencia, the insurgents remained largely out there, out of sight, out of mind, patiently building an alternative society. No one much cared." (p. 4). In brief, the politicians in Colombia believed that the security environment lay in military success alone (FRECHETTE, 2007).

Because of these factors, Civil-Military relations are essential in execution of Plan Colombia. This contextual factor has influenced the approach of Plan Colombia in terms of interagency effort under the label of Social Action, because of the necessity to integrate common efforts to build rule of law and governance while the focusing on protecting the population. For example, the interface between civilians and military is a key element to identify the populace's behavior, what are their needs, expectations, and more importantly, understanding Colombian culture as part of a larger political solution. (McFate, 2005). According to Hooker (2003) civil-military relations are essential to policy making and the interagency process to attain realistic goals and the integration of means, by unifying efforts to procure common goals. That is possible throughout interagency plans and actions to attain success in the mid-term, by considering the current situation in Colombia.

Furthermore, the presence of other government agencies (OGAs), international government agencies (IGOs), and nongovernmental organizations (NGOs) have been active in rural areas; prior to the arrival of Colombian military and other governmental agencies. For that reason, interagency actions are essential, because those organizations have achieved a comprehensive picture of current issues and they already have been in touch with the population building mutual confidence, before military arrive to areas of operations (HAWLEY \& SKOCZ, 2005). For instance, in Colombia, several NGOs and other governmental agencies are integrated in the early alert system or Sistema de Alerta Temprana (SAT). The origin of this system was part of line of action instituted by the USAID in conjunction with the Colombian government. This system was established in the early 2000s is under the direct purview of the Interior Ministry and coordinates closely with the Ministry of Defense. To this end, locally and regionally these organizations work independently and close to key leaders and civilian populace to identify risks, social issues, internal displaced movements, and security issues. As a result, that security issues will be addressed as key inputs for military to take urgent actions to prevent and mitigate violence from non-state actors such 
as insurgency, terrorists, and criminal bands. In particular, at the tactical level, military unit commanders have a responsibility to respond effectively to these alerts addressed by SAT (ORTIZ, 2001).

In short, effective civil-military relations will enhance the planning process at the national and operational level, in unifying and integrating civil-military actions, with the likelihood of close contact with the populace at the tactical level while improving the security environment.

\subsection{VISION OF CONFLICT RESOLUTION}

Figure 1. Strategic Environment and weight of effort.

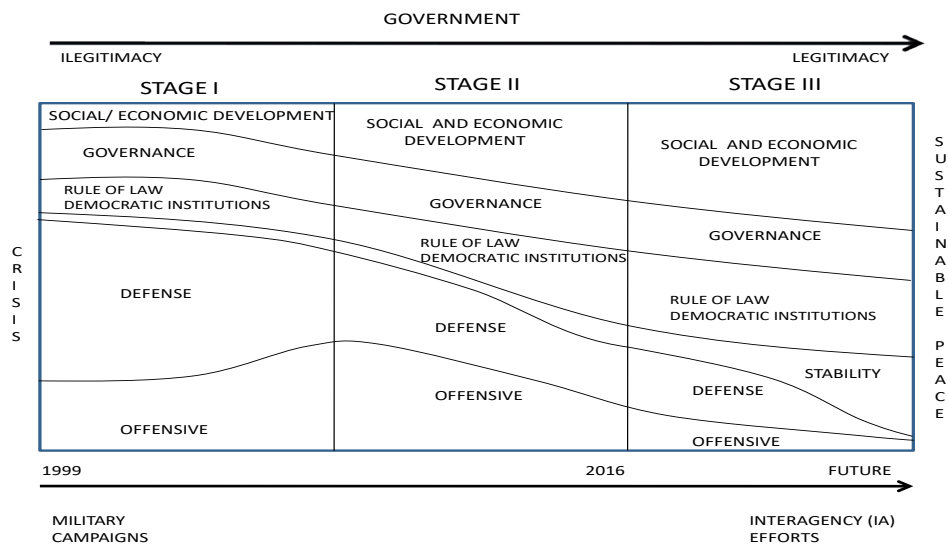

Source: own authorship.

Figure 1 is introduced to illustrate the integration of military effort along with rule of law, democratic institutions building, and governance and social economic development to facilitate conflict resolution. Externally, lines of action are drawn to attain the military conditions and non-military conditions in light of level of legitimacy and interagency efforts. Besides, in this model government integrates and synchronizes the other instruments of power to attain effective long-term solutions through the democratic security policy. In Brief, Figure 1 illustrates and provides justification for Plan Colombia and its military character in the past 17 years. While this Plan continues to be necessary to support social programs thorough USAID supported by multilateral organizations, in other words by means of robust interagency organizations and actions, in the framework of the new chapter Plan Peace Colombia. 
Ultimately, by assessing Plan Colombia and the current strategic environment is possible to assert that in light of both political and military culture Colombia is approaching the final quarter of Stage II (See Figure 1). Similarly, this Figure 1 suggests that future strategies should keep the track while emphasizing in social and economic development, including the private sector and the academic sphere. Government should balance the economic and informational IOP to continue providing good, services and physical infrastructure to attain basic needs of populace. Rule of law as well as democratic institutions are essential to attain legitimacy, while increasing pluralism and participation of the population. Nevertheless, democratic institutions should be supported by military to execute social programs in rural areas where coca eradication is achieved. To this end, stability operations are increasing while protecting the population (defense operations) and neutralizing the hybrid threat in Colombia (offensive operations).

In addition to the key elements analyzed above, the vision of conflict resolution is addressed to build the concept of viable peace in Colombia. The importance of this matter is that it involves concepts of Just War (jus in bello) and conflict resolution. Just War traditions are essential to attain legitimacy both in Colombia and regionally/internationally and to build the ground for conflict resolution for viable peace. In particular, the rules that guide the conduct of military and how it employs force in warfare are important (jus in bello). (ROBERTS, 2002, p. 117).

Also, Plan Colombia has addressed resources to strengthen the Colombian military and low enforcement professionalism in Human Rights. Since 2002, for military every year academic sessions and practicum are dedicated to human rights and the Law of Armed Conflicts (LOAC), while the National AttorneyGeneral or Fiscalía General de la Nación as well as the judicial groups of the National Police investigate and execute the judicial procedures to legitimate every military action in country, when insurgents are killed or captured. Also, the Fiscalia supersedes military justice when cases of human right violations occurred, involving Colombian military or police. As a result, these principles are implicit in the Plan Colombia strategy, by procuring the minimum use of force and protecting the integrity of civilian population, their infrastructure and environment.

In short, it is important to recognize that military conduct in war lays in ground of legitimacy, constrains and decision making process, by considering the counterproductive effects of military actions vis-à-vis military advantage. This holistic approach is a key factor while facilitating the conflict transformation and stable peace (conflict resolution). To this end, the Colombian government, in the light of the democratic security policy, a Justice and Peace law was approved.

By 2005, the Colombian government stated the Law 975 of "Justice and Peace" as mechanism to achieve a viable peace and the vision of conflict resolution in 
Colombia. This Law is resulting from the security achievements of Plan Colombia and the military strategy under the label of the Plan Patriota in security matters and by considering the building of rule of law, because this law address not only peace process with the insurgents and AUC, but individuals that find legitimacy and the conditions to choice and initiate a legal life after a judicial process. Also this law involves the victims of the conflict to meet justice, to obtain the truth and the facts of the crimes in the light of the conflict. Finally, this law enforces the reparation of the victims by mean of monetary and/or material repositions from the offenders (Ley de Justicia y Paz, 2005).

Moreover, in the light of the Law 975, the government implemented the Programa de Atención Humanitaria al Desmovilizado or Demobilized Humanitarian Attention Program (DHAP). The Defense Ministry is chief of the program and address alternatives and social options to former insurgents and their families, by including technical education, temporal housing and integration with the private sector to develop economic projects. This Program links the military achievements and legitimacy in the battlefield, rule of law conducted by the Fiscalia or National Attorney-General and the private sector (Directiva No. 015, 2016). As a caveat, DHAP should be managed by some other government agency, by considering the scale and character of this program. In addition, other executive action was made under the Programa de Acción Social or Social Action Program (SAP).

By 2005, the Colombian government created the SAP in order to enhance the High Commissioner for the Peace and his administration to manage resources and budget coming from governmental and nongovernmental organizations, to develop social programs in focus areas, where population experience extreme poverty, while minimizing the impact of narcotrafficking and violence. The SAP executes close coordination with the U.S. Agency for International Development (USAID) (Presidential Sanction 2467, 2005). In short, Plan Colombia has enhanced the building of the vision of Conflict resolution in Colombia by strengthening the military professionalism in terms of human right indoctrination as well as the concepts of Just War in the Plan Patriota to facilitate conflict resolution. Moreover, the USAID by means of economic aid have supported domestic social programs such DHAP and SAP to foster alternative programs to population in rural areas.

\subsection{LARGER LESSONS OF PLAN}

First, by means of Plan Colombia, key elements were introduced to change military culture. The military transformation in Colombia was necessary to address the hybrid threat in Colombia. This transformation included military training to develop combat and non-combat skills. Also, the Plan provides 
air, brown water, and land assets necessary for enhance mobility. Likewise, intelligence platforms were provided along with core capabilities in terms of precision air attacks and special operations to complement conventional military during defense and offensive operations.

Second, Plan Colombia is a fertile ground for the military to draw successful lessons to address COIN and stability operations. Gradually, joint military organizations have been implemented to strengthen command and control, which was necessary to address military objectives and execute mid-term military campaigns. In the mid-term, extending the state's control of territory was necessary to protect the populace and infrastructure. As a result, today the military need to develop more skills to work along with civilians while facing dynamic and irregular threats. Moreover, the military role needs to be expanded to address full range of military operation such as stability operations while governmental and other agencies lead long-term social programs and provide infrastructure, in rural areas where nation-state presence is still ineffective (RAmireZ et al, 2005).

Third, Law of War and human rights were addressed as critical factors to enhance legitimacy in the mid-term. By law, the Fiscalia or Attorney General addresses all military actions in urban and rural areas investigating friendly and adversary casualties. The law also states that the military cannot retain civilian insurgents for more than seventy-two hours. During this time, the military is accountable for the physical and mental integrity of the insurgents until they can be delivered to the Fiscalia. In other words, the civilian judicial system always overrides military authority in the battlefield. That is an imperative for viable peace.

Fourth, Political culture in Colombia was changed. For the first time in Colombia, national leadership and close military-civilian relations were modified to address security, rule of law, and governance. In addition, in Colombia public opinion has always perceived democratic security policy supported by Plan Colombia. In other words, Plan Colombia has not been assessed as an U.S. intervention in Colombian domestic policies. In consequences, political culture was changed by internal political forces while population shifted to support the government, because of populace and private sector acknowledged that security was necessary to achieve rule of law and governance, while providing favorable conditions for social and economic development. In consequence, a virtual cycle was initiated to rebuild nation-state where security was the initial step in the near-term to carry out a long-term solution.

Fifth, set of conditions for viable peace and conflict resolution were created. The government instituted laws and created governmental agencies to promote 
alternative social programs to demobilized insurgents and populace in rural areas subjected to coca eradication. On one hand, former insurgents have found alternatives, for them and their families, to achieve social development and technical education. On the other hand, the Colombian government, by means of the DHAP and SAP, has executed execute the Law 975 necessary to build a viable peace in light of internal conflict resolution. As a result, insurgents and paramilitaries were able to meet a legal option and correct the path in the civil society. Likewise, this governmental action has provided reparation and compensations for victims. Moreover, victims have known the truth regarding genocides and assassinations of their relatives. Those are conditions essential for conflict termination and viable peace in the long-term.

Finally, the war on drugs requires long-term efforts, multilateral and multinational efforts. Even though there is significant progress for Colombia in this matter, drug production and trafficking are still at an unacceptable level. Furthermore, in Bolivia and Peru, coca production and trafficking are increasing while narcotrafficking routes toward the U.S. and Europe from Colombia are more active in Colombia's other neighboring countries. The latter in absence of a multinational approach to conditions and security issues, related to narcotrafficking.

\section{CONCLUSIONS AND RECOMMENDATIONS}

Plan Colombia has operated, perhaps not perfectly, but well enough to make a significant difference in the strategic and operational environment. Even though Plan Colombia aimed to disrupt, deny, degrade, and neutralize drug production and trafficking, it resulted in a paradigm that has enabled the Colombian government to rebuild the nation-state. There was a political culture change which was internally enforced through the democratic security policy instituted by President Uribe from 2002 and supported in great manner, by President's Santos administration, until today. It means, continued line of strategic effort during 17 years.

For the first time in Colombia, 3 administrations have integrated civilian and military efforts to address security matters, while providing the conditions to strengthen rule of law and governance. However, future strategies in the near and mid-term should emphasize more social and economic development, in conjunction with international aid and support. Today's challenges require innovation to sustain long-term social programs, by integrating the private sector to leverage social and economic development. Also, international cooperation and responsibility is vital, by addressing transnational crime organizations connected with drugs-tarfficking. In the meantime, the military is essential to address the dynamic security environment as well as the supporting element of civilian 
authorities in the territories, by means of interagency planning and execution. Hence, those efforts should be led within an interagency (IA) environment, to achieve long-term social programs in focus areas, to achieve the control of the territory.

Therefore, long term solutions are vital to undermining narcotrafficking, corruption, and social issues, while military efforts are essential to providing the security environment and to support rule of law and governance.

Ultimately, Plan Colombia was a factor to foster internal enforcement and procure political culture change as well as military transformation in Colombia. Contextual factors and culture were encountered during the last 17 years to achieve success. As a result, it is vital to address one final question. Could the Plan Colombia strategy bring success in other scenarios such as Afghanistan and Iraq? The short answer is that one single strategy does not fit in every scenario. In other words, there is no simple solution to respond complex problems. However, statesmen and military leaders may consider the lessons learned in the case of Colombia as points of reference to renew or reinforce strategies in Iraq and Afghanistan, always considering culture and contextual factors to identify realistic goals. Next, the challenge is finding the approach to influence political culture and military change to attain legitimacy as it is understood by a specific culture. That was the case for Colombia. Implementing political culture and military transformation is only one way to conduct a strategy to achieve an end state, albeit a time consuming one.

\section{REFERENCIAS}

Fuentes Primarias

Comando General de las Fuerzas Militares. (2012). Informe Ejecutivo de Rendición de Cuentas CGFM 2012Recuperado de https://www.mindefensa.gov. co/irj/go/km/docs/Mindefensa/Documentos/descargas/Sobre_el_Ministerio/ RendicionCuentas/2012/informeComandoGeneral.pdf

Comando General de las Fuerzas Militares. (2008). Operación Fénix. Recuperado de http://www.cgfm.mil.co/CGFMPortal/Reyes/1_index.html

Comando General de las Fuerzas Militares. (2008). Operación Jaque. Recuperado de http://www.cgfm.mil.co/CGFMPortal/jaque_web/OperacionJAQUE/1_index_jaque.htm

Comando General de las Fuerzas Militares. (2017). Plan Victoria, por una paz estable y duradera. Recuperado de http://www.cgfm.mil.co/2017/02/21/ plan-militar-victoria-una-paz-estable-duradera/ 
Directiva No. 015 (2016). Ministerio de Defensa Nacional. Recuperado de https://www.mindefensa.gov.co/irj/go/km/docs/Mindefensa/Documentos/descargas/Prensa/Documentos/dir_15_2016.pdf

Ley de Justicia y Paz. (2005). Recuperado de http://www.semana.com/documents/Doc-1246_2006518.pdf

Ministerio de Defensa. (2009). Logros de la política de consolidación de la seguridad democrática-PCSD. P. 76.

Presidential Sanction 2467 (2005).

\section{FuENTES SECUNDARIAS}

Bruneau, T. (2003). Conflict and Civil-Military Relations; Strategic Insights, Volume II, Issue 3 (Academic Article) Naval Postgraduate School, Monterrey, California.

Corum, J. \& Johnson W. (2003). Airpower in Small Wars: Fighting Insurgents and terrorists. Lawrence, Kansas: University Press of Kansas.

Counterinsurgency Operations. (05-10-2009). Chapter I, Foundations for Counterinsurgency. Join Publication (JP) 3-24. P. I-1.

Crandall, R. (2008). The U.S. and Latin America After the Cold War. New York, U.S.A: Cambridge University.

Doctrine for the Armed Forces of the United States. (20-03-2009). Joint Publication (JP) 1. P. II-2.

Frechette, M. (2007). Colombia and the United States-The Partnership: But What is the Endgame. Recuperado de http://www.strategicstudiesinstitute. army.mil/pubs/display.cfm?PubID=762

Fuerzas Militares activan Comando Conjunto Pacífico. (2009). Ministerio de Defensa, Recuperado de http://www.cgfm.mil.co/CGFMPortal/index. jsp?option $=$ noticiaDisplay\&idNoti $=3042$

Goldwater, N. (1986). Department of Defense Reorganization Act of 1986. Recuperado de: http://www.ndu.edu/library/goldnich/goldnich.html

Hawley, L., \& Skocz, D. (2005). “Advance Political-Military Planning: Laying the Foundation for Achieving a Viable Peace." In The Quest for Viable Peace: International Intervention and Strategies for Conflict Transformation, edited by Jock Covey, Michael J. Dziedzic, and Leonard R. Hawley, 37-76. Washington, D.C.: United States Institute of Peace Press. 
Hooker, R. Jr. (2003)." Soldiers of the State: Reconsidering American Civil Relations". Recuperado de http://www.carlisle.army.mil/usawc/Parameters/03winter/hooker.htm

Joint Operations. (17 September 2006). Joint Publication 3-0. P. GL-26. Recuperado de: http://www.dtic.mil/doctrine/new_pubs/jp1.pdf

Marcella, G. (2009). "Democratic Governance and the Rule of Law: Lessons from Colombia,". Recuperado de

http://www.strategicstudiesinstitute.army.mil/pubs/display.cfm?pubID=955

MARKs, T. (2002). Colombian Army Adaptation to FARC Insurgency. Recuperado de http://www.strategicstudiesinstitute.army.mil/pubs/display.cfm?pu$\mathrm{bID}=18$

McFate, M. (2005). “The Military Utility of Understanding Adversary Culture." Joint Forces Quarterly issue 38 (3rd Quarter, 2005): 42-48. Recuperado de http://www.dtic.mil/doctrine/jel/jfq pubs/1038.pdf(accessed 8 March 2010)

Ortiz, I. (2001). El Sistema de Alertas Tempranas como Mecanismo de Guerra. Recuperado de http://indh.pnud.org.co/files/rec/Alertas_tempranas_OrtizPalacios.pdf

Plan de Consolidación, Seguridad y Progreso. (2009). Revista Ejército Nacional. Recuperado de https://www.ejercito.mil.co/?idcategoria=236149

Pickering, T. (2009). "Anatomy of Plan Colombia” The American Interest, Fry Communications Inc. Pennsylvania. P. 71.

Pizarro, E. \& Gaitán, P. (2006). "Plan Colombia and the Regional Initiative: Lights and Shadows" In Addicted to Failure: U.S. Security Policy in Latin America and the Andean Region, edited by Brian Loveman, 53-79. Lanham, Maryland: Rowman \& Little Publishers, Inc.

Ramírez, M., Stanton, K. and Wash, J. (2005). "A Vicious Circle of Drugs and War" In Drugs and Democracy in Latin America: The impact of U.S. Policy, edited by Coletta A. Youngers, and Eileen Rosin. Boulder, 99-142.Colorado: Lynne Reinner Publisher, Inc,

ReID, M. (2007). "Forgotten Continent: the Battle for Latin America's Soul" London, England: Yale University Press.

RoBerTs, A. (2002). Counter-terrorism, Armed Force and the Laws of War. p. 117. 


\title{
Cultura institucional PaRa la transición: COMANDO AÉrEO de COMBATE $\mathrm{N}^{\circ} 2$
}

\author{
Teniente Coronel (RA) ALEXANDRA GUZMÁN DURÁN
}

\section{INTRODUCCIÓN}

El presente documento sintetiza uno de los componentes investigativos desarrollados con el objeto de comprender los elementos culturales y de construcción de sentido empleados por los Oficiales y Suboficiales adscritos al Comando Aéreo de Combate $\mathrm{N}^{\circ} 2$-CACOM 2- para pensar prospectivamente el futuro cercano de la Fuerza Aérea Colombiana y de esta unidad militar en particular. Dicho ejercicio se enmarca en un proyecto de investigación más amplio $^{2}$, que busca explorar los elementos psicosociales que determinan y configuran al personal que hace parte de Apiay.

El ejercicio tiene un marco histórico que legitima y justifica su realización y que define el objeto principal de este artículo de investigación: El proceso de paz que se desarrolla con la organización armada de las FARC presupone unas transformaciones institucionales muy importantes del Estado colombiano. Entre las instituciones que han sido llamadas a transformar su estructura, están las Fuerzas Militares, quienes desde ya han iniciado a estudiar este proceso, y a prepararse para estas transiciones.

Sin embargo, los procesos de pedagogía al interior de las Fuerzas no han logrado avanzar con la misma velocidad con la que lo hace el proceso de negociación y la información -falsa o verdadera- que se ha divulgado a partir de los eventuales acuerdos que se logren. Esta falencia ha ocasionado malestares, desinformaciones y rumores, en los que se cuestiona la seguridad jurídica y económica de los miembros de la Institución; y profundas críticas a lo que se viene negociando.

Psicóloga de la Reserva Activa de la Fuerza Aérea Colombiana e investigadora del Grupo Análisis y Contexto.

2 Esta investigación se complementa con un análisis de la Empatía, emociones y estrategias de regulación emocional en diferentes poblaciones afectadas por el conflicto armado en Colombia, la cual fue realizada en conjunto con los psicólogos PhD Hernán Camilo Hurtado y con el PhD Carlos Gantiva; cuyos resultados serán publicados en un informe de investigación más amplio. 
Para poder subsanar este vacío es necesario reforzar los procesos de pedagogía para la paz al interior de las Fuerzas. Para ello, hay que dimensionar que cuando se habla de pedagogía no se limita al acto de transmitir información, sino que se entiende en su sentido más amplio: comprensión de las formas de pensar de un grupo, y a partir de ello, generación de estrategias comunicativas y didácticas acordes para el público específico (RoJANO, 2008; ORTEGA, 2012).

Esto quiere decir, que antes de generar acciones pedagógicas y de sensibilización, es necesario comprender cómo entienden los miembros de la Fuerza Aérea Colombiana este proceso de paz; es decir, cuáles son los referentes políticos y sociales desde los que piensan esta negociación. Lo que en últimas, se entiende como la comprensión de la cultura para la paz de los militares adscritos a la Institución.

Comprender esta cultura es de gran utilidad para liderar de forma efectiva los procesos de transición de las Fuerzas Militares; pero también para romper el imaginario colectivo que señala que estas instituciones castrenses son opuestas y contrarias a la búsqueda negociada de la paz.

\section{METODOLOGÍA}

Para el desarrollo de este proyecto de investigación se realizó un ejercicio investigativo fundamentado en las premisas epistemológicas de la etnografía, entendiendo que el objeto central de esta rama del conocimiento son las formas de actuar y de pensar, determinados por un referente cultural concreto.

Así, la investigación etnográfica trata de develar los elementos culturales (tradiciones, rituales, ideologías-idiosincrasias, y pautas de comportamiento estandarizadas) que justifican y explican la forma en la que piensa y actúa un determinado colectivo, y que les lleva a proyectar estereotipos, prenociones y formas de comprender la realidad social (AGUiRRE, 1995).

En el caso concreto de esta investigación consistió en develar las formas de pensamiento históricamente utilizadas y referidas por los miembros de la Fuerza Aérea Colombiana, para poder comprender por qué se reacciona de una manera determinada frente a los procesos de negociación que se están desarrollando. Así mismo, una determinación de la estrategia pedagógica que se debe desarrollar para generar impactos efectivos en la cultura institucional de los miembros de la Fuerza Aérea Colombiana.

Todo esto se derivó en un procedimiento de investigación específico, que permitió comprender los elementos que definen esta cultura institucional. Este procedimiento se fundamenta en los postulados de los enfoques cualitativos (Delgado, 2006), y se estructuraron en una estrategia puntual desarrollada a partir de unos grupos focales realizados con un personal militar heterogéneo 
(en términos de grados, tiempo de permanencia en la Institución y en la Unidad militar, entre otros factores); así como una revisión documental.

\section{HALLAZGOS}

Fruto del ejercicio investigativo emergieron unos temas concretos sobre los que había coincidencias y acuerdos entre los distintos grupos consultados. Estos hallazgos cabe entenderlos como narrativas comunes que empiezan a determinar rasgos comunes e identitarios del personal adscrito a CACOM 2. Por supuesto, alrededor de estos temas transitan unos puntos de disenso y debate, pero que cuantitativamente no son significativos ni incidentes para impedir que se configuren estos acuerdos.

Con el ánimo de ordenar estas narrativas, acorde con el procedimiento metodológico empleado, se presentan en tres grandes grupos temáticos; estos temas se articulan plenamente con los debates propios del ámbito de la transición, y su diagnóstico es una pieza fundamental para futuros ejercicios pedagógicos que se quieran desarrollar con este personal militar. Se hace una exposición detallada de cada uno de estos debates.

\subsection{LO POLÍTICO EN LO MILITAR: UNA MIRADA A LA NEGOCIACIÓN DE PAZ}

El primer gran tema sobre el que emergió un acuerdo tácito entre los participantes, es la posición favorable a que se alcance la paz en el país, entendiendo que ésta no será resultado exclusivo de intervenciones militares, y que implicará acuerdos políticos y jurídicos con las partes. Sin embargo, este apoyo viene acompañado de profundas desconfianzas sobre lo que se está pactando en los Diálogos de la Habana.

Esta desconfianza es el resultado de una incredulidad sobre los canales de difusión y comunicación que se han desplegado para socializar los acuerdos a los que se han llegado; responsabilizando de esta mala estrategia comunicativa al Gobierno Nacional y los medios de comunicación que, según varios de los consultados, tienen una posición amañada e interesada sobre el resultado final de los acuerdos.

Por supuesto, esta posición no es ligera y desinformada, sino que surge del conocimiento del terreno y de la realidad que ellos tienen, y que no ha sido recogida suficientemente en los informes mediáticos y académicos, fenómeno que ahonda y profundiza las desconfianzas y los recelos.

Es fundamental aclarar que el universo poblacional es absolutamente respetuoso de las decisiones tomadas por el Gobierno Nacional, y que acatan el 
resultado de los procesos, pero en el marco de un ejercicio netamente académico, se permiten manifestar estas dudas e inquietudes.

El primer grupo de dudas se teje entorno a la voluntad real de paz de la organización armada, basados en la labor de inteligencia realizada por tantas décadas, y que no permite apreciar con claridad esta voluntad. De hecho, es importante señalar que aquellos que tienen una relación directa con la especialidad de Inteligencia, fueron los que manifestaron mayores incredulidades y temores con el resultado final de esta negociación.

De este factor, y de la voluntad real que exprese este grupo, dependerán los posibles actos de perdón y de reconciliación que se presenten en el futuro; ya que no puede haber un acto sincero de perdón, si está fundamentado en desconfianzas y resquemores.

En segundo lugar, hay un temor generalizado por la suerte de los territorios que actualmente ocupa este grupo armado, ya que las posibilidades de que otros grupos armados ilegales los ocupen son bastantes altos, tal y como lo ilustra la historia reciente de la desmovilización de las Autodefensas Unidas de Colombia -AUC. Este temor no es particular de este grupo social, sino que se puede rastrear fácilmente en distintos informes académicos realizados en Colombia para determinar los riesgos de seguridad del posconflicto (Observatorio del Programa Presidencial de Derechos Humanos y DIH, 2012).

Esto se concadena con un tercer temor, en el que se preguntan por el futuro inmediato de las bases de las FARC, esos desmovilizados que no van a tener espacios de representación ni inserciones mediáticas en la sociedad civil, y que no conocen otra vida que las armas y la violencia. Allí, consideran que si no se hace un ejercicio serio e integral, se corre el riesgo de que estas personas reincidan en la violencia y la criminalidad a nombre de otros grupos ilegales, con graves consecuencias socio jurídicas derivadas del ámbito del Derecho Internacional Humanitario que no cobijaría a estas organizaciones y que dejaría en un vacío jurídico a la Fuerza Aérea Colombiana (ReTtBerg, 2012).

Este punto es muy importante en la concepción etnometodológica (ESQUIVEL OCADÍZ, 2016) que hacen ellos sobre las FARC, porque entienden que no pueden equipararse las bases con la cúpula de la organización, siendo esta última la que gozará de todos los derechos y reconocimientos propios de las negociaciones. Por ello, entienden que estas bases han sido instrumentos históricos de esas cúpulas, que los han llevado a cometer actos atroces; ante ello, la aplicación de la justicia transicional puede ser más benevolente con esas bases, pero no tanto así con los máximos responsables de los hechos más violentos, según consta en los ejercicios investigativos realizados.

Finalmente, emergen unas desconfianzas materiales y concretas sobre el futuro inmediato de la institución: emergiendo categorías tales como las afectaciones sobre elementos pensionales de los miembros de la Fuerza Pública, reducción de 
ingresos por cuenta de la eventual desaparición de la "prima de orden público"; y en las posibles acciones judiciales descontextualizadas y tendenciosas que podrían realizarse contra los militares y policías. Este último punto es fundamental, porque significa un temor por la seguridad jurídica de los miembros de las Fuerzas Militares, pero también una afrenta contra el honor militar y contra la dignidad de las instituciones castrenses.

\subsection{ELEMENTOS DE AUTODEFINICIÓN: REPRESENTACIÓN DE LO MILITAR}

Una de las conclusiones generales a las que llegaron los entrevistados, es que hay un profundo desconocimiento por parte de la sociedad civil sobre las tradiciones, costumbres y roles militares: lo cual incide en que en ocasiones se juzgue de forma errada el proceder de la Institución. Sobre esta situación se presentó un debate muy interesante del que surgieron dos posiciones:

1. La sociedad desconoce a las Fuerzas Militares porque los órganos (gobierno, medios de comunicación, sector académico, entre otros) que se han encargado de presentarlas, lo han hecho de forma incorrecta y, en ocasiones, tendenciosa e ideológicamente sesgada.

2. Las mismas Fuerzas Militares han fallado a la hora de dar a conocerse a la población, encerrándose mucho en sus instalaciones militares, y sin construir una estrategia comunicacional que impacte a los distintos públicos. Así mismo, ha adolecido de escritores internos o afines, que se ocupen de contar su historia a las generaciones futuras.

Como sea, este desconocimiento incide en que la sociedad juzgue o malinterprete acciones propias del mundo militar, y que tipifique estos comportamientos como arbitrarios o arcaicos. Por ejemplo, un fenómeno tan importante -para la población con la que hizo la investigación-como lo es el honor militar, siempre resulta difícil de explicar a una persona externa a estas instituciones.

Este "honor" está presente en todo el proceder y doctrina de la Fuerza Aérea de Colombia, y sus integrantes lo encuentran en la vocación para tomar esta opción de vida, en la forma en la que se procede en el día a día, en la "mística" con la que se emprenden las tareas y responsabilidades, y en la disposición de servicio y de sumisión institucional. Por ello, fue muy recurrente que en la lectura propia que realizaron estos señores Oficiales y Suboficiales, el término honor emergiera siempre que debían definirse (GONZÁLEZ, 2007).

De hecho, en este punto emergió un tema de debate: las diferenciaciones y rupturas generaciones ${ }^{3}$ que se pueden presentar dentro de la Fuerza Aérea

Este tema determinó uno de los criterios metodológicos de selección de la población para los grupos focales, ya que siempre se esperó contar con personal con gran trayectoria dentro de la Institución, pero también con la posición de aquellos que hasta ahora están entrando a la misma. 
Colombiana; tema importantísimo en este estudio porque habla de las posibles irrupciones y rupturas culturales que se pueden presentar dentro de la Institución.

Lo primero que debe señalarse, es que sí se encontró una autopercepción de la existencia de estas rupturas generacionales: manifestadas en las características de las personas que ingresan, en las aspiraciones de los miembros, y en el perfil de los mismos; a continuación, se analiza brevemente estos elementos.

Lo primero que señalaron los entrevistados se relaciona con las transformaciones sociohistóricas que ha vivido el país en los últimos años, y la imagen que proyectó la Fuerza Aérea Colombiana en cada uno de esos momentos. Así, es muy diferente que una persona ingresara a la Institución en la década de los años 80 , cuando el componente tecnológico era menor, y cuando el impacto mediático de las operaciones aéreas era reducido; o que una persona tomara la elección de enlistarse en la década de los años noventa, cuando las acciones que desarrollaban los grupos armados ilegales ponían en riesgo la vida de todos los ciudadanos y le daban una connotación de mayor peligro a este servicio; y por supuesto, es muy distinto el contexto actual, en el que la Fuerza ha generado operaciones aéreas muy exitosas y contundentes (Fuerza Aérea Colombiana, 2016) y cuando el ambiente social y político apunta a la eventual terminación del conflicto armado, por lo menos en la forma en la que hasta ahora se ha conocido.

Todos estos elementos contextuales, tienden a determinar un perfil general de la persona que ingresa a la Institución, señalándose que el componente militar ha venido disminuyendo, emergiendo una serie de jóvenes, mucho más profesionales y con aspiraciones de avanzar en su formación. Esto se define como una nueva generación de jóvenes que ponen el énfasis en los elementos profesionales, técnicos y burocráticos propios de su actividad, en desmedro de las actividades físicas, disciplinares y doctrinales propios de lo militar; lo primero no elimina lo segundo, pero sí le resta valía e importancia.

Finalmente, es importante señalar que no hay una valoración negativa o positiva de estos cambios, ya que señalan que no es un proceso exclusivo o particular de la Fuerza Aérea Colombiana, sino de la sociedad en general, y de las dinámicas de diferenciación propias de cada generación: los que hoy tienen más de 20 años de servicio dentro de la Institución, igual fueron jóvenes irruptores y transgresores de las costumbres cuando ingresaron a la Institución.

\subsection{Transformación de la Fuerza Aérea Colombiana: el PROCESO DE TRANSICIÓN}

La palabra con la que se afronta este proceso histórico es incertidumbre. Incertidumbre ante el futuro doctrinal, misional y del personal que hace parte de la Institución. Esta sensación no ha desaparecido aun cuando han recibido distintos procesos de sensibilización y capacitación sobre el rol de la Fuerza 
Aérea Colombiana en el eventual escenario del posconflicto, en parte porque consideran que los argumentos no son suficientemente claros, y en parte porque encuentran algunas incongruencias entre discurso y realidad.

Así mismo, como se expresó en un apartado anterior, subsisten unas desconfianzas y miedos sobre el futuro de la seguridad del país, después de que se cierren las negociaciones con las FARC, que llevan a que se problematice el alcance mismo de la transición, o la validez institucional de la misma. Así mismo, el confuso panorama que se cierne sobre el ELN, y su posible fortalecimiento tras la negociación con las FARC, refuerzan el recelo y desconfianza que se presenta en este punto.

Relacionado con esto, hay una tendencia a pensar que la posibilidad real del fin del conflicto o de la violencia va a ser lejana, en cuanto fenómenos como las "bacrim", el narcotráfico o los denominados delitos transnacionales van a ser elementos recurrentes en un futuro cercano y a medio plazo. Esto, acompañado de una incertidumbre jurídica y política sobre cuál será el rol que se le asigne a la Institución en un futuro cercano frente a estos flagelos sociales y de seguridad.

Sin embargo, son respetuosos del poder central y de las decisiones que allí se tomen, y lejos de buscar ser obstáculos o tropiezos en esta nueva fase de la historia del país, generan reflexiones sobre cuál podría ser el rol de la Fuerza Aérea Colombiana en ese nuevo contexto histórico, lo cual se puede apreciar en las siguientes propuestas.

En primer lugar, hay un llamado a recuperar los propósitos iniciales: proteger la soberanía nacional y monitorear las fronteras del país; para ello es necesario replantear las estrategias, modernizar algunos equipos y concentrar esfuerzos en esta importante tarea, máxime cuando hay escenarios complejos con países como Nicaragua y Venezuela.

En segundo lugar, la Institución tiene una fortaleza que ninguna otra fuerza aérea tiene: una amplísima experiencia en operaciones aéreas en el marco de un conflicto armado interno, lo que le permite transmitir este conocimiento a otros países y convertirse en un referente a nivel internacional; en particular, reconocen que CACOM 2 tiene grandes enseñanzas que compartir en este terreno.

Finalmente, aseguran que la Fuerza Aérea Colombiana ha sido central en los procesos de desarrollo de vastas regiones del país, en especial de aquellas que están más alejadas del centro y en donde es muy difícil el ingreso terrestre. A estas regiones, a las que a veces ni siquiera las instituciones del Estado pueden llegar, la Fuerza Aérea Colombiana ha generado presencia y asistencia en temas sociales (educación, brigadas de salud, y demás actividades concentradas en lo que se denomina la Acción Integral), asistencia humanitaria e interconexión de estas regiones con el resto del país. 
Basta señalar, por ejemplo, el caso de Satena y su compromiso con las regiones más apartadas y a las que ninguna aerolínea comercial llega; gracias a ésta se ha podido generar procesos económicos y de desarrollo, ligados con la aviación comercial y de transporte de pasajeros.

De esta manera, aunque hay unos miedos y resquemores ante el proceso que se está dando, tienen una mirada propositiva y abierta sobre la incidencia que podría tener la Fuerza Aérea Colombiana en estos nuevos contextos, sin perder de vista que ante una ruptura de los acuerdos o del cese al fuego bilateral, están plenamente preparados para retomar las operaciones aéreas que conduzcan a garantizar la seguridad de las distintas regiones del país.

\subsection{CACOM 2: APIAY Y SUS APORTES AL PROCESO DE TRANSICIÓN}

Hubo un consenso entre todos, a la hora de señalar la importancia estratégica que tiene CACOM 2 por su ubicación geográfica en el centro del país, lo que le permite alcanzar todas las posiciones del territorio nacional; no en balde, varias de las operaciones áreas más importantes han salido de esta Unidad, o han recibido apoyo estratégico de la misma, tal como lo evidencian las publicaciones académicas que se han desarrollado sobre este tema (MARín, et al, 2016).

A la vez, coinciden en señalar que esta Unidad tiene una "mística" especial, que hace que los más experimentados la definan como uno de los mejores Comandos Aéreos en los que han trabajado, porque es posible ver directamente el impacto regional y nacional que su labor ha generado. El tipo de aeronaves, el dinamismo de la operatividad y la permanente capacitación y actualización del personal hacen que Apiay sea altamente incidente en la seguridad del país (ECHANDÍA, 2013).

Por ejemplo, los que más años llevan en CACOM 2 (se entrevistaron a Técnicos Jefes que tienen más de 20 años en esta Unidad), recuerdan cómo era la situación de seguridad en la antigua vía Bogotá-Villavicencio, una vía donde era imposible transitar a ciertas horas del día, por la presencia de las FARC en municipios intermedios; situación que ya ha sido superada, y que ha permitido que el tránsito entre Bogotá y Villavicencio sea cada vez mayor, con todas las posibilidades de desarrollo, y posibilidades económicas para una importante zona de Colombia (CALDERón, 2015). Este cambio sólo fue posible por la mayor presencia de la Fuerza Pública en la región, y por supuesto, por la labor operativa y de inteligencia que prestó la institución, a través de CACOM 2.

$Y$ es que hay que entender que Apiay está ubicada en la puerta de entrada a la región de la Orinoquia, una zona muy rica en recursos naturales, pero con unas tasas de desarrollo muy bajas, y con una infraestructura vial y de servicios inadecuada e insuficiente (Fundación Ideas para la Paz, 2013). 
Por ello, la institución tiene una oportunidad privilegiada de ser incidente en la transformación económica de esta región del país, apoyando en la consolidación de una economía sólida y de un desarrollo social sostenible. La Fuerza Aérea Colombiana, por medio de CACOM 2 fue clave en la consolidación de la seguridad de la región en el peor momento del conflicto en estos territorios, ahora podrá ser incidente en su transformación económica en un eventual escenario de posconflicto (Observatorio del Programa Presidencial de Derechos Humanos y DIH, 2012).

Así mismo, Apiay está en una posición estratégica fundamental para monitorear las fronteras orientales, occidentales y al sur del país, lo que le permite ser trascendente en la protección de la soberanía del país, ante cualquier intento de transgresión que se pudiese presentar.

\section{REFLEXIONES FINALES}

El enfoque explicativo de este documento, giró en torno a tres niveles de análisis, acorde con los elementos macro y micro que emergen a nivel macro del análisis de los grupos focales, entre ellos están la transformación en la Fuerza, la pregunta por la identidad de lo militar y las relaciones cívico-militares. Esto se puede apreciar en la siguiente imagen, resultado de la entrevista a expertos en esta materia

\section{Imagen. Elementos macro emergentes}

\begin{tabular}{|c|c|}
\hline Transformación de la Fuerza \\
\hline Identidad de lo militar \\
\hline
\end{tabular}

Fuente: Elaboración propia a partir de entrevistas exploratorias realizadas (2016)

Lo interesante de este modelo de análisis, es que partiendo de las premisas etnometodológicas de Aguirre (1995) se puede establecer que hay un orden lógico para entender e interpretar la información encontrada, ya que para poder deducir cómo conciben la transición o el proceso de paz los miembros de la Fuerza Aérea Colombiana, primero hay que entender quiénes son y cuáles son sus rasgos característicos y que definen su identidad como militares.

En ese mismo sentido, cualquier apuesta pedagógica que se quiera desarrollar con esta población, tiene que partir de un conocimiento profundo y concienzudo de la población militar de la institución, para poder diseñar contenidos, estrategias didácticas y lenguajes que sean acordes y adecuados para este grupo poblacional 
y que permita que la sensibilización y construcción de contenido sea la adecuada para las necesidades informativas que ellos tienen.

Por ejemplo, como lo deja claro la lectura de GonzÁLEz (2007) y de las entrevistas realizadas, todo este ejercicio de conocimiento y pedagogía tiene que dimensionar lo que implica para esta población el "honor militar", ya que allí se establecen unos posibles puntos de encuentro, pero también unos elementos intocables y que generan altas sensibilidades en este grupo humano:

\begin{abstract}
"Lo humano está dotado de sentimientos que predisponen a la acción (1) y aquellos cuya conducta profesional más específica es el empleo de la fuerza con la finalidad de imponerse en el enfrentamiento y para ello, si llega el caso, eliminar a otros, deberían estar amparados en sólidas razones y firmes convicciones que legitimaran dicha conducta. El soldado no es un elemento material más de los que intervienen en una guerra, es un individuo dotado de razón y emoción, y que como todo ser humano intenta encontrar unos sólidos fundamentos morales y éticos a su profesión" (GoNZÁLEZ, 2007, p. 7).
\end{abstract}

Es desde este honor desde donde los miembros de la Fuerza Aérea entienden y comprenden el proceso de paz y las posibilidades de transición hacía un escenario de posconflicto; cualquier intento de construir discursos pedagógicos desde ejes conceptuales ajenos a este referente, corren el riesgo de no tener acogida dentro de la Institución, o peor aún, de generar desconfianzas y malestares dentro de estos Oficiales y Suboficiales.

Un segundo eje de conclusión derivado de este ejercicio investigativo, se estructura en torno a la concepción dual que tienen las personas entrevistadas sobre la Institución, señalando que ésta es apta y necesaria en tiempos de conflicto armado interno, pero que también lo es en tiempos de paz.

De hecho, son conscientes que el propósito institucional original no estaba enfocado a este tipo de conflictos, sino que tenían una misionalidad de protección de fronteras, y con ello, de la soberanía del país. Así mismo, en el quehacer de la misma, han emergido una serie de posibilidades de intervención en procesos de desarrollo con las comunidades, que ha dejado una impronta indeleble en estos hombres y mujeres.

Sin importar el contexto histórico, la Fuerza Aérea Colombiana fue, es y será fundamental para generar desarrollo y progreso en las zonas más alejadas e inhóspitas del país, allá donde otras instituciones del Estado no han podido llegar; allí donde el proceso de consolidación no ha iniciado.

En ese sentido, se entiende y explica una de las particularidades centrales de CACOM 2, ya que esta Unidad fue, es y será fundamental para el desarrollo de operaciones aéreas exitosas y efectivas, en razón de su privilegiadísima ubicación estratégica en el centro del país, y en cercanía de todas las fronteras del sur del 
país, lo que le permite ser punta de lanza en cualquier despliegue de poder aéreo que la Institución deba desarrollar.

Pero también Apiay es la Unidad militar que tiene mayores posibilidades para impulsar el desarrollo social y económico en la Orinoquia colombiana, la región llamada a ser la principal despensa agrícola del país, la generadora de hidrocarburos, y una zona de desarrollo demográfico sustentable y sostenible. Esto es un aporte histórico que este Comando le hace a la región, y en función de esto se sustentan las positivas relaciones que ha establecido con los actores sociales, políticos y económicos de la región.

De todo esto son conocedores los hombres y mujeres que trabajan y operan desde el Comando Aéreo de Combate $\mathrm{N}^{\circ} 2$, lo cual les hace sentir orgullosos del papel protagónico e incidente de esta Unidad militar en la historia reciente del país, y en la consolidación de la seguridad y el desarrollo en la región. Por ello, sin tapujos, y reconociendo que los otros Comandos y Grupos Aéreos son muy importantes, no dudan en señalar que "CACOM es el mejor Comando de la Fuerza Aérea Colombiana"'s.

\section{REFERENCIAS}

Aguirre Baztán, Ángel. (1995). La etnografía. Metodología cualitativa en la investigación sociocultural. España: Editorial Marcombo.

CALDERón, Emilse. (2015). Estados Unidos y el combate contra el narcoterrorismo como lineamiento de política exterior central en el vínculo con América Latina: el caso del modelo de cooperación con Colombia. Buenos Aires, Argentina, CERIR.

Delgado, Juan Manuel. (2006). Manual de métodos cualitativos. España: Fondo de Cultura Económica.

ECHANDía, Camilo. (2013). Punto de partida del debilitamiento de las FARC. En Revista Zero, Bogotá, Universidad Externado de Colombia.

Esquivel TrianA, Ricardo. (2016). Fuerza Aérea Colombiana y operaciones decisivas 1998-2015. En La Fuerza Aérea Colombiana y el termino del conflicto armado. Victorias desde el aire. Colombia, Impress Colombia.

EsQuivel OCADIZ, Alejandro. (2016). La Etnometodología, una alternativa relegada de la educación. En: Revista Iberoamericana para la Investigación y el Desarrollo Educativo: RIDE, Vol. 6, No. 12.

$4 \quad$ Fragmento de entrevista realizada en los grupos focales desarrollados. 
Fuerza Aérea Colombiana. (2016). LaZona de distensión y su recuperación por parte de la Fuerza Aérea Colombiana. En La Fuerza Aérea Colombiana y el término del conflicto armado. Victorias desde el aire. Colombia, Impress Colombia.

Fundación Ideas para la Paz. (2013). Hoy y ayer del Bloque Oriental de las FARC. Colombia, Fundación Ideas para la Paz.

GonzÁLEZ, J. A. M. (2007). Aproximación al concepto de moral militar. Boletín de Información, (298), 7-19.

Marín Ramírez, Adriana; Castiblanco Durán, Camilo; Castrillón Riascos, Javier y Cotrina Acosta, Andrés. (2016). La Zona de distensión y su recuperación por parte de la Fuerza Aérea Colombiana. En La Fuerza Aérea Colombiana y el término del conflicto armado. Victorias desde el aire. Colombia, Impress Colombia.

Ortega Valencia, Piedad. (2012). Pedagogía y alteridad. Una Pedagogía del Nos-Otros. En: Revista Virtual Universidad Católica del Norte, núm. 35, febrero-mayo. Fundación Universitaria Católica del Norte Medellín, Colombia

Observatorio del Programa Presidencial de Derechos Humanos y DIH (2012) El Caguán, Colombia, Presidencia de la República.

Rettberg, Angelika. (2012). Caguán 10 años: Más allá de un proceso de paz. Bogotá, Documentos del Departamento de Ciencia Política N 16, Universidad de los Andes.

RoJAno Mercado, Jairo. (2008). Conceptos básicos de pedagogía. En: REDHECS: Revista electrónica de Humanidades, Educación y Comunicación Social, Año 3, No .4

SALAS, Luis Gabriel. (2014). Lógicas territoriales y relaciones de poder en el espacio de los actores armados: un aporte desde la geografía política al estudio de la violencia y el conflicto armado en Colombia, 1990-2012. En: Cuadernos de Geografía, Bogotá, Universidad Nacional de Colombia.

SÁnchez SuÁRez, Pedro Arnulfo (CR). (2014). Poder aéreo en la seguridad y defensa nacional. En Revista Taktika $N^{\circ}$ 5. Colombia, Fuerza Aérea Colombiana.

SAntos, María Alejandra. (2014). El poder de la Fuerza Aérea Colombiana: la Operación Vuelo de Ángel y el cambio en la asimetría de poder entre las FF.MM y las FARC-EP. Bogotá, Universidad Colegio Mayor de Nuestra Señora del Rosario, Facultad de Ciencia Política y Gobierno.

VÁzQUEZ, Teófilo. (2013). El papel del conflicto armado en la construcción y diferenciación territorial de la región del Caguán, Amazonia colombiana. Medellín, Universidad San Buenaventura. 


\title{
LA INNOVACIÓN COMO EJE DE TRANSFORMACIÓN Y DE CONSTRUCCIÓN SOCIAL Y ECONÓMICA
}

\author{
Mayor GERSON RICARDO JAIMES PARADA ${ }^{1}$
}

Partiendo del hecho, que las especies que sobreviven a la selección natural, son aquellas que mejor se adaptan a los cambios, ya que todos los seres orgánicos se esfuerzan por ocupar todos los puestos en la economía de la naturaleza (DARWIN, 1859), es importante comprender que tanto personas como organizaciones deben estar dispuestas a entender los nuevos contextos y transformase o de lo contrario no estarán a la altura tanto de las nuevas necesidades, como de los retos; los cuales pueden ser locales, regionales y/o mundiales.

Este capítulo pretende hacer una invitación a reflexionar, sobre lo fundamental y la importancia que tiene el hecho de estar alertas a las continuas transformaciones de un mundo globalizado, donde cada día aparecen nuevas oportunidades en diferentes campos de conocimiento, el surgimiento de avances tecnológicos y modelos de negocio de impacto mundial. Todos estos nuevos conocimientos, avances tecnológicos y nuevos modelos de negocio con innovaciones incrementales o disruptivas, van cambiando y mejorando la vida cotidiana y el entorno de familia, que pueden contribuir con la generación o creación de nuevas organizaciones y/o comunidades inteligentes, que afectan directamente estructuras económicas, sociales, antropológicas de cada cultura y País.

La definición de innovación no es tarea fácil, debido a que esta puede cambiar en cada persona de acuerdo a su área de desempeño, experiencia y nivel de formación; por lo anterior es posible encontrar diferentes definiciones. Sin embargo, para propósitos del presente capítulo, la definición más aceptada es la establecida por la Organización de Cooperación y Desarrollo Económico (OECD) en el manual de Oslo que dice:

"una innovación es la introducción de un nuevo, o significativamente mejorado producto (bien o servicio), de un proceso, de un nuevo método de comercialización

Licenciado en Matemáticas y Computación-Universidad Francisco de Paula Santander. Maestría en Tecnologías de la Información Aplicadas a la Educación-Universidad Pedagógica Nacional. Magister en Innovación - Universidad EAN. Subdirector de Investigación-Fuerza Aérea Colombiana. 
o de un nuevo método organizativo, en las prácticas internas de la empresa, la organización del lugar de trabajo o las relaciones exteriores" (OECD, 2005).

Así mismo, el manual de Oslo define cuatro tipos de innovación a saber:

1. Innovación de producto: corresponde con la introducción en la empresa u organización de un bien o servicio nuevo, o significativamente mejorado, en cuanto a sus características o en cuanto al uso al que es destinado (OECD, 2005).

2. Innovación de proceso: Es la introducción en la empresa u organización de un nuevo o significativamente mejorado método de producción o distribución. Esta definición implica cambios sustanciales en las técnicas, equipos y/o los programas de software. Sin embargo, hay que tener cuidado con lo que no son innovaciones de proceso, se refiere a cambios o mejoras menores, el aumento de una capacidad de producción o servicio por la incorporación de sistemas de fabricación o sistemas logísticos que son muy similares a los que ya estén en uso, en la organización o la empresa (OECD, 2005).

3. Innovación de mercadotecnia: Es la introducción de un nuevo método de comercialización que implica cambios significativos del diseño o envasado, de la colocación, la promoción o la tarificación de un producto, siempre y cuando sea la primera vez que se hace en la organización o la empresa (OECD, 2005).

4. Innovación organizativa: Es la introducción de un nuevo método organizativo en las prácticas, la organización del lugar de trabajo o las relaciones exteriores, siempre y cuando sea utilizado por primera vez en la empresa u organización (OECD, 2005).

Es común tener dificultad en identificar que son innovaciones organizativas, por eso, se presentan a continuación algunas situaciones explicadas en el manual de Oslo para contribuir con la aclaración de este tipo de concepto de innovación organizativa:

No se consideran como innovaciones organizativas

- Cuando se utilizan métodos organizativos ya existentes en la empresa u organización, para hacer cambios en las prácticas comerciales, la organización del lugar de trabajo o relaciones exteriores.

- Los cambios en la estrategia de gestión, salvo si son acompañados de la introducción de un nuevo método de organización.

- Fusionar o adquirir nuevas empresas.

- Sí se consideró como innovación organizativa 
- En prácticas empresariales

* La creación de una nueva base de datos sobre las buenas prácticas, lecciones aprendidas y otras formas de generación de conocimiento, para hacerlo de más fácil acceso a terceros.

* Introducción, por primera vez, de un sistema de monitorización integrado de las actividades de una empresa u organización, por ejemplo: producción, finanzas, estrategia, mercadotecnia, gestión de calidad, gestión de $\mathrm{I}+\mathrm{D}+\mathrm{i}$, entre otras.

* Introducción por primera vez, de programas de formación destinados a crear equipos interdisciplinarios y funcionales que integran empleados que vienen de áreas, horizontes o ámbitos con responsabilidades y roles diferentes.

- Organización del lugar de trabajo

* Primera aplicación de una descentralización de las responsabilidades inherentes a sus puestos a los empleados de la empresa u organización, por ejemplo, dando un mayor control y una responsabilidad significativamente mayor sobre el proceso de producción al personal de producción, distribución o ventas.

* Creación por primera vez de equipos de trabajo formales o informales para mejorar la generación, el acceso y la distribución de conocimientos que provienen de diferentes áreas o ámbitos de la empresa u organización, por ejemplo, servicios, producción, investigación, mercadotecnia, entre otros.

* Introducción por primera vez de un sistema de notificación anónimo de incidentes, errores y riesgos que contribuya con la determinación de sus causas y disminuir su frecuencia o materialización.

- Relaciones exteriores

* Introducción de normas de control para proveedores y subcontratistas.

* Recurrir por primera vez a la externalización de la investigación o producción.

* Primera iniciativa de colaboración en actividades de Ciencia, Tecnología e Innovación con entidades de la triada Universidad, Empresa y Estado.

Así mismo, en el campo del desarrollo de la industria se han definido dos categorías de innovación, partiendo de su efecto en la literatura existente y su impacto sobre el estado de la técnica; estas dos categoría se conocen como innovación incremental y la innovación radical, las cuales se explican a continuación: 
Innovación incremental: se puede entender como la que contempla cambios menores en la base tecnológica de un producto o servicio, amparándose en el conocimiento, la experiencia y las capacidades existentes en la empresa (ZIRGER \& HARTLEY, 1994).

Innovación radical: se caracteriza porque tiene una nueva base tecnológica o una experiencia novedosa de utilidad para los clientes (Ali, 1994), se puede complementar la definición de innovación radical expresando que tiene un alto nivel de complejidad e incertidumbre, que contribuye con el aumento de la necesidad del aprendizaje, la flexibilidad y la adaptabilidad, todo con el fin de afianzar y lograr una ventaja competitiva y beneficios que sean sostenibles en el tiempo (Salavou, 2004).

La siguiente tabla, se presenta para dar una mayor claridad en la asociación que por lo general desde el desarrollo tecnológico, se hace de las dos categorías de innovación (incremental o radical), en los tipos de innovación de producto, servicio, mercadotecnia o proceso, utilizando los conceptos y características de propiedad industrial aceptados para modelos de utilidad y patentes de invención.

Tabla No 1. Comparación de categorías de innovación con patentes de invención y modelos de utilidad

\begin{tabular}{|c|c|}
\hline CATEGORÍA DE INNOVACIÓN & PROPIEDAD INDUSTRIAL \\
\hline $\begin{array}{l}\text { Innovación Incremental: contempla } \\
\text { cambios menores en la base tecnológica } \\
\text { de un producto o servicio, amparándose } \\
\text { en el conocimiento, la experiencia y las } \\
\text { capacidades existentes en la empresa } \\
\text { (Zirger \& Hartley, 1994). }\end{array}$ & $\begin{array}{l}\text { Modelo de Utilidad: es toda nueva forma, configuración } \\
\text { o disposición de elementos, de algún artefacto, } \\
\text { herramienta, instrumento, mecanismo u otro objeto } \\
\text { o de alguna parte del mismo (La Comisión de la } \\
\text { Comunidad Andina, 2000), con las siguientes } \\
\text { condiciones: } \\
\text { - Novedad } \\
\text { - Aplicación Industrial }\end{array}$ \\
\hline $\begin{array}{l}\text { Innovación Radical: se caracteriza } \\
\text { porque tiene una nueva base tecnológica } \\
\text { o una experiencia novedosa de utilidad } \\
\text { para los clientes (Ali, 1994). }\end{array}$ & $\begin{array}{l}\text { Patente de Invención: se otorga patentes para las } \\
\text { invenciones, que sean de producto o de procedimiento, } \\
\text { en todos los campos de la tecnología (La Comisión de } \\
\text { la Comunidad Andina, 2000), que cumplan con las } \\
\text { siguientes condiciones: } \\
\text { - Novedad } \\
\text { - Nivel inventivo } \\
\text { - Aplicación industrial }\end{array}$ \\
\hline
\end{tabular}

Fuente: Elaboración propia del autor 
La importancia de los tipos de innovación y categorías de innovación es porque le permiten a los sectores productivos de un País, establecer estrategias para llegar a mercados nacionales e internacionales, contribuyendo con el crecimiento económico, sin embargo, es importante tener la claridad que las empresas y organizaciones no pueden lograr este crecimiento económico de forma aislada y se requiere procesos y actividades de relacionamiento que permitan compartir y unir esfuerzos y capacidades, con el fin de lograr productos y modelos de negocio con valor diferenciador, que sean sostenibles en el tiempo. En el siguiente aparte se presenta la necesidad de la articulación de las entidades de triada universidad, empresa y Estado.

\section{Articulación de la Triada, Universidad Empresa Estado}

En Latinoamérica, existe una gran dificultad para la adopción de nuevos conocimientos y tecnologías para lograr sectores productivos y empresariales con mayor competitividad mundial debido a las falencias que existen entre las interrelaciones y las extra-relaciones de las entidades de la universidad, empresa y Estado, las cuales son dispersas; contrario a lo que sucede en Países desarrollados, donde funcionan de manera más integradas y con buenos resultados las relaciones de este triángulo. Por lo anterior, Latinoamérica requiere fortalecer el triángulo científico-tecnológico, conformado por las entidades de la triada Universidad, Empresa y Estado, se deben generar nuevas capacidades y oportunidades de adopción de nuevos conocimientos y tecnologías, a través, de la construcción de cambios, que contribuyan con la construcción de nuevas estructuras, el fortalecimiento de valores y actitudes que permitan el desarrollo de proceso de innovación, apalancando el aparato productivo y empresarial (SÁBATO \& BOTANA, 1968).

Así mismo, la sociedad es un actor fundamental para la construcción de alianzas exitosas de la triada Universidad, Empresa y Estado, ya que la sociedad conoce sus necesidades y es la primera beneficiada de los resultados exitosos que se logran, como lo explica la siguiente cita:

"un esquema de trabajo con estas virtudes estimularía el desarrollo de una estructura productiva para una mejor inserción y cohesión de los integrantes del desarrollo, con resultados positivos para los agentes de la triple hélice y la sociedad en general" (CAstillo, Lavín, \& Pedraza, 2014).

Los nuevos retos mundiales, exigen que la sociedad colombiana, esté más atenta y tenga un papel más protagónico en las relaciones de la triada Universidad, Empresa y Estado; actualmente se destacan como actores integradores de esta triada, las universidades, los centros de investigación, las oficinas de transferencia de resultados de investigación, las oficinas de transferencia de tecnología, las corporaciones de ciencia, tecnología e innovación y los grupos de investigación.

Sin embargo, se requiere impulsar con mayor apoyo el establecimiento de estas alianzas, con la formación de talento humano de alto nivel y experiencia, y promover 
la generación de conocimiento de alto nivel. De igual forma se requiere inversión en la búsqueda de innovaciones radicales e incrementales, que apalanquen programas académicos de alta calidad en los diferentes niveles académicos de educación superior, que redunden en ventajas competitivas en los sectores productivos nacionales; construyendo así, un tejido económico y social sostenible.

En concordancia con lo anterior, Colombia ha venido incrementando su conocimiento y experiencia en alianza de la triada Universidad Empresa y Estado, para el desarrollo actividades y procesos de gestión de la innovación tecnológica, un actor que ha apoyado este crecimiento, es el Departamento Administrativo de Ciencia, Tecnología e Innovación (COLCIENCIAS); lo cual se evidencia con la creación y fortalecimiento de Oficina de Transferencias de Resultados de Investigación-OTRI (Colciencias, 2013), donde se apoyaron las siguientes:

Tabla No 2. Banco de elegibles para creación o fortalecimiento de OTRI

\begin{tabular}{|l|l|}
\hline \multicolumn{1}{|c|}{ TÍTULO } & ENTIDAD PROPONENTE \\
\hline "OTRI Estratégica del Oriente" & Universidad Autónoma de Bucaramanga \\
\hline $\begin{array}{l}\text { "Creación de una oficina de transferencia de resul- } \\
\text { tados de investigación (OTRI) para la ciudad de } \\
\text { Bogotá como alianza entre la Universidad Distrital } \\
\text { Francisco José de Caldas y la Secretaría Distrital de } \\
\text { Desarrollo Económico" }\end{array}$ & $\begin{array}{l}\text { Universidad Distrital Francisco José } \\
\text { de Caldas }\end{array}$ \\
\hline $\begin{array}{l}\text { "Creación de la oficina de resultados del sector de } \\
\text { seguridad y defensa, basados en las capacidades del } \\
\text { sistema de ciencia y tecnología de la Fuerza Aérea } \\
\text { Colombiana y sus aliados" }\end{array}$ & $\begin{array}{l}\text { Fuerza Aérea Colombiana - Centro de } \\
\text { Ciencia y Tecnología de Antioquia }\end{array}$ \\
\hline $\begin{array}{l}\text { "Creación de una oficina de transferencia de tecnolo- } \\
\text { gía Regional para Bogotá y Cundinamarca" }\end{array}$ & Corporación Connect Bogotá Región \\
\hline $\begin{array}{l}\text { "Fortalecimiento del modelo de transferencia de } \\
\text { tecnología en Antioquia" }\end{array}$ & $\begin{array}{l}\text { Corporación Tecnova Universidad Em- } \\
\text { presa Estado }\end{array}$ \\
\hline $\begin{array}{l}\text { "Diseño y puesta en marcha de una OTRI en el } \\
\text { departamento del Atlántico como estrategia para } \\
\text { dinamizar la transferencia de conocimiento entre } \\
\text { universidad-empresa y sociedad" }\end{array}$ & $\begin{array}{l}\text { Asociación Colombiana de las Micro, } \\
\text { Seccional Atlántico }\end{array}$ \\
\hline
\end{tabular}

Fuente: Colciencias (2013). 
Uno de los aprendizajes más importante en la creación de estas oficinas de transferencia de resultados de investigación, fue la necesidad de unir esfuerzos e impulsar la articulación de la triada Universidad Empresa Estado, con el fin de asimilar metodologías de vigilancia tecnológica e inteligencia competitiva, identificación de mercados potenciales, implementar protocolos para la validación de los resultados y productos de $\mathrm{I}+\mathrm{D}+\mathrm{i}$.

La Fuerza Aérea Colombiana, ha sido un actor importante en este proceso de construcción de Oficinas de Transferencia de Resultados de Investigación, con lo cual ha venido afianzando conocimientos y estrategias para la generación de valor agregado o diferenciador en los productos de $\mathrm{I}+\mathrm{D}+\mathrm{i}$ con potencial comercial, la generación de nuevo conocimiento y la creación de modelos de negocio. De esta forma ha contribuido con la construcción del tejido económico y social del País, por medio del escalamiento industrial y apostando a la comercialización de los productos de $\mathrm{I}+\mathrm{D}+\mathrm{i}$, creando así nuevas formas de emprendimiento, ya sea, a través de licenciamientos, o con la creación o fortalecimiento de spin-off y start-up en diferentes sectores productivos.

Otro aprendizaje relevante de esta experiencia para la creación de OTRI's en Colombia, fue la transmitida por los mentores de la universidad de Austin Texas EEUU y la visita tecnológica realizada al País de Suiza, quienes recalcan la necesidad imperiosa de promover la inversión en actividades de ciencia, tecnología e innovación y la formación de alto nivel, para obtener productos y servicios con valor diferenciador que tengan una buena oportunidad de competitividad y desarrollo empresarial a nivel mundial, y de esta manera lograr mejorar la calidad de vida de la sociedad, teniendo como base un tejido económico y social sostenible.

Finalmente la Fuerza Aérea Colombiana, a través de la Jefatura de Educación Aeronáutica, la Dirección de Ciencia, Tecnología e Innovación a través de sus Escuelas de Formación, Centros y Grupos de Investigación han venido generando y desarrollando políticas y estrategias para incentivar la articulación de la triada Universidad Empresa y Estado, con miras a conseguir resultados de $\mathrm{I}+\mathrm{D}+\mathrm{i}$ de uso dual con valor diferenciador, desde los diferentes campos de conocimiento y aplicación industrial para obtener el impulso de sectores productivos exitosos en beneficio del País.

\section{EPÍLOGO DEL CAPÍTULO}

Globalmente, en este capítulo se invitó al lector a realizar una reflexión sobre la importancia de estar continuamente transformándose tanto a nivel personal, como organizacional y poder responder a los nuevos desafíos que nos ofrece el mundo contemporáneo. En lo referente a transformación personal se puede 
profundizar en temas como la inteligencia emocional, a nivel organizacional para lograr equipos de alto desempeño, se puede profundizar en áreas como la inteligencia social, en ambos casos tienen un componente muy fuerte de la comprensión y administración de las células espejo, que son las que nos permiten tener una mejor o menor empatía con nuestros semejantes.

El hecho de comprender la transformación como una actividad constante nos conducirá a obtener resultados con innovaciones en producto, proceso, servicio u organizativas ya sean incrementales o radicales como se abordó en este capítulo, la Fuerza Aérea Colombiana lo ha comprendido y ha asumido el compromiso de transformarse continuamente, prueba de eso son sus actividades continuas de transformación organizacional donde es un componente vital la innovación, donde se evoluciona constantemente desde los procesos más sencillos de gestión organizacional hasta las tecnologías o nuevos conocimientos más avanzados en el campo de las operaciones áreas.

También se evidencia en la articulación de la Fuerza Aérea Colombiana con el Sistema Nacional de Ciencia Tecnología e Innovación-Colciencias, donde se han logrado actividades en CTeI exitosas, como son la Convocatoria Conjunta para proyectos de I+D+i No 666 en el año 2014, donde se articularon empresas y universidades a nivel nacional para el "Fortalecimiento de los Programas Estratégicos de CTeI de la FAC", así mismo, la creación del modelo de gestión de CTeI en el año 2015, fundamentado en el manual de Oslo, el manual de Frascati y la norma Icontec NTC-5801 que comprende la Gestión de la Investigación, Desarrollo e Innovación (I+D+i) Requisitos del Sistema de Gestión de la I+D+i.

Por último, se tiene proyectado para el año 2018 con la ayuda de los aliados del sector académico y del sector productivo de la FAC, la implementación de un modelo de innovación abierta, que disminuirá debilidades y aumentará capacidades, aplicando el concepto de redes inteligentes, que contribuirá con la articulación en equipos de alto desempeño de las entidades de la triada Universidad-Empresa-Estado, con la generación de nuevo conocimiento, además, obteniendo productos de $\mathrm{I}+\mathrm{D}+\mathrm{i}$ con creación de valor, los cuales contribuirán directamente con la construcción del tejido económico y social nacional.

\section{REFERENCIAS}

Ali, A. (1994). "Pioneering versus incremental innovation: Review and research propositions." Journal of Product Innovation Management, 11(1), 46-56.

Castillo, L., Lavín, J., \& Pedraza, N. (2014). La gestión de la triple hélice: fortaleciendo las relaciones entre la universidad, empresa, gobierno. Multiciencias, 14(4), 438-446. 
Colciencias. (2013). Convocatoria para conformar un banco de propuestas elegibles para la creación o fortalecimiento de oficinas de transferencia de resultados de investigación (OTRI). Retrieved from http://legadoweb. colciencias.gov.co/convocatoria/convocatoria-para-conformar-un-banco-de-propuestas-elegibles-para-la-creaci-n-o-fortale

DARWIN, C. (1859). On the Origin of Species by Means of Natural Selection, or the Preservation of Favoured Races in the Struggle for Life. London: John Murray.

La Comisión de la Comunidad Andina. (2000). Decisión 486:: Régimen Común Sobre Propiedad Industrial. Retrieved from http://www.wipo.int/edocs/ lexdocs/laws/es/can/can012es.pdf

Organización de Cooperación y Desarrollo Económico (OECD), \& OECD. (2005). Manual de Oslo, La Medida de las Actividades Cientificas y Tecnológicas, Guía para la recogida e interpretación de datos sobre innovación. OECD (Vol. 30). http://doi.org/10.1787/9789264065659-es

SÁbAto, J., \& Botana, N. (1968). La ciencia y la tecnología en el desarrollo futuro de América Latina. Revista de La Integración, 1(3), 15-36.

Salavou, H. (2004). The concept of innovativeness: should we need to focus? European Journal of Innovation Management, 7(1), 33-44. http://doi. org/10.1108/14601060410515628

ZIRGER, B. J., \& Hartley, J. L. (1994). A conceptual model of product development cycle time. Journal of Engineering and Technology Management, 11(3-4), 229-251. http://doi.org/10.1016/0923-4748(94)90011-6 



\title{
The ADVANCEMENT OF COLOMBIAN DEFENCE POLICY IN THE LATE 1990S AND THE EARLY 2000s:
}

\author{
Teniente JAVIER ALBERTo CASTRILLÓN RIASCOS ${ }^{l}$
}

The advancement and modernization of Colombian military apparatus since the late 1990s has been determinant for the current progress of its internal conflict, which nowadays presents a marked reduction of violence due to a political settlement with the Revolutionary Armed Forces of Colombia (FARC), after more than 50 years of hostilities. Defence policy in all this scenario has became crucial for strengthening the Government of Colombia (GOC) in the face of the challenges presented by guerrillas and organized crime, taking it to regain control of territories, enhance its institutional presence, and state's legitimacy and security. But, how has it been possible all this contemporary process of vibrant military evolution of the Colombian Public Force in the late 1990s and the early 2000s? It seems that a mixture of local and foreign variables made achievable both political will and financial resources, to carry out an ambitious transformation of defence apparatus that ended up by curving the internal conflict in GOC's favor. Such scenario propelled a major plan of military aid sponsored by the United States (US), termed as Plan Colombia, in charge of coping with drug trafficking first and with terrorist-insurgent related activities lately. Thus, the aim of this article is analyzing comprehensively the development of the US-GOC military cooperation in the period 1998-2012, as well as the political underpinnings that triggered the inclusion of both counter-narcotic and counterinsurgent goals. This is going to be done by studying two variables: the GOC's strategy of linking FARC's actions with drug trafficking, international terrorism and human rights abuses to change US perceptions in regard to the use of military cooperation (1998-2002); and the consequences of the Colombian military strengthening in line with US-GOC military cooperation (2002-2012).

The first part, "the FARC and the demilitarized zone (1998-2002): changing US perceptions", helps to comprehend how the political stature of the insurgents was severely damaged given their instrumentalisation of the demilitarized zone (DZ) as operational base for launching illegal actions. The lack of compromise

MSC in Theory and History International relations, London School of Economics - LSE. Oficial Fuerza Aérea Colombiana. 
and the fact of negotiating without a cease fire, was used by the GOC to promote a political strategy that eroded all support to guerrillas in the international realm, taking them to be considered a terrorist organization in the US and Europe. Ultimately, this helped to push forward the limited use of Plan Colombia material and financial resources from merely anti- drug objectives to antiterrorist as well.

The second part, "defeating the FARC: US-GOC military cooperation (20022012)", studies the strengthening of Colombian military forces in line with Plan Colombia and further intelligence cooperation. They were vital elements for weakening the insurgents in the field, taking them to negotiate with the GOC after several defeats to both political and military structures. In this sense, it was crucial the role of technology and air power to cope with the guerrilla warfare movements strategy already present in most of the country. Such advancement was done amid major political changes in the international arena, epitomized in the war on terrorism launched by the US in 2001.

Finally, a series of conclusions emanated from this entire scenario of local and international variables that nurtured a successful US-GOC military cooperation are described. Among the most important results can be highlighted how changes in Colombian military institutions supported a successful political strategy, which in sum press the FARC to start peace negotiations with the GOC. All this was possible thanks to technological and doctrinaire advances present in important fields such as intelligence and interoperability, and bolstered a more offensive strategy from the military forces in all the Colombian territory.

In order to understand this situation is necessary to revise the period before 1998, when drug cartels and both leftist and rightist armed illegal movements made of Colombia a state with deep humanitarian and political issues. Those factors tend to isolate the country from the international political arena and, specifically, from the US. The transition from the administration of Ernesto Samper (1994-1998) to Andres Pastrana (1998-2002) was marked by a realignment of US-GOC relationship and the upsurge of optimism due to the development of a peace negotiation process with the FARC, which served also as electoral platform of Pastrana's campaign. In this context, Colombia's security issues were already articulated with wider scenarios rooted in the advancement of illegal industries with hemispheric connotations. For Mason (2004), some of the local threats that face Colombia are also linked to regional, hemispheric and global security dynamics, which are dominated by two major discourses in international politics: the war on drugs and, human rights. From such rationale the peace process international perception in the late 1990s was built, being represented in the main political world actors: the European Union (EU) and the US.

By 1996, the link between leftist and rightist illegal groups with drug trafficking in the Andean region was a highly sensible topic of hemispheric 
security. In this sense, with the end of the Cold War and the defeat of Communism as political system, leftist groups in South America like the "Shining Path" and the FARC became a hybrid of insurgency politically-motivated and criminal enterprise (Steinitz, 2001). Under this scope was designed the US foreign policy towards Colombia, being a central part of such effort the War on Drugs. Equally important was human rights, whose records were linked to military aid approval in the US Congress (Serafino, 2001).

The fall of both Cali and Medellin cartels left in smaller illegal groups and independent drug traffickers' hands the control of drug economy, one of them the FARC. The displacement of coca crops to FARC controlled territories in Colombia from Peru and Bolivia, given the aggressive campaign of eradication and interception of illegal flights, as well as the central role assured to the rebels by the new drug lords in its operations (Otis, 2014), made of this organization a central piece of the profitable illicit business.

In the human rights field the situation was not different, being registered by organizations like Human Rights Watch (HRW) several infringements to Colombian society; they were done by legal and illegal actors amid the context of political violence. This was epitomized by the complex security situation in 1997; according to HRW (1997), political assassinations, kidnappings, the use of landmines, and attacks to civil objectives, including public buses were part of the repertory of guerrillas and illegal self-defence forces. The perception of a worsening situation in regard to human rights was exacerbated due to the murder of two European citizens by the FARC in the jungles of Choco: Johan Kehrer and Alexander Scheurer. Additionally, by June 1998 the FARC announced its intention to consider any journalist whose discourse was seemingly an apology of militarism, legitimate objective of its actions (Human Rights Watch, 1998). Certainly, such scenario put under scrutiny both FARC and GOC movements in the face of international community.

Literature in the studied area has been wide in terms of the internal conflict, as well as the US leverage when dealing with both the War on Drugs and the War on Terrorism. The latter topic has been highly influential in the US-GOC bilateral agenda, shaping defence policy and military aid in Colombia. According to Tickner (2001), such relation has been ruled by the US national interest that sees drug trafficking as a threat against American system of values, just like Cold War communism. Such approach is similar to the one exposed by Rosen (2015), when he describes the emergence of the War on Drugs in the late 1960s and the early 1970s amid the bipolar confrontation. During this period President Richard Nixon declared that "illicit drugs were America's "public enemy number one", and later Ronald Reagan referred to it as a "threat to US national security". For Mejía (2016), the great increase in cocaine production as well as the notorious 
deterioration of security conditions pushed for a major involvement of the US in the Colombian defence policy; factor that according to Holmes (2011), it was propelled by the dominance of political violence and drug lords' vicious offensive against the state in the early 1990s. Finally, in line with the War on Terror launched after the attacks of September 2001 in the US, Vaicius \& Isacson (2003) argue that the War on Drugs and Terror overlapped, making possible to wider the military aid previously limited to antidrug activities.

On the other hand, human rights influence in the US military assistance towards Colombia as related topic of study has made possible several pieces of research from different sources, whose results shows ambivalent consequences with regard to the Colombian human rights record once regulations have been put in place. For Callaway \& Matthews (2008, p. 15), aid allocation in the post-Cold War environment has been tied to states' human rights profile; topic which certainly was remarkably important during the debates about the Plan Colombia and the US-Colombia Free Trade Agreement. This is supported by the arguments of Serafino, Beittel, Ploch, \& Rosen (2014) about the congressional process that ended up with the approbation of the Leahy amendment in 1998; instrument to forbid the usage of Department of Defence funds "to train units of foreign military and other security forces if there was credible information that a member of a unit had committed a gross violation of human rights" (Serafino, Beittel, Ploch, \& Rosen, 2014). In comparison, Tickner (2001) argues that even though certain focus on human rights was emphasized as part of the military aid allocated to Colombia in the late 1990s and 2000s, the internal dynamic of the conflict maintained in high numbers the violations committed against Colombian society by armed actors; notwithstanding, efforts undertaken by the GOC to reverse such situation.

This article makes use of qualitative research methods and theoretical tools rooted in qualitative comparative analysis, theories of International Relations, and foreign policy analysis. Equally important, it is the analysis over official documents such as diplomatic cables from the US and the GOC, which help to construct a descriptive argument that follows a logic sequence of events that serves to understand the developments of US-GOC military cooperation inner congressional and executive circles. All this was developed through the work with primary and secondary sources found in news articles, journals and academic studies specialized in US-GOC relationship, as well as the making of US foreign policy towards Latin-America. It was invariably important the input of declassified archives from the US government in regard to its relations with Colombia in the 1990s and 2000s; all of them form an important element to comprehend the debate about the enhancement of Colombia's defence apparatus as consequence of a successful US-GOC military cooperation. 


\section{THE FARC AND THE DEMILITARIZED ZONE: CHANGING US PERCEPTIONS (1998-2002)}

Doubtless, the negotiating platform of President Andres Pastrana meant a risky political gamble aimed at finishing the longest conflict in the western hemisphere. Such effort was also directed at addressing both drug trafficking and the humanitarian crisis present in Colombia by that moment; the latter was rooted in violent acts perpetrated by illegal armed actors in great part of the national territory. Therefore, to make viable the peace process characterized by the demilitarization of $42.000 \mathrm{~km}^{2}$ in the departments of Meta and Caquetá was considered by the GOC to articulate a whole system of international pressure over the FARC. This answered to a calculation of the GOC who considered that negotiating with the rebels would be a long process which deserved a powerful backing from reputed and credible actors (U.S. Embassy Bogota, Colombia, 1998). Such movement was equally aimed at attracting international attention to the country, a political strategy that ended up showing FARC's links with global terrorism, and drug and arms trafficking organizations. This assumption summed up to the proved continuous misconduct of the rebels against communities' rights led to a political debacle of the FARC's international public profile; scenario well seized by the GOC in the diplomatic arena. All this was done through a well concerted strategy of bilateral meetings and intelligence information exchange with foreign representatives and security agencies; at the end, the movement served to convince the US Government to widen the military aid from counternarcotics to counterinsurgency objectives as well.

The perception of an insurgent organization linked with international terrorism, illegal drug commercialization, and human rights abuses was already an issue of US-GOC dialogue. For the US, FARC rebels after the end of the Cold War were in a quagmire due to the lack of foreign financial assistance from communist regimes; element that pushed them into illicit economies like drug trafficking, kidnapping and extortion (U.S. Embassy Bogota, Colombia, 1998). The fact that all those threats represented trans-border issues and menaces to US citizens brought the attention of the Clinton's administration in regard to the peace talks in Colombia. Under this entire context, members of both the US and the GOC representatives of the FARC, along with the lawyer Alvaro Leyva acting as middleman sustained several secret meetings in San Jose (Costa Rica) between December 1998 and January 1999. In the early encounters were discussed drug trafficking and the disappearance of US citizens perpetrated by the communist guerrilla, being especially important for the US the cases of Terrence Freitas, Ingrid Washinawatok and Laheenae Gay, American missionaries kidnapped and murdered in February 1999 by the illegal organization (MurILLO, 1999). 
For the US, such early meetings previous to the DZ were an opportunity to demand to the FARC a cease fire against US interests in Colombia, the end of its participation in the drug trade, as well as the renounce to kidnapping as a mean of waging the conflict (U.S. Department of State, 1998). All those requirements certainly were done in order to push the illegal organization towards a credible negotiation with the GOC. However, Raul Reyes, representative of the insurgents in Costa Rica consistently rejected such accusations, just admitting a limited role as tax collectors of a monetary charge imposed by the organization over operations of cocaine paste between peasants and drug cartels (U.S. Department of State, 1998). A similar stand was shown in regard to kidnapping; according to the guerrilla leader, the organization condemned such practice since 1984, which was established in "the Uribe documents and in numerous other declarations and statements" (U.S. Department of State, 1998, p. 6).

Peace talks made President Andres Pastrana reluctant to link publicly the FARC with narcotics trade, preferring to see the rebel negotiating structure as "a political body distinct from drug traffickers" (Miller, 2001). Notwithstanding, in February 2001 operation "Gato Negro" probed the nexus between the insurgents and the industry of illicit drugs, all this while peace negotiations in the DZ were well underway. This joint operation carried out by the Colombian security forces deployed just over 3.500 combatants among officers, sub-officers and professional soldiers during 70 days (Chavez, Morales, \& Vargas, 2003, p. 108) in Barrancominas, Guainia. As part of the most relevant results, it is possible to mention the arrest of Alberto D' Costa, better known as Fernandinho Beira Mar, major Brazilian drug lord in Latin-America in the 1990s. This revealed before both national and international public opinion the relationship between the FARC and mafias in Latin-America around a common criminal goal: the illegal trade of drugs and arms by using complex transnational networks.

In Colombia, antidrug policy was not just part of the agenda of the GOC-FARC negotiation. For the GOC, it was as well a major destabilizing force with several consequences: economic distortion; land concentration; corruption; violence multiplier; financial engine for illegal armed groups; and investment hindrance (Contraloría General de la República, 2006). This had been influencing already Colombian foreign policy and its bilateral agenda with the US, whose main topic in the defence bilateral agenda by the late 1990s was the war on drugs. "Plan Colombia" was created in such context by 2000 , but it was limited to drug control in its early stages. In that sense, Pastrana's administration efforts were also focused on linking counterinsurgency to the program's objectives; assumption partially fulfilled by "Gato Negro" achievements.

The cooperation program was initially designed by the GOC aiming at generating employment, economic incentives for the Colombian economy, 
and recovery of affected areas by the internal conflict (Contraloría General de la República, 2006). However, since the US was the main contributor to "Plan Colombia", it acquired a major military connotation (Chernick, 2012). Air interdiction, training to army battalions and antidrug police groups, and the modernization of equipments and infrastructure of the National Police and Military Forces were the chief goals of the US-GOC military cooperation agreement (Contraloría General de la República, 2006).

The link of the FARC and drug trafficking was not the only topic highlighted by the GOC to the international community and the US during the diplomatic offensive to complement the Plan Colombia. Equally important was the discourse around the relationship of the insurgents with international terrorist organizations, which were documented and exposed to mass media and intelligence agencies in the US. For the GOC, the DZ became a meeting and training center for different kinds of criminal groups around the globe, as well as for arms traffickers. By 1999 an airplane Ilushin 76 dropped a shipload of AK-47 rifles in Barrancominas, Guainia, which were part of an international illegal operation of arms trade departing from Byelorussia (Castro, 2004). To such event was added the arrest in "El Dorado" airport in Bogota of three Irish citizens in the mid 2001 who belonged to the Irish Republican Army (IRA), who were instructing the FARC on urban terrorism and explosives in the DZ (The New York Times, 2003). Those events backed the GOC's accusation towards the FARC and its terrorist networks around the globe.

The denounces were exposed also by Colombian intelligence agencies to their pares in the US; adding the nexus of the FARC with Hezbollah as well as the use of artisan chemical weapons by the rebels during an offensive in the town of San Adolfo in September 2001 (Defense Intelligence Agency, 2001). All those movements in the military diplomatic field were coupled by certain findings from US intelligence agencies in the same year that revealed how the FARC was active in training and organizing leftist antigovernment groups in Argentina; apparently, the Colombian insurgents were trying to revive the "Montoneros", an old guerrilla movement active during the 1970s in that country (Defense Intelligence Agency, 2001a).

By September 2001 the terrorist attacks in the US meant a modification of the US defence paradigm. Since that moment the War on Drugs was displaced by the War on Terrorism, and "standard restrictions prohibiting the use of counter-drug assets for counterinsurgency purposes began to evaporate, replaced by the new term counter-narcoterrorism (CNT)" (Luhan \& Kilroy, 2008). The impact of the terrorist attacks pushed forward the perception inner US bureaucratic circles that drug trafficking and terrorism were interrelated problems (U.S. Department of State, 2001). However, such idea was previously gaining currency inside the 
Republican administration. Robert Zoellick, a top foreign policy advisor to Bush during the 2000 presidential campaign stated that "the narcotraffickers and guerrillas compose one dangerous network", while Bush publicly admitted that "U.S. assistance "will help the Colombian government protect its people, fight the drug trade, [and] halt the momentum of the guerrillas"' (GALEN, 2001).

Five months after the terrorist attacks in the US the DZ and the peace negotiations beween the GOC and the FARC were ended, amid denounces to the international community about the Human Rights abuses of the FARC against inhabitants of the zone. Some of the most notorious actions that contributed to exhaust the DZ political oxygen were the crimes against population, the terrorist attacks to Colombia's security and economic infrastructure, the armed strike in Putumayo in 2000, and the hijack of the "Aires" flight to kidnap senator Jorge Eduardo Gechem Turbay in February 2002.

Since the early days of the DZ several denounces linked the FARC with disappearances; torture; illegal land occupation; forced child recruitment; extortions to peasants; environmental destruction; and illegal trade of both arms and drugs (U.S. Department of Defense, 2000). Equally grave were the attacks carried out by the FARC in neighboring areas to the DZ, as well as the threats and the persecution to local authorities (Observatorio del Programa Presidencial de Derechos Humanos y DIH, 2003). Such actions showed the real compromise of the FARC with the peace process, which took the international community in June 2000 to unanimously accused the FARC of abusing of population's human rights in the DZ; this was done during a visit to the DZ of representatives of the EU, Japan, the US, and the United Nations (UN) (U.S. Embassy Bogota, Colombia, 2000).

However, the FARC secretariat did not hear the claims of the international community, and by the mid and late 2000s concentrated its offensive in the Putumayo, where the GOC's Plan Colombia efforts against illegal crops were taken place. The organization imposed an armed strike in September 2000 to hinder counternarcotics' initiatives, local polls, and the advance of rightist militias. In consequence the illegal action prompted the displacement of about 5.000 inhabitants due to the difficulties for supplying basic necessities, a pronounced economic lost for peasants and small commerce (U.S. Embassy Bogota, Colombia, 2000a), and the pressure to take up arms against the state (VILLAMARIN, 2014, p. 241). The situation was ameliorated in part thanks to an air bridge between Bogota and Puerto Asis done by the Colombian Air Force, which helped to deliver food and medicines to the 350.000 affected inhabitants in the region (El Tiempo, 2000).

The final straw came in February 2002 when a guerrilla command hijacked an Aires Airline flight making it to land in a town nearby to Neiva, where one of the passengers, Senator Eduardo Gechem Turbay, was kidnapped (PALACIO \& QUINTERO, 2002). 
The continuous abuses and crimes committed by the FARC in the DZ and in neighbouring areas pushed the GOC to end the peace negotiation. Through a broadcasted speech, Andres Pastrana ordered to the Colombian Military Forces to retake the demilitarized zone, while showing to the public opinion how the FARC had built landing tracks, structures for vehicles, and supported the expansion of coca crops. According to intelligence reports cited by Pastrana, the rebels were active as well in launching terrorist attacks, kidnapping for ransom, and developing relations with international terrorist organizations (Pastrana, 2002); all this was done by using the DZ as safe heaven. For James Lemoyne, special representative of the UN for the peace talks in Colombia, these acts eroded the negotiation taking it to its end (U.S. Embassy Bogota, Colombia, 2002).

The terrible precedents of the DZ prompted the European Union (EU) to add the FARC in "its list of terrorist organizations" in June 2002 (BBC News, 2008); in the US lists the insurgents were already recognized as such since 1997 (U.S. Department of State, 2016).

Once the DZ and the peace talks ceased, public opinion's frustration propelled Alvaro Uribe's presidential campaign and election for two consecutive periods, 2002-2006 and 2010-2014. For the US, the new president pushed to a higher level the role of security and military forces; moreover, showing a good technocratic sense and will for collecting national resources to finance the strengthening of Colombian military apparatus.

Increasing the number of troops; an aggressive antidrug strategy; establishing a wide intelligence network; and even more importantly, directing extra public sources to defense were all initiatives proposed by President Uribe, which pleased the US Government (U.S. Embassy Bogota, Colombia, 2002a). In response, the Bush administration lobbied in Capitol Hill in favor of achieving congressional approbation for using Plan Colombia's antidrug equipment in counter-insurgent tasks. This was accepted over the base of good results in the war on drugs; human rights protection; and the adoption of a self-help economic strategy that collected local resources for defense budget (U.S. Department of State, 2002). Yet Uribe's government was just engineering in that moment a tax reform to give more resources to Military Forces, by the $30^{\text {th }}$ October, 2002, the US Congress allowed the Bush proposition which meant an strategic change in the Colombian conflict balance (Ospina, 2008).

\section{DEFEATING THE FARC: US-GOC MILITARY COOPERATION (2002-2012):}

The resolute support of the White House towards Colombia was capitalized by the Colombian diplomatic apparatus, which promoted all the positive results of Plan Colombia in the US among the bipartisan Congress. High level bilateral 
dialogue between the Colombian Ministry of International Relations with all public branches in the US and, specially, with the Executive and Legislative powers was a key aspect of a strategic communicative effort (Ministerio de Relaciones Exteriores, 2006, p. 266). In this way, Bush administration deepened US-GOC military cooperation, important factor to propel other regional initiatives that benefited Colombia through diverse US state agencies: the Antidrug Regional Initiative for the Andean Area; the Foreign Military Financing Program; the US Agency for International Development (USAID); and the State Department Antidrug Office (Ministerio de Relaciones Exteriores, 2006, p. 267).

The range of relations linked to Plan Colombia surpassed the military field, reaching the political one through a series of visits to Colombia of a US bipartisan commission whose aim was to support positive lobby before Capitol Hill. One of the most important visits was held in 2005, when Condoleezza Rice, State Secretary (2005-2009), General Bantz J. Craddock, US Southern Command Chief (2004-2006), and a bipartisan delegation of the US Congress came to Bogota to meet President Alvaro Uribe. The visit was a key aspect to strengthen arguments in favor of Colombia in the US Legislative when the continuity of Plan Colombia, advantages of a free trade agreement with the Andean countries, and resources for demobilized programs were discussed (Ministerio de Relaciones Exteriores, 2006, p. 267). A positive political scenario in both Colombia and the US meant that Alvaro Uribe's Democratic Security policy did not find any important hindrance, even though its military connotation was regularly criticized by civil society.

The link between drug trafficking and terrorism was an issue that gain tendency in decision making circles in the US, providing a great room of maneuver for the application of US-GOC military cooperation. The articulation of Plan Colombia to the counterinsurgent effort, with a special dedication to the southern regions of Colombia where coca crops were widespread, was done through a basic principle: more military power and presence in the Colombian territory. This interpretation saw FARC's expansion and influence as a determinant variable in the upsurge of drug trafficking (TOKATLIAN, 2001).

In this perspective, transport capacities were strengthened with helicopters Black Hawk and Huey, benefiting the most to the Colombian Army (Tokatlian, 2001). Yet the influx of equipment product of Plan Colombia cooperation was accomplished, the scarcity of pilots and flight crews was another problem to be solved, and for that reason the accent was placed in training and recruitment of personnel to be dedicated to those functions (U.S. Embassy Bogota, Colombia, 2000 b, p. 2). Crucial to accomplish such objective was the combined school of Flight of the Colombian Air Force in Melgar, Tolima, that according to the Department of State, was a key aspect for the success of Plan Colombia (U.S. Embassy Bogota, Colombia, 2001). 
However, the influence of US cooperation went beyond of equipment donation and training to Colombian military personnel in line with Plan Colombia. Intelligence cooperation and the enhancement of offensive capacities of the Colombian Air Force was a parallel effort of US cooperation, managed by the Central Intelligence Agency (CIA) through a covert action program since the early 2000s (PRIEST, 2013). This important program complemented Colombian Military Forces positive transformation, which made of the Colombian Air Force a decisive power in the military defeat of the FARC.

This initiative between the CIA and the Colombian Military, which also counted with the important participation of the National Security Agency (NSA), was authorized by Bush administration and continued under Obama administration (Priest, 2013). The indirect approach of the US towards Colombian national security, and the Colombian military action in itself, "has helped the Colombian government to re-gain large swathes of territory from the rebels, to work with locals to assuage grievances and to drastically reduce the numbers of kidnappings, homicides, and the hectare area of coca plant cultivation" (Noonan, 2013). In strategic terms, the technological leap and the overall military buildup were greatly important in reducing FARC's ranks and neutralizing top commanders (The Guardian, 2013)

The breaking point that brought the US-GOC intelligence and military cooperation parallel to the Plan Colombia was the kidnapping of three US citizens' contractors (Thomas Howes, Keith Stansell, and Marc Gonsalves) in Guaviare in February 2003. In order to find them as well as the FARC leadership, the US sent a team of CIA to set up the U.S. Embassy Intelligence Fusion Cell in Bogota to link US intelligence information with the work of the Colombian intelligence community; model that was used later for developing regional analogues for collecting and analyzing tactical intelligence (PRIEST, 2013). All these operation was articulated to the usage of precision-guided bombs launched by A-37 Dragonfly airplanes, which gave to the Colombian Air Force the accuracy necessary to hit FARC leaders in the Colombian mountains and jungles (Priest, 2013).

Such measures were facilitated by two presidential findings that allowed first CIA operations against international terrorist organizations and, a second one signed by President Reagan in the mid-1980s that authorized action against international narcotics traffickers (Priest, 2013). Since the FARC was declared as terrorist organization by the US Department of State (U.S. Department of State, 2016), US intelligence actions such as giving spy equipment and participating in training or offensive operations were permitted (PRIEST, 2013).

All this gave to the GOC the advantage over illegal organizations and more importantly, over the FARC. In a period of four years (2007-2011) top FARC leaders were neutralized in joint operations, starting with Negro Acacio and 
Martin Caballero in 2007 (El Espectador, 2011). One year later during operation Phoenix, Raul Reyes (2008), the second in command of the FARC, die in a bombing raid. The same fate was faced by Mono Jojoy (2010) in the department of Meta, and Alfonso Cano (2011), the supreme commander of the FARC, in the department of Cauca (BLURADIO, 2016).

Another important aspect of operations that ended up weakening the chain command of the FARC and eventually its negotiating room before the Colombian state was the release of kidnapped citizens, by either military rescue or negotiations. In October 2008 thanks to an extensive intelligence maneuver named operation Jaque, the Colombian Military Forces rescued former presidential candidate Ingrid Betancour, three US citizens, and eleven members of Colombian Public Forces (El Espectador, 2011). Equally relevant was operation Chameleon in 2010, which served to liberate the Colombian National Police General Luis Mendieta, Colonel Enrique Murillo, Colonel William Donato Gómez, and Sergeant Arbey Delgado Argote; all of them lasted 12 years abducted by the FARC in the Guaviare jungle (El Espectador, 2011).

Other persons that remained abducted by the FARC until 2012 either escaped, died in captivity, were assassinated or released by the guerrilla organization. In 2003 Guillermo Gaviria, former Governor of Antioquia; Gilberto Echeverry, former Minister of Defense; and eight members of Colombian Public Forces were assassinated by their captors during a frustrated rescue operation (El Tiempo, 2012). Four years later in 2007, eleven deputies from the department of Valle were equally executed (El Tiempo, 2012). And in 2011 four members of the Colombian Public Force were executed after more than a decade of kidnapping (Vanguardia, 2011). In contrast, several hostages were liberated by the FARC in the period 2001-2012 as part of negotiating processes with the GOC; until in 2012 the FARC Secretariat announces its renounce to the kidnapping practice for ransom and political ends (El Espectador, 2012).

Eventually, after the state's offensive the FARC ended up negotiating with the GOC its demobilization and reinsertion to legality as a political movement in a process that lasted four years (2012-2016). To achieve this result was necessary a series of transformations inner Colombian Military Forces, which took them to gain the upper hand in intelligence and offensive operations against criminal organizations and, especially, the FARC. Under this schema it was possible not just to weakening the bellicose structure of the guerrilla, but also its political, financial, and strategic ones. By depriving the FARC of some of their more radical ideologues, hostile leaders, and key commanders dedicated to drug and arms trafficking was feasible to compel the secretariat to the negotiating table. At the same time, a great portion of FARC's political capital to negotiate with the government was eroded due to the military rescue of key political hostages such as Ingrid Betancour, the three US contractors, and members of Colombian Public 
Forces. The same can be said with regard to the assassination of hostages, but instead of affecting just its negotiating room of maneuver, caused a very negative image of the FARC in Colombian public opinion; issue that made unpopular the Habana peace negotiation and the later agreement of 2016 inner Colombia in a certain degree.

\section{CONCLUSION}

The different transformations experienced by the Colombian Military Forces since the mid-1990s helped to change the balance of the internal conflict, helping to bring about the military defeat of the FARC. This factor certainly propelled a political settlement in the Habana negotiation (2012-2016), preventing another frustration such as the DZ during President Pastrana Administration. All this was possible thanks to doctrinaire positive changes that bolstered more effective planning and execution of operations, supported by a more offensive and mobile concept; as well as by the enhancement of intelligence, technology, communications, professionalization of human capital, and better structures of command and control (Presidencia de la República, 2008, p. 111).

For President Andres Pastrana the restructuring process of Colombian Military Forces was directed at augmenting their efficiency and efficacy, through the strengthening of equipment; human capital; offensive actions; legal support and integration with the community (Pastrana, 1999). From this perspective was implemented the Plan Colombia with the help of US military cooperation, and later with a huge Colombian budgetary effort during President Alvaro Uribe government. All this enterprise was the base for enhancing Colombian Military Forces that adopted a more robust shape to face the threat posed by the FARC and its huge resources earned through drug trafficking. In this sense, it is important to highlight that apart from a military stand, the Plan Colombia served as the economic structure for the greatest transformation ever experienced for the Colombian Armed Forces (RodríGuez, 2014).

Such developments led to a more efficient application of state's force given a better and faster troops displacement to the different places of Colombia's geography. The military reform that took place in Colombia from the mid-1990s gave enhanced capacities to the state in order to face the threat posed by illegal armed groups; factor that halted the FARC strategic plan of massive expansion and isolation of urban centers, which was already in process through the instrumentalisation of the DZ as a tactic rearguard (Presidencia de la República, 2008).

It might be stated that the presidency of Andres Pastrana was a starting point in the contemporary changes of the Colombian Military Forces, whose positive results were strengthened by Alvaro Uribe's administration and the policy of 
Democratic Security that expanded the presence of Colombian security and intelligence apparatus. In this context were established three new divisions (VI Division; VII Division; and VIII Division); six High Mountain Battalions; sixty Counter-guerrilla Battalions; eleven groups of urban antiterrorist Special Forces; nine regular battalions; fourteen combat service and support companies; and new National Police garrisons (Schultze-Kraft, 2012, p. 210). In terms of the Colombian Air Force, its operative capacity was widened due to the acquisition of fixed-wing and rotary-wing aircrafts; among them, twenty five Brazilian A-292 and thirteen Israeli K-firs (Schultze-Kraft, 2012, p. 411).

On the other hand, meaningful advancements in the planning and performing of military operations were registered. In this scenario, it is important to mention the creation of joint commands in 2004 and the development of the Joint Special Operations Command ${ }^{3}$ in 2008. Particularly, the Joint Command objective was to increase the capacity of Colombian Military Forces to develop and implement joint operations in determined regions under a single chain of command, belonging either to the army, the Navy, or the Air Force (Schultze-Kraft, 2012, p. 410).

The development of joint intelligence was another great advancement which greatly supported the offensive stand of Colombian security apparatus. In order to do it, the Joint Special Operations Command was in charge of increasing tactic intelligence capacity of both Military Forces and the National Police, by centralizing the intelligence collected and analyzed produced by each institution (Schultze-KrafT, 2012, p. 411). This was accelerated thanks to the implementation of the Joint Intelligence Junta, as an answer to the growing necessity of the state to coordinate and integrate the intelligence community (Schultze-Kraft, 2012, p. 411).

All these advancements were coupled to US-GOC intelligence cooperation managed by a CIA program, and the efficiency of air power once articulated to precision guided bombs. The influx of information along with political will in both the US and Colombia due to common security interests were crucial to hit the FARC in previously inaccessible zones. Certainly, the Colombian Military Forces were able to get use to a changing security environment in a quick manner to, as well as to new offensive means product of US-GOC military cooperation. This capacity to adapt to demands emanated from general contexts was a chief strength of Colombian military structures in the period studied.

The result of such transformative initiatives produced by a sense of emergency proper of frustrated negotiations of the DZ brought a scenario of military strengthening, which produced positive strategic results in weakening the FARC.

Better known as "Súper Tucano".

In Spanish "Jefatura de Operaciones Especiales Conjuntas" (JOEC). 
In a period of five years (2005-2012) top FARC leaders and key structures in political, militaristic, logistic and financial dimensions were beaten; thus, generating enough incentives and pressure for the guerrilla to advance towards a political settlement with the GOC. In this whole transition, the air power was a key element to curve the FARC's strategy to occupy large portions of the Colombian geography; attempting to do it with the logistic and financial advantages delivered by a wide knowledge and usage of well established arms and drug trafficking transnational networks.

Certainly, the peace agreement reached in 2016 between the GOC and the FARC will bring more changes in the Colombian Military Forces. For Tickner (2014), the expertise and learnt lessons acquired by Colombian Public Forces will be brought to regional and international scenarios, facilitated by a triangulated cooperation with the US that is already present in countries of Central America. The main objective of such enterprise is to offer training in coping with transnational crime (e.g. drug and arms trafficking) to foreign security corps, with US financing.

The effort for internationalizing the expertise of Colombian military and create links with the international community has gone to multilateral organizations too. In December 2016 the North Atlantic Treaty Organization (NATO) accepted the request of Colombia about establishing a bilateral dialogue to sign a cooperation agreement for exchanging information and fighting organized crime (Efe, 2016). Equally important is the desire of the GOC of making the Military Forces able to participate in Peace Operations abroad. The Ministry of Defense has taken steps in that direction through the Training Center for Peace Operations ${ }^{4}$ dependent of the Colombian Navy, where members of military forces are already being taught in courses of military observers and peacekeeping operations (SAUMETH, 2016).

Notwithstanding, inner Colombia threats to national security from organized crime, post-demobilized groups, FARC's dissidences, and the National Liberation $\operatorname{Army}^{5}(E L N)$ are still present in some regions. In order to address such issues, the Colombian Military Forces aim at occupying the historical rearguards of the FARC to avoid that other illegal groups establish their presence there, while combating FARC's dissidents, the ELN, and criminal bands (El País, 2016). This is a function already exerted by the Colombian security apparatus since the 1960s, in which has developed a remarkable expertise.

Finally, the front of post-conflict places an additional task to Colombian Public Forces in a humanitarian dimension, which even though was already present in Military Force's objectives; it will acquire a higher profile in the upcoming years.

$4 \quad$ In spanish is known as "Centro de Entrenamiento para Operaciones de Paz" (Cencopaz).

5 In spanish known as "Ejército de Liberación Nacional” (ELN). 
In this sense, more resources and human capital can be dedicated in the military to give support to isolated communities; combating illegal and criminal mining; protecting environment and natural resources; building infrastructure; and decontaminating territories of landmines. With regard to these issues, during 2016 the Colombian Military Forces were already giving humanitarian support abroad due to natural disasters, such as the earthquake in Ecuador and the Hurricane in Haiti (El País, 2016); which means an expanded capacity and compromise to intervene in extraordinary situations. This entire trend speaks out about the doctrinaire articulation of international goods, such as human security ${ }^{6}$ and the protection of human rights and liberties in all aspects: the responsibility to protect ${ }^{7}$.

\section{REFERENCE}

BBC News. (2008). EU to keep Farc on 'terror list'. Retrieved September 07, 2016, from BBC News: http://news.bbc.co.uk/2/hi/americas/7203206.stm

BluRAdio. (2016). Los golpes estratégicos propinados por el Estado colombiano a las Farc. Retrieved January 4, 2017, from Bluradio: http://www. bluradio.com/paz/los-golpes-estrategicos-propinados-por-el-estado-colombiano-las-farc-114396

Callaway, R. L., \& Matthews, E. G. (2008). Strategic US Foreign Assistance: The Battle Between Human Rights and National Security. Hampshire: MPG Books Ltd.

Castro, G. (2004). Cuando Montesinos Hizo Llover Armas para las FARC. Retrieved August 31, 2016, from El Tiempo: http://www.eltiempo.com/ archivo/documento/MAM-1541567

Chavez, J., Morales, L., \& Vargas, M. (2003). ¿El Tamaño Importa?: Formas de Pensar el Fortalecimiento Militar en Colombia. Revista de Estudios Sociales(16), 105-114.

Chernick, M. (2012). Acuerdo Posible, Solución Negociada al Conflicto Armado Colombiano. Bogota: Ediciones Aurora.

$6 \quad$ Concept developed in the early 1990s by the United Nations Development Program (UNDP), being a human-centered security concept which "means creating political, social, environmental, economic, military and cultural systems that together give people the building blocks of survival and dignity" (United Nations Trust Fund for Human Security, 2009, p. 5)

7 The term "responsibility to protect" was presented by the International Commission on Intervention and State Sovereignty (ICISS), established by Canada in the late 2001. The report establishes that sovereignty gives a State the right to "control" its affairs, as well as generates on the State the fundamental 'responsibility' for protecting the people within its borders. "It proposed that when a State fails to protect its people - either through lack of ability or a lack of willingness - the responsibility shifts to the broader international community" (United Nations, 2014). 
Contraloría General de la República. (2006). Evaluación Programa Plan Colombia, 2000-2005. Bogota: Contraloría General de la República.

Defense Intelligence Agency. (2001). IIR [Excised] Dragon Tower-Colombians Assert FARC is a Terrorist Organization. Retrieved August 31, 2016, from Digital National Security Archive: http://gateway.proquest.com/openurl?url ver=Z39.88-2004\&res_dat=xri:dnsa\&rft_dat=xri:dnsa:article:CCD01817

Defense Intelligence Agency. (2001a). IIR [Excised] FARC Links to Extremists in Argentina and Spain. Retrieved August 31, 2016, from Digital National Security Archive: http:/gateway.proquest.com/openurl?url_ver=Z39.882004\&res_dat $=x r i: d n s a \& r f t \_d a t=x r i: d n s a: a r t i c l e: C C D 01805$

Efe. (2016). La OTAN acepta conversar con Colombia sobre los programas de cooperación. Retrieved January 5, 2017, from Efe: http://www.efe.com/efe/ america/politica/la-otan-acepta-conversar-con-colombia-sobre-los-programas-de-cooperacion/20000035-3133247

El Espectador. (2011). Los golpes más contundentes dados en los últimos años a las Farc. Retrieved January 4, 2017, from EL Espectador: http:// www.elespectador.com/noticias/judicial/los-golpes-mas-contundentes-dados-los-ultimos-anos-farc-articulo-309633

El Espectador. (2012). Cronología de liberaciones de secuestrados por las Farc. Retrieved January 4, 2017, from El Espectador: http://www.elespectador.com/ noticias/paz/cronologia-de-liberaciones-de-secuestrados-farc-articulo-335876

El País. (2016). "Empezaremos operaciones contra disidencias de las Farc": comandante de Fuerzas Militares. Retrieved January 5, 2017, from El País: http://www.elpais.com.co/elpais/colombia/proceso-paz/noticias/empezaremos-operaciones-contra-disidencias-farc-comandante-fuerzas-mil

El Tiempo. (2000). Putumayo Espera que Concluya Paro Armado. Retrieved September 8, 2016, from El Tiempo: http://www.eltiempo.com/archivo/ documento/MAM-1217774

El Tiempo. (2012). Los Secuestrados Muertos a Manos de las FARC. Retrieved January 4, 2017, from El Tiempo: http:/www.eltiempo.com/ Multimedia/galeria_fotos/colombia2/los-secuestrados-muertos-a-manosde-las-farc_10890225-5

Galen, T. (2001). Plan Colombia: The Drug War's New Morass. Retrieved August 31, 2016, from Cato Institute: http://object.cato.org/sites/cato.org/ files/serials/files/policy-report/2001/9/drugwar.pdf

Holmes, J. S. (2011). Colombia and U.S. Foreign Policy: Coca, Security, and Human Rights. In R. G. Carter, Contemporary Cases in U.S. Foreign Policy, from Terrorism to Trade (pp. 74-107). Washington: CQ Press. 
Human Rights Watch. (1997). Human Rights Watch Report 1997. New York: Human Rights Watch.

Human Rights Watch. (1998). Human Rights Watch World Report 1998. New York: Human Rights Watch.

LuHAn, F., \& Kilroy, R. F. (2008). Latin America and Regional Cooperation. In I. Wilson III, \& J. Forrest, Handbook of Defence Politics: International and Comparative Perspectives (pp. 195-212). London: Routledge.

Masson, A. (2004). Colombia's Conflict and Theories of World Politics. Retrieved August 22, 2016, from Social Science Research Council: http://conconflicts. ssrc.org/andes/mason/

Mesía, D. (2016). Plan Colombia: An Analysis of Effectiveness and Costs. Retrieved August 23, 2016, from Brookings Institute: https://www.brookings. edu/wp-content/uploads/2016/07/Mejia-Colombia-final-2.pdf

Miller, C. (2001). Rebels Blur the Lines in Drug War. Retrieved August 30, 2016, from latinamericanstudies.org: http://www.latinamericanstudies.org/ farc/blur.htm

Ministerio de Relaciones Exteriores. (2006). Memorias de la Gestión del Ministerio de Relaciones Exteriores Durante el Período 2004-2005. Bogotá: Ministerio de Relaciones Exteriores.

Murillo, M. L. (1999). FARC Admiten Triple Asesinato. Retrieved August 30, 2016, from El Tiempo: http://www.eltiempo.com/archivo/documento/ MAM-884261

Noonan, M. P. (2013). A Better Model of Military Intervention?: How covert assistance to Colombia shows the viability of the so-called indirect approach. Retrieved January 3, 2017, from U.S. News: http://www.usnews. com/opinion/blogs/world-report/2013/12/23/what-covert-assistance-to-colombia-shows-about-us-military-interventions

Observatorio del Programa Presidencial de Derechos Humanos y DIH. (2003). Panorama Actual de los Municipios que Conformaron la Zona de Distensión. Bogota: Consejería Presidencial para los Derechos Humanos.

Ospina, H. C. (2008). Colombia, laboratorio de embrujos. Democracia y terrorismo de Estado. Madrid: Ediciones Foca.

Otis, J. (2014). The FARC and Colombia's Illegal Drug Trade. Washington: Wilson Center.

Palacio, A., \& Quintero, F. (2002). Secuestro Aéreo, Puntillazo Final. Retrieved January 10, 2017, from El Tiempo: http://www.eltiempo.com/archivo/ documento/MAM-1308661 
Pastrana, A. (1999). Vientos de Transformación y Modernización: Presentación del Proyecto de Reestructuración de las Fuerzas Militares. Retrieved January 4, 2017, from Andrés Pastrana: Biblioteca Presidencial: http://andrespastrana. org/portfolio-items/vientos-de-transformacion-y-modernizacion/

Pastrana, A. (2002). Texto de la alocución del presidente Andrés Pastrana. Retrieved September 9, 2016, from Latin American studies: http://www. latinamericanstudies.org/colombia/alocucion.htm

Presidencia de la República. (2008). Impacto de la Política de Seguridad Democrática sobre la Confrontación Armada, el Narcotráfico y los Derechos Humanos. Bogotá: Presidencia de la República.

PRIEST, D. (2013). Covert action in Colombia:U.S. intelligence, GPS bomb kits help Latin American nation cripple rebel forces. Retrieved January 3, 2017, from The Washington Post: http://www.washingtonpost.com/sf/investigative/2013/12/21/covert-action-in-colombia/

Rodríguez, T. (2014). Nuevo Escenario en las Fuerzas Militares de Colombia, Proyección 2030: Transgformación y Adaptación. Retrieved January 4, 2017, from Docplayer.es: http://docplayer.es/24325892-Nuevo-escenario-en-las-fuerzas-militares-de-colombia-proyeccion-2030-transformacion-y-adaptacion.html

Saumeth, E. (2016). Colombia y su Cencopaz. Retrieved January 5, 2017, from Infodefensa: http://www.infodefensa.com/latam/2016/06/09/opinion-centro-entrenamiento-operaciones-cencopaz-colombia.php

Schultze-Kraft, M. (2012). La Cuestión Militar en Colombia: la Fuerza Pública y los Retos de la Construcción de la Paz. In A. Rettberg (Ed.), Construcción de paz en Colombia (pp. 405-433). Bogotá: Universidad de los Andes.

Serafino, N. M. (2001). Colombia: Conditions and U.S. Policy Options. Washington: Congressional Research Service.

Serafino, N. M., Beittel, S. J., Ploch, L., \& Rosen, L. (2014). "Leahy Law" Human Rights Provisions and Security Assistance: Issue Overview. Retrieved August 23, 2016, from Federation of American Scientists: https://www.fas. org/sgp/crs/row/R43361.pdf

Steinitz, M. S. (2001). The Terrorism and Drug Connection in Latin America's Andean Region. Washington: Center for Strategic and International Studies.

The Guardian. (2013). Covert CIA program helped Colombia kill rebel leaders. Retrieved January 3, 2017, from The Guardian: https://www.theguardian. com/world/2013/dec/22/cia-helped-colombia-kill-rebel-leaders

The New York Times. (2003, August 12). Colombia Arrests 3 as I.R.A Bomb Experts. 
Retrieved August 31, 2016, from The New York Times: http://www.nytimes. com/2001/08/15/world/colombia-arrests-3-as-ira-bomb-experts.html

Tickner, A. (2014). An Emerging Security Cooperation Model: Colombia is Training Third Countries with US FUnds. Retrieved January 17, 2017, from Washington Office on Latin America: https://www.wola.org/analysis/ colombia-the-united-states-and-security-cooperation-by-proxy/

Tickner, A. B. (2001). U.S. Foreign Policy in colombia: Bizarre Side Effects of the "War on Drugs". Retrieved August 23, 2016, from University of Notre Dame: https://www3.nd.edu/ kellogg/faculty/research/pdfs/Tickner.pdf

Tokatlian, J. G. (2001). El Plan Colombia: ¿un modelo de intervención? Revista Cidob d'Afers Internacionals(54-55), 203-219.

U.S. Department of Defense. (2000). IIR [Excised] Problems Faced by Displaced Families from the FARC Demilitarized Zone. Retrieved September 7, 2016, from Digital national Security Archive: http://gateway.proquest.com/openur1?url_ver=Z39.88-2004\&res_dat=xri:dnsa\&rft_dat=xri:dnsa:article:CCD01578

U.S. Department of State. (1998). Memorandum of conversation between USG representatives and representatives of the revolutionary armed forces of Colombia (FARC). Retrieved August 30, 2016, from Digital National Security Archive: http://gateway.proquest.com/openurl?url_ver=Z39.882004\&res_dat=xri:dnsa\&rft_dat=xri:dnsa:article:CCD01363

U.S. Department of State. (2001). Enhancing Our Counterterrorism Strategy forColombia. Retrieved August 31, 2016, from Digital National Security Archive: http://gateway.proquest.com/openurl?url_ver=Z39.88-2004\&res dat=xri:dnsa\&rft_dat=xri:dnsa:article:CCD01818

U.S. Department of State. (2002). Colombia-Démarche on the Way Ahead. Retrieved September 2016, 2016, from Digital National Security Archive: Colombia-Démarche on the Way Ahead

U.S. Department of State. (2016). Foreign Terrorist Organizations. Retrieved January 3, 2017, from U.S. Department of State: https://www.state.gov/j/ ct/rls/other/des/123085.htm

U.S. Embassy Bogota, Colombia. (1998). Acting A/S Romero's visit to Bogotá, Nov 8-10 1998. Retrieved August 29, 2016, from Digital National Security Archive: http://gateway.proquest.com/openurl?url_ver=Z39.88-2004\&res_ dat $=$ xri:dnsa\&rft_dat=xri:dnsa:article:CCD01354

U.S. Embassy Bogota, Colombia. (2000). GOC-FARC International Conference. Retrieved September 08, 2016, from Digital NAtional Security Archive: http://gateway.proquest.com/openurl?url_ver=Z39.88-2004\&res_dat=xri:dnsa\&rft_dat=xri:dnsa:article:CCD01594 
U.S. Embassy Bogota, Colombia. (2000a). What Is the FARC Up to in Putumayo? Retrieved September 8, 2016, from Digital National Security Archive: http://gateway.proquest.com/openurl?url_ver=Z39.88-2004\&res_dat=xri:dnsa\&rft_dat=xri:dnsa:article:CCD01665

U.S. Embassy Bogota, Colombia. (2000b). STAFFDEL Mackey. Retrieved January 3, 2017, from Digital National Security Archive: http://gateway. proquest.com/openurl?url_ver=Z39.88-2004\&res_dat=xri:dnsa\&rft_da$\mathrm{t}=\mathrm{xri}$ :dnsa:article:CCD015 $\overline{5} 7$

U.S. Embassy Bogota, Colombia. (2001). INL A/S Beers August 30, 2001, Meeting with Colombian Armed Forces Commander Tapias and General Staff. Retrieved January 3, 2016, from Digital National Security Archuve: http://gateway.proquest.com/openurl?url_ver=Z39.88-2004\&res_dat=xri:dnsa\&rft_dat=xri:dnsa:article:CCD01792

U.S. Embassy Bogota, Colombia. (2002). Further Post-despeje Developments. Retrieved September 8, 2016, from Digital National Security Archive: http:// gateway.proquest.com/openurl?url ver=Z39.88-2004\&res dat=xri:dnsa\&rft_dat=xri:dnsa:article:CCD01873

U.S. Embassy Bogota, Colombia. (2002a). Key Bilateral Issues and President-Elect Uribe's Washington Visit. Retrieved September 8, 2016, from Digital national Security Archive: http:/gateway.proquest.com/openurl?url ver=Z39.88-2004\&res dat=xri:dnsa\&rft dat=xri:dnsa:article:CCD01913

United Nations. (2014). Background Information on the Responsibility to Protect. Retrieved January 11, 2017, from United Nations: http://www.un.org/ en/preventgenocide/rwanda/about/bgresponsibility.shtml

United Nations Trust Fund for Human Security. (2009). Human Security in Theory and Practice. Retrieved January 5, 2017, from United Nations: http://www.un.org/humansecurity/sites/www.un.org.humansecurity/files/ human_security_in_theory_and_practice_english.pdf

Vaicius, I., \& Isacson, A. (2003). The "War on Drugs" meets the "War on Terror". Retrieved August 23, 2016, from Center for International Policy: https:// www.ciponline.org/images/uploads/publications/0302ipr.pdf

Vanguardia. (2011). Con 'tiros de gracia', las Farc asesinaron a cuatro secuestrados. Retrieved January 4, 2017, from Vanguardia: http:// www.vanguardia.com/actualidad/colombia/133226-con-tiros-de-gracia-las-farc-asesinaron-a-cuatro-secuestrados

Villamarín, L. A. (2014). La Silla Vacía: Análisis politico-estratégico del fracasado proceso de paz del presidente Andrés Pastrana con las FARC. Bogota: Ediciones Luis Alberto Villamarín Pulido. 



\section{UN BALANCE FINAL}





\title{
EL APORTE DE LAS FUERZAS MILITARES A LA PAZ EN Colombia
}

\author{
Mayor General (RA) JUAN GUILLERMo GARCÍA SERNA ${ }^{l}$
}

Un alza en el pasaje de buses en Bogotá llevó a un grupo de universitarios y otros inconformes a realizar mítines en el cruce de la Avenida Jiménez por carrera Séptima. En tanto repitieron los mítines durante un par de meses y cada vez más violentos, al grupo de inconformes se fueron uniendo toda suerte de opositores políticos al Frente Nacional hasta ex guerrilleros amnistiados. Reunidos luego en asamblea el grupo adoptó el nombre $\mathrm{MOEC}^{2}$ y al cabo de dos años, en 1961, ya articulaba cuadrillas en Cauca, Urabá y Vichada para tomarse el poder por las armas (FrANCO, 2012). En el caso del Vichada el gobierno del presidente Lleras Camargo ordenó al Comando General de las Fuerzas Militares actuar de inmediato.

En consecuencia, el Ejército Nacional primero envió una comisión que, luego de estudiar la situación, recomendó promover la acción comunal y la atención social a los indígenas. En seguida envió el Batallón Colombia cuyo jefe, el coronel Valencia Tovar, determinó dos cursos de acción: recuperar el control territorial y mejorar la vida de los colonos. Pero, en octubre de 1961, la cuadrilla del Vichada atacó a Puerto López en lo que sería la primera acción de este tipo emulando el modelo cubano (DíAz, 2013, p. 93).

Lo anterior confirma que en 1961, cuando estalló el conflicto armado interno en Colombia, fue de la mano de grupos armados ilegales cuya pretensión era tomarse el poder. Esta caracterización del conflicto, avalada por miembros de la Comisión Histórica (2015) de La Habana como Gutiérrez, Duncan, Giraldo y Torrijos, no discute si las causas del conflicto se remiten a un alza en el pasaje de buses o deben buscarse en el origen de los tiempos como sugirieron otros comisionados. Esta caracterización evidencia que las vías de hecho asumidas

Candidato a PhD en Derecho, Magíster en Seguridad y Defensa Nacional, Especialista en Derechos Humanos y Derecho Internacional Humanitario. Especialista en derecho penal. Abogado. Mayor General (RA) de la Fuerza Aérea Colombiana.

2 MOEC: Movimiento Obrero Estudiantil Campesino, primero se llamó "Movimiento Obrero Estudiantil 7 de enero", fundado en esa fecha de 1959 por Antonio Larrota acogió bandoleros como 'Pedro Brincos' y 'Minuto' Colmenares. En 1965 una escisión dio origen al MOIR, liderado por Francisco Mosquera (Franco, 2012). 
por algunos ciudadanos, independiente de sus motivaciones, no han contribuido a la paz en Colombia.

Como también evidencia que las Fuerzas Militares, aún actuando por órdenes expresas del Ejecutivo, han cumplido también con su deber constitucional de contribuir al desarrollo del país. En el caso del Vichada en 1961 las Fuerzas Militares ya procuraban paliar la situación de poblaciones cuyo aislamiento era aprovechado por los grupos ilegales para sus exacciones, contra la misma población y contra el Estado colombiano.

\section{EL ESTADO-NACIÓN Y LA PAZ}

Las particularidades del conflicto colombiano no le sustraen de la caracterización de la guerra. KEEGAN, el destacado historiador inglés, sostuvo que la guerra está arraigada en el corazón humano, en el que se diluyen los propósitos racionales (KEEGAN, 1995, p. 21). Ello para afirmar luego que el gran avance de la cultura occidental no fue desaprobar la guerra sino legitimar su empleo, es decir, establecer pactos. Uno de esos pactos fue crear ejércitos oficiales, regidos por sus propias reglas las que se conocen hace siglos como fuero militar. Otro pacto fue limitar el uso de la violencia, cuya expresión es el derecho internacional humanitario. De allí que el objetivo de la guerra no es aniquilar al contrincante, pues desde Sun Tzu se ha dicho que el mejor estratega es el que logra la victoria sin siquiera combatir.

Es deber de los colombianos para consolidar la paz, reconocer que como nación hemos sido consecuentes en ese propósito. A través del Estado, se han procurado todos los instrumentos a tal fin. Incluso en exceso, entre 1981 y 2006 , se cuenta casi una veintena de comisiones y consejerías para negociar con los grupos armados ilegales (FIP, 2003). La lista de amnistías e indultos otorgados por los diferentes gobiernos colombianos incluye más de cincuenta, si se prolonga al siglo XIX (SÁNCHEZ, 1985, p. 217).

Recuérdese que cuando en 1961 estalló el conflicto, el país se esforzaba por superar otro conflicto donde el bipartidismo tradicional fue actor principal. Pero si se observan ambos momentos a la luz de los instrumentos usados por el Estado, debe admitirse que la nación ha sido más que generosa para preservar la paz. Justo en 1957 el país votó un plebiscito para instaurar el régimen del Frente Nacional, un medio por el cual los dos partidos tradicionales coadyuvaban a mantener la paz. En 1991, como resultado de diálogos de paz y la desmovilización de algunos grupos armados, el país aceptó reformar su Constitución Política para dar cabida a las minorías étnicas y políticas, fortalecer la democracia representativa y el respeto a los derechos humanos, entre otros logros garantistas para la pacífica convivencia de los colombianos. 
Algunos refieren que entre 1982 y 1987 fue la primera vez que hubo propiamente negociaciones con algunos grupos armados ilegales (VILLARRAGA, 2009 , p. 2). En ese marco se estableció una tregua bilateral con tres grupos, se decretó una amnistía y garantías para sus delegados en las mesas de diálogo. Aunque el contexto sociopolítico de entonces llevó a la ruptura del proceso con algunos, se firmó la paz con el M-19, el EPL, el PRT y el MAQL; sin olvidar que ese mismo contexto llevó a la reforma constitucional de 1991 ya mencionada. Más reciente, entre 1998 y 2002, el país fue más que generoso al conceder una zona de distensión para los diálogos con el grupo FARC, convocando a la comunidad internacional y al persistir durante tres años en el proceso mientras aquel grupo intensificaba sus exacciones.

El Estado también incentivó la desmovilización de los miembros de los grupos armados. Tanto en 1982 como en 1990 tal desmovilización hizo parte de los procesos de paz ya aludidos. La exigencia de un grupo ilegal de izquierda para dialogar era que el Estado promoviera la desmovilización de los grupos ilegales de autodefensa. Lo que se cumplió entre 2003 y 2006, pese al controvertido proceso con estos y los alcances de la Ley 975 que tocan a la justicia transicional. No obstante, apenas en 2012, después que una política integral del Estado debilitó su influencia sobre la población y neutralizó la cúpula dirigente, aquel grupo de izquierda aceptó reiniciar diálogos.

En función de resolver las causas del conflicto en Colombia, solo recientemente los planes de desarrollo nacional hicieron confluir ambas instancias (causas vs. desarrollo). Ello fue más notorio desde el "Plan Nacional de Rehabilitación" del gobierno Betancur (1982-1986), cuando también se estableció la elección popular de alcaldes, un paso en la descentralización y fortalecimiento de la democracia. Su sucesor, el gobierno Barco (1986-1990), estableció una segunda comisión de estudio con recomendaciones respecto al conflicto que dirigió el sociólogo Gonzalo Sánchez y publicadas como "Comisión de Estudios sobre la Violencia" (1988).

\section{LAS FF.MM. Y LA PAZ}

Debe recordarse que en 1953 las Fuerzas Militares tuvieron que asumir el gobierno para lograr la paz entre los grupos armados ilegales de todos los partidos, en conflicto durante el lustro previo. Entonces se promovió la desmovilización y el desarme voluntario de tales grupos. Fue el mismo gobierno de las Fuerzas Militares el que decretó la primera amnistía entonces para los individuos comprometidos en el conflicto. Así como creó la "Oficina de Rehabilitación y Socorro" para cumplir las tareas de desarrollo local y atención a las víctimas.

Los grupos comunistas se negaron a entregar las armas, al tiempo que algunos desmovilizados prefirieron organizar bandas dedicadas al pillaje en los campos. Por esta razón, en 1958, junto con la firma del acuerdo del "Frente Nacional" 
para desactivar la confrontación del bipartidismo tradicional, se decretó una segunda amnistía, se reorganizó el "Programa de Rehabilitación" y se encargó a una comisión de estudiar las causas del conflicto. El estudio publicado bajo el título "La violencia en Colombia" y dirigido por Monseñor Germán Guzmán, equivale a lo que hoy "podemos considerar el informe de una comisión de la verdad” (VILlarRaGa, 2009, p. 9).

Lo cierto es que la acción integral para superar las causas del conflicto fue también iniciativa de las Fuerzas Militares. El ya citado coronel Valencia Tovar la puso en práctica en 1959, en el occidente de Caldas, para contrarrestar la acción de los bandoleros allí (VALENCIA, 1992, p. 370); de nuevo en 1961 en el Vichada, como ya se mencionó. Precisamente, en 1960, al ser nombrado Comandante del Ejército, el general Alberto Ruiz Novoa anunció que la Fuerza Armada contribuiría a desarrollar la infraestructura y recuperar el tejido social en las regiones donde el conflicto era latente. Directriz que amplió al desempeñarse como Ministro de Defensa, entre 1962 y 1965, coordinada con la política gubernamental de reforma agraria, construcción de carreteras, escuelas, puestos de salud, acueductos y sistemas de irrigación, con el apoyo estadounidense de la Alianza para el Progreso (RemPe, 1995).

Desde entonces las Fuerzas Militares están comprometidas con la paz. Otrora adelantaron la construcción de obras que conforman la infraestructura del país, entre ellas la carretera al Mar en Urabá, la Marginal de la Selva, la transversal de La Macarena, los aeropuertos de Palanquero y de Acandí. Además de ser las primeras en acudir cuando las crisis por la erupción del volcán Nevado del Ruiz en 1985, el desbordamiento del río Páez en 1994, los sismos de Pereira en 1995 y Armenia en 1999 (PAREDES, 2010); hoy conforman unidades de prevención y atención de desastres. También participan en el programa nacional de desminado, desactivando los artefactos explosivos improvisados (AEI) que sembraron en los campos los grupos ilegales.

\section{REFERENCIAS}

Comisión Histórica del Conflicto y sus Víctimas (2015, febrero). Contribución al entendimiento del conflicto armado en Colombia. Recuperado de:https:// www.mesadeconversaciones.com.co/sites/default/files/informe $\% 20$ comisi_n $\% 20$ hist rica $\% 20$ del $\% 20$ conflicto $\% 20 \mathrm{y} \% 20$ sus $\% 20$ v_ctimas. $\% 20$ la $\% 20$ habana $\% 2 \mathrm{c} \% 20$ febrero $\% 20 \mathrm{de} \% 202015$.pdf

DíAz, J. (2013). La crítica de las armas: Tulio Bayer Jaramillo y el levantamiento armado del Vichada, 1961-1962. Historia y Espacio, 41: 81-103. Recuperado de: $\mathrm{http}: /$ historiayespacio.univalle.edu.co/index.php/historiayespacio/ article/view/2533 
FrANCO, R. (2012). El MOEC 7 de enero, origen de la guerrilla revolucionaria en Colombia. Bogotá: Universidad Javeriana (Trabajo de pregrado en Historia). Recuperado de: http://repository.javeriana.edu.co/handle/10554/14295

Fundación Ideas para la paz-FIP (2003). Comisiones y Consejerías del Gobierno Nacional encargadas de los procesos de acercamiento y negociación con los grupos ilegales armados. Boletín informativo, 7. Recuperado de: http://www. ideaspaz.org/proyecto03/boletines/download/boletin07

Keegan, J. (1995). Historia de la guerra. Barcelona: Planeta.

Paredes, L. (2010). Ingenieros militares en Colombia 200 años de historia: 1810-2010. Bogotá: Planeta.

Rempe, D. (1995, Winter). Guerrillas, Bandits, and Independent Republics: US Counter-insurgency Efforts in Colombia 1959-1965. Small Wars and Insurgencies, 6 (3).

SÁNCHEZ, G. (1985). Las raíces históricas de la amnistía o las etapas de la guerra en Colombia. En: Ensayos de historia política social y política del siglo XX. Bogotá: El Áncora.

Valencia, Á. (1992). Testimonio de una época. Bogotá: Planeta.

Villarraga, A. (2009). Procesos de paz entre el estado y las guerrillas en Colombia, experiencias y lecciones. 
Esta obra se terminó de imprimir en mayo 2019 en los talleres gráficos de Grupo Editorial Ibáñez Cra. 69 Bis No. 36-20 Sur Tels:2300731 - 2386035 Bogotá D.C. - Colombia 




\section{NOTAS}





\section{NOTAS}


